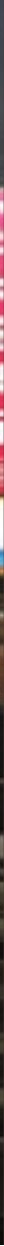

a)

E

Edited by Yves Cabannes, Mike Douglass, and Rita Padawangi

\title{
Cities in Asia by and for the People
}


Cities in Asia by and for the People 


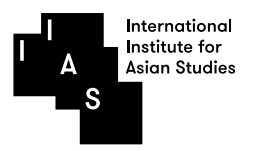

\section{Publications}

The International Institute for Asian Studies (IIAS) is a research and exchange platform based in Leiden, the Netherlands. Its objective is to encourage the interdisciplinary and comparative study of Asia and to promote (inter)national cooperation. IIAS focuses on the humanities and social sciences and on their interaction with other sciences. It stimulates scholarship on Asia and is instrumental in forging research networks among Asia Scholars. Its main research interests are reflected in the three book series published with Amsterdam University Press: Global Asia, Asian Heritages and Asian Cities.

IIAS acts as an international mediator, bringing together various parties in Asia and other parts of the world. The Institute works as a clearinghouse of knowledge and information. This entails activities such as providing information services, the construction and support of international networks and cooperative projects, and the organization of seminars and conferences. In this way, IIAS functions as a window on Europe for non-European scholars and contributes to the cultural rapprochement between Europe and Asia.

IIAS Publications Officer: Paul van der Velde

IIAS Assistant Publications Officer: Mary Lynn van Dijk

\section{Asian Cities}

The Asian Cities Series explores urban cultures, societies and developments from the ancient to the contemporary city, from West Asia and the Near East to East Asia and the Pacific. The series focuses on three avenues of inquiry: evolving and competing ideas of the city across time and space; urban residents and their interactions in the production, shaping and contestation of the city; and urban challenges of the future as they relate to human well-being, the environment, heritage and public life.

\section{Series Editor}

Paul Rabé, Urban Knowledge Network Asia (UKNA) at International Institute for Asian Studies, The

Netherlands

\section{Editorial Board}

Henco Bekkering, Delft University of Technology, The Netherlands

Charles Goldblum, University of Paris 8, France

Xiaoxi Hui, Beijing University of Technology, China

Stephen Lau, University of Hong Kong, Hong Kong

Rita Padawangi, Singapore University of Social Sciences, Singapore

Parthasarathy Rengarajan, Gujarat Institute of Development Research, Gujarat, India

Neha Sami, Indian Institute of Human Settlements, Bangalore, India 


\title{
Cities in Asia by and for the People
}

\author{
Edited by \\ Yves Cabannes, Mike Douglass, and Rita Padawangi
}




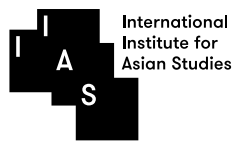

\section{Publications}

ASIAN CITIES 7

Cover illustration: The Umbrella Movements occupies Mongkok, Hong Kong, October 2014 Photo by Mike Douglass

Cover design: Coördesign, Leiden

Lay-out: Crius Group, Hulshout

$\begin{array}{ll}\text { ISBN } & 9789462985223 \\ \text { e-ISBN } & 9789048536252 \\ \text { DOI } & 10.5117 / 9789462985223 \\ \text { NUR } & 740\end{array}$

(C) Yves Cabannes, Michael Douglass \& Rita Padawangi / Amsterdam University Press B.V., Amsterdam 2018

All rights reserved. Without limiting the rights under copyright reserved above, no part of this book may be reproduced, stored in or introduced into a retrieval system, or transmitted, in any form or by any means (electronic, mechanical, photocopying, recording or otherwise) without the written permission of both the copyright owner and the author of the book.

Every effort has been made to obtain permission to use all copyrighted illustrations reproduced in this book. Nonetheless, whosoever believes to have rights to this material is advised to contact the publisher. 

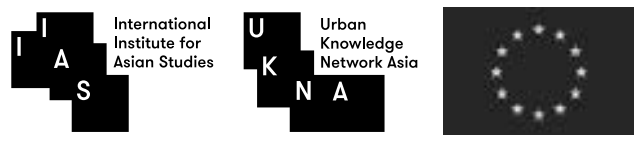

\section{About the Three UKNA Volumes}

This book is part of a series of three edited volumes published in the Asian Cities series of Amsterdam University Press and the International Institute for Asian Studies, and coordinated by editors from the Urban Knowledge Network Asia (UKNA):

- Volume 1: Ideas of the City in Asian Settings

- Volume 2: Cities in Asia by and for the People

- Volume 3: Future Challenges of Cities in Asia

The UKNA was established in 2012 with a grant from the European Union's Marie Curie Actions International Research Staff Exchange Scheme (IRSES) mobility scheme to bring together scholars from thirteen universities and planning institutions in greater China, India, Europe and the United States around collaborative research on urbanization in Asia ${ }^{1}$. Since then the network has expanded to include also other partners in Northeast Asia, South Asia and Southeast Asia, and today represents a broad coalition of scholars and practitioners united by a common objective of promoting "human flourishing and the creative production of urban space". The focus is on cities across Asia, as well as cities beyond Asia in comparative perspective.

UKNA seeks to influence scholarship on cities as well as on policy by contributing insights that put people at the center of urban governance and development strategies. The emphasis is on immediate problem solving as well as the identification of long term, transformative processes that increase

1 The original UKNA partners that participated in the research staff exchanges covered by the IRSES grant comprised: Ambedkar University Delhi (India); College of Architecture and Urban Planning, Beijing University of Technology (China); China Academy of Urban Planning and Design (China); CEPT University (India); Centre for Urban and Regional Studies, Shanghai Academy of Social Sciences (China); Development Planning Unit, University College London (UK); Ecole Nationale Supérieure d'Architecture de Paris-Belleville (France); Department of Architecture, Hong Kong University (Hong Kong SAR); International Institute for Asian Studies, Leiden (the Netherlands); Indian Institute for Human Settlements (India); School of Architecture, Tianjin University (China); Faculty of Architecture and the Built Environment, Delft University of Technology (the Netherlands); and Sol Price School of Public Policy, University of Southern California (USA). 
the scope for the active engagement of people in the creative production and shaping of their cities - particularly in the realm of knowledge. UKNA seeks to develop a new, multi-disciplinary body of knowledge on cities, one that goes beyond the 'scientific' approaches transmitted in the curricula of classic urban studies programs. It seeks to encompass alternative epistemologies of the city rooted in everyday urban life. These epistemologies seek to embrace non-Western knowledge and traditions and the contributions of a wide range of methods of investigation in the humanities, social sciences and natural sciences.

These three edited volumes represent the output of urban scholars who participated in the UKNA mobility schemes from 2012 to 2016 , as well as other scholars who were invited to contribute to the series through separate calls for papers.

The diversity of essays in these volumes represents the diversity of the UKNA itself, which brings together young scholars, including $\mathrm{PhD}$ candidates and post-doctoral researchers, as well as established contributors from over twenty countries and from a multiplicity of backgrounds and interests. The wide range of topics covered in these three volumes, reflecting crossdisciplinary perspectives and different kinds of expertise, embodies the "diversity of ways to read the city" that UKNA propagates.

The three volumes would not have been possible without the generous support of the European Union in making possible the exchanges of scholars that were at the basis of the collaborative research that led to many of the book chapters. In addition, UKNA wishes to acknowledge the following institutions and UKNA partners for their financial support and initiatives in bringing together the chapter authors and editors: the Rockefeller Foundation's Bellagio Center; the Asia Research Institute of the National University of Singapore; the Bartlett Development Planning Unit of University College London; the Ecole Nationale Supérieure d'Architecture of Paris-Belleville; the Faculty of Architecture and the Built Environment of Delft University of Technology; CEPT University; the City Government of Pingyao, Shanxi Province, China; and the International Institute for Asian Studies in Leiden.

Paul Rabé, D.P.P.D.

UKNA Coordinator and Editor, Asian Cities book series 


\section{Table of Contents}

Acknowledgements

1 Cities by and for the People

Yves Cabannes, Mike Douglass, Rita Padawangi

2 How to Prove You are Not a Squatter

Appropriating Space and Marking Presence in Jakarta

Jörgen Hellman

3 Inhabitants of Spontaneous Settlements in Bangkok: Networks and Actions Changing the Contemporary Metropolis

Fanny Gerbeaud

4 Collaborative Urban Farming Networks in Bangkok

Promoting Collective Gardens and Alternative Markets as Theatres of Social Action

Piyapong Boossabong

5 The Struggle to Create Alternative Urban Spaces An Attempt by a Theatre Group in Hong Kong

Ngai Ming Yip

6 Making the Music Scene, Making Singapore

Jumping Spatio-Sonic Scales in a Southeast Asian City-State Steve Ferzacca

7 Connecting with Society and People through 'Art Projects' in an Era of Personalization

Motohiro Koizumi

8 Activating Alternatives in Public Market Trade

The Resilience of Urban Fresh Food Provisioning in Baguio, the Philippines

B. Lynne Milgram 
9 From Street Hawkers to Public Markets

Modernity and Sanitization Made in Hong Kong

Maurizio Marinelli

10 Street Vending from the Right to the City Approach

The Appropriation of Bhadra Plaza

Lila Oriard Colin

11 Surviving Existence through a Built Form

283

The Advent of the Daseng Sario

Cynthia R. Susilo and Bruno De Meulder

12 Ethnic Place-Making in Cosmopolis

The Case of Yeonbeon Village in Seoul

Myung-rae Cho

Index

341

\section{List of Figures, Maps and Tables}

Figures

Figure 3.2 Tolerated spontaneous extensions on shophouses, around Ratchathewi BTS Station

Figure 3.3 Pom Mahakan's domestic architecture and traditions:

Thai massage, cock fighting, fireworks, bird cages

Figure 3.4 Two phases: a permanent hairdresser's shop on the sidewalk (left, 2007); a repair shop and a grocery under consolidation (right), Klong Toey Lock 1-10

Figure 3.5 Rented areas for spontaneous commercial structures behind the yellow line. Bonkai housing estate's commercial corridor

Figure 4.2 City farm training programme

Figure 4.3 Community gardens developed on vacant land

Figure 4.4 Communicative forum for urban farming networks to deliberate

Figure 5.2 Banner on the ground to attract attention

Figure 5.3 Banner on the ground to define the performance area

Figure 5.4 Performance on issues of political dissent 145

Figure 6.2 The Hood, 2011 
$\begin{array}{lll}\text { Figure 6.3 Inside the Hood, } 2011 & 163\end{array}$

Figure 6.4 Having a good time at the new Hood 169

$\begin{array}{llr}\text { Figure 7.2 Akihabara, Tokyo } & 179\end{array}$

$\begin{array}{lll}\text { Figure 7.3 The } 3331 \text { Arts Chiyoda } & 180\end{array}$

$\begin{array}{lll}\text { Figure 7.4 The } 3331 \text { Arts Chiyoda, 'Kirigami workshop' } & 188\end{array}$

Figure 7.5 The 3331 Arts Chiyoda, 'Free Space' 191

Figure 8.2 A Baguio City Public Market retailer selling upland Baguio vegetables 204

Figure 8.3 A Baguio City Public Market retailer stocks her display with vegetables grown in the neighbouring lowland $\begin{array}{ll}\text { provinces } & 216\end{array}$

Figure 8.4 Itinerant vendors obtain vegetables on consignment from store retailers and sell their produce in the aisles and streets of the Baguio City Public Market 219

Figure 9.2 Number of unlicensed hawkers, 1990-2011 236

Figure 10.2 Organization of street vending in the plaza before the renovation 266

Figure 10.3 Bhadra Plaza transformed into a pedestrian area $\quad 267$

Figure 10.4 Expansion of the Bhadra Plaza street market $\quad 269$

Figure 11.2 The Sario fishermen's protest against the BCP expansion 296

Figure 11.3 Location of the Daseng Sario between the Mantos Mall and the Boulevard Mall, and the image of Daseng Sario 298

Figure 11.4 The Daseng Sario with and without activities. Upper: the Daseng Sario when there was no activity. Below left: the Daseng-held negotiation among Komnas HAM, Sario fishermen, the local government, and the developer. Below right: daily educational activities for children at the Daseng

Figure 12.2 After the developmental city - two modes of urban space production

Figure 12.3 Distribution of foreign residents by nationality (2011)

\section{Maps}

Figure 2.1 Maps of (a) Jakarta, (b) Indonesia, (c) Kampung Pulo

Figure 3.1 Maps of (a) Thailand and (b) Bangkok with Pom Mahakan and Bang Bua

Figure 4.1 Maps of (a) Thailand and (b) Bangkok and urban farms 100 
Figure 5.1 Maps of (a) Mong Kok District, (b) Hong Kong, and

(c) Mong Kok Neighbourhood

Figure 6.1 Maps of (a) Singapore urban areas, (b) Singapore, and

(c) Guitar 77, The Hood, and Bugis+

Figure 7.1 Maps of (a) Japan, (b) 3331 Arts Chiyoda, and (c) Tokyo

Figure 8.1 Maps of (a) the Philippines, (b) Baguio City, (c) Central Business District and (d) Baguio City Public Market

Figure 9.1 Maps of (a) Hong Kong, (b) location of markets,

(c) Smithfield, Shek Tong Tsui, Sai Ying Pun, and

Sheung Wan markets, (d) Bridge Street, Western and

Central Markets

230

Figure 10.1 Maps of (a) India and (b) urban area of Ahmedabad $\quad 260$

Figure 11.1 Maps of (a) Indonesia, (b) the location of the BCP along the coast of Manado, (c) the location of the (ex-)fishermen-influenced areas, (d) contrast conditions between Wenang and Sario areas: Map 1 (above right): the Wenang (ex-)fishermen's dwellings with direct access to neighbourhood streets, Map 2 (below right): the Sario fishermen's dwellings with lack of direct access to neighbourhood streets

Figure 12.1 Maps of (a) South Korea and (b) location of Yeonbeon in Seoul

Tables

Table 9.1 Population and Market Stalls: Demand, Supply and Shortage

Table 9.2 Population and Market Stalls: Change in Demand $\quad 252$

Table 9.3 Number of supermarkets 253

Table 12.1 Globopolis versus Cosmopolis 320 


\section{Acknowledgements}

This book is the outcome of collaborations and kind support from many sources. The idea for the book originated at the first Roundtable on Urban Heritage Policies in November 2012 at the Faculty of Architecture, Delft University of Technology, organized by the International Institute for Asian Studies under the Urban Knowledge Network Asia (UKNA) program. Through support of the Rockefeller Foundation, UKNA organized an intensive meeting at the Bellagio Center in 2014 to further develop its scope and desired content. In April 2016, the chapter authors and editors were brought together at the International Conference on Alternative Urban Spaces: Cities by and for the People, which was funded by and held at the Asia Research Institute (ARI), National University of Singapore. Final joint discussions with UKNA were held and presented to an international audience at the International Convention of Asia Scholars (ICAS) 9 in July 2016. Editing, proof reading and indexing of the book chapters have been made possible by the unstinting financial and staff support of ARI and the Development Planning Unit, University College London. The editors are grateful for all of the support this book project has received. 



\title{
1 Cities by and for the People
}

\author{
Yves Cabannes, Mike Douglass, Rita Padawangi
}

\begin{abstract}
'Cities by and for the people' indicates the active role of urban citizens in constructing spaces in the cities. The collection of narratives in this book brings together research from ten cities in Asia to contribute to re-theorizing the city from the perspective of ordinary people who face moments of crisis, contestation, and cooperation to create alternative spaces from those produced under prevailing urban processes. The chapters in this book accent the intertwining of 'human flourishing' with the exercise of human agency through daily practices in the production of urban space, placing people in the centre as agents of city-making with discontents about their current conditions and desires for a better life. The cases brought together in this volume each tell us what people strive for when they mobilize with others to produce urban spaces. One of the important theoretical lessons is that the appropriation of space for de-commodified, alternative visions of urban life is not permanent. Sharing space is an opportunity to build collective actions and initiate discussions on the collaborative management of the place. In practice, these processes may be far from ideal and may be subjected to local forms of power imbalances. Although they are spaces of continuous struggles and are embedded with specific limitations that include local hierarchies and contradictions, these convivial spaces are places that actively demonstrate the possible alternative ways to produce urban spaces.
\end{abstract}

Keywords: human flourishing, human agency, alternative spaces, place-making

Cabannes, Yves, Douglass, Michael and Padawangi, Rita, Cities in Asia by and for the People. Amsterdam: Amsterdam University Press, 2018 DOI: $10.5117 / 9789462985223 / \mathrm{CHO1}$ 
The sources of urban discontents in Asia today are manifold and are increasing. As Asia continues its accelerated urban transition, its cities are found to be becoming more unequal in both participation in public decision-making and the distribution of material and social benefits (Padawangi, Marolt, and Douglass 2014). Convivial spaces for the 'pure enjoyment of social life' (Peattie 1998) are being appropriated by commercial interests on a massive scale (Chang and Huang 2008; Daniere and Douglass 2008). In addition, Asia's cities are now adding substantially to environmental pollution and deterioration, including global climate change (UNESCAP 2012). These and many other issues provide the contexts and motivations for people to claim the right to make and change the city—-to assert through their actions that cities are by and for the people (Lefebvre 1991; Harvey 2003). This book covers a wide array of social mobilizations, which together show that expressions of human agency in cities in Asia are not solely directed toward economic or material benefits, but they instead reach toward human flourishing much more broadly through ways of living that validate personal worth through shared cultural and social relations and meanings as use-values.

The issues highlighted in this book arise from corporate-driven, statesupported transformations of cities in a region that is now undergoing the fastest and most comprehensive urban transition in world history. In this context, Cities by and for the People is an exploration of a wide spectrum of counter-hegemonic mobilizations demonstrating that another urban future-one that supports human flourishing for all—is possible. The specific foci of these efforts are manifold. While some succeed, others do not; yet despite failures, the numbers grow. Taking a longer-term view, the stories in this book reveal that human agency, collectively mobilized, can effect changes in the everyday life of cities at small as well as large scales of the urban condition.

The collection of narratives contained in the present book, Cities by and for the People, brings together research from ten cities in Asia to contribute to re-theorizing the city from the perspective of ordinary people facing moments of crisis, contestation, and cooperative quests to create alternative spaces to those produced under prevailing urban processes. As one volume in a three-volume series on Asia's urbanization processes and cities that adopts the guiding concept of 'human flourishing', the chapters in this book accent the intertwining of this concept with the exercise of human agency through daily practices in the production of urban space. The intention is 
not to create a romantic or utopian vision of what a city by and for people ought to be. Rather, it is to place people in the centre, as agents of city-making with discontents about current conditions and desires for better lives. The cases brought together in this volume each tell us what people are striving for when mobilizing with others to produce urban spaces.

2

\section{Cities by and for the People}

'Cities by and for the people' indicates the active role of urban citizens in constructing spaces in cities. Critical urban theorists have rightly decried the impact of urban restructuring in response to economic crises and alternative visions of urban life, which has led scholars' attention towards cities for people (Brenner, Marcuse, and Mayer 2012). Although we continue to examine how the right to the city is made manifest, our emphasis on cities 'by', rather than just 'for', people intends to highlight the role of citizens as active agents of urban change rather than as passive victims of global capitalism. This focus on citizens as active agents is meant to fill the gap between critical theory and urban futures that continues to widen in present urban development trajectories, which persist with business as usual. The acknowledgement of the importance of citizens' active roles, how these roles arise, and the ensuing possibilities are key issues to be thoroughly addressed to enable alternative visions to grow and be consistently implemented against the urban development paradigms that have been rebuked by critical urban theorists. Central to the endeavour of proposing cities by and for the people is this question: What are possible alternative spaces in the city, and how do they come together to reflect a city by and for the people?

Since the 1970s, the flow of global assembly work to cities in Asia has altered the peripheral urban landscapes to facilitate large industrial economic zones. This has triggered waves of urbanization in the search of perceived better livelihoods in rapidly growing cities. By the late 1980 s, finance capital and new consumptive lifestyles arrived along with increases in disposable income and people's participation in the global economy. From this point on, the urban core has experienced thorough transformations through the privatization of urban spaces for mega-projects ranging from shopping malls to world business hubs and the world's tallest buildings. Large-scale gated housing estates and private new towns began to occupy agricultural land in peri-urban areas. Cities that had fewer than 1 million residents in 1970 have grown to as much as 30 million within the short space of three decades, 
driven by globalization and the new international division of labour. Along with this growth and change has come new urban lifestyles that widen social differences and disparities as countries become more complexly urban. The attention given by governments and commercial interests to these new lifestyles and global consumption has diverted urban development discourse away from vernacular landscapes and public spaces-no matter how contested they are-as well as from building meaningful urban neighbourhoods and communities.

Together, the following chapters illuminate the paths and struggles of people working hand-in-hand to prevent the appropriation of life spaces, reclaim those they have lost, and create new spaces of hope. Regardless of outcomes in terms of achieving specific objectives, contestations are expressions of agency through self-empowerment in the specific contexts and aspirations of those engaged in them. They evoke the long-held understanding of the city as a theatre of social action (Mumford 1961; Friedmann 1962) that is diverse in identities and aspirations for defining what the city is and should be. From this perspective, the city is always a process and an outcome of social and political mediations.

With the ascendancy of neoliberal ideology from the 1980s onward, the long-standing idea of the city as a social process has been actively displaced by state and corporate interests claiming the city to be first and foremost an ultra-competitive engine of economic growth and maker of wealth-which justifies a constant prioritization of the economy over social, political, and cultural relations (EIU 2012). Ideologically, this discourse comprises a conscious forgetting of the city as an inclusive polis of participatory politics and as spheres of everyday social life (Kirby 2002). By asserting that there is no alternative to the subordination of society to the mechanics of global economic competitiveness, it deflects critical thinking about and attempts to depoliticize the social unevenness of globalization.

Despite increasing corporatization of cities, efforts continue to be made to counter the alienating forces of capitalist urban growth, including resistance, mobilization, and cooperative projects for alternative development pathways. The practices-simultaneously physical and social - through which urban space is produced are observable, and may help in theoretically defining the 'people' who could (and should) build the city. Local initiatives in neighbourhoods and districts, including efforts to manage and govern these areas, are key manifestations of an inclusive city by and for the people. For example, local practices such as community gardening might start at a small scale but can spread 
throughout the city and to other urban areas. Several cities in Asia have begun to practice participatory budgeting, in which district residents are involved in identifying problems that need to be rectified in their localities. In some countries, communities are printing and using their own currency as a way to enhance synergistic economic linkages within them. Other communities are adopting collective tenure as a means to prevent land speculation and gentrification.

In drawing from real world experiences, the case studies in this book also expose the limitations of collective efforts to confront and transform structures of power. Inequalities and uncertainties have grown together with the urban population and its diversity in today's megacities. Cities with annual high rates of economic growth over many decades continue to have widening social divides with a persistence of very low-income employment and inadequate housing ('slums'). These trends reveal that the role of cities as generators of increased prosperity for all and as new forms of egalitarian civilization - as portrayed in Western theories that inequalities will decline at high levels of per capita income or assessments that Asia's 'miracle economies' demonstrate exceptional experiences of growth with equality-has not occurred.

For these reasons, redefining and reiterating the idea of the city in urban theory is critically needed to connect epistemologies with current urban experiences. Redefining the idea of the city fundamentally means revisiting the right of people to be principal agents in constructing urban spaces, both socially and physically. Such a reconceptualization would include, but also go beyond, economic and material aspects of what is summarized as 'development' to include other important elements of human flourishing as defined in the process of social attempts to create alternative cities to those that are appearing today.

In exposing the sources of and responses to discontents, each chapter in this book is a reflection of particular moments in a specific setting. While variations among specific local contexts in Asia are substantial, the problematics arising in Asia have common elements that have changed with global dynamics over the past half-century, both spatially and socially. For example, in an increasingly multi-cultural world in which both international and intra-national migrations are fuelling the growth of cities throughout Asia, an inclusive society cannot limit the idea of 'cities by and for the people' to citizens or legal residents, but will instead be judged by how it creates the city as a cosmopolis that welcomes the stranger (Sandercock 1997; 2003). However, the notion of the 'stranger' in the city is unequal, as one group of strangers may be more welcomed politically and socially than others. 
In Asia today, international and intra-national migrant workers receive incomes well below those of registered residents of the city, are quickly disposable, have exceptionally limited rights to collective consumption and to the city, and are not in line to become either permanent residents or citizens of the city or nation. In these circumstances, the idea of the city and the epistemologies used to understand the urban condition require a greater appreciation of how cities can accommodate and thrive from social, ethnic, and cultural diversity - which appears to be one of the greatest urban challenges of the twenty-first century.

A key point of departure for the re-conceptualization of the city through the lens of 'by and for the people' is understanding that human action is space-forming and space-contingent (Friedmann 1987), and that, as proclaimed by Lefebvre (1991), changing society requires the production of enabling spaces. The research in this collection reveals why and how social efforts toward human flourishing are also efforts to produce spaces that are realized (or not) through both contestations and collaborations, through both resistance and cooperative projects for alternative processes of city making and dwelling.

\section{Theorizing the City by and for the People: Actors and Processes}

Accepting society-space reflexivity as a core element in theorizing the city as a social process invokes a series of further questions. First, who are the people that are to be viewed as the protagonists? Second, what kinds of communities for collective action do they form and how do they form them? Third, at a broader scale, what are the relations between social collectivities and government - the state - and the larger political economy that structures the production of space? Abstracting insights from the intersections of all of these questions allows the last inquiry into the longer-term viability of the momentum from particular episodes of encounters and struggles to appropriate or create alternative spaces.

Each of these questions is addressed in the context of the experiences of the cases assessed in this book through an examination of the innovations, tools, and strategic options that are created or chosen as contestations turn toward collective projects. This book, then, investigates three different lines of inquiry: the actors who create alternative city spaces; the alternative spaces themselves; and the prospects for the longer-term resilience of efforts to create alternative spaces. 


\subsection{Who are 'the people' that mobilize to produce alternative life spaces?}

In the chapters of this book, quite a broad spectrum of those usually considered to be invisible, vulnerable, or excluded from the system are engaged in producing alternative spaces in one form or another: street hawkers and street traders, as exemplified in Ahmedabad and Hong Kong (Oriard, this volume; Yip, this volume); rockers - and not only young ones - in Singapore (Ferzacca, this volume); common people who will become artists in Japan (Koizumi, this volume); kampung (traditional forms of neighbourhoods) builders (Hellman, this volume); fishermen (Susilo and De Meulder, this volume); and urban farmers and low-income housing tenants (Boossabong, this volume; Gerbeaud, this volume). One of our major findings is that there is life below the radar of neo-liberal or developmentalist cities, and that, despite difficulties, people are resisting and struggling for a better 'everyday life' and for living in dignity.

Human agency is an important concept for understanding people's ability to struggle and resist developmentalist paradigms in the various case studies presented in this book. In the psychology literature, the modes of human agency are differentiated into personal, proxy, and collective, which are related but have different purposes. Human agency is essential in the effort to push for political and social change as a collective. 'The conjoint influence of perceived collective political efficacy and trust in the governmental system predicts the form and level of people's political activity' (Bandura 2000, 78): whether it is participatory, such as the case of Seoul's migrants with the mayor (Cho, this volume) and participatory housing and gardening in Bangkok (Gerbeaud, this volume; Boossabong, this volume), or resistance like the Sario fishermen on the Manado coast (Susilo and De Meulder, this volume). Between participation and resistance, the cases of Kampung Pulo in Jakarta (Hellman, this volume) and musicians in Singapore (Ferzacca, this volume) reflect another manifestation of human agency in the form of grassroots initiatives that do not depend on engagement with the government. Intentionality, forethought, self-reactiveness, and selfreflectiveness - the four core properties of human agency — contribute to social circumstances within neighbourhoods; these are only possible when people can both observe and directly experience the effects of their actions in changing their surroundings and making things happen (Bandura 2006). Although individuals and groups are also shaped by social structures, human agency has the potential to impact the social level more broadly by shaping a better and more sustainable future (Battilana 2006; Bandura 2006, 177). 
How do communities gain the collective agency to intervene for better neighbourhood spaces? In urban development, late capitalism has created a socially disempowering economy that has made human agency precarious (Chandler 2013; Jokinen 2016). With precarious agency, everyday life floats without moorings and has to endure disorientation and insecurities (Jokinen 2016). The existing social structures and institutions may give power to some actors and not to others (Battilana 2006, 660); this power is dependent on how the actors' subjectivities are empowering under the conditioning of the social and spatial settings of the city (Häkli and Kallio 2014). Positions (both formal and informal) in neighbourhood organizations affect individuals' willingness and modes of engaging in efforts that are different from the mainstream (Battilana 2006). The papers in this book demonstrate that while neighbourhood- and urban-scale interventions can only take place officially when acknowledged by the government, they may still happen without official approval through self-help and communal support.

The studies selected for this volume cover the actions of a broad spectrum of people, many of whom would be listed under the categories that Iris Young (2004) categorized as oppressed through exploitation, marginalization, powerlessness, cultural imperialism, and violence. In cities in Asia today, many forms of oppression come from powerful actors in urban politics, which result in systematic dispossession by both market forces and state control, quite often through gentrification and eviction (Shin 2015; van Voorst and Padawangi 2015). These oppressions affect financially and politically weaker groups such as street hawkers and street traders, slum dwellers, migrant workers, ethnic minorities, small-scale producers such as fishermen, low-income populations in vernacular neighbourhoods produced by people who live in them, and many others who in turn become the agents of insurgent action for alternative cities. Although they mobilize through self-empowerment, these groups also find allies within the middle and elite classes who champion their causes. These patterns show that life below the radar of smart, neo-liberal, or green cities has its own potential and vitality, and that despite difficulties, people are resisting and struggling for a better everyday life and to live in dignity in the city and beyond.

\subsection{What are 'communities' and how do we understand social 'networks'?}

'Community' can be a vague concept, but the formation of communities is universal and central to social mobilizations for alternative city-making. While the term 'community' can mean collectives of people with common 
interests that are not spatially defined, the subjects of the chapters in this book invariably gather at specific locations, ranging from a construction site or public square to a neighbourhood or even larger-scale urban arena in front of city hall. Some of these communities might be composed of members of specific groups, but as struggles unfold they can become more diverse. They might exist for only the moment in which they reach a shared 'moral high ground', or they might endure through time as named organizations. In all of these communities, networks are formed. In the contemporary world, mobilizations for reform or for changing the city can instantly reach global scales through social media, although such mobilization is unlikely to last very long in most instances. In sum, these case studies show communities and networks to be dynamic processes, with some core elements longer lasting than other. Such dynamics lie at the heart of the question of the durability and sustainability of a city by and for people, which is in essence the continuous contradiction between the spontaneity and agility needed to confront new oppositional configurations and the predictability and continuity needed to maintain organizations.

Although the chapters in this book consistently show hopeful cases to highlight the possibilities of alternative visions of urban life, none of the presented alternatives is ideal. First, the contemporary fragmentation of urban visions among different groups of residents may result in contradictions between the aspirations of different communities and other forms of domination and subordination. The case of street vendors in Ahmedabad (Oriard, this volume) illustrates this complexity, as the street traders exert the right to their existence, but at the same time convert segments of public spaces into their own commercial spaces. Susilo's chapter shows how the Sario fishermen of the city of Manado continued to fight reclamation and re-assert their existence through the construction of the Daseng space, but at the same time another fisher community considered the building of a commercial boulevard on reclaimed land to be a sign of progress.

Second, religious and gender identities can provide different layers to the dynamics of alternative spaces. For example, the chapter by Hellman on kampung (urban village) as a commons describes an interesting alternative form of communal land tenure, although it is not acknowledged by the state and part of it was evicted in August 2015 as we were writing this introductory chapter. At the same time, the community has very clear gender roles and women are not yet fully involved in anti-eviction meetings, although there are no restrictions on women becoming district heads. The area is also infused with factions of several different political parties and the conservative Islamic Defenders Front. 
Third, communities may form networks beyond their immediate neighbours to work with others in different neighbourhoods, districts, cities, or even different countries. Gerbeaud's case of the community-based upgrading of Bang Bua Canal is now one of the models in the region, to which different riverbank communities look for inspiration. Visits by different riverbank communities from various cities in the region were also linked through the Asian Coalition for Housing Rights (ACHR) network. The start of the Bang Bua Canal upgrading was also not a simple task in which everyone in the neighbourhood immediately came to a consensus that they would reduce the size of their houses. It took months of deliberations, discussions, meetings, and the initial implementation for others to follow through.

In spite of the complexities of the many layers of social identities that may make contemporary alternative urban spaces less than ideal, these efforts by urban citizens to collectively and socially construct their spaces are significant movements to counter the overwhelming capitalist economy that lurks in many aspects of urban life, including land tenure and livelihoods. Because they are not ideal, these alternative spaces are realistic and thus able to illustrate the existing possibilities for counter-narratives of the city.

\subsection{Local state and capital and their relationships with communities}

How do we understand the local state (municipal or urban level) in relation to the idea of the city by and for the people? Classic theories that treat civil society as the organised face of society juxtapose it to the state, or, alternatively, to the state and what Friedmann (1992) calls the corporate economy (capital). From these perspectives, a social contract with the state is implicitly or explicitly formed, which gives the state a monopoly over violence through police and regulatory powers that extend into all levels of the city, down to the street corner. In practice, these relationships can become rife with corruption, authoritarian rule, corporate capture, and other forms of governance that have become exceptionally problematic in city-making.

The chapters in this book illustrate different possibilities of relationships among local state, capital, and communities in the social construction of alternative urban spaces. In the case of the urban farming network in Bangkok, Boossabong argues that the collaborative governance approach to acknowledging NGOs, CBOs and laypeople as partners in urban development resulted in state support for the network, which also includes funding provisions for trainings, consultancies and events. In Ahmedabad, the 
city government has legalized street vending, although this by no means eradicated all problems and contradictions. In the case of the kampung in Jakarta [Chapter 2 in this book], on the other hand, the state does not recognize the legal existence of the community. Similar struggles for recognition are experienced by the communities of Pom Mahakan and Bang Bua Canal in Bangkok (Gerbeaud, this volume), and the Sario fishermen (Susilo and De Meulder, this volume).

Following Castells (1998), and in the context of the state's monopoly of means of violence and problematic urban governance, the relationship between civil society and the state takes three possible forms: first, support of the state and its actions; second, contestation of the state through, for example, strikes or protest movements; and, third, going beyond protest to generate alternative projects. The studies in this book highlight all three tendencies. We can see how the great majority of people often do not join insurgencies of any kind, while others do. Occasionally, issues increase in scale until the majority begins to demand change. In other cases, people create their own alternative spaces with or without state support. The cases presented in the following chapters represent all points in this spectrum of civil society-state engagement.

In the cases presented in this collection, the narratives of civil society relationships with capital, or corporations, are more consistent than those with the state. Most of the cases of alternative urban spaces in this book concern communities that are marginalized by state power working in tandem with the interests of private developers that encroach on their land and thus threaten their livelihoods. This is evident in the cases of the Sario fishermen in Manado and the Baguio market [Chapter 11 in this book] that is threatened by potential development of a big supermarket in the area. As previously discussed, the consistency of the discontents reflects the unequal benefits of urban development in the region, which promotes inequality in an era of global consumption.

Other theoretical formulations bring state-civil society relations into a triangular relationship with capital as a third source of power. In Asia from post-World War II independence to the early 1980 s the state played a dominant role in economy and society, giving rise to what became known as the 'developmental state' characterized rapid state-led economic growth under authoritarian rule. Since the 1980 s, two new dynamics have entered the scene. The first was the increasing prominence of neoliberal policy regimes that sought to subordinate state authority to (global) capital through reforms intended to deregulate national economies and fully open them to global flows of trade and investment. This shift has included the severe 
reduction of government welfare programs. The second dynamic was democratization and, at least in some cases, the devolution of power to local levels of government. Together, these two changes set the stage for new possibilities in state-civil society-capital relationships, which simultaneously brought an ever more powerful surge in the corporatization of cities as well as more open expressions of discontent. In this context, the local state can be seen as ambivalently shifting between supporting various civil society movements while also promoting public-private partnerships with corporate enterprises. Civil society, particularly the middle classes, expresses the same ambivalence. As the cases in this book demonstrate, wherever discontents move from contestations to alternative projects, a visible element of middle class support - whether in the form of NGOs or political activists - is found to be involved.

In a few cases, the local state is also a positive actor: for example, in Hong Kong or Bangkok the local state plays a positive and facilitating, though partial and ad hoc, role in the creation of alternative spaces. In some cases, too, the Petite Noblesse d'État or Petty State Nobility identified by Pierre Bourdieu (1998), which is composed of usually low-ranked (or low-paid) civil servants - such as social workers or primary school teachers-who are in direct contact with citizens are shown to be a transformative force in society, beyond the role of the social movements weakened by years of repression and neoliberal policies.

Of particular interest in this collection of studies is the possibility of creating alternative spaces, which remains a largely understudied subject. How are such spaces maintained through resistance, appropriated through long-term occupation, or remade through community projects?

\section{The Production and Appropriation of Alternative Urban Spaces}

In the current era, Asia is experiencing a massive transformation of urban spaces toward global(ized) cities characterized by large-scale corporate mega-projects, chain stores chains and franchises, privatization of public space, and demolition of the vernacular. Alternatives to these changes require the production of space as well. Efforts toward making these spaces ask several key questions. What forms do these alternative spaces take? How are such spaces appropriated? In the context of the geography of capital, where are they most likely to be found? What are the projects and physical, social and institutional content of such alternative spaces? 


\subsection{Strategic Issues to Initiate Actions}

Giving attention to alternative spaces points toward innovations in creating and maintaining such spaces in the wider context of an ever-present capitalist economy that today has taken neoliberal tendencies. Some of these innovations that are already well known include the implementation of a community currency, social enterprises, collective tenure, and (re-)creating the commons. As shown by the case studies from Japan and Hong Kong, the conviviality of cultural and art festivals can also create social solidarity around alternative projects. In other cases, solidarity forms around shared occupational spheres, such as among fishermen in Manado [Chapter 11 in this book]. In cases where the local state is involved, innovations such as participatory budgeting can play a significant role. Self-provisioning and localizing through linking the production and consumption of food within smaller geographical scales than those of global industrial food production has also become an important activity in alternative city-making, which is shown to have positive multiplier effects in generating allied production. The cases of synergistic links between local small-producer food crops and small-scale venders in the city illustrate these connections. Engagement in food production can also have beneficial effects by contributing to the conviviality of social relations and fostering a greater appreciation of human-nature relationships.

The experiences brought together in this book uncover several issues that can be strategically used to promote alternative urban spaces that can potentially build towards cities by and for the people. These issues are typically considered mundane in urban life, but precisely because they are essential parts of everyday life that lack of access to them may trigger collective action to change the situation. These issues are identified as follows:

\section{a. Culture and art}

In his chapter, Koizumi argues that art projects are potential tools to bring diverse people together. Because the process of doing an art project is a process of forming 'new creations together with other people', the site of the project becomes a place of connection that offers opportunities for bridging groups who might not interact otherwise. In this case, art can be a strategy to connect different groups in an advanced industrial society that is rife with individualism. This can be compared with the case of Singapore (Ferzacca, this volume), which argues that music can create a space for gathering to not just enjoy 
the tunes but also to discuss social and political concerns. This appropriation of sonic space to promote critical thinking connects with the politics of popular culture, which theorizes that while popular culture can be a numbing force of escapism and conformity to market forces of production, it also has the potential to be a tool of resistance and social critique.

\section{b. Markets and trades}

Traditional markets are subjected to modernization projects in line with mainstream urban development trajectories, but which are, at the same time, full of innovations meant to sustain traditional supply systems. Milgram (this volume) reminds us that although the organized sellers in the traditional Baguio City Public Market are practicing a politics of resistance towards the recent construction of shopping complexes, they also show internal inequalities. Marinelli's chapter highlights the dwindling association of marketplaces with communities' public spaces as interpretations of modernity as the sanitization of the urban landscape come at the expense of the vibrant public life of urban marketplaces.

\section{c. Food production and distribution}

Although the definition of the 'urban' is often linked to 'non-agricultural' modes of production, the discussion of food production provokes an exploration of variations and alternatives in the age of planetary urbanization, particularly when considering the power of humans as agents of change. The chapter on collective urban farming in Bangkok (Boossabong, this volume) informs us of how food production becomes a strategic issue that draws different groups of people in the city together and to connect collaboratively with the city government. Similarly, the traders in Baguio market base their social relationships with their customers on trust, which creates the sense that they care about the quality of the food that their customers obtain from them. Likewise, Sario fishermen in Manado [Chapter 11 in this book] might seem to be fighting for their land and homes, but in practice the existence of fisheries in Manado is part and parcel of the cultural identity of the Manadonese, for whom fish is a primary feature of their culinary traditions. The growing sense of care for others and for the urban environment, and the creation of natural landscapes that support the production of and access to edible food in the city are potentially strategic for imagining the environment as a commons, on which social collectives can be formed 
to address problems and to maintain and improve conditions through integrating cultural and social-economic practices with environmental concerns.

\section{d. Settlements and housing provision}

Putting a roof over every head is often a contentious issue exacerbated by the domination of the market, which commodifies housing as property. Our use of the term 'settlements' alongside 'housing provision' highlights differences among actors involved in making and living in them. In this light, the action of making places for settlement can be interpreted as a manifestation of human agency; however, such action is still inseparable from the influences of mainstream discourse. Alternative urban settlements are subjected to the land-property regime that affects residents both materially and mentally, through consistent exposure to the aspirational lifestyles brought by Asia's accelerated urban transition. The chapters in this collection mostly look at settlements that are built by the people in the communities for their use rather than commercial exchange value, and who have faced challenges in the form of threats of eviction in rapidly developing cities as well as bearing the brunt of region-wide environmental degradation. The case of Kampung Pulo (Hellman, this volume) is an example of settlements threatened by both evictions and severe pollution as well as flooding as the population density of the settlements has also increased because of the rapid, spatially concentrated urban development of the capital city.

Housing provision - and eviction - involves direct action by the state, either local or national. Typically lacking the capacity to control or deliver sufficient housing in pace with the rate of urban expansion, government provisions of public or social housing nonetheless remains limited in most countries in Asia. As a result, urban slum populations continue to grow even where national economic growth rates are high. In being mostly produced by dwellers through mutual assistance, lower-income neighbourhoods are experiencing the contradictions of self-help housing being under siege by commercial interests that are leading the production of urban space. As such they have become strategic issues in challenging the mainstream development trajectory of trickle-down economics through filtering of housing from rich to the poor. Pom Mahakan and Bang Bua Canal (Gerbeaud, this volume) are contrasting examples of strategies and results of social movements aimed at maintaining local settlements in the city. 


\subsection{Appropriation and place-making}

What are the possible forms that urban projects by and for the people can take, and how do these urban projects reflect the city as both idea and reality? This question entails an inquiry into the people's roles in place-making practices, the historical-cultural-political and social contexts of alternative development, and the process of obtaining spaces for alternative development. The forms of urban projects by and for the people are inseparable from their functional aspect of fulfilling daily needs and the processes by which they fulfil those needs. Settlements, marketplaces, and production spaces, which are generally subjected to a capitalist development paradigm that reduces these spaces into quantified, abstract values, are strategic entries into the social construction of urban landscapes by and for the people as the civil society act together to survive.

Through their respective cases studies in Jakarta and Bangkok, Hellman and Gerbeaud demonstrate how urban scholars' dominant discourse of understanding settlement improvements in terms of land tenure security is not corroborated by the data. Hellman considers the possibility of seeing the kampung settlement as a 'commoning' process through which self-built neighbourhoods are both collective and non-commodified, partly because their precarious existence has been sustained long enough to establish non-material relationships among the residents. In Bangkok, Gerbeaud has found that heritage preservation and environmental improvement inspire residents to become engaged with civil society, particularly in spontaneous settlements like poor neighbourhoods under threat of redevelopment.

Although most of these case studies feature place-making efforts by the urban poor, to think that cities by and for the people are only relevant for the poor is misleading. Rather than mere tools of survival, alternative urban projects are actions and strategies meant to construct a meaningful urban life. While the empirical cases presented in this volume largely feature the efforts of marginalised groups in urban landscapes, including the poor, because they are disadvantaged in the mainstream urban development trajectory, and thus have the imperative to push for alternative actions, the meaningfulness of place-making is not limited to poor and marginalised groups. This is demonstrated in the chapter on art projects in Japan (Koizumi, this volume), in which middle-class citizens, artists, and concerned citizens from any other group can join hands through the catalyst of art projects. Again, the acknowledgement of street vending by the city of Ahmedabad 
(Oriard, this volume) suggests that city governments can play a supporting role in facilitating the making of cities by and for the people through legal frameworks that are relevant to grounded realities, rather than tools of power used to control space as a commodity.

5

\section{The geography of alternative spaces: Where do alternatives take place? What are the places of resistance and affirmative actions?}

Another important question addressed in this volume is how and where alternative spaces are to be found and (re-)vitalized. The answers are complex, but they also show common patterns. First, as with the formation of organic settlements, they often arise on public land under traditional land-use regimes, or where private-sector control is not in place. Thus some of the contestations detailed in these chapters take place in public parks, plazas, sidewalks, and streets. This raises difficult questions about who should have access to these spaces for what kinds of activities. Another possibility is the revalorization of areas that capital has abandoned, such as old industrial areas, docklands, or even severely environmentally degraded areas. Such places have often become well known as the 'Bohemian' art and music scenes in many cities throughout the world, including in Asia. Similarly, many lower-income neighbourhoods that are undervalued by the market can become sites of alternative development. However, all of these spaces are subject to gentrification, commercialization, and shifts from residential to commercial districts as their very success attracts new rounds of investment. In these instances, the local state becomes a major source of either helping to prevent such colonization or, on the other hand, siding with commercial interests to create cultural economies for economic growth. In Marinelli's terms: “The City's [Hong Kong] "sterilized" regime cleaned off street trade and at the same time killed street performance that often associated with street trades' (this volume).

In their diversity, the various experiences recorded here echo Lefebvre's (1968) writings on the right to the city, which consists of the collective appropriation and use of space rather than individual ownership per se. In that sense, Lefebvre's conception is quite different from, if not opposed to, the commodified, neo-liberal city. In this book, the authors further apply Lefebvre's Right to the City by focussing on the delineation of a city of the people by giving an extraordinary account of streets, markets, housing tenements, central marketplaces, kampung, and the like. While Lefebvre's 
perspective is often critiqued as lacking consideration of scales much below 'the city', the chapters in this book show precisely that the Right to the City is built on limited and specific spaces, thereby echoing Manuel Castells' (1996) theory of spaces of place.

The experience shed light on the process of 'commoning' in David Harvey's sense, or of building common goods, either physically — such as building settlements in a kampung in Jakarta—or sonically—such as music jam sessions in a guitar shop in the basement of a mall in Singapore. The experience in both cases is transformative for the participants, encouraging them to transform their built environment and their everyday lives. This echoes De Certeau's (1984) conception of the practice of everyday life as re-appropriating spaces as one's own. Throughout the examples in this collection, the practices of 'communing' lead to the identification of spatial characteristics that provide a sense of personal efficacy to the people. This is evident in the case of street vendors in Oriard's chapter on Ahmedabad and in Hellman's interpretation of the commons in kampungs. Spaces that are welcoming and open to different groups of people in the city continue to be subjected to appropriations and re-appropriations that may not be consensual, since each group has its own interests. However, it is in the existence of the possibility of appropriations and re-appropriations that human agency can be spatially manifested in the city; this, in turn, is an essential precursor to politically, culturally, socially, and physically constructing cities by and for the people.

How do public spaces enable people to continuously recalibrate their skills to build social relationships and social capital? This is easily observable in the case of urban markets, such as in Baguio or Hong Kong. As previously mentioned, the traders in the market of Baguio [Chapter 8 in this book] build social relationships in conjunction with economic practices in support of their livelihoods. Marinelli's chapter elaborated how Hong Kong street markets are public spaces where social relations are formed. Koizumi's chapter on art projects examines the role of the arts in public spaces as a way to bring people together in the midst of rising individualism. And the importance of public space is also seen in the case of the Sario fishermen in Manado [Chapter 11 in this book], in which the shared space of the Daseng becomes a physical manifestation of resistance against the corporate-driven reclamation of the coast.

One of the theoretical lessons of our analysis of the quest for appropriation of spaces for a better life rather than for more property or more money is that this appropriation is not permanent. It can range from a couple of hours each day, such as street vendors' stalls, to occasional uses during the week or the month, such in art projects and the music jams in Singapore. This 
opens the opportunity for multiple uses of the same space, be it a street, park, or square. At the same time, shared arrangements among the publics of the city emphasize the importance of collective action and decisions to 'manage' this space through time.

An important point to be made here is that solutions to these problems only work if they are collectively organized, rather than individually resisted or attempted. These struggles also highlight the difference between the city as a space of flows and as an outcome of the place-making of the people who reside or work in them. Different property regimes are also at play; from a collective action perspective, many of the tools for alternative spaces revolve around the attempt to create or recreate the commons, i.e., common property regimes. This is highlighted by Hellman's research on Jakarta, which proposes the kampung as a commons, rather than a property regime: it is much more a space of collective consumption. This treatment of land is the outcome of the interconnections among everyday life needs, including public services and public goods; concerns over public safety; and collective identities with the kampung.

What are these alternative spaces used for? In a few cases they are 'venues for expression, and social and political deliberation', as in the Umbrella Movement in Hong Kong (Ming, this volume). Public space may be a landscape of conflicts and resistance, but this is part and parcel of the preservation of functions that matter for people, such as art and cultural expression, trade or agriculture, and conviviality.

From the cases in this book, what is clear is that collaborative actions to construct alternative visions of urban life have ideological resources framing their strategies, intentions, and actions. Koizumi's chapter on the use of art projects in bringing people together has cultural resonance with the machizukuri ('community development') after the collapse of Japan's bubble economy in the early 1990s. The art projects are re-interpretations of the machizukuri, which has also been associated with the construction of public spaces and buildings. Ferzacca's chapter demonstrates the ideological identities of the groups who utilize music as shared spaces to exchange life stories. Conviviality through music uses the space to share social concerns about Singapore as a city-state and to make these conversations meaningful and pleasurable. In Bangkok, where city dwellers consume considerable amounts of vegetables that are usually transported from more than $100 \mathrm{~km}$ away, collaborative urban farming is another expression of the ability to intervene in the soil, in this case to produce good food to be shared (Gerbeaud, this volume). All of these cases show that the alternative spaces that are necessary to make cities by and for the people are ideologically 
rooted in the society. These spaces emerge through the initiative of the existing members of the society, often with networks or linkages beyond the immediate neighbourhood.

\section{$6 \quad$ Policy implications for the sustainability and scaling-up of alternatives}

\subsection{Sustaining alternative spaces in the longer term}

By their very position as alternatives to powerful prevailing modes of citymaking, alternative spaces are likely to continually face the possibility of being eliminated through a variety of well-known processes, including gentrification, government land confiscation for urban revival or renovation, the commercialization of residential areas, and the invocation of land-use regulations, to name a few. In the face of these always imminent threats, how can those who produce alternative spaces find ways to sustain them in the longer term?

Evidence from the studies presented here and from the wider literature suggest three important dimensions of longer-term sustainability of cities by and for people. One is creating virtuous chains of projects in which the success of one contributes to the solidarity and sense of purpose that can in turn generate other projects one after another. Boossabong's chapter demonstrates the possibility of the city-wide spread of urban farming in Bangkok, which started from small-scale individual and collective efforts. A second dimension involves creating the legal and institutional development infrastructure to go beyond a single leader or group of activists by laying foundations in law and governance. Examples include success in the progressive change of eviction laws, the creation of legal bases for collective tenure, and the implementation of institutional arrangements for participatory budgeting. The third is communities engaging with communities through associations that, in raising the scale of collaborative support, increase the voice of civil society in the public sphere.

The expansion of projects along these three dimensions faces many difficulties. The diversity of social identities within and among communities can result in animosities rather than cooperative engagements. Some of the chapters, such as those on street traders in Hong Kong (Marinelli, this volume) and Ahmedabad (Oriard, this volume), show internal community tensions between groups with different interests. Sustainability very much depends on the capacity of a given community to solve these disagreements 
internally. This is similar to the conclusion of URBACT, a cooperation program in Europe that promotes networking and the sharing of experiences and best practices in various urban challenges such as governance, environment, inclusion, and the economy, on conflicts of interest and uses between different groups in the same community. On the other hand, two chapters (Koizumi, Ferzacca, this volume) show how festivals, art projects, and music can assist in bridging social differences, increasing the likelihood of different groups coming together to craft common objectives and work together to achieve them.

Sustaining alternative spaces indicates the resilience of those involved in making spaces and places. Milgram's chapter on the fresh food market in Baguio City is a case in point, in which she discusses the traders' resilience and ability to sustain the process. She concludes that resilience was neither related to 'heroic confrontations with the authorities' nor to collaborative strategies. 'Rather, marketers' everyday politics of resistance to fashion gray spaces of practice materialize a "quiet encroachment" of the "ordinary" through familiarization of the fissures in the working of city government power (Bayat 2004, 81)' (Milgram, this volume). This 'quiet encroachment of the ordinary' is the key to spatial appropriations when constructing alternative urban landscapes, through which the people who are involved become active agents of change in the city through incremental, but relatively consistent, interventions in urban spaces made possible through their daily routines and practical knowledge about how the city functions on both the ground and the policy level.

\subsection{Multiplication of spaces by and for the people}

Most of the experiences recounted here involve a city by the people created through insurgent actions, resistance, and affirmative actions of all kinds. Very few are disseminated at the city level or at higher spatial or political scales. Most of the narratives give an account of alternative place-making at quite a limited scale in relation to the city as a whole, such as a market and its surroundings or a low-income neighbourhood. Limited evidence was gathered on the impact or expansion of such alternative experiences on the city as a whole, whether through getting bigger or multiplying throughout the city. This being said, some of the chapters do shed light on how limited locales by and for the people do connect with the city as a whole. This is the case of Bardha Market (Oriard, this volume) that connects socially and economically with areas far beyond the heritage city where it is located; the same holds true in Ferzacca's chapter on 'jumping spatio-sonic scales 
in Singapore', which shows how various extremely small locales such as a shop or basement are able to gather fans and musicians from the City-State as a whole. Again, Yip's chapter relating the struggle to create alternative urban spaces by a theatre group in Hong Kong illustrates an experience that expanded or sprouted derivations beyond its original boundaries to avoid direct conflict in a repressive situation: "The theatre group eventually decided to withdraw from Sai Yeung Choi Street South and launch new initiatives of diversifying their performance in other areas and new venue of street performance. For instance, "Theatre Everywhere" is a "guerrillas type performance" in open spaces or other busy areas'. Some of the narratives indicate the following mechanisms through which alternative actions can expand far beyond their original limits:

\section{a. Collaborative modes of urban governance}

In his analysis of collaborative urban farming networks in Bangkok in this volume, Piyapong Boossabong argues that 'collaborative modes of governance' were crucial to expanding the City Farm Program beyond its original location. He indicated that local governments recognized NGOs, CBOs, laypeople, and their social networks and development partners. The results of these new forms of collaborative governance included - and this seems quite essential—formulating visions, missions, and strategies that ended up expanding the City Farm Program, and was not limited to supporting grassroots initiatives for alternative development.

\section{b. Removing 'unfreedoms' and bureaucratic hurdles}

Each of these studies demonstrate the numerous difficulties and official hurdles faced by groups engaged in alternative action, including requirements for licensing, harassment, bribes, and the acquisition of health certificates. These barriers come from each city's existing planning rules and regulations, political forces, or private economic interests. A central argument that emerges from these case studies is that the local state can contribute greatly by removing 'unfreedoms' and bureaucratic hurdles, thereby facilitating the upscaling and dissemination of alternative experiences in the city and allowing human flourishing to expand. In the light of Nobel Laureate works, Development as Freedom by Amartya Sen (1999) and Jane Samuel (2005) complements upon Citizens as Agents of Change in Urban Development, to remove unfreedoms, one crucial difference between our case studies and Sen's argument is the importance of collective, as opposed to individual, action and the relationship between citizens and multiple forms of 
organizing. Likewise, in his chapter on Hong Kong, Maurizio Marinelli stresses the importance of 'markets as spaces of social inclusion and testing grounds for collective experiences of public spaces, and in some cases, practices of democratization' (this volume).

c. Changing people, who then change their cities

Instead of promoting the city for the people from a top-down perspective, a more sensible way of city-building is empowering people and supporting their initiatives. There are already existing mechanisms, such as participatory budgeting, that allow people to decide a portion of the municipal or district public budget, which are conducive to empowerment and often generate multiple proposals that can help create a city by and for the people. Even if experience with these tools is still limited in Asian cities as a whole - and notably absent from the present book - they have gained a critical mass in places like Seoul, Korea and Chengdu, China where, in the latter, 40,00o projects decided by people have been funded through participatory budgeting (Cabannes and Ming 2014). Lessons from these initiatives in Asia are consistent with those from cities in other regions of the world (Cabannes and Delgado 2015) and clearly indicate their capacity to expand residents' involvement at the city scale in a short time, generate new ways of producing and managing the city, and lead to significant people-centred changes. Particularly interesting is the shift from public programs that intend to change a given reality to ones that generate a paradigm shift towards a city by and for the people. One testimony brought from a community leader engaged in Guarulhos, São Paulo Region in Brazil highlights this change: 'PB [participatory budgeting] is a way to change people to change their city' (Cabannes and Delgado 2015).

\section{Towards Human Flourishing, Agency and Alternative Urban spaces}

'The common purpose of the city is human flourishing.' (Aristotle, Politics)

'Exercising agency is integral to human flourishing.' (Lacey 2015, 278)

Although often connected with Aristotle's fourth century BCE concept of eudaimonia, the concept of human flourishing is not unique to Western philosophy. In Asia, Confucianism speaks of human flourishing as learning 
to be human' through the continuous 'creative transformation' of the self in 'an ever-expanding network of relationships encompassing the family, community, nation, world and beyond' (Tu 1993, 142). In the interpretations of Aristotle, Tu, and others (Rasmussen 1989; Lacey 2015), human flourishing is about well-being, derived from the capacities to strive, validate one's personal potential, gain self-fulfilment, and cultivate love and friendship, all of which emerge from engagement with others in society. In contrast to 'happiness', which is a state of satisfaction, 'human flourishing' 'conveys the idea of a process, of both a personal project and a goal for humanity' (Triglav Circle 2015). While individual freedoms are critical (Sen 1998; 2005), human flourishing is realized through inclusive engagement with the society, not in isolation from it, and involves obligations to others. Flourishing is thus a 'communal act'; the self is 'never an isolated individual but a centre of relationships' (Tu 1993, 142). This understanding echoes the idea that the right to the city is a collective, rather than individual, right (Harvey 2003).

Two more aspects of human flourishing are important with regard to the collection of urban research brought together here. First, it provides a much broader, holistic concept of the human condition than the more common formulations that presume human motivations to be wholly economic and material. Defining human flourishing as a fundamental human right to the 'full development of intellectual, physical and spiritual potentials in the context of wider communities', Friedmann $(2000,466)$ establishes it as the central idea of an alternative development meant to counter the hegemony of the prevailing neoliberal world system that diverts human energies to global accumulation. Second, as the actualization of human potential, human flourishing directs attention to human agency. Rather than something that can be defined by a universal set of criteria, human flourishing is a process experienced differently by each person-even as it is simultaneously a collaborative expression of people's capabilities and aspirations for 'another city' (Lacey 2015).

As previously noted, one of the important theoretical lessons of this book is that the appropriation of spaces for de-commodified, alternative visions of urban life is not permanent. The sharing of space is an opportunity to build collective actions and initiate discussions on collaborative management of a place. In practice, these processes may be far from ideal and may be subjected to local forms of power imbalances. The reform and opening of spaces for public use does not guarantee unlimited stability of spatial accessibility, as societies evolve and developmental trajectories may sustain materialist ideologies (Padawangi 2014). However, this is the process through which 
cities by and for the people continue to evolve, with the appreciation that citizens, individually and collectively, are active agents of change, and through which cities are re-established as theatres of social action.

Most of these case studies give an account of a city by the people through insurgent actions, resistance, and other affirmative actions, and very few disseminate outward at the city level, or expand upscale. Moreover, at least two of the cases in this volume (Kampung Pulo in Jakarta and Pom Mahakan in Bangkok) have been evicted or partly demolished while this book was in the process of publication. Nevertheless, the grounded and limited experience of a particular community can have an impact on the city as a whole. Because Ahmedabad's marketplace connects with the whole city, knowledge of the experiences of street traders in Bhadra Plaza is extended throughout the city as a social, cultural, and political entity. Singapore's Blues 77 band meets in specific clubs, but gatherings include fans and musicians from throughout the city. 'Theatre Everywhere' in Hong Kong and Bangkok's network of urban farmers bring people from different and loosely connected communities together at the metropolitan level. Furthermore, through social mobilisations alternative housing improvements in maintaining settlements in various cities in Asia have expanded, not just in Bang Bua Canal (Gerbeaud, this volume), but also in other cities in Thailand and neighbouring countries. We argue that these convivial spaces, albeit being the sites of continuous struggles and embedded with specific limitations that include local hierarchies and contradictions, are places that actively demonstrate the possibility of alternative ways to produce urban spaces. These alternative urban spaces are tangible resistance towards the capitalist production of urban spaces that continues to encroach upon various neighbourhoods, but the sustenance of alternative urban spaces that are socially constructed by the people of the city also indicates the possibility for social imaginations to work towards cities by and for the people.

\section{Works Cited}

Bandura, Albert. 'Self-Efficacy Mechanism in Human Agency'. American Psychologist 37, no. 2 (1982): 122-147. doi/10.1037/0oo3-066x.37.2.122.

---. 2000. 'Exercise of Human Agency Through Collective Efficacy'. Current Directions in Psychological Science 9(3): 75-78. doi:10.1111/1467-8721.00064.

---. 2006. 'Toward a Psychology of Human Agency'. Perspectives on Psychological Science 1(2): 164-180. doi:10.1111/j.1745-6916.2006.00011.x. 
Battilana, Julie. 2006. 'Agency and Institutions: The Enabling Role of Individuals' Social Position'. Organization 13(5): 653-676. doi:10.1177/1350508406067008.

Bourdieu, Pierre. 1998. Contre-Feux. Paris: Liber-Raisons d'agir.

Brenner, Neil, Peter Marcuse, and Margit Mayer. 2012. Cities for People, Not for Profit. London: Routledge.

Cabannes, Yves and Zhuang Ming. 2014. 'Participatory Budgeting at Scale and Bridging the Rural-Urban Divide in Chengdu'. Environment and Urbanization 26(1): 257-275. doi:10.1177/0956247813509146.

Cabannes, Yves and Cecilia Delgado. 2015. Participatory Budgeting, Dossier $N^{o}$ 1. Another City Is Possible! Alternatives to the City as a Commodity. Lisbon: Creative Commons.

Castells, Manuel. 1996. The Rise of the Network Society. Malden, MA: Blackwell. Castells, Manuel. 1998. The Power of Identity. Malden, MA: Blackwell.

Chandler, David. 2013. "Human-Centred" Development? Rethinking "Freedom" And “Agency” In Discourses of International Development'. Millennium:Journal of International Studies 42(1): 3-23. doi:10.1177/0305829813492184.

Chang, Tou and Shirlena Huang. 2008. 'Geographies of Everywhere and Nowhere: Place-(Un)Making in a World City'. International Development Planning Review 30(3): 227-247. doi:10.3828/idpr.30.3.3.

Daniere, Amrita and Mike Douglass. 2008. The Politics of Civic Space in Asia. London: Routledge.

EIU (Economist Intelligence Unit). 2012. Benchmarking Global City Competitiveness. London: Economist Intelligence Unit, Inc.

Friedmann, John. 1962. 'The City in History'. The Town Planning Review 33(1): 73-80. ---. 1987. Planning in the Public Domain. Princeton, N.J.: Princeton University Press. ---. 1992. Empowerment. Oxford: Blackwell.

---. 2000. 'The Good City: In Defense of Utopian Thinking'. International Journal of Urban and Regional Research 24(2): 460-472. doi:10.1111/1468-2427.00258.

Häkli, Jouni and Kirsi Pauliina Kallio. 2013. 'Subject, Action and Polis: Theorizing Political Agency'. Progress in Human Geography 38(2): 181-200. doi:10.1177/0309132512473869.

Harvey, David. 2003. 'The Right to the City'. International Journal of Urban and Regional Research 27(4): 939-941.

Jokinen, Eeva. 2016. 'Precarious Everyday Agency'. European Journal of Cultural Studies 19(1): 85-99. doi:10.1177/1367549415585548.

Kirby, Andrew. 2002. 'Do Cities Have a Purpose?'. Cities 19(6): 371-372. doi:10.1016/ s0264-2751(02)00067-7.

Lacey, Hugh. 2015. 'Food and Agricultural Systems for the Future: Science, Emancipation and Human Flourishing'. Journal of Critical Realism 14(3): 272-286. doi:10. 1179/1572513815y.0000000002. 
Lefebvre, Henri. 1991. The Production of Space. Oxford, UK: Blackwell.

Lefebvre, Henri. 1996. Writings on Cities. Oxford, UK: Blackwell.

Mumford, Lewis. 1961. The City in History. New York: Harcourt Brace Jovanovich.

Padawangi, Rita, Peter Marolt, and Mike Douglass. 2014. 'Introduction to the Special Issue: Insurgencies, Social Media and the Public City in Asia'. International Development Planning Review 36(1): 3-13. doi:10.3828/idpr.2014.1.

Padawangi, Rita. 2014. 'Reform, Resistance and Empowerment: Constructing the Public City from the Grassroots in Jakarta, Indonesia'. International Development Planning Review 36(1): 33-50. doi:10.3828/idpr.2014.3.

Peattie, Lisa. 1998. 'Convivial Cities'. In Cities for Citizens: Planning and the Rise of Civil Society in a Global Age, 247-253. Mike Douglass and John Friedmann, 1st ed. London: John Wiley.

Rasmussen, Douglas. 1989. 'Individual Rights and Human Flourishing'. Public Affairs Quarterly 3(1): 89-103.

Sandercock, Leonie. 1997. Towards Cosmopolis. Chichester, England:J. Wiley.

Sandercock, Leonie and Peter Lyssiotis. 2003. Cosmopolis II. London: Continuum. Sen, Amartya. 1998. 'The Possibility of Social Choice'. Nobel Lecture, December 8, 1998. https://www.nobelprize.org/nobel_prizes/economic-sciences/laureates/1998/sen-lecture.pdf

---. 1999. Development as Freedom. New York: Knopf.

---. 2005. 'Human Rights and Capabilities'. Journal of Human Development 6 (2): 151-166.

Shin, Hyun Bang. 2015. 'Economic Transition and Speculative Urbanisation in China: Gentrification Versus Dispossession'. Urban Studies 53(3): 471-489. doi:10.1177/0042098015597111.

Triglav Circle. 2016. 'Human Flourishing and Social Justice'. Triglav Circle. http:// www.triglavcircleonline.org/2005/12/human-flourishing-and-social-justice.

Tu, Wei Ming. 1993. 'Our Religions'. In the Seven World Religions Introduced, 139-227. Arvind Sharma, 1st ed. San Francisco: Harper.

UNESCAP. 2012. The State of Asian Cities 2010/11. Bangkok: UNESCAP.

Van Voorst, Roanne and Rita Padawangi. 2015. 'Floods and Forced Evictions in Jakarta'. New Mandala. http://asiapacific.anu.edu.au/newmandala/2015/08/21/ floods-and-forced-evictions-in-jakarta.

Young, Iris. 2004. 'Five Faces of Oppression'. In Oppression, Privilege, and Resistance, 37-63. Lisa Heldke and Peg O'Connor (eds.). New York: McGraw-Hill. 


\section{About the authors}

Yves Cabannes is an Urban Planner and activist, Emeritus Professor of Development Planning and former Chair of Development Planning [2006-2015] at Bartlett Development Planning Unit (DPU), University College London, UK. His previous appointments include visiting post-graduate scholar positions in European and Latin American universities and a lectureship in Urban Planning, Harvard University Graduate School of Design (2004-2006). In 1997-2003, he was the regional Coordinator of the UN Habitat/UNDP Urban Management Program for Latin America and the Caribbean. He has particular experience and interest in participatory budgeting, urban agriculture \& food sovereignty, collective and communal forms of land tenure, local currencies, participatory planning, municipal public policies, low cost housing, community-based micro credit systems and appropriate technologies for local development. He is an advocate on development and rights issues and was the convener for the UN Advisory Group on Forced Evictions (2004-2010).

Mike Douglass is Emeritus Professor and former Chair of the Department of Urban and Regional Planning at the University of Hawai'i where he was also Director of the Globalization Research Center. He holds a Ph.D. in Urban Planning from UCLA. From 2012-2018 he was Professor and Leader of the Asian Urbanisms Cluster in the Asian Research Institute and also Professor in the LKY School of Public Policy, National University of Singapore. He has served as consultant and staff member of international agencies and governments, including the United Nations. His recent books are: The Rise of Progressive Cities East and West; Crossing Borders - Governing Environmental Disasters in a Global Urban Age in Asia and the Pacific; and Disaster Governance in Urbanising Asia.

Rita Padawangi is Senior Lecturer at the Singapore University of Social Sciences. Previously, she was Senior Research Fellow of the Asian Urbanisms cluster at the Asia Research Institute (ARI), National University of Singapore (NUS). She received her PhD in sociology from Loyola University Chicago, where she was also a Fulbright Scholar for her master of arts studies. She holds a bachelor of architecture degree from the Parahyangan Catholic University. Her research interests include the sociology of architecture and participatory urban development. She is a member of the collaborative Southeast Asia Neighbourhoods Network (SEANNET), a four-year initiative for urban studies research, teaching and dissemination through the perspective of the neighbourhood, funded by the Henry Luce Foundation through the International Institute for Asian Studies (IIAS). 


\title{
2 How to Prove You are Not a Squatter
}

\author{
Appropriating Space and Marking Presence in Jakarta \\ Jörgen Hellman
}

\begin{abstract}
In Margaret Everett's notes on the urban poor in Colombia, she observes that 'the threat of eviction makes people reluctant to invest labor and resources in their homes' (Everett 1999, 1). Tunas and Peresthu (2010, 315) report from Jakarta that, 'Without security of tenure, the inhabitants of informal settlements are reluctant to invest in improvements to their living conditions'. They continue by emphasizing, 'Without clear legal status regarding land, the residents will never be encouraged to upgrade either the housing or the living environment' (Tunas and Peresthu 2010, 320). However, these observations differ significantly from my experience of working in informal neighbourhoods on urban river banks in central Jakarta where tenure security is weak. Although they were exposed to both annual flooding and constant threats of eviction, the residents were persistent in renovating and extending their houses and improving their environment. In this chapter I address this apparent paradox by discussing the strategies used by squatters to secure ownership of their houses and transform squatter areas into recognized neighbourhoods. ${ }^{1}$
\end{abstract}

Keywords: commons, squatter, Jakarta, kampung, neighbourhood, floods

1 The material was collected as part of a joint project together with Docent Marie Thynell, Peace and Development Research, School of Global Studies, Gothenburg University, entitled, 'Coping with recurrent emergencies: the self-organization of civil society in Jakarta during flooding'. The research was financed by the Swedish Research Council.

Cabannes, Yves, Douglass, Michael and Padawangi, Rita, Cities in Asia by and for the People. Amsterdam: Amsterdam University Press, 2018 DOI 10.5117/9789462985223/CHO2 
Figure 2.1 Maps of (a) Jakarta, (b) Indonesia, (c) Kampung Pulo

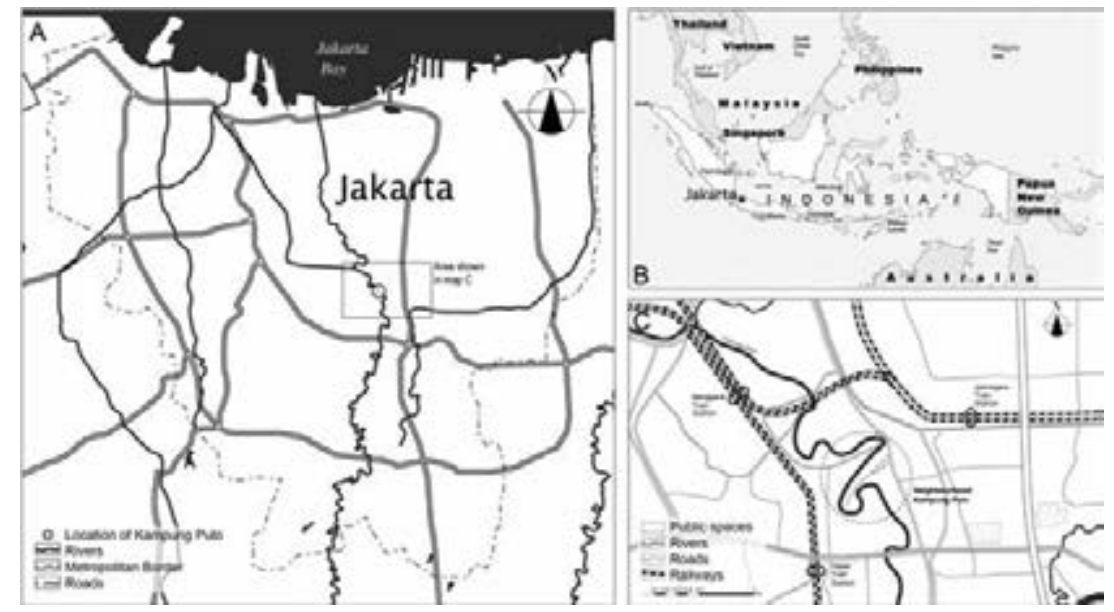

Source: Ariel Shepherd

1

Introduction

The history of urban development in Jakarta is filled with forced evictions (Jellinek 1991; Sheppard 2006; Silver 2008). Although resistance occurs and can sometimes become violent, it is often fragmented and short-lived (Jellinek 1991; Silver 2008; Somantri 2007). However, the city's civil society has a strong capacity to recreate social and economic networks after natural disasters and emergencies (Hellman 2015). Kampungs ('impoverished neighbourhoods') in Jakarta have therefore been characterized not only as transient, exposed, vulnerable, and fragmented (Jellinek 1991), but also as resilient, active, and enduring (Wilhelm 2011).

Extremely weak tenure security is a common feature of descriptions of urban kampungs. Although kampungs form an undisputable part of Jakarta's history, their legal status and even definition remains unclear. This uncertainty puts people at a disadvantage when relocation programs are implemented. Households practise a variety of strategies to enhance their 'bargaining capacity' vis-à-vis government authorities. Buildings, signposts, street names, and so on are used to demarcate presence and signal endurance (Raharjo 2010, 129-42, 200-13). This sort of 'boundary sharpening' (Raharjo 2010, 90) process is intended to claim the area as part of a kampung, rather than allowing it to be defined as a squatter settlement-an informal construction of social space that precedes (or enhances) the secure tenure of a settlement. This 'planning from below' 
confronts political administrators when implementing policies to re-green the city, upgrade infrastructure, or exploit centrally located urban land to attract the economically strong middle class. As Vollmer and Grêt-Regamey point out, urban river banks tend to be attractive to 'low-income residents' as well as 'a growing middle class' and they therefore become highly 'contested areas' $(2013,1553)$.

This chapter considers a number of issues-including the disposition of people to invest in risky projects such as illegal houses on a flooded riverbank, the images of the kampung as both resilient and transient, and the question of what constitutes a kampung — to be closely intertwined. The ethnographic questions guiding this inquiry concern how houses are established as legal buildings and how this affects the opportunities of the inhabitants to create viable livelihoods. I discuss the roles that documents, heritage traditions, the choice of materials, and architecture play in defining the legal status of a house and how those accused of being squatters use the built environment, infrastructure, political system, and social activities to establish their community as part of local society (i.e., become recognized as a kampung). I contend that the building and repair of a house is not only a financial investment, but also a strategy for becoming included in local society and for transforming squatter areas into legal neighbourhoods that are recognized by state authorities. Private investment in one's house thereby forms part of a broader resource-building strategy that is not only a financial venture at the household level.

The chapter starts by establishing a working definition of 'commons', with which I analyse kampungs as a form of collective, social, and material resource. After this, I discuss the problem of defining the kampung and the contradictory images of kampungs. The subsequent section, which focusses on Kampung Pulo, is the main ethnographic section; it illustrates how houses fit into the socio-political context. By analysing the kampung as a commons, I show how squatters mark out their presence, appropriate space, and create resources for themselves.

Questions brought up in the intellectual debates about 'cities by and for the people' include: how spaces for alternative development are appropriated and sustained; what potential exists for people to create commons in urban settings; what theoretical and conceptual tools may generate ideas about cities by and for the people; and how the notion of 'collective' is defined. My focus on illegal settlements and house building addresses these questions through a discussion on people's rights to be agents in the construction of urban spaces and how they can achieve greater influence 
over the management and governance of these spaces. These are questions that concern not only economic and material conditions, but also issues of identity, belonging, and sustainability.

2

Theory: Analytical Strategy and Argument

As an analytical framework, I employ the concepts of 'commons' and 'commoning'. I use these concepts to analyse what, exactly, people create by investing in their houses and what effect(s) this investment might have, or is expected to have, on relocation processes. These concepts also provide a tool for understanding the contradictory images of kampungs as both resilient and fragile.

\subsection{Commons: From Material to Immaterial Resources}

As in the well-known article by Garrett Hardin (1968), the term 'commons' is conventionally used to refer to a natural resource that is used by a specific community. However, in certain academic traditions the term has developed into an analytical concept for describing how various tangible and intangible resources are created and for examining the struggle for ownership over these resources (Casas-Cortés, Cobarrubias, and Pickles 2014, 451). ${ }^{2}$ Pablo Alonso Gonzalez (2014, 359-90) provides a comprehensive review of the shift from regarding commons as natural resources to seeing them as 'any natural or manmade resource that is or could be held and used in common' (Berge and van Laerhoven 2011, 161). These resources can be either material or non-material, and may take symbolic or social forms, such as social services (Nonini 2007). In fact, Pranab Bardhan and Isha Ray $(2008,9)$ point out that even 'shared understandings are themselves a sort of common resource'. Vijayendra Rao $(2008,168)$ deals with such shared knowledge in the form of identity constructions and contends that 'common property can also be social—defined within symbolic space'. When used to refer to social construction, the concept draws attention to the power plays that frame, intersect with, and are entangled in the process. The notion of commons has, then, changed from indicating resources to

2 'From an anthropological perspective, perhaps the most productive rethinking of the commons emerges as a result of efforts to take the word as a verb, "to common"' (Casas-Cortés, Cobarrubias, and Pickles 2014, 455). 
an 'analytical and political, rather than a physical, category' (Bardhan and Ray 2008, 18).

Without further elaborating on the history of the academic debates about commons, I take this broad approach to the 'commons' as an analytical concept as my point of departure. I rely mainly on the work of Ida Susser and Stéphane Tonnelat (2013) and David Harvey (2012) to construct an analytical strategy for understanding the 'messy' way issues of belonging, social relations, space, land, and material assets are interwoven in a local neighbourhood in Jakarta. More broadly, I examine how investments in kampungs may be better understood by viewing such neighbourhoods as commons.

\subsection{From Commons to Commoning: From a Noun to a Verb, and from a 'Thing' to a Relation}

The shift from seeing commons as community-owned natural resources to viewing them as jointly produced and consumed resources, both material and non-material, entailed an interest in phenomena such as guerrilla gardening, knowledge communities, and cultural heritage. These phenomena concern how commons are not only consumed, but also produced, something termed commoning.

'Commoning' according to Harvey, is a social practice that establishes a 'malleable social relation between a particular self-defined social group and those aspects of its actually existing or yet-to-be-created social and/ or physical environment deemed crucial to its life and livelihood' (Harvey $2012,73)$. In an urban context Susser and Tonnelat $(2013,108)$ argue that social movements play an important role in creating social groups that can claim and reclaim commons, building on the idea that people have 'the right to urban everyday life, the right to simultaneity and encounters, and the right to creative activity.' Hence the commoning process is dependent on a social group that defines itself as stake holders with collective objectives.

Commons are neither state-owned nor market commodities. Nonetheless, they are a resource that is exploited by a group of people. 'At the heart of the practice of commoning lies the principle that the relation between the social group and that aspect of the environment being treated as a common shall be both collective and non-commodified' (Harvey 2012, 73). Hence, commons are 'neither private nor public' (Susser and Tonnelat 2013, 107). The market may feed on these commons in the sense that a neighbourhood or city may, for example, be marketed as a tourist attraction 
even though it is something that has been created by and belongs to the citizens (Susser and Tonnelat 2013, 74). In short, commons are resources but not commodities.

Susser and Tonnelat identify three types of urban commons. The first is located in everyday life and 'revolves around issues of production, consumption, and use of public services and public goods reframed as a common means for a decent everyday life'; the second is public space, exemplified by streets, subways, cafés, and public gardens; the third is art and 'collective visions within which each individual may find a place', which help urbanites to 'conceive of the city as a collectively produced living place'. These commons are not necessarily 'perceived as such', but are instead a form of 'potential urban commons' or even 'the commons of tomorrow' (Susser and Tonnelat 2013, 108-9). Citizens should be the 'primary stakeholders' in urban commons; one of the 'practical as well as theoretical challenges is to invent for each commons, the right mix of institutional and community controls and their reach' (Susser and Tonnelat 2013, 108).

Susser and Tonnelat's three kinds of commons can all be found in Jakarta's kampungs. However, the social and political structures in the kampungs are designed to manage individual and household crises and to satisfy the authorities' need for governance tools, rather than to protect commons or to address collective needs. In the conclusions I will return to this need for organizing a collective of 'primary stakeholders' to control and sustain the commons.

\subsection{Cities as Commons}

Cities constitute a specific issue in the debate about commons. 'The ambience and attractiveness of a city [...] is a collective product of its citizens [...] and thereby create something common as a framework within which all can dwell' (Harvey 2012, 74). As I understand Harvey in this case, is that the commons of a city is not only or always connected to a certain identity but also a mode and way of being, what Simone has referred to as 'cityness' (Simone 2010). It is intangible, still a resource. However, this resource is not just lying there, ready to be harvested (as a common field, or natural resource) but is produced (and presumably reproduced as well). Harvey sees 'the metropolis [... as] a vast common produced by the collective labor expended on and in the city' $(2012,78)$. Simone has a similar view of urban commons as 'work in progress' (Simone 2014, 6). The commons are not 'an assortment of public goods' but rather a way 
of creating relations and envision collaboration (Simone 2014, 261-63). I understand this production as a creation of relations, and the more socio-economic, cultural and political relations that exist in the city the stronger, or more 'fertile', is the urban common. In my view this way of conceptualising urban commons rhymes closely with Susser and Tonnellat's idea about urban commons as collective visions and the importance of having stake holders 'producing' (in Harvey's terms) and controlling these resources.

A more specific way of commoning urban space is squatting (Casas-Cortés, Cobarrubias, and Pickles 2014, 460-61). Maribel Casas-Cortés, Sebastian Cobarrubias, and John Pickles illustrate this with the European tradition of house occupation, describing Cañada Réal in Spain as an example of squatting that creates informal settlements. These commons are especially vulnerable to threats of eviction and market exploitation (Harvey 2012, 77). When they disintegrate, there are severe ramifications for the community: 'By the time the market has done its destructive work, not only have the original residents been dispossessed of that common which they had created [...] but the common itself becomes so debased as to be unrecognizable' (Harvey 2012, 78). This has repercussions for the daily life of citizens: 'Those who create an interesting and stimulating everyday neighbourhood life lose it to the predatory practices of the real estate entrepreneurs, the financiers and upper class consumers' (Harvey 2012, 78). The parallel between the loss of the commons and the kampung evictions in Jakarta described by Lea Jellinek (1991) is striking. In these evictions, families are not only dispossessed of their houses; their livelihoods and life worlds are also shattered. The conclusions I take with me from Harvey is that although being crucial to the communities 'life and livelihood' commons in the kampungs are transient 'work in progress' lacking a social group of stakeholders for their protection.

\subsection{Argument and Analytical Strategy}

I argue that the private investments locals make in their houses are not simply made for economic profit, but also partly an effort for them to be incorporated into kampung society and to build a sustainable livelihood. Hence, evictions cause severe repercussions. Kampungs are not necessarily perceived as a commons by their inhabitants, and they are fragile resources that depend on weak institutional arrangements.

To elicit the reasons underlying people's choice to invest in housing, kampungs need to be examined as an intangible common comprising 
material structures, socio-economic relations, the political administration, and juridical agreements. Just as the metropolis is a common created through collective work that adds or create value (Harvey 2012), a kampung is a work in progress produced by the people living in it and formal inclusion in a kampung protects people to some extent. Being recognized as part of a kampung entails paying taxes for houses, having an official address, taking part in elections to the local political administration, etc., all of which are used by the inhabitants to argue that they cannot be defined as illegal. However, although they sustain the lives of the inhabitants, the kampungs are vulnerable to various pressures since they are not supported by any explicit institutional framework and are not defined as commons either by the people living there or by other citizens. Kampungs are vulnerable for three main reasons. First, they lack what Ostrom (1990) has defined as crucial for a common, namely an institutional framework that defines the responsibilities and rights of a specific social group in relation to this resource. Second, the kampung is an immovable resource that people cannot take with them if they are evicted. Third, the kampung is difficult to use as a base for political mobilization because it combines a variety of value regimes rather than constituting a single resource. They constitute a kind of assemblage of resources that varies from social networks, influence over political decision makers, work opportunities, access to loans, etc. These are resources embedded in social, economic and political fields that, although being intertwined, have their own values and logic.

\section{$3 \quad$ Method and Implementation}

This chapter builds on material from my own fieldwork and from burgeoning research on kampungs in Jakarta. The ethnographic material derives from three periods of fieldwork (one month in 2012, two months each in 2013 and 2014). Three neighbourhoods along the Ciliwung River in Jakarta were chosen as research sites. One main reason for choosing these specific kampungs was that they included established and long since recognized settlements and on their fringes, more recent housing areas that aspired to be incorporated into the settlement and to transform their official status from illegal to legal. A mixture of participant observation, interviews, casual conversations, and structured and unstructured observations was used. Thirty formal, recorded interviews were conducted with people living in the three kampungs; each series of interviews was initiated with a focus 
group of four to five people. After the initial meeting with each focus group, individual interviews were set up with each of the participants. In addition, interviews with leaders in the political and administrative systems of the kampungs were also conducted. Apart from these three neighbourhoods, regular visits were made to two additional kampungs. In one, relations were established with representatives of a local non-governmental organization (NGO) that focussed on search and rescue activities. The cooperation with this specific NGO resulted in boat trips along Ciliwung river and several discussions about hazards experienced by people living along the river. In the fifth kampung, several meetings were held with an NGO that focussed on poverty reduction and social work. In the meetings with the two NGOs, a variety of issues ranging from search and rescue procedures to eviction and the socio-economic strength of the communities were discussed. Apart from formal interviews, observations and casual conversations were conducted throughout fieldwork. These included everyday conversations with people living and working in the neighbourhoods and with the participants from the focus groups (but without recording devices or prepared questions). Notes taken on these observations and conversations were compiled in a field diary.

\section{Jakarta Kampungs-A History of Transience or Resilience?}

In the Indonesian-English dictionary, the kampung is translated as 'village' (Echols, Shadily, Wolff, Collins 1992, 258). In Poerwadarminta's lexicon kampung is equated with desa ('village'), but also with city blocks of low status and uncivilized behaviour (Poerwadarminta 1996). However, the definition of kampung remains a matter of debate (Guinness 2009; Krausse 1975). John Sullivan has made the case that kampung were 'a modern development of relatively recent vintage', where the 'Indonesian state provides the crucial vessels which give this type of community its characteristic outer form-its shape and social boundaries-plus some of its internal structuring' (1992,11). In his discussion on community building in urban kampungs, Patrick Guinness (2009) argues against the idea that community values are being undermined by modernity and the state, which posits that the kampung is a 'state construction without strong foundations among urban residents'. Nor does he share the scepticism of Hans-Dieter Evers and Rüdiger Korff $(2000,237)$ about the 'potential of kampung communities to defend their location or achieve 
their demands against state pressures' (Guinness 2009, 23). ${ }^{3}$ Instead, in Guinness's view, kampung society is full of acting subjects and 'strong local impulses to community' (2009, 24). Although Guinness conducted his study in Yogyakarta, his findings are echoed in Jakarta (see Hellman 2015; van Voorst 2013; Wilhelm 2011). Given these contrasting images of the kampung that have emerged from the research, in this chapter I explore how the notion of a resilient civil society might be compatible with that of fragile communities that are unable to mobilize enduring political resistance.

\subsection{Kampung Kota}

In this section the ambiguities and contradictions inherited in the concept kampung is described. In the end of the paper I will return to my view of the kampung as an assemblage of resources which has the potential of being constituted as a form of urban common.

Jakarta is often referred to as a kampung kota ('urban village') because of its peculiar skyline with skyscrapers surrounded by low-rise village buildings and the ambiguity of its social forms, which do not readily fit into a binary system of modern vs. traditional or city vs. village (Sihombing 2010). ${ }^{4}$ The concept of kampung carries the connotation of rural life (Krausse 1975; Sihombing 2010), but is definitely part of forming the city of Jakarta. The term kampung does not correspond to an administrative unit in Jakarta and has no clear-cut criteria for delineation (Krausse 1975). ${ }^{5}$ However, many kampungs are old settlements (Krausse 1975) that form part of the city's history and constitute landmarks for local belonging to a territorially bound community (Krausse 1975, 34; Sihombing 2010, 84).

The kampung consists of a certain type of housing, with one- and two-storey buildings crammed into densely populated areas that have under-dimensioned infrastructure in terms of roads, water supply and sanitary equipment (Sihombing 2010). Living in a kampung also denotes

3 Somantri (2007) also concludes that resistance happens but is not formalized into an enduring form and does not affect decision-making processes or build long-term empowerment.

4 Terry McGee relates the concept of kampungkota to the development of kotadesa ('village cities') where he argues against the conventional idea of urbanization as a 'spatial separation of rural and urban activities' (1991, 4). Jakarta is placed in a category of desakota ('city village') with a 'mixture of agricultural and nonagricultural activities' (McGee 1991, 7).

5 A specific administrative unit adapted to the kampung level, called Rukun Kampung, has been phased out in favour of one at the Rukun Warga ('neighbourhood') level (Guinness 2oog, 12; Jellinek 1991, 124) 
a particular quality of life. The word kampung can be used adjectivally as kampungan to refer to 'uncivilized social behaviour' (Harjoko 2009, 7). Kampung communities are usually regarded as backward, pre-modern, poor, and unhygienic. However, this has changed somewhat as kampung has also become a 'symbol of identity, a nostalgic link to the past or to one's kin or adat (tradition)' (Guinness 2009, 33). Kampungs are often described as poor and containing semi-permanent buildings that are easily washed away by floods and destroyed by fires, and this creates an image of vulnerability and transience (Jellinek 1991). ${ }^{6}$ On the other hand, they have a documented capacity to quickly re-establish social relations and physical structures after floods and fires (Hellman 2015; Wilhelm 2011). In his doctoral thesis, Sihombing explores this ambiguous relationship by starting out from Jellinek's (1991) research of an urban kampung in Jakarta in which she highlighted the different views held by kampung dwellers and planners: 'The former saw the kampung as a bustling hive of activity and a place of hope, a stepping stone to a better standard of living. The latter saw it as a slum whose inhabitants were caught in a vicious circle of poverty' (Jellinek 1991, xix).

Thus, although the kampung is a symbol of belonging that is imbued with a certain nostalgia, it is also frowned upon as backward and uncivilized. These conflicting images can coexist in the concept of kampung kota (Sihombing 2010). The kampung and kota ('city') are structuring tropes in the self-image produced in and of Jakarta. They seem to be antagonistic (corresponding to a rural village versus an urban space), but in reality they are symbiotic. The large malls, administration, and business communities that are usually associated with kota are dependent on the cheap labour force living on inexpensive plots of centrally located urban land. Since the prices of land and housing in central Jakarta are high, labourers are forced to illegally occupy land. For their part, kampung dwellers are economically dependent on the jobs created by the service sector. Hence, for people with a weak economy and insecure working conditions the kampung is a key to the city (Jellinek 1991, xviii-xxiii).

\subsection{Kampung as Community}

In her fine grained ethnography of a local neighbourhood in Yogyakarta, Newberry (2006) unravels the meanings of community. However, as

6 Although often depicted as poor and vulnerable, most kampungs include a broad socioeconomic spectrum ranging from dirt poor to middle-class. 
Newberry points out the term community is multi-layered and at a closer look becomes rather ambiguous in the kampung context (see also Guinness 2009, 4-15, 33; Jellinek 1991, xxii; Sihombing 2010, 93-115; Wilhelm 2011, 43-5). In Clarke's excellent overview of the concept of community, he points out that it has been used to connect-and moves effortlessly between'vernacular discourses with governmental ones; political discourses with academic ones; emotional discourses with analytic ones; and nostalgic discourses with ones in which futures are imagined and anticipated' (Clarke 2014, 54). This malleability makes the concept hard to pinpoint, but gives it a certain attraction. Among other things, 'community' may be used to refer to a place, a particular form of social relations or identity, or a social and analytical scale (Clarke 2014, 48). All of these usages can be found in the literature on kampungs. Although being an academically inconsistent concept, 'community' has been a concept regularly used in both politics and everyday lives of many people.

According to Sihombing's (2010) research, the closest one can come to a sense of community in the kampung is found in social formations such as the Rukun Tetangga (RT) which is an administrative section of a kampung (Sihombing 2010). Antony Sihombing $(2010,93)$ defines 'community' as a 'group of people living together [...] united by shared interests or sociocultural background'. While he describes the kampung as a geographically delineated space, this sense of community is found in the RT. The RT has an elected leader and is the smallest administrative unit in the political administration of Jakarta; Sihombing locates the 'community' in the RT because it is the administrative level and social formation in which mutual help and collective work are organized and performed. My own fieldwork partially corroborates Sihombing's observations. I found that some mutual help, locally termed gotong royong, was conducted by neighbours at the RT level, but that it was not necessarily organized by the RT leader. The RT was an important link between households and the government, as well as between NGOs and charity organizations. However, socio-economic safety nets were not constructed in relation to the formal RT organization; instead, they were built through individual networks of reciprocity (Hellman 2015, 474-76). Hence, according to my findings, the RT did organise some practical work but did not foster any strong notions of identity or community.

Widely used but loosely defined, the meaning of kampung rests somewhere between 'community' and 'neighbourhood' (Sihombing 2010, 115). The concept of the commons may shed light upon this space between a neighbourhood and community, as it frames the kampung as a socially 
constructed resource and includes, but is not limited by, geographical and material dimensions while still expressing a sense of belonging.

\section{Kampung Pulo-Building Houses and the Construction of} Commons

In contrast to the people in Everett's (1999) report, cited in the introduction, the squatters of Pulo are long-time residents who live on the margins of an established neighbourhood. The settlement has slowly grown beyond its original boundaries and invaded the riverbanks. Several of those I interviewed recalled that the river had been wide and clean a few decades ago and that the riverbank had been their playground when they were small. Most of the houses on the riverbank date from the 1960 or or later. Syafrudin, one of the RT leaders in Kampung Pulo, for instance, has lived his whole life (about forty years) in the same house on the riverbank. After a severe flood in 2007, it was levelled and he had to rebuild it from scratch. For this reason, most of the houses were rebuilt recently, although their histories in fact date back several decades. Kampung Pulo is one of the oldest kampungs in Jakarta and is well known to a broad audience because the media frequently uses it as an illustration of the annual problem of urban flooding, which takes a hard toll on buildings all over the city and negatively impacts health and the economy.

Administratively, Kampung Pulo is part of the Kelurahan Kampung Melayu district. ${ }^{7}$ As with other parts of Jakarta, Kelurahan Kampung Melayu is divided into RTs, with a few hundred people, and RWs (aggregations of RT), each level represented by an elected administrative leader. The official task of RT and RW leaders is to create harmony and stability and assist the state bureaucracy in producing and processing documents and implementing political decisions. However, the leaders are elected by the local community (through a kind of informal elective constituency), who then expect them to represent their opinions (and not the government). The RWs are in turn aggregated into the Kelurahan level (i.e., Kelurahan Kampung Melayu), which has a lurah ('leader') appointed by the Governor. ${ }^{8}$

Kampung Pulo is in many ways a typical Jakarta riverbank settlement (Vollmer and Grêt-Regamey 2013, 1552). It offers a good illustration of what

7 By coincidence, the Kelurahan includes the term kampung in its name.

8 Kelurahan Kampung Melayu consists of about 30,000 inhabitants, while the geographic area of Kampung Pulo comprises approximately 15,000. 
happens when urban development from below meets top-down city planning efforts that fail to take into consideration the existing local 'socially constructed spaces' (Padawangi 2012, 336). The part of the neighbourhood that is threatened with eviction has been built without permission on the state-owned land of the riverbanks. While the majority of houses in Pulo have unclear legal status, whether a household is identified as a squatter household is only of real concern for those on the riverbank, which is affected by flood mitigation projects. ${ }^{9}$ These projects involve the construction of protective walls and inspection roads along the riverbank, and therefore require all households close to the river to be relocated. Jakarta's flood mitigation projects are 'bluntly' formulated, with little or no consideration of the local context (Vollmer and Grêt-Regamey 2013, 1552; Padawangi 2012). Their main weakness is a failure to acknowledge that simply offering financial compensation or substitute housing in apartments is inadequate. Eviction implies both immediate economic losses and further effects on people's livelihoods. As will be described in the next sections, houses play an important role as a node of relationships in the kampung; they are not only material assets, but provide a means for people to become established as social and juridical subjects, which in turn is key to the pursuit of sustainable livelihoods.

\subsection{The Creation of Legal Houses and Subjects}

Tenure security is not only about ownership, but also about establishing a proper house and positioning it within a wider environment of legal and social space and everyday living. In my fieldwork, I found that although the households were included in the administrative system the legal status of property owners and their tenure rights were constantly being called into question. Those who live on the riverbanks are by default defined as squatters by the authorities, since the law prohibits building on the riverbank..$^{10}$ Although recognized as a formal RT, the people did not possess any formal building permits or tenure documents. When I asked about the legal status of the buildings, they produced receipts for taxes paid for the land and surat keterangan ('formal sales contracts') that had been stamped by the lurah. However, surat keterangan simply document the completion of a transaction that has been accepted by the involved parties and witnessed

9 For an overview of Indonesia as a 'project society', see Aspinall (2013).

10 The Jakarta Governor Joko Widodo stated in 2014, 'We will not tolerate people occupying riverbanks anymore' (Jakarta Post, 2014). 
by the lurah; it does not include formal acceptance of tenure rights by the authorities. ${ }^{11}$ Acquiring formal recognition of landownership is an expensive and complex bureaucratic process that involves seventeen administrative steps and eighteen different agencies (Nikmah 2010, 11; Tunas and Peresthu 2010, 320). ${ }^{12}$ The costs and knowledge required makes the process unfeasible for most kampung dwellers, and the result is that most have only informal rights to their property. This means that from a legal perspective they can easily be evicted. ${ }^{13}$

The strongest evidence used to demand acceptance as legal residents were receipts from the Pajak Bumi dan Bangunan ('tax for land and houses'), also known as the PBB. The PBB is a tax based on the size of land occupied, its location, and the standard of the house. Documents like surat keterangan and PBB receipts were treasured and considered valuable assets, and they were among the first items to be protected in an emergency, such as a flood or fire. However, many people lacked this piece of evidence, whether for economic reasons, ignorance, or destruction by floods and fires. In these cases, people might appeal to their inheritance or informal rights to the land. People living in the kampung referred to land as their inheritance and claimed that their situation was different from that of squatters in other areas, who were first-generation settlers. They argued that even without any formal or documented ownership they had certain rights. In interviews, they stressed that the land was a turun temurun ('inter-generational inheritance') and that they lived in a 'real kampung', meaning that they considered inheritance rights as applicable to the land there.

Having one's house accepted as part of an RT is the first step in avoiding being labelled as a squatter, and therefore enhances tenure security. RT status positions a house in a specific place and is a means of acquiring a Kartu Tanda Penduduk ('identity card'), also known as a KTP, which is mandatory for all Indonesian citizens. The KTP is an important piece of evidence proving that a person has been recognized as a citizen at a specific location. To secure a KTP, the applicant requires an address. This means that

11 See Mercy Corps $\left(2008,5^{-9}\right)$ for a comprehensive overview of the complexity of informal and formal ownership of land in Jakarta.

12 See Raharjo (2010) for an overview of Basic Agrarian Law (BAL), which gives the state the right to control land, water, and airspace. See Winayanti $(2010,86-9,141-66)$ for a more detailed presentation of this law and obstacles confronting people who try to register land rights. Kusno describes the situation as a tacitly accepted 'legal dualism' $\left(2013,145^{-49}\right)$ that regulates the formal and informal ownership of land.

13 This is not unique to the urban context. Only 1 per cent of all land in Indonesia is claimed for private ownership (Tunas and Peresthu 2010, 320). 
the house is not only a physical building, but also a tool for gaining recognition as part of the legal and administrative system. The status of belonging to an RT provides the person with an address and hence the possibility of getting a KTP. The registration of a KTP at a particular address means that the house has been incorporated into the local community and is accepted by the authorities. The existence of the house is proven by a PBB receipt and/or the surat keterangan, which vouches for the physical permanence of the house and its historical record. In turn, the house legitimizes the KTP connected to its address.

A KTP is necessary to prove one's identity as a citizen of Jakarta. KTPs give the right to schooling, healthcare, and other social services; those without them are treated as illegal citizens of Jakarta (Winayanti 2010, 169). Migrants from other parts of Indonesia who move into houses and rental spaces are not granted a permanent KTP for Jakarta. Their KTPs place them in their villages of origin; in case of eviction, they are directed back to their home village. It is therefore not the legal status of land ownership that concerns people in Pulo per se, but how it affects their status as citizens. 'It is not the illegality of land tenure that kampung residents consider to be a problem; rather it is how their rights as citizens are affected because of the status of their land tenure' (Winayanti 2010, 221). In short, property ownership is a way to be recognized as a citizen. Owing land provides people with an address and hence a KTP. According to Nikmah (2010), the two major reasons people are evicted as squatters are because they lack land certificates and do not possess a KTP Jakarta.

The RT has a restricted geographical outreach that does not correspond to either the kampung or individual's socio-economic networks. The RT administration and the services it provides can be used to articulate specific needs of the community or individual households. At the same time, it is an administrative form that fragments political mobilization and helps govern the political space. While this administration affects all inhabitants, it does not correspond to any ethnic, religious, or socio-economic criteria that strengthens a sense of belonging. Everyone is more or less dependent on an efficient RT administration, but RTs do not nourish a sense of solidarity (cf. King and Idawati 2010, 2).

\subsection{Commons as Public Space, Labour, Consumption, and Services}

Raharjo $(2010,2)$ argues that 'in informal settlement development tenure is gained gradually through unauthorised territorial claims, largely by means of the production of the built form'. This description is very much 
in agreement with how the establishment of riverbank settlements in Pulo has happened. ${ }^{14}$ People invested not only in their own houses, but also in the environment and infrastructure. They bought water pumps to clear the streets from floods and to extract ground water for cooking and washing. Some of these were financed by allocations from the lurah's budget, but most of them were paid for either by private charity or neighbours pooling their money. Water, drainage, and sanitary facilities were not fully provided by the authorities; instead, they were left for local, private, and community organizations to solve. Although it is possible to link up with tap water facilities, the costs are prohibitive for most people living on the riverbank. In Pulo, several sanitary facilities have been built by the community to cater to the needs of the large number of households that lack private bathrooms. These facilities were financed by either neighbours pooling their resources or by private enterprises that charge a small fee.

When Syafrudin described the changes that had taken place since he was a child, he noted modifications in the environment: houses are now built with more permanent materials; they have communal water pumps; and there is cement on the roads. These changes were corroborated in interviews with other people. Such changes both indicate economic prosperity and signal historical permanence: the anticipated endurance of the neighbourhood into the future. When I was walking through the kampung with one of the residents, he pointed out that the whole community had adapted to the recurrent floods by building two-storey houses, attaching ladders to the upper floor so boats could be accessed during floods, and tying ropes along the pedestrian paths to help people walk through minor inundations. He claimed that this shows how people adapted to the local circumstances, and in turn demonstrated that the neighbourhood had existed for a long time and was not a recent illegal settlement.

The lanes between the houses are used for shops and warungs ('small eateries'), washing, drying clothes, and breeding chickens. Most households have established some sort of trade, often in everyday commodities and food products. Usually they place a few chairs on the street, which become meeting places for gossiping and socialising in public spaces. Syafrudin's house is a good example. As we sit outside the front door chatting, we are constantly interrupted. His wife is selling instant coffee and everyday household items from a rack at the front door. The drinks are made to either take away or consume on the spot while talking with Syafrudin, his wife, me, 
or other visitors. Others come by to have their phones repaired. Syafrudin makes money by selling cell phones at the market. He recently took a course in repairing and servicing phones, and now offers these services at his home as well. Since Syafrudin is an elected RT leader, people drop by to have letters signed, to claim social services, or for other administrative matters. A dog starts barking in the distance and the visitors begin to gossip about the stress people have been feeling because of a roaming stray dog. This description of one visit to Syafrudin is typical. Apart from being the home of an extended family, the house functions as a social hub, an administrative office, a repair shop, a storeroom (for cell phones), a convenience shop, and a small restaurant.

Syafrudin's house mirrors the kampung as a whole by mixing private, state, and collective ownership and usage. Kampung houses are open to the public space of the street, but privacy increases as people move into, and up the stairs of, the house. Every front door is open and everyday life is played out in the semi public/private sphere of the front room. There is no sharp distinction between private and public space; one simply fades into the other. The privately owned houses stretch outward through warungs and public facilities, and the public space seeps into the privacy of the house through the same activities and the open doors. The same goes for the administrative, political, and juridical space in which the RT-level activities move between the private (for example, the administrative archives kept inside the house) and public (street) sphere.

The borders between public, private, and semi-public space in the kampung are diffuse. However, this also makes space into a sort of public good: a commons to be used for the establishment of cafés, new streets (as houses are built), and public facilities such as sanitary services and water pumps. Space may be appropriated for private purposes when building a house or a raft for transporting people over the river. However, the space that is considered private by the house owners is seen by the authorities as a public space occupied by squatters.

\subsection{Commons as Risk Management}

Pulo is hit every year by floods ranging from a few decimetres to several metres. These are recurrent disasters that take a hard toll on houses and the environment, as well as on human resources. Major repairs are needed every year. All families living on the riverbank struggle to raise the financial and human resources to cope with the floods, unemployment, and disease. Ibu Sunayan, who has single-handedly managed one of the poorest families 
in the kampung ever since her husband's death, has rebuilt her house three times. To manage these uncertainties, socio-economic networks in the form of family, neighbours, employment contacts, and rotating savings organizations have developed in Pulo, as is common in poorer communities that lack formal social security systems. ${ }^{15}$ These networks are built on reciprocity and exchange, rather than on shared values or solidarity based on identity (e.g., religion or ethnicity). The networks are spun from each household and differ according to people's skills and circumstances. Sunayan, for example, used a combination of state emergency relief, private charity, and personal networks of neighbours and relatives to raise credit and resources for rebuilding. The saving systems and socio-economic networking in urban kampungs described by Hellman (2015), Lont (2007), Simone (2010), and Simone and Fauzan (2012) provide a certain degree of security and supports Guinness' perception that kampungs are communities with strong agency.

However, when it comes to external actors involved in risk management the picture is more diverse. In some places external actors are very active and present while in other they are not. According to interviews and a provisional compilation by Forum Permukiman Jakarta (Forum of Jakarta Housing and Settlement for the Poor), also known as Forkim, surprisingly few NGOs or Community Based Organizations (CBOs) engaged in long-term empowerment projects have been established in Kampung Pulo. The NGOs that are present tend to focus on emergency relief and charity. One exception is Ciliwung Merdeka, an NGO known to be working with empowerment projects in Pulo. However, their main location and activities are in Bukit Duri across the river. This partly contrasts with Padawangi's (2012) findings in kampungs located in North Jakarta, where there are NGOs with long-term commitments to advocacy and mobilisation of the locals in negotiations with the authorities. What does correspond if one compares the different

15 In their book Ropewalking and Safety Nets: Local ways of Managing Insecurities in Indonesia, Koning and Hüsken (2006) analyse the weaknesses of the official security systems in modern Indonesia. In the absence of a state-regulated social security system, risk has been dealt with through reciprocal networks. Lont (2005) also points to the multitude of self-help organizations concerned with microcredit that exist independently of the state in Javanese communities. Sullivan (1992, 71-84), Jellinek (1991, 34-40), and Guinness (2009, 101-16) have all documented the importance of locally embedded social security nets in small-scale, poor societies in Java. Drawing on decades of research, Wisner et al. (2004) conclude that in general resilience systems in poor communities consist of diversifying incomes and the development of social support networks. The World Bank also acknowledges that although having livelihoods that are relatively fragile $[, \ldots]$ well established social networks $[\ldots]$ are $[\ldots]$ one of the adaptive strengths of Jakarta's urban poor' $(2011,21)$. 
kampungs is that civil society, NGOs and state institutions parallel each other and work both in cooperation and in conflict with each other. ${ }^{16}$ So, although a certain coherence exist in how socio-economic networks are established to deal with risk the engagement of external actors differs a lot between kampungs.

\subsection{Commons as Collective Visions}

A common may be constituted by a sense of community, the community itself being a resource to draw on in times of crises. However, of the three commons described by Susser and Tonnelat (2013) the sense of a collective identity may, at least in Kampung Pulo, be the weakest, and I will return to this point in the conclusion. The term kampung is a living, vernacular notion in Jakarta that forms part of daily life. However, there are few social, economic, administrative, or political forms that correspond to or are articulated through this concept. It is nevertheless a concept that is used in relation to belonging and it is crucial in the imaginary of Jakarta and is sustained in research and the media as well as by locals. It is an expression that is used to identify a place (e.g., 'I live in Kampung Pulo'). Kampungs are marked on maps of Jakarta, but the term is also used to refer to a particular way of living and to a judicial sphere. People say, for instance, ini benar benar kampung ('this is really a kampung') when claiming hereditary land ownership rights. The term is also used in expressions such as pulang kampung ('going home to one's origins, family, place, and village') and there is even a Facebook community for Kampung Pulo (that is mainly used to communicate flood warnings). The term also frequently appears in the media to denote a place or a way of life, such as in kampung kumuh ('dirty, poor kampungs'). For example, in Tribun Jakarta (2014) the Governor of Jakarta was quoted as saying that he hopes that Jakarta will rid itself of kampung kumuh and replace them with kampung deret ('well organized and state-built, small-scale housing').

The collective visions of the future of the kampung is strikingly contradictive and although being a living concept there seem to be few visions of a kampung community or kampung solidarity. There is no 'group of stake holders' protecting the kampung albeit the mass of resources assembled under this conceptual umbrella.

16 A good example of how this works is van Voorst's (2014) description of rights and the relatively autonomous way people search for support from different actors and organizations. 


\subsection{The Intertwining of the Three Commons}

The three commons (located in everyday life, public space and collective visions) described by Susser and Tonnelat (2013) are intertwined in Jakarta's kampungs. The every day life commons, labour, consumption, and services are, in different ways, located and related to the house and to the status that the house provides to its inhabitants as legal citizens. A 'squatter' is usually defined as someone who lives in or on property that they have occupied. However, in Kampung Pulo, a well-built house (on occupied land) is the best form of proof that the inhabitant is not a squatter. It is also a hub that interconnects the three commons. The house opens up avenues into different forms of collective visions of belonging, that of the citizen as well as of being part of a kampung community. Owning a house is the key to becoming a legitimate citizen: it provides the owner/builder with receipts for taxes and contracts for transfer of ownership that are witnessed by legal authorities in the political system. The house represents one's longstanding presence; the tiled floors and concrete walls are symbols of an anticipated enduring future existence. The house enables a person to establish their presence in an RT, and also in the socio-economic life of the kampung and beyond. The house also constitutes a crossroad between every day life and the public. It is a place where a shop may be established, and it provides a hub for entrepreneurship and socio-economic security nets that extend beyond the RT and the kampung. The private space inside the house fades into the public space of the street, where everyday chores such as laundry and drawing water are done and where the public sanitary facilities are located.

The commons of the kampung consist of an assemblage of privately, jointly, and collectively owned space, material assets (such as houses, pumps, and sanitary facilities), and social relations (such as safety nets). The value created is a common, the kampung. This resource is used by people living within the geographical parameters of the kampung to create a viable livelihood. The patchwork of administrative institutions, private organizations, working spaces, socio-economic safety nets, social relations, and bonds of affection add value to the kampung. This value is not easily verbalized or conceptualized, although it is implicit in expressions such as betah di sini ('I like it here') or aman di sin ('I feel safe here'). Indeed, such value may not be recognized at all until it is threatened by eviction. When evicted, 'relationships of mutual aid and social networks are dismantled as populations disperse. These social networks are a critical survival tool for the urban poor who must constantly weather economic fluctuations and uncertainty. Even when families receive compensation for lost homes, 
these social relations are virtually irreplaceable' (Everrett 1999). Since the kampung is a commons that lacks the institutional framework necessary for sustainable use, it easily falls apart.

As mentioned, the kampung is what Simone terms a constant 'work in progress' (Simone 2014, 6) and Susser and Tonnelat label a potential (emerging) or even future commons. These commons are not necessarily 'perceived as such', but are rather a form of 'potential urban commons' or 'the commons of tomorrow' (Susser and Tonnelat 2013, 108-9). They provide services that are often taken for granted by their users. Recalling Mattei's remarks on the intrinsic value of commons, 'many of those who benefit from the commons do not take into account their intrinsic value, only acknowledging it once the commons are destroyed and substitutes need to be found' (Mattei 2012, 38). The kampung is, as I see it, a shorthand for a temporary assemblage of resources (such as fresh water, sanitary facilities, access to political structures and private donors, socio-economic security, and work) that together provide a sustainable livelihood. Although it is private property, the house is the entry point of a relationship with, and a way of creating, these commons. It is a living and working place, but it is also a ticket for establishing oneself as a juridical subject (a citizen) and neighbour. It is therefore not only a house, or simply a material or social space. It is a key for establishing people as stakeholders in a social relation with the intangible commons that are subsumed within the notion of the kampung.

\section{$6 \quad$ Conclusions and Future Research}

Commons take different forms in different cities according to context and history. In this chapter, I have argued that in Jakarta the kampung is an important form of commons. Although Jakarta's kampungs have been dismantled for a long time through evictions and expropriations, they are part of the city's history and continue to play an important role in the everyday lives of the city's vulnerable inhabitants. It is therefore worth considering what role these vaguely defined but significant social formations may play in the city's future and what rights and expectations citizens have in their formation.

Kampungs are strong and resilient in the sense that their inhabitants are able to establish socio-economic safety networks for dealing with natural disasters. The RT is part of this security system and functions to link households with state bureaucracy and private charities. However, neither the RT nor private socio-economic networks generate a strong 
sense of local identity that can be used to mobilize political solidarity and support. This means that these communities tend to be fragile with regard to political change.

The everyday handling of risk and livelihood through personal socioeconomic networks is ineffective for mobilising collective resistance to eviction threats. People who live only a few hundred metres apart but are separated into different RTs therefore fail to coordinate and organize to create solid resistance or establish themselves as a collective and active counterpart in negotiations about evictions. Dealing with the threat of eviction demands different strategies than coping with everyday threats (such as floods, diseases, accidents, and economic issues). The threat of eviction cannot be handled by households through their socio-economic networks, since these networks focus on providing support during individual and household crises rather than on collective action. Consequently, the socio-economic networks that form the backbone of these communities' resilience do not translate into political strength.

To create a sustainable commons, a group of 'stakeholders' or social group relating to the commons must be delineated (Ostrom 1990). However, in Indonesia, the state will be one of the main actors deciding the future of Jakarta's kampungs. Entering into non-violent communication with the state requires certain conditions, including 'a common subjectivity' (Bertho 2013, 129), a collective vision forwarded by a united group of people, where this vision and the unity may count as a common in Susser and Tonnelat's use of the word. As noted, the urban commons that Susser and Tonnelat have described are only possibilities; it is only collective mobilization that can make them an urban reality. In Pulo, and allegedly in many of Jakarta's other kampungs, the lack of collective subjectivity tends to prevent these resources from being explicitly recognized as commons that deserve appropriate institutional forms of management.

Neither the RT nor socio-economic networks are sufficient for generating political mobilization or claiming ownership of urban space. To strengthen the chance of citizens gaining greater influence in managing and governing urban spaces and create urban commons, 'the future of the commons would be much brighter if the state would begin to provide formal charters and legal doctrines to recognize the collective interests and rights of commoners' (Bollier and Helfrich 2012, xviii). Just as private ownership of houses may seem paradoxical to the establishment of urban commons, it may also seem paradoxical to suggest that the state should protect these commons. Indeed, Bollier and Helfrich warn about the potentially conflicting interests that may arise if commons are managed 'within the existing 
system of law and policy' (Bollier and Helfrich 2012, xviii). However, in Jakarta the legal, social, and political situation of kampung dwellers is extremely unclear. Citizens' rights crisscross between private, civil, and state domains, where responsibilities may be either honoured or ignored. To establish the kampung as an urban commons, an explicit institutional and organizational setup and knowledge of how to manage this kind of non-material commons are required. Future research needs to map out 'the observable processes of 'commoning' and what boundaries, exclusions, and regulations produce urban space as an equitably accessed resource' and how these boundaries are entangled 'with local, political, and administrative institutions such as regional or municipal governments' (Narotzky 2013, 123). It remains a challenge 'to invent for each common the right mix of institutional and community controls' (Susser and Tonnelat 2013, 108). If citizens are to gain influence over urban space as a commons, more research is needed on the potential of establishing local institutional arrangements to build, regulate, and manage commons in the form of social relations, social services, and public space. We need to know about the forces that inhibit the emergence and definition of these spaces as urban commons and also about the forces that may be mobilized to sustain them and build viable institutional management systems.

\section{Works Cited}

Alonso Gonzalez, Pablo. 2014. 'From a Given to a Construct: Heritage as a Commons.' Cultural Studies 28(3): 359-9o. doi: 10.1080/09502386.2013.789067.

Aspinall, Edward. 2013. 'A Nation in Fragments: Patronage and Neoliberalism in Contemporary Indonesia.' Critical Asian Studies 45(1): 27-54. doi: 10.1080/14672715.2013.758820.

Bardhan, Pranab and Isha Ray. 2008. 'Economists, Anthropologists, and the Contested Commons.' In The Contested Commons: Conversations between Economists and Anthropologists, edited by Pranab Bardhan and Isha Ray, 1-24. Malden, MA: Blackwell.

Berge, Erling and Frank van Laerhoven. 2011. 'Governing the Commons for Two Decades: A Complex Story.' International Journal of the Commons 5(2): 160-87. doi: $10.1835^{2} /$ ijc.325.

Bertho, Alain. 2013. 'Urban Commons and Urban Struggles.' Focaal-Journal of Global and Historical Anthropology 66: 128-29. doi:10.3167/fcl.2013.660115.

Bollier, David and Silke Helfrich, eds. 2012. The Wealth of the Commons: A World Beyond Market \& State. Amherst, MA: Levellers Press. 
Casas-Cortés, Maribel, Sebastian Cobarrubias, and John Pickles. 2014. 'The Commons.' In A Companion to Urban Anthropology, edited by Donald M. Nonini, 447-69. Chichester: Blackwell.

Clarke, John. 2014. 'Community.' In A Companion to Urban Anthropology, edited by Donald M. Nonini, 46-64. Chichester: Wiley-Blackwell.

Echols, John M., Hassan Shadily, John U. Wolff, and James T. Collins. 1992. Kamus Indonesia Inggris [Indonesian-English Lexicon]. Jakarta: Gramedia.

Everett, Margaret. 1999. 'Human Rights and Eviction of the Urban Poor in Colombia.' Land Lines 11(6): 6-8.

Evers, Hans-Dieter, and Rüdiger Korff. 200o. Southeast Asian Urbanism: The Meaning and Power of Social Space. New York: St. Martin's Press.

Guinness, Patrick. 2009. Kampung, Islam and State in Urban Java. Honolulu: University of Hawaii Press.

Hardin, Garrett. 1968. 'The Tragedy of the Commons.' Science 162: 1243-48. doi: 10.1126/science.162.3859.1243.

Harjoko, Triatno Yudo. 2009. Urban Kampung: Its Genesis and Transformation into Metropolis, with Particular Reference to Penggilingan in Jakarta. Saarbrücken: VDM Verlag Dr. Müller.

Harvey, David. 2012. Rebel Cities: From the Right to the City to the Urban Revolution. London: Verso.

Hellman, Jörgen. 2015. 'Living with Floods and Coping with Vulnerability.' Disaster Prevention and Management 24(4): 468-83.

Jakarta Post. 2014. 'Jokowi issues ultimatum to riverbank squatters'. Jakarta Post, 22 January. http://m.thejakartapost.com/news/2014/o1/22/jokowi-issuesultimatum-riverbank-squatters.html.

Jellinek, Lea. 1991. The Wheel of Fortune: The History of a Poor Community in Jakarta. Honolulu: University of Hawaii Press.

King, Ross and Dyah Erti Idawati. 2010. 'Surabaya Kampung and Distorted Communication.' Sojourn 25(2): 1-8. doi: 10.1355/sj25-2c.

Koning, Juliette and Frans Hüsken. 20o6. 'Between Two Worlds: Social Security in Indonesia.' In Ropewalking and Safety Nets: Local Ways of Managing Insecurities in Indonesia, edited by Juliette Koning and Frans Hüsken, 1-26. Leiden: Brill.

Krausse, Gerald Hans. 1975. 'The Kampungs of Jakarta, Indonesia: A Study of Spatial Patterns in Urban Poverty.' PhD diss., University of Pittsburg.

Kusno, Abidin. 2013. After the New Order: Space, Politics, and Jakarta. Honolulu: University of Hawaii Press.

Lont, Hotze. 2005.Juggling Money: Financial Self-help Organisations and Social Security in Yogyakarta. Leiden: KITLV Press. 
Mattei, Ugo. 2012. 'First Thoughts for a Phenomenology of the Commons'. In The Wealth of the Commons: A World Beyond Market \& State, edited by David Bollier and Silke Helfrich, 37-44. Amherst: Levellers Press.

McGee, Terry G. 1991. 'The Emergence of Desakota Regions in Asia: Expanding a Hypothesis.' In The Extended Metropolis: Settlement Transition In Asia, edited by Norton Ginsburg, Bruce Koppel, and Terry G. McGee, 3-25. Honolulu: University of Hawaii Press.

Mercy Corps. 2008. Urban Bulletin No. 2: Summary of Land Tenure Research Findings in Jakarta. Portland, OR: Mercy Cops.

Narotzky, Susana. 2013. 'What Kind of Commons are the Urban Commons?' FocaalJournal of Global and Historical Anthropology 66: 122-24.

Newberry, Jan. 2006. Back Door Java: State Formation and the Domestic in Working Class Java. Broadview Press.

Nikmah, Siti Khoirun. 2010. Pengabaian pemerintah terhadap eksistensi penduduk pinggir sungai: Wajah pengelolaan sungai di Indonesia [The negligence of the government towards the living conditions of riverbank dwellers: A management perspective on rivers in Indonesia]. Jakarta: International NGO Forum on Indonesian Development.

Nonini, Donald M., ed. 2007. The Global Idea of the Commons. New York: Berghahn Books.

Ostrom, Elinor. 1990. Governing the Commons: The Evolution of Institutions for Collective Action. Cambridge: Cambridge University Press.

Padawangi, Rita. 2012. 'Climate Change and the North Coast of Jakarta: Environmental Justice and the Social Construction of Space in Urban Poor Communities.' In Urban Areas and Global Climate Change, edited by William G. Holt, 321-39. Bradford: Emerald Group Publishing.

Poerwadarminta, W.J.S. 1996. Kamus umum Bahasa Indonesia [Indonesian word book]. Jakarta: Balai Pustaka.

Raharjo, Wiryono. 2010. Speculative Settlements: Built Form Tenure Ambiguity in Kampung Development. Ph.D. diss., Melbourne School of Design, The University of Melbourne.

Rao, Vijayendra. 2008. 'Symbolic Public Goods and the Coordination of Collective Action.' In The Contested Commons: Conversations between Economists and Anthropologists, ed. by Pranab Bardhan and Isha Ray, 168-86. Oxford: Blackwell Publishing Ltd.

Sheppard, Bede. 2006. 'Condemned Communities: Forced Evictions in Jakarta.' Human Rights Watch, September 5. https://www.hrw.org/report/2006/og/o5/ condemned-communities/forced-evictions-jakarta.

Sihombing, Antony. 2010. Conflicting Images of Kampung and Kota in Jakarta: The Differences and Conflicts, and the Symbiotic Links between Kampung and Kota. Saarbrücken: Lambert Academic Publishing. 
Silver, Christopher. 2008. Planning the Megacity: Jakarta in the Twentieth Century. London: Routledge.

Simone, Abdoumaliq. 2014.Jakarta:Drawing the City Near. Minneapolis and London: University of Minnesota Press.

Simone, Abdoumaliq, and Achmad Uzair Fauzan. 2012. 'Making Security Work for the Majority: Reflections on Two Districts in Jakarta.' City \& Society 24(2): 129-49. doi:10.1111/j.1548-744X.2012.01072.x.

Simone, Abdoumaliq. 2010. City Life from Jakarta to Dakar: Movements at the Crossroads. New York: Routledge.

Somantri, Gumilar Rusliwa. 2007. Migration Within Cities: A Study of Socio-economic Processes, Intra-city Migration, and Grass-roots Politics in Jakarta. Jakarta: Lembaga Penerbit Fakultas Ekonomi UI.

Sullivan, John. 1992. Local Government and Community in Java: An Urban Case-study. Oxford: Oxford University Press.

Susser, Ida and Stéphane Tonnelat. 2013. 'Transformative Cities: The Three Urban Commons.' Focaal-Journal of Global and Historical Anthropology 66: 105-21. doi:10.3167/fcl.2013.660110.

Tribun Jakarta. 2014. 'Jokowi: Semoga di Jakarta Tidak ada Kampung Kumuh Lagi [Jokowi: Hopes that slum areas will disappear from Jakarta]'. Tribun Jakarta, 8 May. http://www.tribunnews.com/metropolitan/2014/o5/o8/ jokowi-semoga-di-jakarta-tidak-ada-kampung-kumuh-lagi.

Tunas, Devisari and Andrea Peresthu. 2010. 'The Self-help Housing in Indonesia: The Only Option for the Poor?' Habitat International 34(3):315-22. doi:10.1016/j. habitatint.2009.11.007.

van Voorst, Roanne. 2013. 'Get Ready for the Flood: Risk-handling Styles in Jakarta Indonesia.' Ph.D. diss., University of Amsterdam.

van Voorst, Roanne. 2014. 'The Right to Aid: Perceptions and Practices of Justice in a Flood-hazard Context in Jakarta, Indonesia.' The Asia Pacific Journal of Anthropology 15(4): 339-56.

Vollmer, Derek and Adrienne Grêt-Regamey. 2013. 'Rivers as Municipal Infrastructure: Demand for Environmental Services in Informal Settlements Along an Indonesian River.' Global Environmental Change 23(6): 1542-55. doi:10.1016/j. gloenvcha.2013.10.001.

Wilhelm, Mario. 2011. 'Approaching Disaster Vulnerability in a Megacity: Community Resilience to Flooding in Two Kampungs in Jakarta.' PhD. Diss., University of Passau.

Winayanti, Lana and Heracles C. Lang. 2004. 'Provision of Urban Services in an Informal Settlement: A Case Study of Kampung Penas Tanggul, Jakarta.' Habitat International 28(1): 41-65. doi:10.1016/So197-3975(02)ooo72-3. 
Winayanti, Lana. 2010. Community Struggles for Land in Jakarta: A Case Study of Kampong Community Struggles to Obtain Security of Tenure. Saarbrücken: Lambert Academic Publishing.

Wisner, Ben, Piers Blaikie, Terry Cannon, and Ian Davis. 2004. At Risk: Natural Hazards, People's Vulnerability and Disasters. London: Routledge.

World Bank. 2011. Jakarta: Urban Challenges in a Changing Climate. Washington, DC: World Bank.

\section{About the author}

Jörgen Hellman is Associate Professor in Social Anthropology at the School of Global Studies, Gothenburg University. He is currently working on a project titled 'Coping with Recurrent Emergencies: The self-organization of Civil Society in Jakarta During Floods'. This is an interdisciplinary project conducted with his colleague Associate Professor Marie Thynell, researcher in Peace and Development Studies. In the project they analyse how civil society organizes itself in times of hazards and how it interacts with the city administration and NGOs. The project studies how city government and citizens in flooded areas of Jakarta act to deal with the risks induced by recurrent floods. What strategies and actions do they formulate to confront these challenges? 


\title{
3 Inhabitants of Spontaneous Settlements in Bangkok: Networks and Actions Changing the Contemporary Metropolis
}

\author{
Fanny Gerbeaud
}

\begin{abstract}
Bangkok is conducive to squatter settlements, that is to say, often illegal settlements developed from an opportunity and need for housing. These houses, which offered shelter to nearly 20 percent of the population of the Thai capital in 2000 (Pornchokchai 2003, 6), represent an opportunity to rethink not only urban development, but also the role of citizens in the fabrication of the city. My research in several spontaneous settlements between 2005 and 2011 shows that people are mobilizing networks to assert their right to the city and their ability to ensure a portion of its management, particularly around issues of historical and cultural heritage and cleaning canals. In the renovated and legalized parts, and in social housing, spatial and social appropriation bring real added value to the neighbourhood. The installation of professional activities, leisure spaces, meeting points, and additional spontaneous housing restore the functional diversity so precious to the Thai people while creating attractive connections at the neighbourhood level. Finally, these illegal but gradually institutionalized transformations renew the practices of city professionals (architects, social housing organizations, urban planners) and the vision of the authorities on how to think about the future of the metropolis. Are informal settlements - once a symbol of poverty - gradually renewing the international image of Bangkok? The participation of these residents in urban fabrication offers an interesting alternative to the planning, construction, and transfer of the construction of Bangkok to a few specialists. The discussion in this chapter is based on interviews with
\end{abstract}

Cabannes, Yves, Douglass, Michael and Padawangi, Rita, Cities in Asia by and for the People. Amsterdam: Amsterdam University Press, 2018 DOI 10.5117/9789462985223/CHO3 
city stakeholders (the population of shanty towns, architects, landlords, and elected officials) and illustrations from spatial analysis.

Keywords: neighbourhood, spontaneous settlements, metropolization, Bangkok, Pom Mahakan, Bang Bua

In 2000, ${ }^{1}$ nearly 20 per cent of the population of Bangkok, Thailand was living in spontaneous housing settlements, making it a good example of metropolises in emerging countries (Pornchokchai 2003, 6). While in the past the principal cause of using spontaneous housing was rural exodus, nowadays the lack of affordable housing near workplaces, along with demographic and land pressures lead residents with different living standards and educational backgrounds to reside in such settlements. The housing is sometimes irregular (squatting), sometimes governed by implicit contracts (rent or unreported taxes) whose terms are frequently re-negotiated with the major landowners. ${ }^{2}$ Some settlements existed even before Bangkok became the capital of the Kingdom; when there is no proof of land ownership, one claims common law rights inherited from Thai 'feudalism' - the so-called Sakdina System.

Tenure insecurity and the changing nature of housing are common denominators, even for residents who may at the same time have financial comfort and a rewarding professional status. Pornchokchai notes that most residents of spontaneous housing settlements have been Bangkokian for generations. They stabilize their economic and housing situation over time, which tends to confirm that such spaces play their full role as a

1 A census in 2000 reported 796 communities in Bangkok that concentrated 19 per cent of the inhabitants of the capital (Pornchokchai 2003, 6-11). Housing in slums in 2005 accounted for only 5 per cent of the capital, according to the Thai Appraisal Foundation (Interview with Sopon Pornchokchai, president of the Thai Appraisal Foundation, by the author, February 2007). Spontaneous settlements developed due to a lack of jobs in the provinces, impoverishment of a part of the population, and soaring property prices. Today, it is mostly due to the urban growth of Bangkok. The seasonal movement of provincial farmers into Bangkok to work on construction sites partly explains the persistence of these sectors.

2 The Crown Property Bureau and the Buddhist monasteries own large plots in the heart of the capital. Some institutions (the Department of Public Works, Bangkok Metropolitan Administration) manage non-constructible land. Canal banks, land adjacent to roads, and rail infrastructure are often filled with spontaneous housing because the Town Planning Code does not allow construction there. 
Figure 3.1 Maps of (a) Thailand and (b) Bangkok with Pom Mahakan and Bang Bua
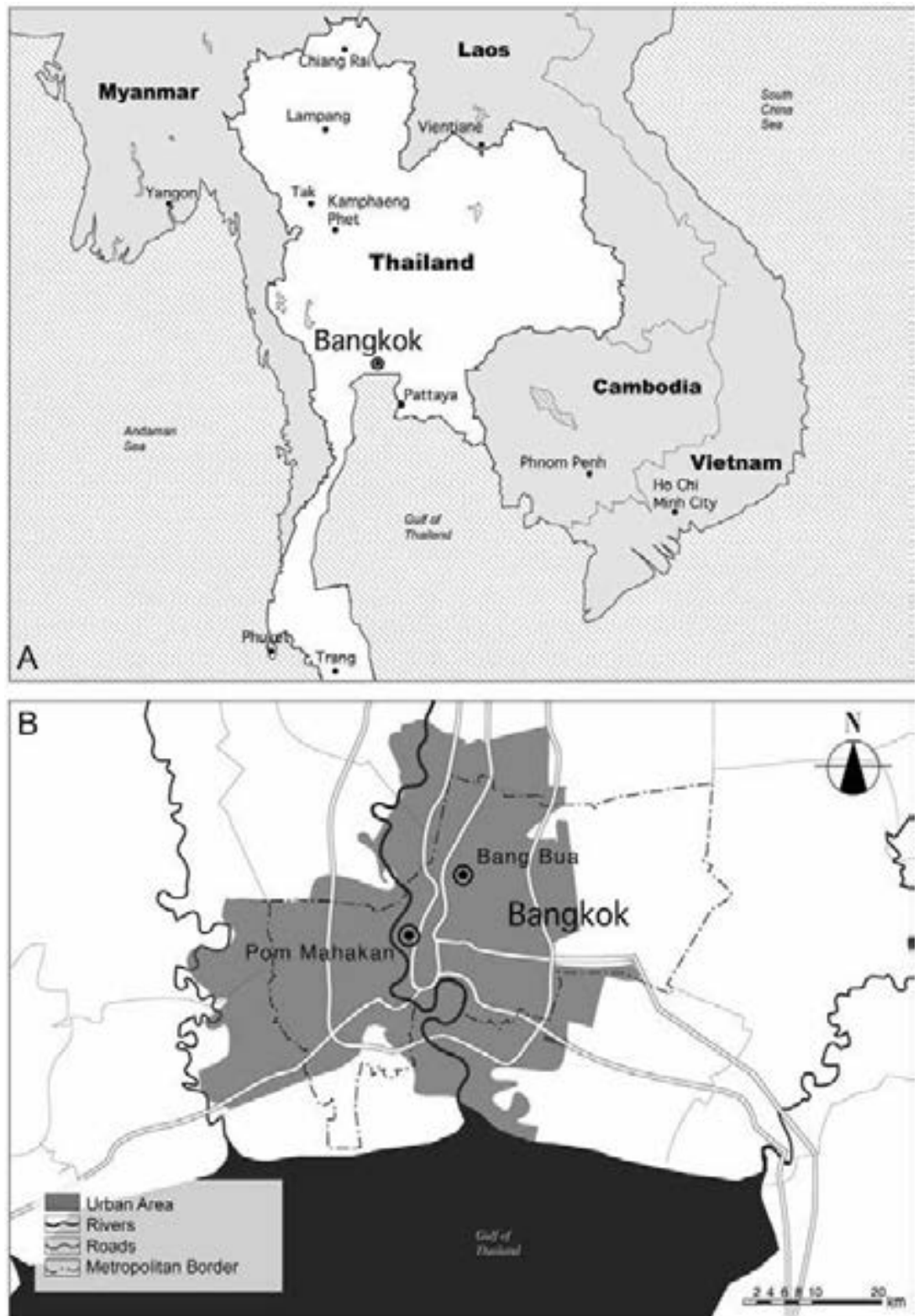

Source: Ariel Shepherd 
place of integration (socially and economically) and may contribute to the social advancement of individuals. However, spontaneous housing settlements mostly remain home to the disadvantaged and to newcomers with low incomes. Nice air-conditioned houses stand side-by-side the cramped shelters of the underprivileged. Housing densification in and around these spontaneous settlements implies both the overcrowding of shelters and good-neighbourly relations in shared spaces. According to the needs of the residents, each square metre is used and draws a subtle, permeable limit between private and public space: drying of clothes, two-wheeler parking, repair or material storage prevent outsiders' access to the house; more welcoming flower pots and chairs indicate an entrance and a possible meeting point. A wider bit of lane allows the storage of benches or games for children. There is a progression from the outside to the private sphere through these mobile amenities that are meeting and pausing spaces. The dwellings themselves also remain highly porous, both in their design and in their daily use and practices, which sometimes recall Thai vernacular architecture. The housing generally includes a salaa ('outdoor veranda or multipurpose room') used for cooking and housework, which bridges the common corridors and the private space of the house. Along with the gradual upgrading of spontaneous settlements, the inhabitants tend to take more space in the public debate over land management and rights.

Access to the city by inhabitants is frequently negotiated, while their legitimacy is growing in dealing with the urban actors. Although the production process of these settlements is largely informal, ${ }^{3}$ regularization now takes precedence over the evictions and forced relocations common between 1960 and 1980. These spatial characteristics and evolutions are found in all informal settlements, be it today in Brazil or in post-war France (Pétonnet 2002).

In this chapter, I use the term 'spontaneous' to emphasize the context of the emergence and evolution of these constructions. 'Spontaneous housing' can be defined as a process of incremental and opportunistic construction based on more or less legal spatial appropriation. This definition applies

3 The adjective 'informal' was initially adopted for the labour market or the unofficial sector in the 1970 (Charmes 2003, 1) to describe loosely structured small-scale activities in which actors use knowledge acquired outside the education system. The designation gradually spread to informal settlements, defined as built-up geographical areas managed by the informal sector. The Thai architect Davisi Boontharm $(2005,11)$ has written that the cities of Southeast Asia 'are principally characterized by the size, diversity and flexibility of their devices, and physical space, tied to the economy and trade', mainly helped by the informal sector. All the translations from non-English sources are by the author. 
Figure 3.2 Tolerated spontaneous extensions on shophouses, around Ratchathewi BTS Station

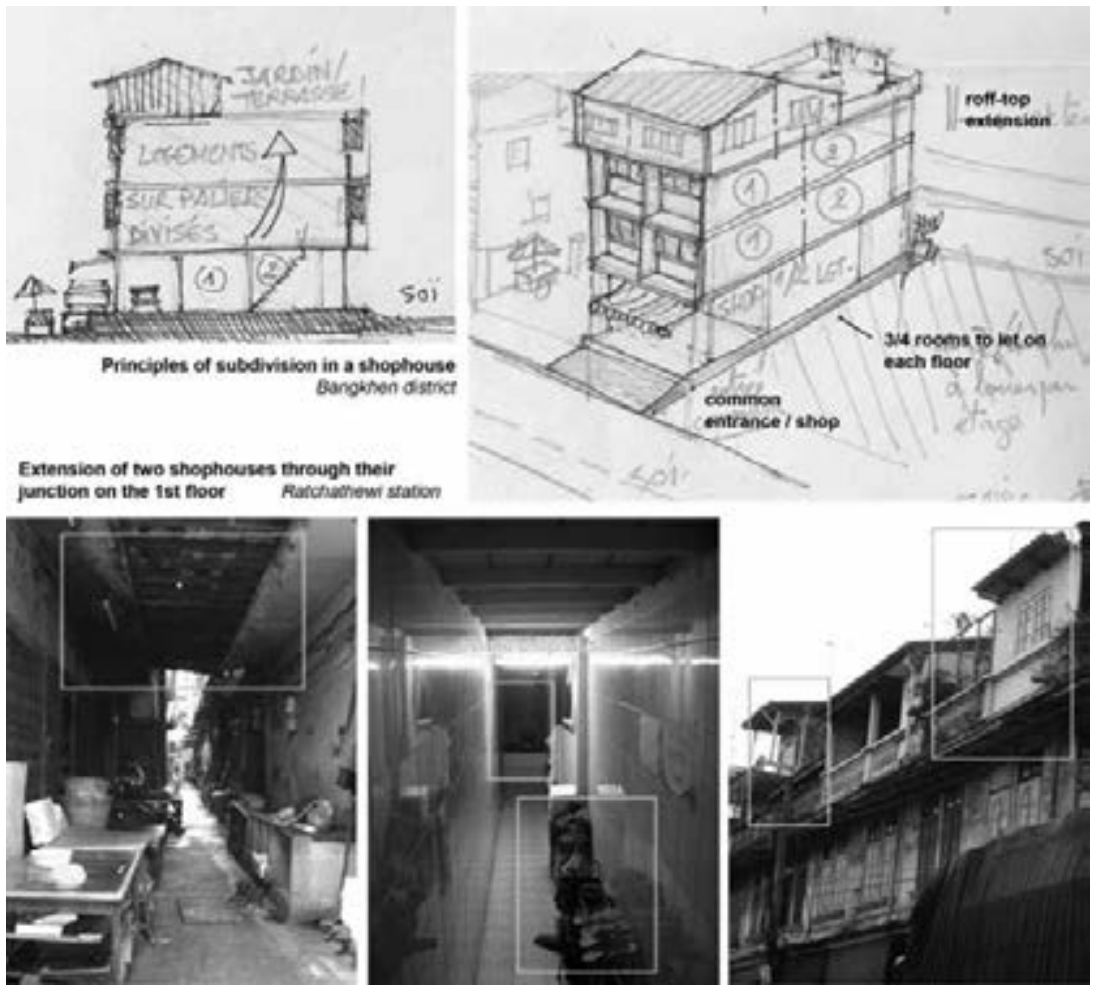

Source: author

to Brazilian favelas, the villas of Argentina, or comparable settlements in Southeast Asia or Central America. These spontaneously constructed housing complexes gradually become an integral part of the normal urban fabric, despite the persistence of a certain insecurity and spatial promiscuity. This chapter gives credit to Chryssanthi Petropoulou's analysis presenting 'spontaneous' as the most correct term 'because it gives a dynamic definition of these areas that could help planners to create a different opinion of the phenomenon' (Petropoulou 2007, 1).

Spontaneous practices also exist in the current formal property market-for example, the elevation of buildings and extension of shops and row houses into the public space (see Figure 2). Between the regular and the spontaneous, it is rather a question of a transition than of a limit, which helps the assimilation of dense communities (Chumchon ae at, the official Thai name for spontaneous settlements) and its people as well as space and 
economic activities mix with the formal urban fabric and shops around. As Chulasai $(1985,30)$ pointed out: 'Some of these changes are done illegally but without problems, since there is insufficient surveillance from government inspectors and the regulations are obsolete.'

Spontaneous building practices are more tolerated than accepted by the Bangkok Metropolitan Authority (BMA), which is unable to restrain such excesses. The BMA must handle these in-between situations, as there is no absolute control of the urbanization of the capital. The surprise comes when urban projects are launched and people have to be compensated: 'If they stay over 10 or 20 years [...] when there are many invaders, the BMA must pay or offer compensation for these households. It's not easy, that's why we now have CODI. Before, it was the NHA [who was meant] to solve these problems' (City Planning Department, BMA, interview by author, 26 June 2009).

\section{The Metropolis, Context of a Battle for Recognition}

In this chapter, I focus on the spatial dimension of 'spontaneous housing', with the assumption that such building practices have become actively involved in the construction of the capital and reorientation of its development priorities through the involvement of slum dwellers. These results are based on my PhD research (Gerbeaud 2012), in which I studied the phenomenon of spontaneous housing and its close relationship with the metropolitan process.

Primarily an urban phenomenon, spontaneous housing is particularly significant and a great source of tension in global metropolises and cities. For François Ascher, metropolitanization is 'an increasing concentration of men, activities and wealth in urban areas of several hundred thousand inhabitants, multifunctional, highly integrated into the global economy' (2010, 33, translation by the author). As such, cities are rich in opportunities at the local, national, and international level. They constitute a large pool of low-income households whose main asset is providing physical labour and cheap services. Cities represent interfaces where contradictory objectives, uses, and radically different representations pool, meet, and communicate ${ }^{4}$ in a context of increasingly rapid exchanges.

4 Sassen writes, 'metropolitanization does not only refer to amplification or intensification of international mechanisms affecting these poles, at the cost, sometimes brutally, of reconciling divergent interests - to the new realities of the global economy. It is not a geographically 
Metropolitanization is somehow also a territorialized globalization, ${ }^{5}$ generally materialized by internationally networked large metropolitan areas; the global dynamics outweigh the local ones. On the one hand, this may result in the production of margins (Goldblum and Franck 2007): areas where the heightened pressure from exogenous spatial dynamics allows other interfaces. These margins (i.e., slums) at the limit between several urban systems may link or unlink urban centres and thereby rapidly change the attractiveness and influence of cities in a territory. On the other hand, the area becomes more utilitarian and abstract. Because the city works as a network, it is not just a physical territory. With information and communication technology, the worth of the space lies in the quality and speed of connections with related spaces it offers, and less in its local peculiarities. Still, the territory remains one of the main reasons for social, political, and economic negotiation. This symbolic dimension, via the local culture or the image issue (in line with the city's reputation), will strengthen the advantages of one city or another, often linked to the development and individualization policy of the metropolis in a competitive environment.

In this context, media coverage and metropolitan networking tend to enhance the visibility of the 'excluded.' Inequality and hierarchy strongly mark the Metropolis (Sassen 2004), both locally and nationally. It is these inequalities associated with the relative loss of power and legitimacy that allow the emergence of a 'parallel urban political geography' (Sassen 2004, 20). These tensions play a role in making the metropolis 'one of the places of connection (nexi) where new claims from the powerful and the disadvantaged, can be materialized' (Sassen 2004, 22). Cities are 'in this sense favourable to the emergence of a new range of political, "cultural" and subjective operations, or even a new way of claiming which could open the way to unprecedented forms of "citizenship"' (Sassen 2004, 19).

For Sassen (2010), global slums equipped with facilities and an urban organization serve as a platform for their inhabitants in a dual society. The

circumscribed dynamic, but an expanding process constituting a hierarchical network of metropolitan areas maintaining (selectively or globally) privileged interrelationships with certain common features, reflected throughout the "metropolitan areas" as the verticalized international business centre (CBD—Central Business District), the industrial parks vowed to high technology (high "tech") often coupled with new residential areas (or "new towns"), major infrastructure networks (multimodal platforms) and major international airports' (as cited in Goldblum 2010, 1-10).

5 Globalization is described by Giménez $(2005,484)$ as 'the process of deterritorialization of very important sectors of social relationships on a global scale or [...] the multiplication and intensification of supra territorial relations, that is flows, networks and transactions that go beyond territorial constraints and implementation in areas defined by borders'. 
global slum is the 'poor' counterpart of the gentrified areas (leading edge). Its growth and characteristics are then closely related to metropolitan issues, and the metropolis itself is obliged to take this spatial production into account to avoid its functioning being threatened. The highly ethical question of the right to the city raised by the inhabitants of these margins and their international supporters is used as an argument enforceable to jus soli (their right to stay on the land they live on). As they become spatially more visible and in their speeches more tangible, their marginal situation becomes a pressing issue of urban governance via the concepts of civil society and empowerment.

In this chapter, I test this phenomenon in Bangkok. Transforming the urban fabric allows the residents of spontaneous settlements to gain access to the city and to become fully-fledged city dwellers. By designing and building these dwellings, these 'ignorants' enter the metropolitan fabric and force spatial professionals - such as city planners - to reflect on their practices. They become proactive managers of some parts of the city's territory, even providing attractive alternatives to planned urbanization.

My argument is divided into three parts. The first is devoted to negotiations over the right to the city in spontaneous housing settlements through the development of networks of communities that lead to shared land management. The second tackles the spatial dimension itself, showing how the residents' actions play a role in the adaptation of the city to its users and encourage urban actors to better calibrate their responses. Finally, I discuss the repositioning of spatial professionals in favour of greater involvement of residents, which leads to a promising multiple actors and joint-metropolitan design.

Community Networks: Empowering People to Weigh in on City Politics

The phenomenon of spontaneous housing is often associated with poverty, underdevelopment, and deviance. This terminology encourages a negative and overly simplistic perception of these spaces. 'Slums' or 'over-crowded communities' are logically viewed as an eyesore to eradicate in the metropolises of emerging countries, especially as the international exposure of these cities increases. The process of metropolitanization also implies a strong attractiveness of the region conditioned by fierce inter-metropolitan competition; spontaneous housing develops in environments with population and land pressure. Spontaneous settlements can also harm the long-term outreach of Bangkok as well as exacerbating transportation problems, 
pollution, and the implementation of urban policies. They are disturbing to the very heart of the metropolis. Thus, adaptations such as public transport network extensions and the release of attractive real estate are necessary for its further development. They also represent alternatives to current urban development that grapple with local uses and interests.

To be accepted as proper residential neighbourhoods in the capital, locals address urban development's key issues such as tourism, popular heritage, attention to the environment, and business dynamism in their own way. The clever use of the media and new means of communication helps networks of residents be heard within the contemporary metropolis and by the local government. They also receive help from influential public and private organizations that are active on a large scale and act as spokespeople by putting their actions around particular issues of urban development and empowerment into perspective. Two cases are particularly evocative: Pom Mahakan, on the peninsula of Rattanakosin (the historic centre of Bangkok), and Bang Bua, a settlement on the bank of a channel on the outskirts of Bangkok. In each case, the space serves as an interface and a tool between inhabitants and the authorities to achieve social, environmental, and economic goals.

\section{4 \\ Pom Mahakan: Defining a Popular Heritage for Touristic Bangkok}

Inhabited even before Bangkok became the capital of the kingdom, Pom Mahakan is an ancient community with its own architecture and traditions. It is known as the birthplace of Likay ('traditional Thai theatre'), and for its local handicrafts (i.e., bird cages and sculptures) and cuisine (see Figure 3). According to metropolitan authorities (City Planning Department, BMA, interview by author, June 26,2009 ), the residents - sometimes called the invaders - of Pom Mahakan do not have a land lease to prevent eviction. This situation is both controversial and highly publicized internationally. Pom Mahakan occupies a strategic piece of land in the heart of Bangkok's heritage area, near the canal, the Golden Mount, and Ratchadamnoen Avenue. This avenue is considered the Thai version of the Champs Elysées, a 'status symbol of Bangkok as in many Western countries' and 'civilization' (NESDB 2003, 1, 4). As addressed in the Rattanakosin masterplan, the authorities (i.e., the owners) are considering the creation of a more secure and attractive urban park for tourists in Pom Mahakan as part of the beautification of the city centre. The community is living its last days as Pom Mahakan is being demolished in the beginning of this year 2018. 
Figure 3.3 Pom Mahakan's domestic architecture and traditions: Thai massage, cock fighting, fireworks, bird cages
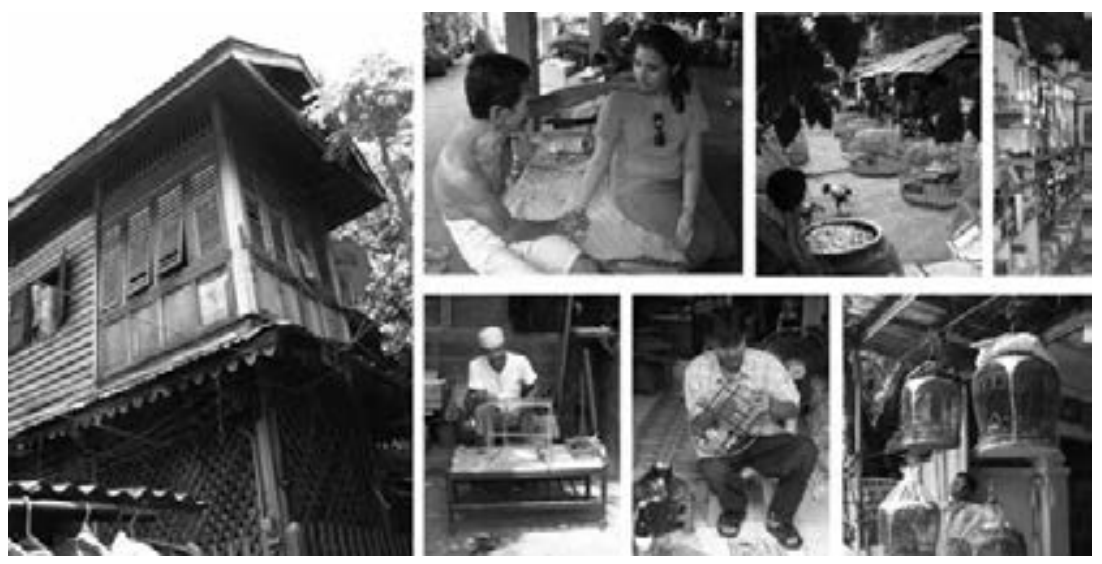

Source: author

For Pimonsathean (a researcher at Thammasat University, Bangkok. Interview by author, October 2010; NESDB 2003), the Rattanakosin masterplan corresponds to the implementation of a vision: the conservation area should ensure the promotion of Thai culture and lifestyle and highlight the symbols of both the Chakri dynasty and Western influences. Not only would this plan damage the image of the historic site that the public sector is trying to safeguard, but it would also spoil tourism, economic stimulation, natural resource management, and the urban context that operate as a means of improving the quality of life of the inhabitants (NESDB 2003, 1, 4).

The BMA justifies the objectives of the master plan for security reasons and the common good. According to Herzfeld (2006,135-146), the eradication of parasitic elements not only matches the visual optimization of this urban renewal-i.e., spaces free from any permanent appropriation, street vending, or squatters representing the residents of spontaneous housing — but also is the embodiment of state power.

Some inhabitants whose families have lived in the area for 200 years have learned that their community can contribute to metropolitan development and beautification with their part of the city's architectural and intangible heritage. Over ten years of conflict, the population has adopted arguments that guarantee the support of influential international actors, who put pressure on the BMA. Out of the nearly twenty Rattanakosin communities predating the shift of the capital to Bangkok, identified by the BMA, Pom Mahakan is the first to have received a notice of eviction. For the BMA 
it is important to resist pressure, as this case 'will affect the progression of events in the rest of the area covered by the Rattanakosin Island Plan' (Herzfeld, cited in Wungpatcharapon 2009, 3). Although the fate of Pom Mahakan remained unknown until 2018, it largely depends on Thai and international opinion, thanks to the network that has made it both a global and a governance issue.

Though initially the architecture of Pom Mahakan was not at the heart of the residents' concerns, space is highly representative of the inhabitants' quest for regularization. Residents have renovated common areas in accordance with their intended tourist functions. Some examples include surface treatments (brick and stone pavement) comparable to the archaeological sites of Ayut thaya and Sukhothai and explanatory signs in Thai and English to guide tourists to discover the community and its traditions. At the level of housing, the residents stay ahead with a renovation plan based on a 'self-development' approach (Herzfeld 2003, 104). This strategy of 'moral rehabilitation' is aimed increase the authorities' trust in them by showing their sense of responsibility and ability to be legitimate citizens of Bangkok.

The residents have mastered their negotiating tools by working with academics, the media, and certain Non-Governmental Organizations (NGOs). ${ }^{6}$ Their smooth speeches, including those by the former head of Pom Mahakan, perfectly boast of the strengths of the community. Meanwhile, residents have had recourse to the implication of multiple actors with authority in the heritage matters: various universities have proposed actions in response to eviction measures taken by the BMA; and some community architects (namely, Community Architects for Shelter and Environment - CASE Studio) have also held talks with the residents over three years. The debate has also become an issue of international importance with the interference of organizations such as UNESCO and human rights' associations and the actions of foreign scholars, ${ }^{7}$ particularly those studying the issue of heritage and the

6 On the communication level, NGOs and associations such as the Asian Coalition for Housing Rights support the protesting communities and provide expertise comparable to that of the authorities. For Marc Askew, they ensure local and international support that can weigh heavily in the decisions of the state.

7 Bristol $(2007,12)$ provides a table of the various organizations involved in the Pom Mahakan issue, including: professionals; local, national, and international communities; universities (including the four largest in Thailand, and Harvard); and international organizations such as the Chumchonthai Foundation, Centre on Housing Rights and Eviction (COHRE), Asian Coalition for Housing Rights (ACHR), and Community Organizations Development Institute (CODI). Also see Wungpatcharapon (2009), who details the chronology of all support received for the preservation of Pom Mahakan and the requests made to the Thailand National Human Rights Commission (NHRC) and submitted to the United Nations. 
democratization of access to the city. As space is at the heart of their struggle, at the same time it aims to propose another renovation model of the ancient city centre. Bristol (2003) and Herzfeld (2007) for example, have highlighted the historic architecture and traditions in Pom Mahakan, as well as the cohesion of the inhabitants who plead for the area's maintenance. These approaches have resulted in an undemocratic and even authoritarian image of the actions of the BMA (Herzfeld 2003). By displaying a community acting transparently and using popular participation against the government's project for the Pom Mahakan area, the media participates in discrediting urban services.

This case demonstrates how a controversial notion (i.e., cultural heritage) can be mobilized to justify the appropriation of space in the city and to gain recognition. The quest for Thai identity and real Thai values is very relevant in a time of globalization. Here, heritage becomes a collective construction and a means to achieve regularization, economic development, and the preservation of a popular architectural 'corpus'. The community cohesion demonstrated by the adherence of residents to this argument undoubtedly has a strategic dimension, while orienting the issue on historical value, taking an opposite view to the authorities by exploiting some of the goals of development. it also provokes a new level of awareness on the part of the residents. A community architect who has been active in the community of Pom Mahakan since 2006 realizes this:

Some said it was a very old community with a historical value, so we worked on this aspect to develop a housing plan with the people. At that moment I thought it was not a slum problem but rather that of the city, a challenge for Bangkok. It seemed that everyone in Bangkok had to know about this issue because it involved many communities on Rattanakosin Island. We invited the media (TV, magazines) to inform about it and mediate the case. Some have written books, articles, [while] others [have] made films on Pom Mahakan [...] Heritage is a way to create a network, to bring people together around a common issue, but in practice we have to find more than that $[. .$.$] the reality [...] and not an imagined romantic way of living. The$ heritage issue can gather a lot of people. (interview by author, 5 August 2009)

This is also the case for other projects in Bangkok that focus on architectural value, for example the renovation of Na Phra Lan that has been carried out by private individuals by inviting residents to preserve and take possession 
of the architectural heritage they live in. ${ }^{8}$ Residents are encouraged to follow the preservation recommendations for their built heritage in exchange for a valorization of their surroundings-a positive renovation for tourism and for the image of the city. This process marks the beginning of a re-appropriation of heritage architecture and conservation of a living heritage.

Heritage preservation, with the reduction of pollution, and the environment, have become issues of collective action in the historical areas of Bangkok. Further, they allow the development of an engaged local civil society. These objectives are in line with the sustainable development targeted by the Thai constitution and promoted by major international organizations. The second case study (i.e., Bang Bua) described below highlights the development of collective action across several dense communities in the form of networks.

\section{$5 \quad$ Bang Bua: From Canal Cleansing to Managing Communities}

In Thailand, the term 'community' becomes meaningful in the context of social networks. Presented as a valorizing socio-spatial organization, communities are associated with notions of slowly evolving solidarity, mutual assistance, and sharing (values, beliefs, and resources). They are also groups in opposition ${ }^{9}$ to or support of something -i.e., 'people who share the same interests or activities and form a relatively new group, [in] five-ten years' or 'a group that shares the same problems' (community architect, interview by author, 2009). It is the community of conditions (Pornchokchai 1992; UNHabitat 2005). The term 'community' also has a legal definition, given by the BMA in 1991 for operational purposes (Archer 2009, 32): a community has at least fifty dwellings and must be registered in the district. It can then receive aid and appear on official maps as part of the city. The networks of dense communities sometimes include a large number of settlements in several provinces of the country; the main goal of such communities is to give a voice to their inhabitants, either to protest urban projects that would affect them or to work upstream for their regularization. These networks are generally

8 This project, led by Yongtanit Pimonsathean, has been awarded the 2011 UNESCO Asia-Pacific Heritage Awards for Cultural Heritage Conservation.

9 Askew (2002) explains that the 1990s saw the development of community networks as local organizations (federated inhabitants) under the impulse of local and international NGOs whose number is increasing. 
locally managed by a committee or representative of the community, who acts as the intermediary with local authorities and as referent in the affairs of all informal settlements. ${ }^{10}$ As much as the charisma of the community leader, group cohesion is fundamental for getting a community's claims and projects progressed towards the local authorities. The ability to define a common course of action is in fact a prerequisite for public funding ${ }^{11}$ for spontaneous housing settlements, which therefore sometimes excludes very poor groups (Gerbeaud 2012). Space - through regularization-is generally the main demand of the inhabitants, but other communities might federate around urban agriculture projects, pollution control programs, and joint activities (i.e. caring for the elderly, proposing activities for the community children). By organizing, a group enters the process of negotiating urban space-especially with the development of community-based organizations, ${ }^{12}$ where 'the more educated leaders [...] facilitate access to NGO networks and media' (Ockey, cited in Tapie et al. 2008, 45). ${ }^{13}$ At the same time, international networks are active in disseminating the news of actions, participatory projects, and concepts. In return, they contribute to 'unlock[ing] people energy' (DPU 2012; Boonyabancha n.d.). This 'people energy' means that poor people gain confidence in their ability to change the environment and begin to 'believe in their relationship with the others in the city' (Boonyabancha n.d.). The following quotation illustrates the urban and even societal vision of the organizations working with these community networks:

Klong Bang Bua was the first network of canal communities in Bangkok to successfully negotiate a long-term lease to the public land they occupy, which is under Treasury Department ownership. This lease could never have been negotiated by a single community, which has no bargaining power. But

10 According to Pornchokchai $(1992,64)$, in 1990, 54 per cent of the slums had a community committee; 24 per cent were assisted by the BMA, 4 per cent were assisted by the National Housing Authority (NHA), and 12 per cent were held by the residents independently.

11 In this, I am particularly referring to the Community Organizations Development Institute (CODI), a leading public body for affordable housing, and the NHA, whose main objective is the absorption of dense communities and housing renovation.

12 The institution of community committees in the 1970s, corresponding to the increasing involvement of international NGOs, also saw growing community influence in the media landscape - the 'weapon of the urban poor' (Ockey, as cited in Tapie et al. 2008, 45).

13 According to Askew $(2002,146)$, the 'emergence of slums as organized localities, has developed through the increasing intervention of the state as well as the reformist middle class-in the guise of academics, specialists and NGOs-in response to concerns for social, environmental and housing conditions in the slums'. These actors play a role in the changing vision and the subsequent actions of authorities towards the spontaneous settlements. 
as a network of 12 communities, and with the 'network power' support of the city-wide network of 200 canal-side communities in Bangkok, Bang Bua was able to convince the authorities that redeveloping their communities in the same place is good for the people and good for the city as a whole. (Wungpatcharapon and Tovivich, cited in ACHR, CODI, and CAN 2011, 6)

Being part of a Community Based Organization or a community network helps to develop community projects with the local actors and owners. Through the empowerment of the several communities involved, it gives way to more balanced discussions with the authorities, thanks to this 'network power', and broadens the issue of spontaneous settlements to metropolitan environmental and social challenges.

The development of national and international community networks is closely related to media coverage of globally relevant challenges. In Bangkok, where water pollution in the canals is worrying, spontaneous housing settlements - which are often accused of being responsible for the pollution-are also the origin of interesting water treatment initiatives. This is the case of Bang Bua, a high-profile member of the Canal Community Network. Despite an eviction notice, the inhabitants of Bang Bua had expressed a desire to remain on the site and to comply with the district legislation if the community was regularized. They also appealed to the Community Organizations Development Institute (CODI) and received help from its community architects. In this way, the residents have been able to retain control of the renovation program by receiving technical support from professionals, enabling the protection of community relations and the existing social fabric. The residents' participation in the construction and management also facilitates a sense of belonging of the project that continues after its completion. After cleaning the canal (CODI, n.d.; CODI, 2004; ACHR, Kerr, n.d.), residents worked on the reconstruction of a densified community on the mainland. Two to three storey-houses replaced the single-storey houses on land and those built on the canal. This densification allowed for three common spaces to be created for recreation purpose (playground and gardens). Community architects and residents jointly worked on a masterplan and then designed several types of housing depending on inhabitants' desires, neighbourhood relationships, and ability to pay. The number of households remained equal and the participative process reinforced social bonds, both with the authorities and within the community. Regularization in Bang Bua has initiated a renewal rather than a complete assimilation into the capital, thanks to the never-ending 
appropriation and transformation process. The rebuilt community now keeps on adapting to its users' needs following the masterplan.

In this and other regularized spontaneous housing settlements, the residential fabric slowly creates a road structure comparable to the hierarchy of city road systems, with the same layout of businesses and services. Around the Central Business District, ${ }^{14}$ houses and dense communities tend to disappear into the urban landscape as they adopt the aesthetic codes and comforting equipment of the formal housing market: airconditioning, bigger rooms, proper construction details and standardized materials. These transformations make some settlements attractive to the middle classes due to their centralized location and offers of profitable financial goods and services. There is therefore a tendency to accept these constructions as a way to generate both housing and an urban fabric that is attractive to a more prosperous population-although it always remains affordable for low-income families. These operations contribute to normalizing the area's residents and adapting the inhabitants' territorial uses of the city. While houses are gradually assimilated into the urban fabric, this housing stock challenges the current housing market and its inhabitants' evolving practices are also attracting metropolitan interests: gentrification is for the moment avoided in projects supervised by CODI thanks to the principle of community tenure of land in Bang Bua. Both the inhabitants and the entire community are owners. For this reason, regularized housing units remain financially accessible to the less well off, who also find a potential network of solidarity and integration in the community. In settlements where land pressure is higher, adjacent to the Central Business District, the future could resemble Brazil's favela tourism, especially when the rental price of a condominium flat is the same as that of a house with a garden (Valladares, 2006). Legalized settlements have less need for community networks than more remote or vulnerable populations.

The Canal Community Network (CCN) acts as an interface of exchanges, an opportunity to share experiences between settlements that have already started their renovation and those in the process of preparing a project. As a source of inspiration, a community hall in Bang Bua that was built as part of the renovation features a display with a model of the project and panels explaining the natural filtration of wastewater before it is discharged into the canal. This exhibition space is frequently visited by the members of the network as well as NGOs and foreign associations (American victims of

14 I studied the evolution in Sanam Polo (near Lumphini Park) and several spontaneous settlements near Pahon Yothin and around Kasetsart University. 
Hurricane Katrina, Southeast Asians, and so on). The CCN gives residents both local visibility - by bringing together a number of urban dwellers living in comparable situations - and an international dimension. It has also had knock-on effects, ${ }^{15}$ especially because of the positive international reception of the project, and has made Thailand an exemplary example of the defence of dense communities. Because of this international presentation, dense communities indirectly exert pressure on the policies of the metropolitan government and bring changes to the methods of integrating public participation and consultation. The effects can be witnessed at the district level and within the public institutions dealing with housing issues (e.g., NHA, CODI) or owning land. The effects on the BMA are less evident due to the composition of the Board, and generally depend on the impact of groups of people in the news. This trend also applies to other communities (e.g., rural communities, including interest groups), confirming the development of the civil society that is initially born of urgency.

Spontaneous settlement is a connecting interface of the city that is able to offer tailored solutions for the use of residual spaces from which it is impossible to make a profit - at least, according to the planning regulations. In their reactivity to the environment and ability to create links around participatory projects, these architectural activities are comparable to the urban farming communities analysed by Boossabong (this volume). Whether it is the production of housing in urban interstices or organic food grown on the roofs of buildings, the actions of these groups are subversive interventions demonstrating alternative interests and the need to adapt the production system.

Spontaneous housing offers a way of making the city within the spaces, activities, and social relationships that it fosters. It challenges the methods and process of making the city, beginning with the delegation of its design to specialists where so little authority is given to its residents. The changes observed in some of these settlements in terms of housing show that nonspecialists can be responsible for architectural and urban design, and even for the adjustment to standardized and planned production. This calls for the rehabilitation of this residential design process, especially in terms of public participation, equity in access to urban areas for the poorest weigh heavier in the management of the metropolis. Here too the commitment and energy devoted to the qualitative production of space significantly

15 As an anecdote, a photograph of our team has been incorporated into a presentation board in the community room as 'evidence' of the international outreach of Bang Bua in the academic world. 
exceeded that of the ordinary city dweller, mostly because people have had to find their own answer to their needs and, by doing so, have retained their connection to building their environment.

If people's participation can greatly contribute to city-making, lot servicing and connecting to networks remain necessary to ensure the sustainability of such sectors. Working alongside the expertise of urban actors, spontaneous production is undeniably an asset in people's interaction with the city, especially because it offers original forms - and means - of development.

Spontaneous Spatial Action: Building the Metropolis Jointly

This section elaborates how direct spatial transformation in the context of spontaneous practices participates in the adaptation of Bangkok to its users. One example of spontaneous additions to buildings on the current real estate market can to be found in the social housing projects of the National Housing Authority. ${ }^{16}$ These standardized buildings have been built since the 1960 s according to Bangkok's policy of the relocation of slum dwellers. They usually consist of several-storey buildings designed according to the principles of modern architecture - a free façade, roof terraces, and sometimes following the free plan ${ }^{17}$ with the use of stilts on the ground floor. Wide lanes separate the large grassy outdoor areas of the buildings, which are set back from the sidewalk. Each floor of often more than 10 flats has $24 \mathrm{~m}^{2}$ to $33 \mathrm{~m}^{2}$ apartments. ${ }^{18}$ The covered stairwells overlook the service corridors and common garbage chutes. The production of these facilities continues, albeit in improved versions.

These social mass housing facilities were meant to provide decent housing and a minimum amount of comfort by incorporating former slum dwellers into a system of regular practices (monthly payment of rent, bills, and contact with the administration) in an appropriate urban setting. The buildings were built to withstand the relocation and rehousing of slum dwellers, without

16 The NHA is responsible for social housing programs at the national scale (mass housing projects and plans), including the 1 million housing units 'Baan Mankong Plan' and 'Baan Eua Arthorn Plan' launched in 2003 by the Shinawatra government. Under the Baan Eua Arthorn Plan, 600,00o housing units were supposed to be built by 2008, where the Government Savings Bank (GSB) was to finance 100,000 of these units. CODI (Community Organizations Development Institute) was to renovate 400 ooo units in 'communities' (spontaneous housing settlements) via the Baan Mankong Plan.

17 The Free Plan or 'plan libre', defined as one of the five points of Modern architecture by Le Corbusier, stands for an open floor plan generally supported by concrete beams and poles and without being interrupted by bearing walls.

18 All Din Daeng stands out, with an apartment area of about $40 \mathrm{~m}^{2}$. 
Figure 3.4 Two phases: a permanent hairdresser's shop on the sidewalk (left, 2007); a repair shop and a grocery under consolidation (right), Klong Toey Lock 1-10

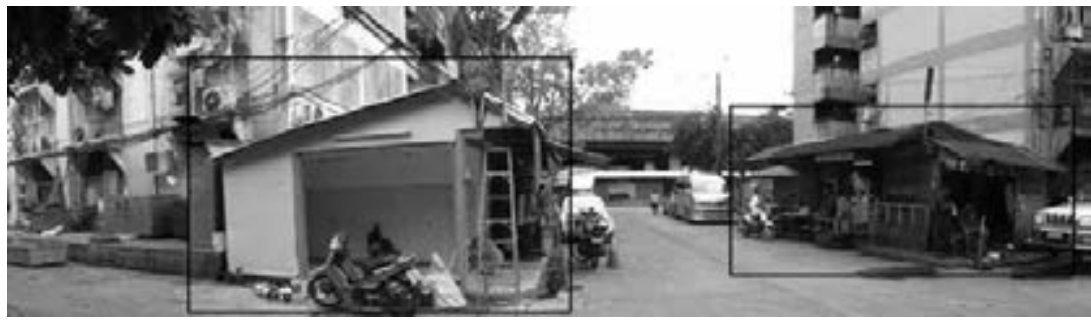

Source: author

integrating transformation of apartments and social relations of the tenants. Mass relocation into public housing has certainly brought better residential living conditions, but irregular incomes, lack of space, the inherited slum lifestyle, and finally the residents' daily way of living has done away with the orderly and normalizing design of the NHA housing blocks. For example, some street vendors have continued their work (e.g., food preparation, crafts) in their apartments, although the space was too small for such activities.

Thirty years later, more or less important additions to the buildings and outdoor areas have developed and consolidated the structures that were too narrow and poorly adapted for use. Some residents have built groundfloor extensions from their balconies into public areas. The vast outdoor areas have been covered with temporary (storage, playgrounds, sheltered parking) and permanent (workshops, micro-enterprises, subsidiary housing services) activities recreating closed areas and shopping streets instead of the intended sidewalks exposed to sunlight (see Figure 4).

In Klong Toey Lock 1-10 near the port of Bangkok, a group of ten blocks of flats was built in the 1960-70's opposite the Klong Toey settlement to relocate families whose homes had burnt down. As in earlier experiences of social housing, these flats are located in a highly urbanized area, close to workplaces and key public services. In this housing complex, spontaneous grafts have recreated a 'commercial corridor' in the main street, (see Figure 5) from the site entrance to the channel, which marks the boundary of the NHA land. These two types of architecture connect at a place where an indoor market, a Thai boxing ring, and community meeting rooms have been established. These spontaneous grafts provide continuity with the street, reducing the difference between the social housing and the neighbourhood. Residents have access to restaurants, cafes, and hairdressers at the ground 
Figure 3.5 Rented areas for spontaneous commercial structures behind the yellow line. Bonkai housing estate's commercial corridor

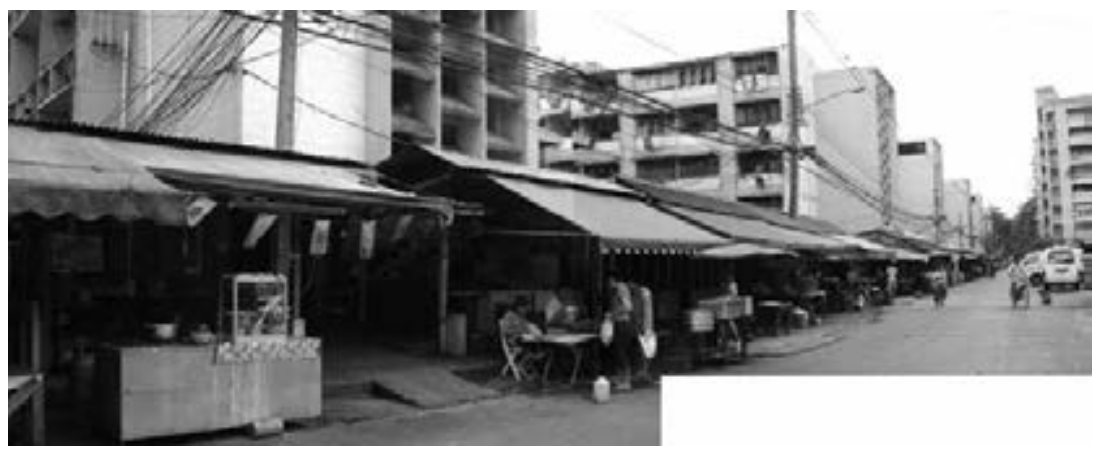

Source: author

floor of their building. Not only do these attract outside customers-ensuring social diversity and mixed usage - but their linear configuration, where each staircase has an airlock effect, also controls and thus secures the area as a buffer between the street and the intimacy of the residential buildings. ${ }^{19}$

Spontaneous grafts act as a service by the complexity of the spaces, uses, and connections created to perform different functions. Klong Toey residents of flats 1-10 benefit from a planned, standardized, and already realized base, on which they can improve their everyday surroundings. Spontaneous grafts respect the pre-existing elements while also highlighting their shortfalls. Thus, they invite the appropriation of more space and changes to the architecture, including the incorporation of more flexibility into the design process. They also open the social buildings to greater functional and programmatic diversity and consider the changing needs of future residents in the design and development of relocations.

However, as spontaneous actions can become endemic and turn these areas into bigger 'slums' than what they were considered to be before their relocation, it is necessary to create a framework for these grafts. In cases of high land or population pressure, total lack of supervision has resulted in the development of spontaneous housing that overrides the original spatial organization. These practices were unforeseen by the NHA at the time of the housing complex's design, and are difficult to manage once in place. They have required reflection on the part of NHA so that they can take advantage of these grafts to monitor and improve on Klong Toey rather than banning them. Extensions are now possible in specific zones, 
regulated by a monthly commercial location fee. By this means, the NHA controls the evolution and densification of its housing stock and reinvests the received financial contributions into the maintenance of the green areas and buildings. The fact that external renters are allowed shows that this social housing is attractive to both outside vendors and passers-by.

Unable to obtain better-located land closer to transportation and commercial amenities, due to land prices in the capital, the NHA acts on other determining factors to improve its social housing services. These improvements include lowering building heights and increasing the surface area of the apartments, providing commercial and storage space at the ground floor of the buildings, and including community halls and other areas for residents' daily use. Such improvements result in an enriched residential area made by and for the people because mainly maintained by the once informal activities the former slum dwellers developed in the social housing estates. The advantage of this system is that it provides win-win solutions and demonstrates how the people can be a source of ideas for new practices. These grafts onto public housing show that a common understanding of space is possible, especially because the Thais living in the spontaneous settlements are still engaged with the construction of their own living environment. When relocated, they use their past experience to better adapt social housing to their needs The case of mass social housing also questions the relevance of extensive urban planning and the attitudes of spatial professionals. Over time, these actors have changed their approach to metropolitan management and even architectural design in response to the improvements made by spontaneous building activity. By appropriating the transformations made by the people, they enrich their interventions in the city and better meet the objective of an inclusive and participatory city.

The Changing Role of Spatial Professionals: City-Making, a 'Four-Handed Project'

\subsection{Popular Participation to Legitimize and Improve Projects among Public Actors}

One of the fundamental aspects of this adaptation is the integration of participatory processes into the design and the evaluation of housing projects a posteriori Popular participation involves, for example, the co-design of projects (at least in some phases) and a greater degree of communication to facilitate the involvement of each actor. The projects of CASE-or in 
some cases CODI - cannot be done without the participation of residents starting from the design phase; the new use of satisfaction surveys by the NHA and the increasing number of information meetings conducted by the BMA require a similar re-organization of standard practices. Evaluation and satisfaction questionnaires are frequently used to upgrade social housing projects and improve their management. Integrating a participatory dimension taking into account the opinion of users implies a moral questioning of the actors: the project time will be extended in the definition phase of the program, the financial package, the presentation of the project, and the construction of a new typology.

Allowing semi-fixed structures made by the inhabitants on empty areas was the first step to recognizing the added value of the people's spatial transformation of the site. It is used to reveal the missing amenities and weaknesses of social housing programs, including the geographic distance with the employment centres - a departure point for enhancing participative action in social and economic goals. The NHA does more than evaluate previous projects. In fact,

CODI deals with slum settlements but we create new communities, so [that participation will take place] after the residents moved in. We try to set up recreation or cooperative spaces so that they can develop a community. [We] also [try] to generate more income activity so that when they move to our project [...] we [can] try to help them with the income generation, occupation, or training. Quite often we have to provide some participation because we build in new areas [...] so we have to provide transportation or we try to coordinate with the BMA so that they bring in services. (NHA, interview by the author, 2008)

This respondent is a member of the Government Housing Bank, which finances social housing projects. To him, the participation of residents in the development of new types of social housing like condominiums is important. Representative techniques encourage co-designing and testing of ideas. ${ }^{20}$ For example, the use of three-dimensional models by the NHA

20 A member of the Government Housing Bank (GHB, interview by the author, July 2009) explained how the architects at the NHA tend to materialize people's ideas rather than designing the projects: 'Actually, the people involved in the project already have their ideas about the project, a design basis, so they give their ideas for the architect to conceptualize it in a $3 \mathrm{D}$ model, and show how the housing units are, [and] how the building is, which is the concept of the building. But I would like to tell you that in terms of design we got the ideas from the people, not the NHA.' 
and CODI allows more flexibility and provides a more accessible rendering for people who have not mastered the tools of an architect or planner. Such representative techniques are both a way to present and jointly develop the project and a tool for raising residents' awareness of their desires and opportunities. Such participation allows the residents to 'imagine their fate' and involve them in urban renewal projects to make 'projects perhaps easier' (GHB, interview by author, 2009) as people work on a similar visual basis. In general, urban authorities and designers play an arbitration role in the participatory process and tend to 'propose' rather than 'impose' projects, which are also sometimes less detailed to allow a margin for appropriation and transformation after delivery.

The issues of participation and the legalization of spontaneous housing are indicative of a vision of society, in the sense that they involve delegating the control of space. Participation requires stronger cooperation between different actors and paves the way for decentralization and strengthening the role of the population as a major actor in the fabrication of the urban environment. According to Somsook Boonyabancha (architect and Founder of CODI), community architects have a highly social role. The objective of CODI is to strengthen civil society through its most involved membersi.e., the residents of dense communities - and to open a 'space of change' (DPU 2012). Spatial intervention is therefore more a way than a goal to keep a largely vulnerable and low-income population in the capital. It is above all a mean to reach a democratic ideal where participation could help in elaborating a more flexible urban frame able to accommodate the transformations and appropriations of its users.

Although the context has changed, this phenomenon is parallel to the right to the city in the sense of Henri Lefebvre (1974). Empowered non professionals actively build the urban environment while the actions of dense communities embody a questioning of the architects' interpretation 'of the perceived and experienced meanings by those who live there' (Lefebvre 1974, 113). This is the realization of urban space of high 'utility value' and 'intended for "users"' that is created by a part of the 'working class' of Bangkok, thus blurring the line between professionals and users in their capacity to create a qualitative environment.

Unlike CODI, the BMA is more oriented toward gathering information or allowing a limited participation than on the joint development of projects with the population. Participation is not an integral part of the organizational changes, although one of my interviewees said that the people had become 'much more involved in the affairs of the city, [...] much more active' (BMA intern, interview with the author, 2010). Abandoning control of the 
city, even partially, is still difficult for the BMA, especially when it comes to validating the growing importance of residents illegally occupying attractive land. The BMA therefore reacts in a way that is more in line with its general scale of action. A researcher from Thammasat University reported positive developments in urban planning, showing the willingness of the BMA to better control real estate and buildings in the future (although the 'Bangkok Project Plan' was not in place at the time of my interviews). These developments include pre-emption of land and buildings of different functions, the adoption of a comprehensive plan in 2006 with demographic projections, and the requirement that the proposed construction of new buildings undergo an Environmental Impact Assessment certification. The BMA always seems to act alone, without really taking housing into account while the private sector adapts faster, however, a form of emancipation of institutional actors of the BMA can be observed. We find changes in the attitude of urban governmental bodies followed by new modes of action, experiments and joint working. Not only do these adjustments provide more weight to the public housing actors in front of the private sector, but they seem to act in the direction of the assimilation of spontaneous housing and Bangkokian 'illegal or non-standard' practices at the cost of internal reforms and their partial calling into question.

If you look from the beginning at what CODI is doing, we can say that this is not acceptable to the local authorities, because sometimes they do things outside the law. But after the process of raising awareness by Somsook [Boonyabancha, former Director of CODI], after some time, the opinion of the local authorities turned positive, so there is a collaboration between CODI and local authorities at the national level.

There is also an impact on the environment. It is a joint effort between the City Plan and housing [issues] and the building capacity of the local government. That changed in terms of attitude, for the local authorities, even for the politicians. It is better accepted. When we try to make laws that make the building code flexible or the 'second standard' for low-income people [...] it did not happen in the past, but it is possible today because the attitude of people has changed, the low-income people change [...] they agree with the way low-income people work. So, why not try to make all that legal by easing the building code? (NHA, interview by the author, 2009)

While regulations are 'relaxed' to give wayto experiments, the emergence of an architectural practice dedicated to dense communities shows that certain practitioners have reconnected with the social role of architecture 
by recognizing the value of the practices of non-informed persons in the metropolis (Tovivich 2010).

\subsection{Rethinking the Architecture Project by the Experience of Spontaneous Housing}

Spontaneous housing can also be a direct source of inspiration for architects and planners. Beyond the architectural heritage issue and land management issues lie the question of spatial design, especially for the urban poor. Spontaneous architecture now involves less self-construction, but it also represents the antithesis of the production of architects. Without denying the debate on inadequate housing and self-made architecture, the community architects work in a form that is closer to militant activism than a service provider. Spontaneous construction occurs incrementally and in response to strong constraints, which is the opposite to an architectural project that generally emerges in detail as a finished object. Working for CODI or CASE, the Thai architectural agencies active in Southeast Asian communities, are poorly paid and require a strong commitment. For some students or young architects, it provides the opportunity to work differently, targeting a shared learning objective with residents also acting as designers (ACHR, 2008). In addition to numerous publications of the ACHR (ACHR, 2010a; ACHR, 2010b) and Community Architects Network (CAN) on the methods and objectives of working in spontaneous settlements, ${ }^{21}$ university courses are being developed to train future community architects. For example, Arsomsilp Institute of The Arts, acting as an educative non profit organization, offers a master's degree in Community and Environmental Architecture.

The experience of community architects extends to other areas of spatial design in Thailand. The TEN project in Minburi (in the outskirts of Bangkok), designed by the founder of CASE and some of her architects, gathers several characteristics from spontaneous settlements and community design,. These included co-design, incremental architecture, and sharing spaces to optimize costs and access to services that are otherwise inaccessible: a swimming pool, shared gardens and covered spaces, a shadow theatre, and the rooftop terrace. Additionally, the heterogeneous aesthetic constructions

21 See the websites of ACHR, CAN, Open Network Architecture, and CODI (in particular the 'What is a "Community Architect"?' section), which refer to online brochures and videos describing the values, strengths, and conditions of work in dense communities at the international level. One such example is the Baan Mankong Program: Participative Approach in CODI (http://www. codi.or.th/housing/Participatory.html). 
and constructive intelligence based on the local climatic and cultural conditions (roof overhangs, natural ventilation, outdoor kitchen instead of airconditionning etc.) were also incorporated. This project has not only been the subject of numerous publications, but has also been visited by architecture students and NGOs during CODI conferences. This meeting point between 'serious' architecture and the inherited knowledge represented by popular architecture represents a pivot in the way of doing projects.

\section{$8 \quad$ Conclusion}

The challenge of spontaneous construction does not only concern housing, but also the social and civic involvement of the population in a city's affairs. Individual actions regarding equity, heritage, participative design, or the recognition of spontaneous actions raise questions about the standardization of practices, relevance of standards, and more generally how to 'think' and 'make' the city. The act of building becomes subversive and transgressive. This goes beyond a philosophical positioning on control through regulations and prioritization, and the 'right response' to a site in terms of consumption (space, materials) and the way of doing a project.

Residential production also has a social influence on the city. Through the physical construction of a spontaneous 'community', the links between residents strengthen and create (what they call) an 'identity'; space is its material expression. This identity is claimed during conflicts about illegally occupied land. What has been built becomes the key tool in demanding the status of a citizen and legitimizing the group and its weight in political affairs. The defence of a common good and the environment create civic awareness in cases of pollution or environmental disaster. Through good land use or cleaning polluted channels, they prove that they are worthy to stay on the land. This moral rehabilitation exists in Brazil and Mexico, ${ }^{22}$ where the interventions of neighbourhood architects and the implication

\footnotetext{
22 See the following international projects of contemporary architectural intervention in spontaneous settlements: The biblioteca Parque Espana in Medellin (architect: G. Mazzanti) for the Integral Urban Project 'Acciones en mi barrio'; Playground structures in Klong Toey and Minburi in Bangkok by CASE architects; the Casa Familiar Project and other participative actions (architect: T. Cruz); and the 'Favela-barrio' program in Rio de Janeiro led by the architect and researcher S. Ferraz Magalhaes. Widely publicized, these projects and quite often iconic architectures contribute to the impact of the residents of spontaneous settlements on urban development and socio-economic issues in the metropolitan context. It also spreads interest in developing a shared conception of urban space.
} 
of the residents in the spatial improvement of their spontaneous housing settlements provide a respectable status to the city.

Informal settlements may well be a way for Bangkok to distinguish itself as a culturally active city highlighting its history and heritage. It is, then, in terms of urban governance that spontaneous housing highlights the need to rethink the process of renewal and urban development and take into account its potential in terms of both the participatory process and the creation of a culture of negotiation and skill sharing.

Spontaneous housing creates new opportunities in the management of urban space and a more inclusive and shared governance (Berner 2001), of which Sassen (2004) showed the importance in the context of competition between metropolises. It is a way to access, by claiming land, to equal rights and status despite the absence of a title of ownership. It is also a way to strengthen the link between the user and the city as residents transform and manage bits of territorial space. It is what Lefebvre calls the 'proclamation and implementation of urban life as the rule of use' (Lefebvre 1974, 146). As far as the transformation of space, the Thai case illustrates the Right to the City that Harvey defines 'not just [as] a right of access to what already exists, but [as] the right to change this ${ }^{23}$ (Harvey 2003, 1-2). Though paved with difficulties, as shown in the case of Pom Mahakan, this way to a shared design and management of land is particularly stimulating for other countries, giving way to more flexibility and cohesion between the users and what space embodies both physically and symbolically.

\section{Works Cited}

ACHR [The Asian Coalition for Housing Rights]. 2008. 'A Conversation about Upgrading at Bang Bua'. ACHR Thailand report.

http://www.achr.net/upload/downloads/file_13122013115706.pdf.

ACHR. 2010a. Design With People. Bangkok: ACHR.

ACHR. 2010b. 'The community architects movement in Thailand', Regional Gathering of Community Architects, Chiang Mai, 12-16/o6/2010. http://www.docstoc.com/ docs/69861243/Panel-2-Community-Architects-in-Thailand-WITH-PHOTOS.

23 'The right to the city is, therefore, far more than a right of individual access to the resources that the city embodies: it is a right to change ourselves by changing the city more after our heart's desire. It is, moreover, a collective rather than an individual right since changing the city inevitably depends upon the exercise of a collective power over the processes of urbanization. The freedom to make and remake ourselves and our cities is, I want to argue, one of the most precious yet most neglected of our human rights' (Harvey 2003, 1-2). 
ACHR, CODI, and CAN. 2011. Interactive Bang Bua Canal Guide Book 2011.

ACHR and Kerr Thomas. n.d. 'Notes on Canal-side networks in Thailand: in Bangkok and other cities...' CODI.

http://www.codi.or.th/webcodi/downloads/english/Baanmankong/Canal_side/ Klong\%2oNetwork\%2oNotes\%201999.pdf.

Archer, Diane. 2009. 'Social Capital and Participatory Slum Upgrading in Bangkok, Thailand'. Ph.D.. diss., University of Cambridge.

Ascher, François. 2010. Métapolis ou l'avenir des villes. Paris: Odile Jacob.

Askew, Marc. 2002. Bangkok, Place, Practice and Representation. London: Routledge.

Berner, Erhard. 2001. 'Learning from Informal Markets: Innovative Approaches to

Land and Housing Provision, Development and Cities'. Paper presented at the ESF/N-AERUS and UNRISD Workshop, Geneva, 3-6 May.

Boontharm, Davisi. 2005. Bangkok, formes du commerce et évolution urbaine. Paris: Editions Recherche/IPRAUS, collection Archithèses.

Boonyabancha, Somsook. n.d. 'Unlocking People Energy'. Our Planet: The magazine of the United Nations Environment Program 16(1): 22-23.

Bristol, Graeme. 2007. 'Strategies for Survival: Security of Tenure in Bangkok'.

In Global Report on Human Settlements 2007: Enhancing Urban Safety and Security, ed. By UN-HABITAT, 317-18. http://unhabitat.org/wp-content/uploads/2008/07/5403_7323_GRHS.2007.CaseStudy.Tenure.Thailand.pdf.

Charmes, Jacques. 2003. 'Les origines du concept de secteur informel et la récente définition de l'emploi informel'. Report for the Institut de Recherche pour le Développement. http://info.worldbank.org/etools/docs/library/218175/IIES\%20 Secteur\%2oInformel.pdf

CODI [The Community Organizations Development Institute]. n.d. 'Bang Bua Canal Community Network in Bangkok: The redevelopment of 12 canal-side Communities along Klong Bang Bua'. http://www.codi.or.th/downloads/english/ Baanmankong/Canal_side/Bang\%2oBua\%2oStory\%2oMarch\%2020o6.pdf.

CODI. 2004. 'Canal Community Development and Canal Cleaning Activities in Bangkok'. http://www.codi.or.th/downloads/english/Baanmankong/Canal_side/ Vichai\%2oInterview\%2oEdited.pdf.

DPU [Development Planning Unit]. 2012. 'In Short with Somsook Boonyabancha'. YouTube video, 16:52. Posted by 'Bartlett Development Planning Unit', 9 September. https://www.youtube.com/watch?v=XVrgmjHH-RU.

Gerbeaud, Fanny. 2012. 'L'habitat spontané: Une architecture adaptée pour le développement des métropoles? Le cas de Bangkok, Thaïlande'. PhD diss., University of Bordeaux.

Giménez, Gilberto. 2005. 'Cultura, identidad y metropolitanismo global'. Revista Mexicana de Sociología 67(3): 483-51. 
Goldblum, Charles. 2010. 'Dynamique urbaine et métropolisation en Asie du SudEst: une perspective à partir de Bangkok et de Singapour'. Annales de Géographie 671-672:174-18o.http://www.cairn.info/resume.php?ID_ARTICLE=AG_671_0174.

Goldblum, Charles and Manuelle Franck. 2007. 'Les villes aux marges de la métropolisation en Asie du Sud-Est'. L'espace géographique 3(36): 229-236.

Harvey, David. 2003. 'The Right to the City'. International Journal of Urban and Regional Research 27(4): 1-2. doi: 10.1111/j.0309-1317.2003.00492.x.

Herzfeld, Michael. 2003. 'Pom Mahakan: Humanity and Order in the Historic Center of Bangkok'. Thailand Human Rights Journal 1(1): 101-19.

Lefebvre, Henri. 1974. Le droit à la ville. Paris: Editions Anthropos.

NESDB [National Economic and Social Development Board]. 2003. The Master Plan for Land Development: Ratchadamnoen Road and Surrounding Area. Bangkok: NESDB.

Pétonnet, Colette. 2002. On est tous dans le brouillard. Edited by Catherine ChoronBaix. Paris: Editions Comité des Travaux historiques et scientifiques.

Petropoulou, Chryssanthi. 2007. 'Quartiers d'origine spontanée: Approche critique de la planification urbaine (villes d'Amérique Latine et de la Méditerranée)'. Revue d'Aménagement PRAXIS. http://www.revue-praxis.fr/document.php?id=7 Pornchokchai, Sopon. 1992. Bangkok Slums, Review and Recommendations. Bangkok: School of Urban Community Research and Actions Agency for Real Estate Affairs. Pornchokchai, Sopon. 2003. Global Report on Human Settlements 2003. Bangkok: National Housing Authority.

Sassen, Saskia. 2004. 'Introduire le concept de ville globale'. Raisons politiques 3(15): 9-23. http://www.cairn.info/revue-raisons-politiques-2004-3-page-9.htm.

Sassen, Saskia. 2010. 'The Global Slum'. The European. http://theeuropean-magazine. com/96-sassen-saskia/97-urban-life.

Tapie, Guy, Claire Parin, Céline Malignon, and Fanny Gerbeaud. 2008. Développement durable territorial: Une comparaison Franco-Thaïlandaise. Bordeaux: Ministère de l'Écologie (MEDAD).

Tovivich, Supitcha. 2010. 'Architecture for the Urban Poor, the "New Professionalism" of "Community Architects" and the Implications for Architectural Education: reflexions on Practice from Thailand'. PhD diss., University College London.

UN-Habitat. 2005. Financing Urban Shelter: Global Report on Human Settlements. London: Earthscan.

Valladares, Licia do Prado. 2006. La favela d'un siècle à l'autre. La Maison des sciences de l'Homme.

Wungpatcharapon, Supreeya. 2009. 'The Roles of Informal Community Networks in Public Participation: The Case of Thailand'. Paper presented at the 8th International Conference on Urban Planning and Environment (UPE 8), Kaiserslautern, Germany, March 23-26. 
About the author

Fanny Gerbeaud is an architect and sociologist. She works as a researcher and research engineer at the Ecole Nationale Supérieure d'Architecture et de Paysage de Bordeaux (France), in the PAVE research unit (Professions, Architecture, Ville, Environment). Highly interested in architecture made by non-professionals, she dedicated her doctoral thesis in sociology (2012) to the spontaneous production of space in the metropolises of Bangkok, Thailand, and in Brazil. She has participated in urban and architectural studies on sustainable development in Thailand, urban policies and storytelling on energy and mobility addressing climate change (in Cincinnati and Curitiba), and on the architectural culture of the French population. More recently she has focussed on the notion of 'comfort' in individual housing, on modern housing estates facing the energy transition in Bordeaux and is working on the publication of her doctoral results. 


\title{
4 Collaborative Urban Farming Networks in Bangkok
}

\author{
Promoting Collective Gardens and Alternative Markets as \\ Theatres of Social Action
}

Piyapong Boossabong

\begin{abstract}
Asian cities are recognized as places where food is abundant. This is also true of Bangkok, the capital of an agriculturally fertile country. However, most vegetables that are consumed within the city are transported from remote rural areas and contaminated with chemicals. Governmental policies have failed to control this chemical use, while simultaneously benefitting the monopolistic food corporations that constrain the sustainability of local food systems. This chapter sheds light on the collaboration of the urban farming networks in Bangkok that aim to produce alternative food sources within the city and create alternative markets. I argue that these networks can construct alternative urban spaces that act as theatres of social action. I also argue that it is useful to bring in the concepts of social capital, incentive structures, and communicative action when generating ideas about cities by and for the people. Social capital brings urban heterogeneities together as social agents of change in the city. It is a resource for collaborative actions. Local governments and quasi-autonomous national government organizations (QUANGOs) have been progressive in adopting forms of governance that create incentive structures and communicative forums that support grassroots initiatives.
\end{abstract}

Keywords: urban farming, community gardening, commons, social capital, right to the city, Bangkok

Cabannes, Yves, Douglass, Michael and Padawangi, Rita, Cities in Asia by and for the People. Amsterdam: Amsterdam University Press, 2018 DOI 10.5117/9789462985223/CHO4 
Figure 4.1 Maps of (a) Thailand and (b) Bangkok and urban farms
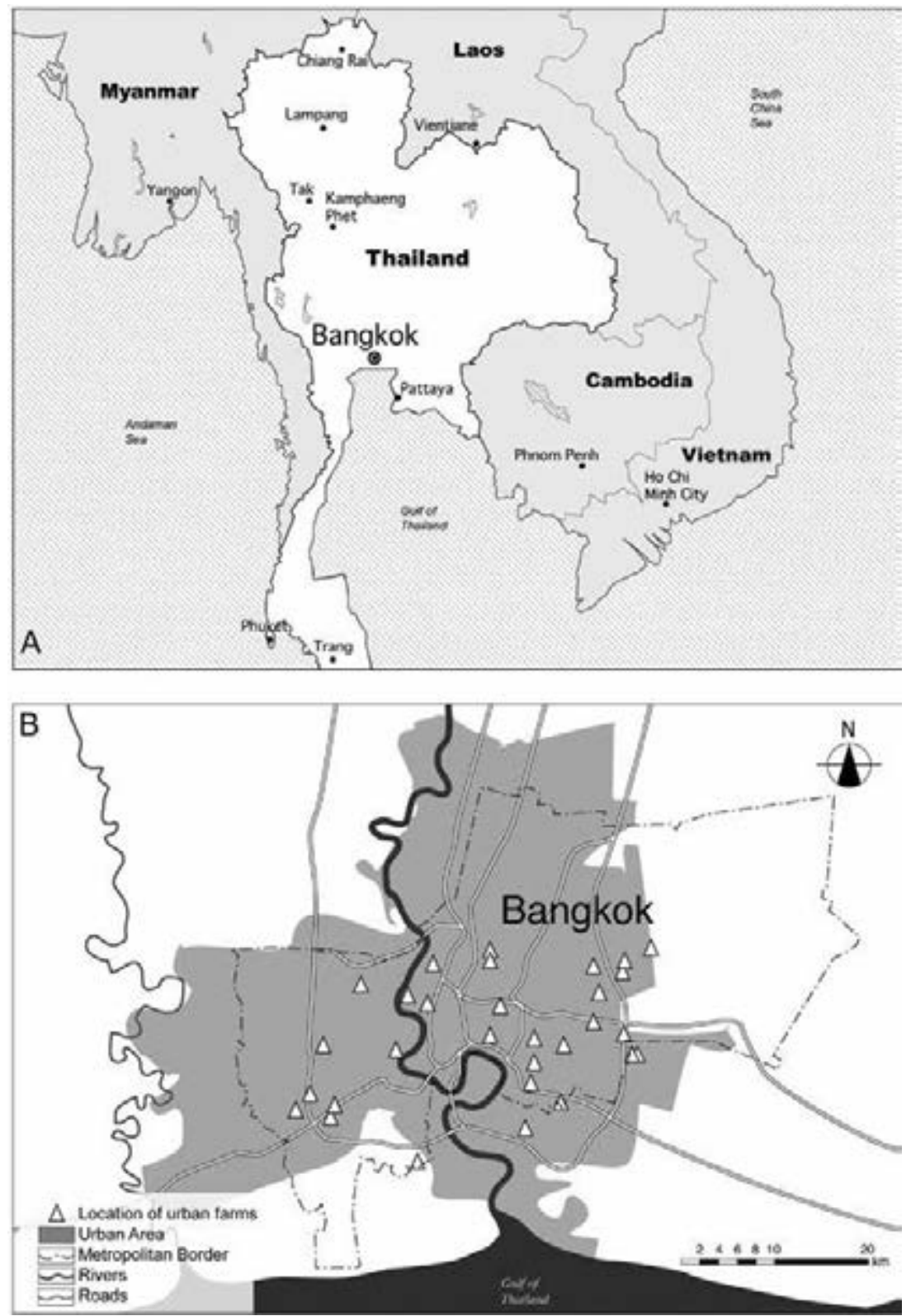

Source: Ariel Shepherd 
Asian food is well known throughout the world, including Thai food. Asian cities are also recognised as places where food is abundant. This is also true of Bangkok, the capital of Thailand, but like many other Asian (and other) cities, Bangkok's mainstream food system is shaped by monopolistic food corporations who own 232 discount and convenience stores throughout the city. Of these, the 25 largest stores are built on a total land area of 1,157 acres, which is more than the total land used for the 25 largest public parks in Bangkok (Thai Climate Justice 2012, 13). The mainstream food system also depends on the transportation of produce from remote rural areas. A survey exploring the impact of food miles on Bangkok's ecological footprint found that city dwellers consume $240 \mathrm{~g}$ of vegetables on average per day, but only 30 per cent of all vegetables consumed in Bangkok are produced within $100 \mathrm{~km}$ of the city (Suteethorn 2011, 81, 83). In the largest central market, Talat Thai, $5^{\circ}$ per cent of vegetables are produced more than $200 \mathrm{~km}$ away (Suteethorn 2011, 85). Every day, roughly US $\$ 24,048$ is spent on vegetable transportation by trucks from rural Thailand to the central city markets in Bangkok (Suteethorn 2011, 87).

In this chapter, I discuss the attempt to develop an alternative food system by and for the people of Bangkok. I argue that promoting collective gardens and alternative markets through collaborative urban farming networks provide an alternative way to construct Asian cities as theatres of social action in the way that an urban space is perceived as an interactive and inclusive social space where collective activities are regularly organized. Within such space, each participant plays a particular role which allows them to exchange ideas and learn to enhance their performance. The lessons from collaborative urban gardening in Bangkok are raised to illustrate this claim. This collaboration has been facilitated by a public programme entitled 'City Farm' that was initiated by non-governmental organizations (NGOs) and community-based organizations (CBOs), and has been supported since 2010 by a quasi-autonomous national government organization (QUANGO) and local governments. The information for this chapter was gained through observations of collective action, interviews, and focus group discussions. Some information was also gained from the review of relevant grey literature, including the analysis of legal frameworks, policy documents, project proposals, organizational and group profiles, meeting reports, progress reports, databases, websites, and Facebook pages.

This chapter starts with a discussion of the theoretical framework linking related topics such as the commons, right to the city, collaborative 
governance, and social capital. Subsequently, I analyse possible alternative ways to construct urban spaces as theatres of social action through a case study of collaborative urban farming networks in Bangkok. In particular, I focus on how these networks are governed and the potential of collective gardens and alternative markets to create the commons in an urban setting. The analysis also explores the networks' capacity to provide a way to build the right to the city. I then propose the concepts of social capital, incentive structures, and communicative action as the theoretical basis for new ideas about cities by and for the people. As an example, I examine the progressive forms of governance adopted by local governments and QUANGOs to create incentive structures and communicative forums that can support grassroots initiatives for sustainable forms of alternative development. Finally, I discuss the workable scale and the position of different sectors in creating and maintaining collaborations.

\section{The Commons, Right to the City, Collaborative Governance, and Social Capital: The Theoretical Framework}

\subsection{Claiming the Commons as a Way to Claim the Right to the City}

'The commons' refers to common-pool resources or common property. According to Nives Dolsak and Elinor Ostrom (2003), commons can include not only local resources like community forests and lakes, but also resources shared in a larger scale, such as international rivers, oceans, air, sky, energy, cross-boundary forests, historical heritage, and regional climates. Commons can be small, like microcredit, and large, like the global atmosphere. They can be mobile (e.g., water and wildlife) or stable (e.g., forests, parks, public car parks, and even landing strips for airplanes). In relation to the issue of food, Chang (2013) proposes that advocates frame the alternative food regime and system as a commons. Like Chang, this chapter defines collective gardens and alternative markets as an urban commons. These commons can be also framed as theatres of social action where various stakeholders exercise their right to the city. In other words, creating and engaging with these commons are ways to exercise the right to the city.

Many Neo-Marxists have argued that all city dwellers, whether rich or poor, should be able to access the public facilities of a city. As argued by Edward Soja (2010), this right has a geography. To guarantee people's right to the city is to ensure the equitable distribution of resources, services, and access. 
The more radical side of this argument states that resistance and revolution are necessary to enhance the public's right to the city. For example, David Harvey $(2008,23)$ argues that the right to the city entails far more than the individual liberty to access urban resources: it is a right to change ourselves by changing the city. This is also a common rather than individual right, since this transformation inevitably depends upon the exercise of a collective power to reshape the processes of urbanization. Harvey also argues that the freedom to make and remake both ourselves and the city we live in is one of the most precious, yet most neglected, of our human rights.

By conceptualizing the city as space in the tradition of Henri Lefebvre $(1995,2003)$, this chapter recognizes the right to the city as the right to economic, social, cultural, and even leisure spaces. Apart from that, I propose that the right to food in the city is one of the concrete forms of the right to the city. Advocacy for the right to food is a fundamental part of the food sovereignty movement (Wittman, Desmarais, and Wiebe 2010). As argued by Christopher Yap $(2003,12)$, the food sovereignty movement understands food as one aspect of a set of human rights, and therefore advocates for the rights of vulnerable and marginalized groups in society. The role of local organizations and their networks is essential for sustaining local food systems, livelihoods, and the environment - all of which generate the right to food-by fighting for the right of the people to access land for the self-production of food (Pimbert 2009). Urban farming contributes to the enhancement of the right to food in many ways. For example, urban farming can create an alternative food system by which the poor and marginalized obtain better access. It also proposes using urban land to improve both the livelihoods of city dwellers and the environment. In addition, it enhances economic, social, and environmental justice, particularly in times of crisis (Allen and Frediani 2013; Boossabong 2017).

Moreover, the idea of the right to food in the city allows us to think differently about cities. In general, we tend to think that farming is out of place in the city. This alienation of farming from the modern city has been constructed through the logic of capitalism. As argued by Jane Jacobs (1969), agriculture originated in cities; in the ancient world (around 9ooo BCE), the cultivation of plants and animals was only city work. Outside of cities, wild food and other things were hunted and gathered. For this reason, agricultural cities emerged before agricultural villages, which were transformed from small and simple hunting settlements. Productive agriculture has recently been reinvented through innovations from the cities (e.g., farming knowledge, chemical fertilizers, tractors, sprinklers, pumps) (Jacobs 1969, 31). Lefebvre $(2003,4)$ also noted that ancient civilizations 
created both urban and agricultural life. Farming should therefore not be seen as an alienation of the city. In other words, the promotion of urban farming brings farming back to the city (or recognizes it as part of the 'urban fabric'). In the same way, claiming the commons through urban farming should also be recognized as a way to claim the right to the city.

\subsection{Governing the Commons Collaboratively to Exercise the Right to the City}

Learning how to govern the commons collaboratively is important for exercising the right to the city (through the right to food in the city). As argued by Derek Armitage (2008), governing the commons is crucially dependent on the collaboration of multiple social actors across different levels and scales of organization. The notion of collaborative governance is used to capture the collaboration of cross-sectoral multi-actors, including both governmental and non-governmental bodies (Ansell and Gash 2007; Chhotray and Stoker 2010; Donahue 2004). As argued by Christ Ansell and Alison Gash (2007, 543), collaborative governance is usually adopted for sector-specific governance issues and is regularly implemented at small scales, such as community health partnerships, natural resource co-management, and, as in this case, urban farming network governance. In this section, I give a brief overview of the literature on collaborative governance so as to frame the understanding of commons governance I refer to in the rest of this chapter.

Elinor Ostrom and her followers have developed an approach to understanding the collaborative governance of the commons, which is called polycentric or multi-layered governance. Ostrom $(1990,2010)$ emphasizes the importance of overcoming the dilemmas involved in collective action, particularly the problems of repeated cooperation. Influenced by the Institutional Rational Choice Theory, Ostrom and her followers assume that without effective incentive structures each actor will tend to be a free rider (i.e., not cooperate but take the offered benefits) because their decision will be based on self-interest. They will not invest time and effort in cooperation that is not expected to make a satisfactory return. According to James March and Johan Olson (1989), incentive structures are a way to reward and sanction certain behaviours, and thereby make a change to them. Ostrom (1990) clarifies that incentive structures could support a new set of rules and ensure credible commitments to follow the rules, which, in turn, helps to obtain long-term collective benefits and support for mutual monitoring.

Ostrom's approach has been critiqued for conveying a highly reductionist view of social actors, who actually act through both instrumental and 
psychologically complex sets of motives such as, love, jealousy, and other emotions shaped by cultural factors (Green and Shapiro 1994). Ostram's approach also reduces the significance of belief systems, ideologies, altruism, mutual learning, negotiation, and bargaining in influencing behaviour, and is usually a biased account of politics as a market mechanism although it pretends to be politically neutral (John 2012). Besides, for Yvonne Rydin $(2003,45)$, 'deliberation' and the 'discursive dimension' are largely missing from such a perspective. So, Ostrom's Institutional Rational Choice Theory should be complementary to Habermas's Communicative Action Theory which concerns more on such missing. This approach emphasizes the role of communication in enhancing collaboration by building a mutual understanding and consensus to handle cooperation and conflicts (Fischer and Forrester 1993; Fischer and Gottweis 2012; Habermas 1987; Hajer and Wagenaar 2003; Healey 2006). This suggestion becomes an alternative way to overcome the problems that arise among collaborative stakeholders, as highlighted by Ostrom's Institutional Rational Choice Theory. The next question is: What are the conditions required to develop effective incentive structures and good quality communication? Both the Ostromian Institutional Rational Choice Theory and Habermas's Communicative Action Theory give credit to social capital.

\subsection{The Role of Social Capital in Governing the Commons}

When examining the concept of social capital, it should first be noted that there has been extensive discussion about social capital in the literature that has generated several contrasting conceptualizations. However, the common understanding is that social capital is a resource that can be invested and expected to make returns in similar ways as financial and physical capital (Bourdieu 1986; Lin 2010). If this is so, what does this resource look like? James Coleman (1990), Nan Lin (2010), and Michael Woolcock (1998) have described it as a strong tie that brings together plural actors. Robert Putnam (2002) adds that this strong tie might be constituted by 'bond' or 'bridge' relations. While 'bonding' refers to ties between homogeneous members, 'bridging' represents ties among heterogeneous members (e.g., across communities and between cultural or ethnical groups). Therefore, a social tie is the minimum standard for social capital.

What kinds of social capital can glue plural actors together to develop a collaborative governance system? According to Nick Gallent and Steve Robinson (2012), a study of social capital should be scoped by particular theories and fields of study as different theories and fields perceive forms of 
social capital differently. In this chapter, I capture different forms of social capital by engaging with both Institutional Rational Choice Theory and Communicative Action Theory; together, these two map out the different forms of social capital by distinguishing between rational and normative commitments (Warren 1999). Institutional Rational Choice Theory emphasizes rational commitment based on predictable and concrete strings-attached relationships, such as shared rules, a reputation for trustworthiness, and predictive trust. The theory assumes that these forms of social capital can support the effectiveness of incentive structures by reducing transaction costs and increasing relational benefits, which in turn affect the decision making of each collaborative stakeholder to collaborate in collective actions (Ahn and Ostrom 2010; Ostrom 1994, 1995). Communicative Action Theory focuses more on normative commitments based on unpredictable and abstract strings-attached relationships, such as shared norms, altruistic trust, and moral obligations. This theory posits that these forms of social capital can create public spheres for interactions to take place and facilitate good quality communication that achieves mutual understanding and consensus, which in turn enhances collaboration (Healey 2006; Innes and Booher 2003, 2010; Pennington and Rydin 1999). These two theories make different assumptions; combining them could provide analytical insights for understanding cities by and for the people.

\section{Collaboration of Urban Farming Networks: A Possible Alternative Way to Construct the City as a Theatre of Social Action?}

As farming is part of the cultural identity of Thailand, many Thai people who are not full-time farmers, including many inhabitants of inner-city Bangkok, attempt to grow their own food in their backyard and in collective gardens. The city has the capacity for farming, as it is usually teased by the proverb 'Use the best land for farming to build the worst city.' This proverb means the geology of the Bangkok area is proper for farming the most, but this area is instead used for building the most densely populated and polluted city of the country. Lack of water is also not generally a problem, as people can use water from the 1,165 rivers that gave Bangkok the name 'River City' or 'Venice of the East' (Bell 2003, 77). Most city dwellers farm for their own consumption, but some also grow vegetables to supply restaurants. Others sell surplus products in local markets or to their neighbours, or even join a vegetable box delivery scheme under the community-supported 
agriculture system supported by the Green Market Network. Some have also developed farming (and gardening) training centres and sell basic inputs such as ready-for-use soil, organic fertilizers, farming instruments, and food-growing containers. These people also form or engage in various natural networks created through informal relationships developed along food production chains.

Even though inner-city farming is small-scale and could not replace the mainstream food system shaped by large-scale monocropping and the monopoly of large food corporations, it is able to play an important role for the urban poor including slum dwellers and informal labourers, who need to reduce their food spending in order to exercise their right to food and to live in the city. It is also significant for vulnerable groups, such as hospital patients and school children, who require a secure intake of food as hospitals and schools are the main target groups of public programmes aiming to support urban gardening. Inner-city farming has also become a choice for other city dwellers who want to escape from the unjust and irresponsible mainstream food system, particularly members of the middle and upper classes. They distrust food from the markets and realize that healthy food must be either home-grown or grown by producers they know. Their farming practices are different from the mainstream, as they usually do not use mono-cropping or chemicals. Therefore, inner-city farming can promote an alternative food system for the city.

The most up-to-date and collaborative forms of support for urban farming are the actions by plural actors under the umbrella of the City Farm Programme, which began in 2010. This programme was proposed and managed by many non-governmental bodies, led by the Sustainable Agriculture Foundation, the Media Centre for Development, the Working Group on Food for Change, and the City Farm Association, and funded by the Health Promotion Foundation. The programme later combined many projects under its umbrella and supported many networks of organizations and groups. Those networks include full-time farmers on the city's fringes who engage with the community-supported agriculture (CSA) system, part-time farmers that develop their household and community gardens within the inner city, social and green enterprises, active online green customers, community-based organizations, non-governmental organizations, and public organizations that have developed their institutional gardens as learning centres. These policy networks were driven by collective gardens - which were almost all located within the inner city of Bangkok (as shown in Figure 1) -, green markets, and the community-supported agriculture system. A survey of twenty-seven community garden projects 
(50 per cent) by the City Farm programme's coordinator in the first nine months of the programme found that each project can create edible green spaces in an average space of $2,202 \mathrm{~m}^{2}$ and re-use city waste by composting roughly 4,179.5 kg (City Farm Programme 2011, 46).

The City Farm programme develops collaborations between the existing urban farming networks through campaigns, competitions, and other creative collective events that open spaces for raising awareness, inspiring newcomers, and sharing and learning across networks. These spaces in turn could be alternative ways to construct the city as theatres of social action as such spaces facilitate intensive interactions among different individuals, organizations, and groups from different networks. Their interactions also develop collaborative action plans to deal with food shortages during disasters (Boossabong 2012, 2014). In this chapter, I highlight the role of the constituent networks in promoting collective gardens and alternative markets as a commons, and how these commons construct the city as theatres of social action.

\subsection{Collective Gardens and Alternative Markets as the Commons in an Urban Setting}

The constituent networks under the umbrella of the City Farm Programme promote collective gardens, including community gardens and institutional gardens (e.g., gardens of schools, hospitals and governmental offices) that adopt low-input innovations for producing food in limited areas, such as rooftop, vertical, and floating gardens. They also organize alternative markets, including farmers' markets and support community agriculture. Additionally, they support green restaurants and city farming training and learning centres. Following Yves Cabannes (2004, 2012), I categorize urban farming practices into three different types, and analyse how each type can be a commons that functions as a theatre of social action. The first type is subsistence-oriented urban farming practices. This type emphasizes subsistence livelihoods and crisis mitigation and links to the enhancement of food security and social inclusion. The second type focusses on leisure and recreational activities related to farming. This type links farming to education, culture, and health. It also captures the role of urban farming practices as a strategy for maintaining the link between urban citizens and nature, raising awareness of environmental issues, and allowing urban children to understand the cycles of life and food. The third type consists of market production enterprises, which are related to market-oriented activities and linked with economic development. Mixed types, such as 
subsistence-oriented practices that are also leisure and recreation activities, are also possible (Cabannes 2012, 8-9). All real-life practices are in fact mixed types; here, I have highlighted the primary type and its contribution to the construction of spaces for social action.

a. Subsistence-oriented urban farming practices: Building community gardens as edible social space

The urban farming networks under the umbrella of the City Farm Programme have played a crucial role in the promotion of community gardens as self-sufficient economic practices among community members. The lessons from the On-nut Sibsee Rai and Keha-Tung Songhong community gardens are illustrated here. The On-nut Sibsee Rai slum community consisted of seventy-three households that once lived under bridges located in various places in Bangkok. Almost all of them worked as collectors of household waste, which they then sold to recycling industries. The leader of the community was also one of the leaders of the slum movement which has been fighting for housing rights since the 1980 s. This community first developed a community garden in 2002 and has since helped other slum communities do the same. The leader said that after they had received their own house, they needed to have their own food (Group leader, interview by the author, 20 February 2012). The community garden plays a main role in producing food for the community members for the whole year. The members help each other take care of the garden. They can take any vegetable and catch as many catfish as they want, but in return they are expected to donate by leaving some money in the box at the gate for garden maintenance purposes. Some of the community members even cook and eat together. The community leader mentioned that each member was usually worried about taking too much food from the garden; they would consider whether there was enough left for others before gathering food for themselves. They also felt obliged to help care for the garden after taking some food from it. The garden also became a public space for community members to work, meet, chat, and share with others; for children, the garden was their playground. In 2010, the community was supported with US $\$ 1590$ by the City Farm Programme to raise catfish in its garden. This programme supported the integration of farming and organic waste management in this community. The City Farm Programme also organized a tour of the garden in 2011 to facilitate learning and share sustainable farming practices among the urban farming networks that engaged with the programme. It became a model for slum community 
development recognized by the public sector, and proved that building community food security is possible.

Keha-Tung Songhong community garden was developed by a group of 104 informal workers. Almost all members of this group were women (only seven were men) who worked at home as subcontractors for the garment industry. The group played an active role in the activities organized by the network of home workers called 'Homenet' since 1992. The group leader had even criticized the Minister of Labour about his ignorance of informal labour rights during their social movement for pushing the informal labour right bill in 2008 (Group leader, interview by the author, 12 February 2012). Their community garden helped them reduce food costs. The City Farm Programme supported the group by providing inputs and know-how. During the dramatic flooding of Bangkok in 2011-2012, the group demonstrated that small-scale farming in the inner city could be a safety net for a vulnerable group, and supported crisis mitigation by providing valuable emergency food. Their garden has also become a place for meeting and sharing, including organizing social movements. It has inspired other groups of informal workers that work from home to build their own gardens.

b. Leisure- and recreation-oriented practices: Creating community and institutional gardens as healthy and enjoyable learning spaces Many community and institutional gardens do not contribute in terms of food volume to feeding all members of the community or institution, but instead contribute to the construction of spaces that facilitate learning and support good health and enjoyment. The first example is the community garden of Tarareanake Go Green Condominium. This organic vegetable garden was developed on the rooftop of a modern condominium where high-income Bangkok dwellers lived. Initiated by the condominium committee, it was decided by a vote that the common space should be used to create a rooftop garden. The City Farm programme provided know-how and sent a mentor to train and support food growing and garden maintenance. This garden then became a learning space for the condominium dwellers, who were not familiar with non-urban lifestyles. They learned how to grow and take care of different vegetables together, following the suggestions of the mentor. After the mentor left, they needed to do it on their own (do-it-yourself - DIY - practice). This community garden was a space for them to learn by doing, and gardening became an activity for both exercise and relaxation. It also gave them the opportunity to meet and chat with other dwellers of the condominium at the garden, which had hardly 
happened before. The members of Tarareanake Condominium became the next generation mentors for the gardens of nearby condominiums. In this practice, knowledge can also be understood as a commons, as it was shared and transferred across groups and spaces.

The second example is Organic Way's learning garden. The garden was developed by the green restaurant 'Health Me Organic Deliver', which used organic vegetables and supported local food production. The restaurant created its own vegetable garden in an area of roughly $100 \mathrm{~m}^{2}$ in its backyard. Apart from using the produce in the restaurant (which uses merely $25^{-} 30$ percent of the produce), the garden became the new playground and learning centre for urban children. Since 2012, the garden has become the learning centre for the City Farm Programme. It aims to enhance family relations and facilitate an environment where city children can learn about nature, growing food, and insects. Roughly five to ten groups of people and schools visit the garden each month. Two cases of institutional gardens, on the rooftops of the Health Promotion Foundation and Laksi District Administration Office's buildings, demonstrate how organizations, and even the government, can construct spaces for social action that promotes healthy and enjoyable learning processes. The institutional gardens of the Health Promotion Foundation (the funder of the City Farm Programme) were created as a learning centre to show that the organization took urban farming promotion seriously (i.e., 'show-case' gardens, for viewing rather than for producing food to eat). Like its name, this organization focussed on the integration of farming (and gardening) and the promotion of healthy living. The garden also became the meeting place for the members of the City Farm Programme, particularly for sharing lessons from previous activities, discussing current issues related to the urban farming movement, and brainstorming shared strategies for the next step.

The rooftop garden of the Laksi District Administration Office (a local government office) was the first rooftop garden of any public organization in the country. It was built as a city farm learning centre in 1998, and has become a training and learning centre of the City Farm Programme since 2010. The garden supports household gardening through knowledge transfers and providing some inputs (e.g., seeds and fertilizer). It has also become the model for building rooftop gardens, and has been visited by individuals, organizations, and groups from all over the country. Its success has inspired many other public organizations to build institutional gardens as learning centres; 14 of 50 District Administration Offices in Bangkok currently have rooftop gardens. 
Figure 4.2 City farm training programme

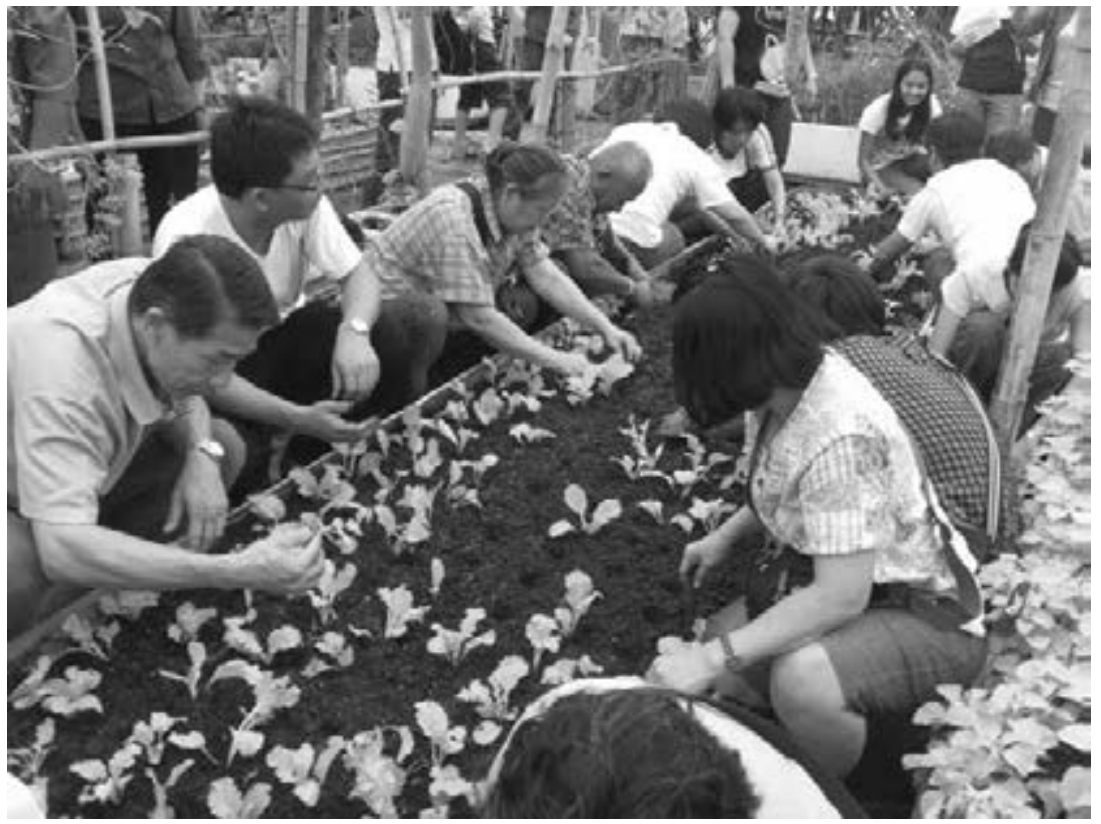

Source: author

c. Market-oriented practices: Promoting alternative markets as spaces for reciprocal exchange

Since 2010, the City Farm Programme has promoted social enterprises. In particular, the programme supports social enterprises that organize city farm training programme ('know-how') markets and organic farmers markets. The support aims to promote reciprocal relationships among social enterprises and producers, and between producers and customers. For example, the programme has developed reciprocal relations among the social enterprises that organize training programmes by opening a space for them to share information, knowledge, techniques, ideas, and innovations through a magazine titled 'Natural Agriculture Magazine'. The programme also attempted to diversify the training programmes (see Figure 2): for example, one enterprise would focus on inspiring the next generation, while another focussed on setting up activities for childhood development. The programme also facilitated mutually beneficial exchanges: for instance, each enterprise could borrow the gardening handbooks and trainers of others', and help each other publicize events designed for different target groups. Enterprises also sell gardening 
products developed by other groups, such as ready-to-use soil bags. The variety of training programmes provided by various enterprises has created a new type of market, a 'know-how' market, in which city dwellers can 'shop' for skills that they would like to develop.

The new producers who met during the training sessions organized an online social network called 'City Farms, City Friends' through Facebook. They shared problems, obstacles, and photos of their products online. They also organized a monthly meeting called 'Eating and Sharing in the Garden', during which they shared food made from their own produce and discussed particular issues related to food, the environment, and the city. The City Farm Programme later supported this monthly meeting by facilitating the discussion. At the time of writing this chapter (late April 2018), there were 51,900 members in this online group and about 13,650 photos had been shared.

The development of reciprocal relationships between producers and customers is reflected in the attempt of the City Farm Programme to promote each green market as a Metra market, which means a market based on mutual benefits rather than profits. The Green Market Network was formed and facilitated learning across markets. In cooperation with the City Farm Programme, this network aimed to develop more trustworthy organic food sources compared to the organic foods sold in modern trade supermarkets, which are randomly tested to determine any chemical contamination. They also developed a CSA system to create a direct link between organic producers and green customers by establishing a contract that would allow customers to buy vegetables directly from farmers and pre-pay them. The vegetable box delivery method was also adopted. The CSA system enhanced producer-customer relationships by promoting mutual responsibility: the producers were obliged to produce real organic vegetables, while the customers were expected to take risks with the producers when produce was lost as a consequence of the changing climate. Mutual understanding was also developed through the customers' understanding that they might not be able to get certain vegetables, as the producers may not be able to produce them; at the same time, the producers needed to adapt by learning to grow some of the vegetables requested by the customers and to be open-minded about the feedback they received. The Green Market Network in cooperation with the City Farm Programme also organized farm visits that took groups of customers to visit their producers. These customers also took part in the process of monitoring farming practices according to the adoption of the participatory guarantee system (PGS) that allows active customers to be the 
members of the committee for guaranteeing the quality of farmers' produce. Social spaces for the enhancement of producer-customer relationships were also made through an annual meeting called 'Green Fair' and the information exchanges provided through the Green Market Facebook page and magazine.

\subsection{The Capacity to Provide a Way to Build the Right to the City}

The collaboration of urban farming networks through the City Farm Programme has not only allowed those networks to be recognized, but also empowered them to negotiate and bargain with the formal power of urban governance mechanisms. As a consequence, the people involved in them can claim their right to the city as agents of change. They did that through exercising their right to (better) food in the city. I have already addressed in 3.1 how urban farming networks could provide the opportunity for people to exercise the right to food through the creation of an alternative local food system. This section highlights the impact of the collaboration of urban farming networks for advocating pro-poor urban agriculture. In particular, the focus is on how these networks have encouraged and supported slum dwellers and informal labourers to gain access to land and create their community gardens.

Accessing land for living and growing food is a difficulty commonly faced by slum dwellers. Most slum communities have realized that it has been rendered 'illegal' to live and grow food on public land, leading to many conflicts with public organizations. For example, before establishing the 'On-nut' Sibsee Rai slum community, members lived under bridges in inner-city of Bangkok and survived by collecting garbage and selling it for recycling. In the $1980 \mathrm{os}$, the police forced them to move out, making them fight for their right to housing since then. In September 2000, the government provided land owned by the State Railway of Thailand for them to establish a community but demanded rent for 30 years that increased every year. They could not pay this rent, so finally, the government attempted to force them to leave. The situation has improved since 2004, when the government endorsed the public policy of Baan Mankong ('Secure Housing') in cooperation with a quasi-governmental body called the Community Organizations Development Institute. However, only 361 communities in $5^{0}$ districts of Bangkok have been involved with this programme (Community Organizations Development Institute 2008; Rapeepat 2009), while there are still many slum communities left behind-including 'On-nut' Sibsee Rai slum community and many other communities engaged in the City Farm Programme. 
In Thailand, groups of informal workers have a long history of fighting both corporations and the government for labour rights and welfare. For example, the 'Solidarity' group leader described how his group members had all been laid off from the same factory that closed down in 1992 without a pension scheme (Group leader, interview by the author, 11 February 2012). They started by learning about labour laws and demanding their right to get a pension from the factory owner, but the owner refused to pay. Then they demanded that the Minister of Labour help them, but were ignored. As a result, roughly goo laid-off labourers protested in front of the Ministry of Labour. This protest had no effect: the government took no action and the owner of the factory went back to Texas. Subsequently, the workers formed their own small factory to sew and screen-print T-shirts with the support of NGOs. As this group could not provide welfare to their members, they developed a collective vegetable garden around the factory to produce food for the workers.

The urban farming networks engaged in the City Farm Programme promote pro-poor urban agriculture for slum dwellers and informal labourers by coordinating with the owners of vacant lands to create contracts allowing the poor to produce food in their land for three to five years (see Figure 3). Some of the owners asked for rent (1000-200o Baht per year), while the rest allowed the use of their land without rent as they wanted to avoid taxes, clear their untidy land, help the poor, and access the organic vegetables grown in the new gardens. The role of District Administration Offices as witnesses and mediators to these contracts was essential, as it gave the land owners confidence in the agreement. The coordinator of the Laksi District Administration Office, for example, noted that there was more demand from the owners for the poor to use vacant land to grow food than there was from the poor themselves. The reasons are that most of the vacant lands lacked the basic facilities such as water and were located far from the places that either slum dwellers or informal labourers lived and worked (Urban agriculture trainer, interview by the author, 23 March 2012).

The urban farming networks also played a role in negotiating with the National Housing Organization to allow the use of firebreak blocks (vacant lots within a housing project used for preventing fire from spreading and destroying all the homes) to grow food. For example, they were able to negotiate the building of a community garden in the firebreak block at Nuggeela national housing community. The District Administration Office and the City Farm Programme jointly brought the backhoe to the land and helped clear and plough the soil (Interviews with community leaders by author, 24 June 2012). The urban farming networks under the umbrella of 
Figure 4.3 Community gardens developed on vacant land

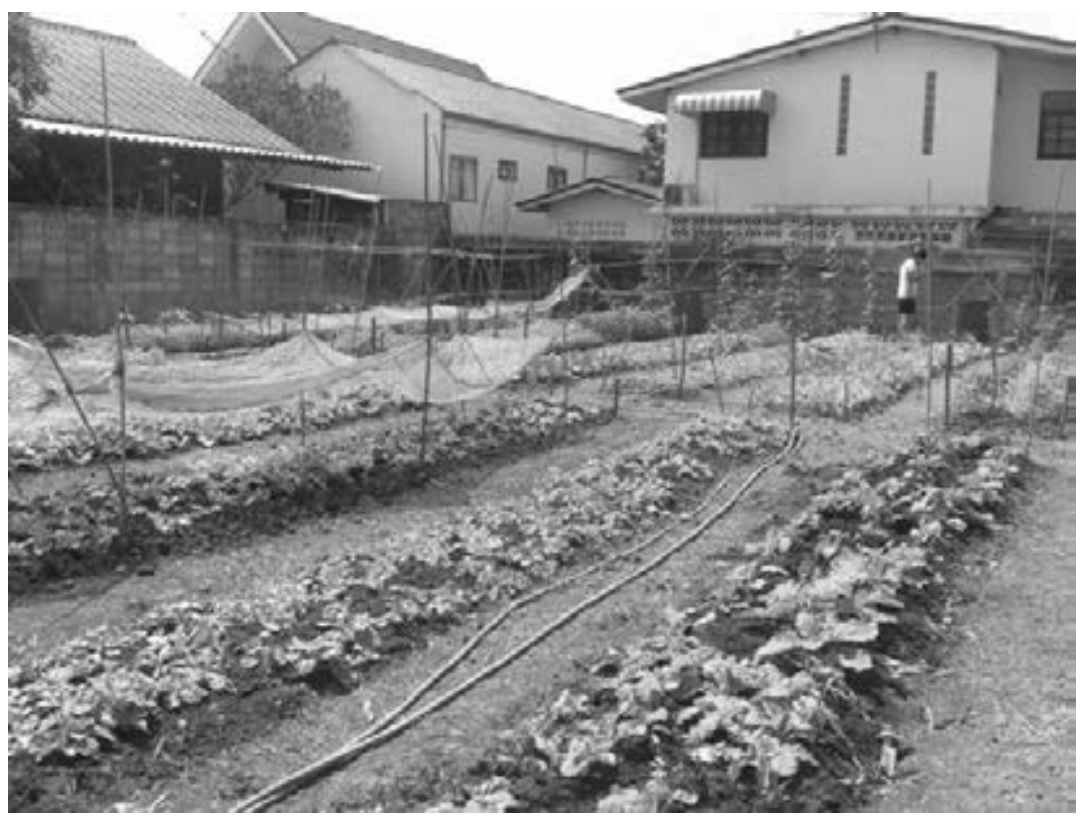

Source: author

the City Farm Programme also pushed the On-nut Hoksibhok community to develop a community garden under an electric line and a Muslim community to create a community garden under the airport rail link. They negotiated with the Thai Railway Organization to allow the urban poor to develop community gardens along railway lanes at Bangkoknoi. The networks backed up workers' demands to build a collective garden within the grounds of a cement company. If there was limited available land, the networks promoted the creation of floating gardens (i.e., the river was used as a space for food production), such as in the Bang Bour slum community that was settled informally along the river in the inner city.

\section{Articulating Social Capital, Incentive Structures, and Communicative Action: The Theoretical Bases for Generating 'Cities by and for the People'?}

The previous section addressed how the urban farming networks under the umbrella of the City Farm Programme construct alternative spaces of social action through promoting collective gardening and alternative markets. This 
section analyses how different actors could be engaged collaboratively as members of the networks. I argue that to understand collaborative urban governance is to understand the possible mechanisms that can construct cities (as urban spaces) by and for the people, because collaborative governance recognizes the role of people's organizations and informal groups as change agents and partners for development. This chapter analyses the idea that collaboratively generating ideas about spaces by and for the people requires the articulation of social capital, incentives, and communication. It was found from the aforementioned case studies that social capital brought different actors together as agents of social change in the city by acting as a resource for collaborative actions.

There were multiple forms of social capital actively holding urban farming networks together: shared rules, reputations, trust, reciprocity, moral obligations, shared norms, and shared knowledge. For example, shared CSA rules facilitated the collaboration of CSA members and related organizations, groups, and networks. The reputation of training centres supported their role in developing and extending networks of trainees. Public trust in local governments and QUANGOs allowed them to organize meaningful collective actions that a lot of people participated in. Reciprocity among city farmers, green enterprises, and green customers strengthened their networks and cooperation. Moral obligations based on kindness and an altruistic mind-set promoted mutual aid among members of urban farming networks, particularly in times of crisis. Shared norms that were in favour of local food systems (anti-monopolistic food corporations) and organic farming (anti-chemical food production) brought many actors closer and in support of one another. Last but not least, people who shared knowledge usually liked to share and learn from each other, which in turn facilitated collaboration. These forms of social capital can both support and obstruct each other. For example, reputations support the development of trust, while shared rules of financial provision (grant management) as a rational commitment based on self-interest can obstruct the development of moral obligations as normative commitments based on an altruistic mind-set.

The power of social capital alone could not make a sustainable change, as social capital (like financial and natural capital) can increase or decrease over time. Instead, sustainability required the activation of good incentive structures. For instance, social enterprises collaborated with urban farming networks engaged in the City Farm Programme as a result of the expected benefits of doing so, such as getting more future customers (e.g., trainees, members, buyers, etc.), reducing costs by exchanging resources with other enterprises (e.g., staff and know-how), and receiving funding 
Figure 4.4 Communicative forum for urban farming networks to deliberate

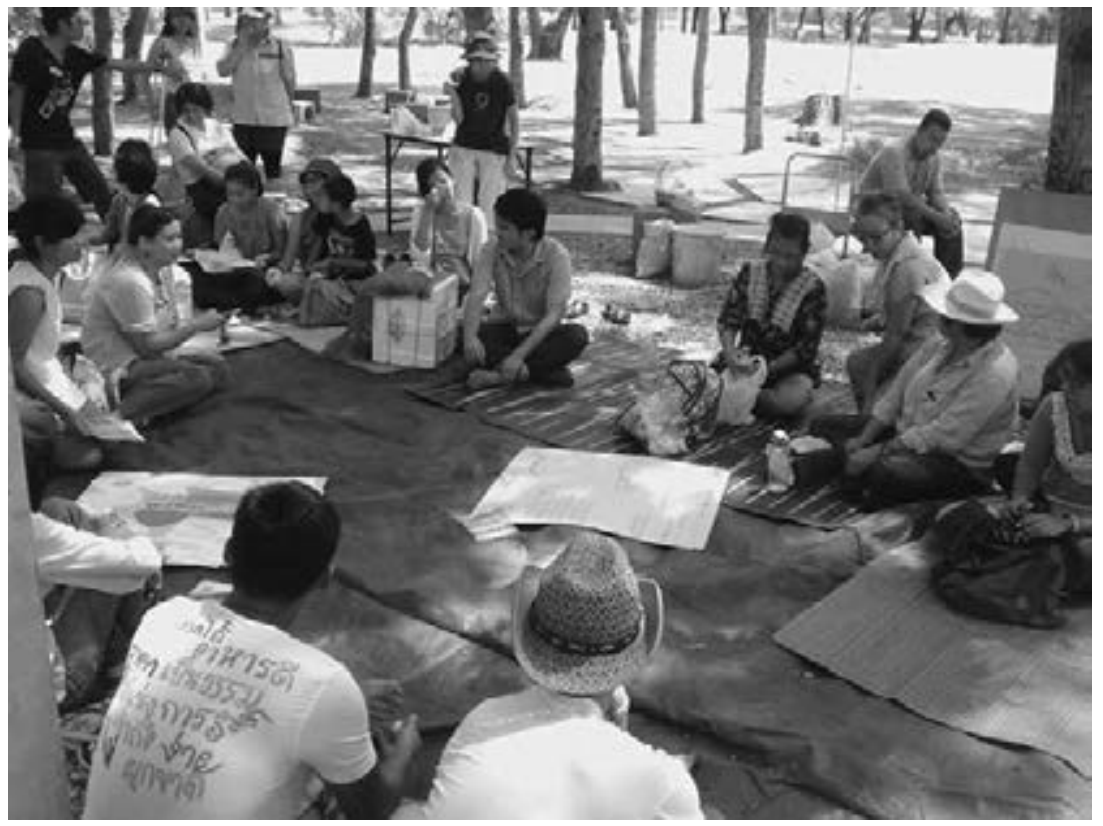

(Source: author)

support from the City Farm Programme for the organization of training. These examples support the assumptions of Institutional Rational Choice Theory. However, creating sustainable change also required the stimulation of social capital through regular interactions. For instance, NGOs and CBOs chose to collaborate with the urban farming networks engaged in the City Farm Programme because they agreed with the pro-poor approach and strategies to strengthen the local food system advocated by the networks in repeated discussions in various communicative forums. These examples also support the theoretical assumptions of Communicative Action Theory.

However, sometimes it was hard to identify why some individuals, organizations, groups, and networks decided to collaborate, as it depended on the particular situation. For example, some enterprises might expect benefits from certain situations, such as the expectation of receiving funding from the City Farm Programme, while did not think about benefits in different situations, such as during training to new coming producers and joining green markets as in these situations they could contribute to their ideology (e.g., dream of 'green society'). Some of them decided to collaborate because they would gain specific expectable returns while easing their conscience at the same time. For example, 'Health Me Organic Delivery' collaborated with 
urban farming networks to both expand its circle of restaurant and home delivery customers and provide a source of learning for urban children. This example demonstrates that it is essential to take both of these theoretical assumptions into account for a comprehensive analysis.

Last but not least, the case study indicates that local governments (District Administration Offices) and QUANGO (Health Promotion Foundation) have been progressive in developing collaborative forms of governance through the creation of effective incentive structures and communicative forums. They have adopted a collaborative governance approach by recognizing NGOs, CBOs, laymen, and their social networks as development partners and supporting grassroots initiatives for sustainable alternative development. For example, they have incentivized enhancements in the collaboration of urban farming networks by providing funding, rewards, free training, free inputs, and free consultants under the condition that each organization should initiate and participate in collective events. They have also enhanced collaboration by organizing communicative forums that individuals, organizations, and informal groups engaged in any kind of urban farming network could participate in to share their knowledge, ideas, and experiences. For example, they organized a meeting focussed on formulating the visions, missions, and strategies of the City Farm Programme; an exhibition meant to share food innovations; and a monthly event called 'Eating and Sharing in the Garden' that involves a discussion on current issues related to food and the city.

\section{$5 \quad$ Workable Scales and the Positions of Different Sectors in Creating and Maintaining Collaboration}

Another important topic to mention is workable scales and the position of different sectors - the state, the private corporate sectors, and the people-in collaborative urban farming. The place making practices of collaborative urban farming networks in Bangkok involve several scales: the individual community, the whole city, and the country. Enhancing food security and social cohesion is most possible at the community scale, because the community creates and maintains the collective garden together. Such contributions are also possible at larger scales, such as the whole city, but they are limited and depend on the specific situation. For example, vegetables collected from the community gardens were shared with other communities within Bangkok during severe flooding in 2011 (Boossabong 2014). Some collective gardens have also opened opportunities for volunteers from elsewhere to join in the gardening. This has helped to 
develop social cohesion among both community members and outsiders. The monthly event called 'Eating and Sharing in the Park', where people across communities within Bangkok cooked their own produce and shared with others in a public park, developed social cohesion.

It is clear that reciprocal exchanges have been enhanced at the whole-city scale, as there were a lot of alternative markets scattered both within the inner city and at the fringe of the city (e.g., green markets and delivery food boxes under community supported agriculture schemes). So, people from different parts of Bangkok could access nearby alternative markets. However, it should be noted that this contribution was mostly limited to rich and middle-class customers because the city's organic food programme promotion still failed to reduce the price gap between organic and non-organic food. The poor and a large portion of the middle class could not afford to buy organic food, which in turn excluded them from the alternative markets that advocated organic food. However, this does not mean that there was no place for the poor and marginalized in these alternative markets, as most of the farmers engaged in community supported agriculture schemes were poor. In fact, there were special events where these alternative markets provided food for the poor and marginalized for free or at a lower price; for example, the Green Market Network in cooperation with green restaurants often organized events aimed at providing free food to homeless people in Bangkok.

The impact on producing sharing, learning, and leisure spaces ranges from the local community scale to the national scale. This can be seen from the fact that people from every corner of the country have come to visit many collective and learning gardens. It is hard to deny that the vertical and rooftop gardens in Bangkok are the most innovative and productive when compared with practices in other cities in Thailand. These practices have also been promoted by the national media through television programmes, magazines, and newspapers. Many organizations, groups, and networks related to urban farming practices in Bangkok have their own websites and Facebook pages, and the online group called 'City Farm City Friends' comprises members from everywhere in Thailand. Although these media and online channels were limited to the Thai language — thereby having little reach outside of Thailand-, the impact of sharing and learning have extended to wider regional and global scales as urban farming networks started developing connections with a number of international organizations and networks. These practices can act as concrete examples of an alternative food system, which can benefit anyone who realizes the problems of monopolized and irresponsible global and national food regimes. Although these individuals might not have a chance to engage closely in those practices, they can get 
inspiration from them and try in turn to gradually transform themselves and claim their right to food (and to a better food regime).

The above scales are interrelated and affected by the collaboration of different sectors. As argued by Brandon Born and Mark Purcell (2006), the outcomes produced by a food system are contextual no matter what the scale. They depend on the actors (and agendas) that are empowered by the particular social relations in a given food system. At the national level, the City Farm Programme was endorsed by the central government and implemented using national taxes. Although the programme was limited to the boundaries of Bangkok, Thai people elsewhere could also develop their sense of belonging and even critique this programme and its successes and failures in Bangkok because they also paid taxes. In addition to the media and online channels, this role of the state (through QUANGO) has been partially responsible for the promotion of urban farming practices beyond Bangkok.

Although Bangkok farming practices would have remained fragmented without state intervention (granting), these networks would not be as strong without the local governments, NGOs, CBOs, social and green enterprises, green customers, and urban famers functioning at the city and community scales. At these scales, cross-scale interactions were intensive, and the collaborative actors were also more interdependent. They built links to others at the same scale by developing bonding social capital, while collaboration across scales was made through bridging social capital. Hence, as argued by Dolsak and Ostrom $\left(2003,35^{2}\right)$, social capital plays a role in mediating and shaping multiple scales.

The last point about the scale of impacts and collaboration is the prospective challenge of urban farming practices (in particular the development of collective gardens and alternative markets) crossing formal political and governmental boundaries (similar to the phenomenon of the world-wide transition town movement ${ }^{1}$ ). This trend creates a 'blurred' scale and makes it harder to organize effective incentive structures and communicative forums. It is also harder to determine the appropriate positions of different sectors for creating and maintaining the collaboration. Without a clear centre, urban farming networks starting from Bangkok might need a more decentred governance approach in the future. Given this, the long-term prevalence of collaboration may not necessarily depend on scales.

1 It is a movement of laypeople who attempt to enhance their self-reliant capacity, especially on food and energy. They try to make changes to themselves and then scale up to their household, neighborhood, community and city. Nowadays, the transition town movement is everywhere and it develops its global network which facilitates sharing and learning across borders. 
By analysing the impacts of the collaborative urban farming networks endorsed by the City Farm Programme, this chapter provides the example of the social construction of urban spaces as theatres of social action. In particular, the chapter illustrates that promoting community and institutional gardens and alternative markets can create alternative spaces by and for the people, and that a pro-poor urban agricultural approach could support the right to the city of the urban poor through exercising their right to food. I have provided numerous examples of how collaboration enhances the recognition and power of slum dwellers and informal labourers to bargain and negotiate support for gaining access to land for food self-production.

I also propose a theoretical framework that is useful for understanding collaborative governance for constructing cities by and for the people. These case studies indicate the benefits of theoretical assumptions about social capital, incentive structures, and communicative action for understanding how collaboration by and for the people works. This theoretical framework is developed from a combination of Institutional Rational Choice Theory and Communicative Action Theory. As these two theories have contrasting assumptions (as a consequence of their ontological and epistemological differences), previous studies have usually only used one at a time. In contrast to this perspective, I argue that it is useful to take both of them into account to create a more comprehensive approach. The case studies also indicate that the local governments and QUANGO have been progressive in adopting a collaborative form of governance by promoting social capital, developing effective incentives, and organizing inclusive spaces for communication. The role of power relations in shaping networks and collaboration is a subject for further studies.

\section{Works Cited}

Allen, Adriana, and Alexandre Apsan Frediani. 2013. 'Farmers, Not Gardeners: The Making of Environmentally Just Spaces in Accra'. City 17(3): 365-81.

Ahn, Theodor K. and Elinor Ostrom. 2010. 'Social Capital and Collective Action'. In The Handbook of Social Capital, edited by Dario Castiglione, Jan W. van Deth, and Guglielmo Wolleb, 70-100. Oxford: Oxford University Press.

Armitage, Derek. 2008. 'Governance and the Commons in a Multi-level World'. International Journal of the Commons 2(1): 7-32. 
Ansell, Chris and Alison Gash. 2007. 'Collaborative Governance in Theory and Practice'.Journal of Public Administration Research and Theory 18(4):543-71. Bell, Barry. 2003. Bangkok: Angelic Allusions. London: Reaktion Books.

Born, Branden and Mark Purcell. 20o6. 'Avoiding the Local Trap: Scale and Food Systems in Planning Research'. Journal of Planning Education and Research 26(2): 195-207.

Boossabong, Piyapong. 2012. 'Collaborative Governance on Urban Food Agenda during Floods in Bangkok'. Paper presented at the RGS-IBG International Conference, Edinburgh, 3 July.

Boossabong, Piyapong. 2014. 'Coping with Flooding in Bangkok: Urban Agriculture as a Climate Change and Disaster Risk Reduction Strategy'. Urban Agriculture Magazine 27(March): 27-29.

Boossabong, Piyapong. 2017. 'Floods and Food in the City: Lessons from Collaborative Governance within the Policy Network on Urban Agriculture in Bangkok'. In Environmental Justice, Urbanisation and Resilience, edited by Adriana Allen, Liza Griffin, and Cassidy Johnson, 215-30. London: Palgrave Macmillan.

Bourdieu, Pierre. 1986. 'The Forms of Capital'. In Handbook of Theory and Research for the Sociology of Education, edited by John G. Richardson, 241-58. New York: Greenwood.

Cabannes, Yves. 2004. 'Public Financing and Investments for Urban Agriculture'. Paper prepared for the World Urban Forum 2004, Barcelona, Spain, 13-17 December.

Cabannes, Yves. 2012. Pro-poor Legal and Institutional Frameworks for Urban and Peri-urban Agriculture. Rome: Food and Agriculture Organisation of the United Nations.

Chang, Marina. 2013. 'Growing a Commons Food Regime: Theory and Practice'. PhD diss., University College London.

Chhotray, Vasudha and Gerry Stoker. 2010. Governance Theory and Practice: A Cross-disciplinary Approach. New York: Palgrave Macmillan.

City Farm Programme. 2011. City Farm Programme Progress Report. Bangkok: Sustainable Agriculture Foundation and Health Promotion Foundation.

Coleman, James. 1990. Foundations of Social Theory. Cambridge, MA: Harvard University Press.

Community Organisations Development Institute. 2008. Security House Programme Evaluation 2003-2008. Bangkok: Community Organisations Development Institute.

Dolsak, Nives and Elinor Ostrom, eds. 2003. The Commons in the New Millennium: Challenges and Adaptation. Cambridge: MIT Press.

Donahue, John D. 2004. 'On Collaborative Governance'. Working paper no. 2, John F. Kennedy School of Government, Harvard University, Cambridge.

Fischer, Frank, and John Forrester, eds. 1993. The Argumentative Turn in Policy Analysis and Planning. Durham: Duke University Press. 
Fischer, Frank and Herbert Gottweis, eds. 2012. Argumentative Turn Revisited:Public Policy as Communicative Practice. Durham: Duke University Press.

Gallent, Nick and Steve Robinson. 2013. Neighborhood Planning: Communities, Networks and Governance. Bristol: Policy Press.

Green, Donald P. and Ian Shapiro. 1994. Pathologies of Rational Choice Theory. New Haven: Yale University Press.

Habermas, Jurgen. 1987. The Theory of Communicative Action: Reason and the Rationalisation of Society. Translated by Timothy McCarthy. Cambridge: Polity. Hajer, Maarten A. and Hendrik Wagenaar, eds. 2003. Deliberative Policy Analysis: Understanding Governance in the Network Society. Cambridge: Cambridge University Press.

Harvey, David. 2008. 'The Right to the City'. New Left Review 53: 23-40.

Healey, Patsy. 2006. Collaborative Planning: Shaping Places in Fragmented Societies. New York: Palgrave Macmillan.

Innes, Judith E. and David E. Booher. 2003. 'Collaborative Policymaking: Governance through Dialogue'. In Deliberative Policy Analysis: Understanding Governance in the Network Society, edited by Maarten A. Hajer and Hendrik Wagenaar, 33-59. Cambridge: Cambridge University Press.

Innes, Judith E. and David E. Booher. 2010. Planning with Complexity: An Introduction to Collaborative Rationality for Public Policy. New York: Routledge.

Jacobs, Jane. 1969. The Economy of Cities. New York: Random House.

John, Peter. 2012. Analysing Public Policy. London: Routledge.

Lefebvre, Henri. 1995. Writings on Cities. Translated by Eleonore Kofman and Elizabeth Lebas. Oxford: Wiley-Blackwell.

Lefebvre, Henri. 2003. The Urban Revolution. Translated by Robert Bononno. Minneapolis: University of Minnesota Press.

Lin, Nan. 2010. 'A Network Theory of Social Capital'. In The Handbook of Social Capital, edited by Dario Castiglione, Jan W. van Deth, and Guglielmo Wolleb, 50-69. Oxford: Oxford University Press.

March, James D. and Johan P. Olsen. 1989. Rediscovering Institutions: The Organizational Basis of Politics. New York: Free Press.

Ostrom, Elinor. 1990. Governing the Commons: The Evolution of Institutions for Collective Action. Cambridge: Cambridge University Press.

Ostrom, Elinor. 1994. 'Constituting Social Capital and Collective Action'.Journal of Theoretical Politics 6(4): 527-62.

Ostrom, Elinor. 1995. 'Self-organization and Social Capital'. Industrial and Corporate Change 4(1): 131-59.

Ostrom, Elinor. 2010. 'Beyond Markets and States: Polycentric Governance of Complex Economic Systems'. American Economic Review 100: 1-33. 
Pennington, Mark and Yvonne Rydin. 1999. 'Researching Social Capital in Local Environmental Policy Contexts'. Policy and Politics 28(2): 233-49.

Pimbert, Michel. 2009. Towards Food Sovereignty: Reclaiming Autonomous Food System. London: IIED.

Putnam, Robert D. 2002. Democracies in Flux: The Evolution of Social Capital in Contemporary Society. Oxford: Oxford University Press.

Rapeepat, Akin. 2009. Rural Population, City Dwellers, and Social Justice in Thailand. Chai Mai: Wanida Publishing.

Rydin, Yvonne. 2003. Conflict, Consensus, and Rationality in Environmental Planning: An Institutional Discourse Approach. Oxford: Oxford University Press.

Soja, Edward W. 2010. Seeking Spatial Justice. Minneapolis: University of Minnesota Press. Suteethorn, Kanokwalee. 2011. 'The Impacts of Food Miles on the pattern of Footprint of Bangkok's Food Supply'. NAJUA Architecture, Design and Built Environment 26(1): 71-93.

Thai Climate Justice. 2012. Rethinking Urban Life. Working Paper. Bangkok: Focus on the Global South.

Warren, Mark E., ed. 1999. Democracy and Trust. Cambridge: Cambridge University Press.

Wittman, Hannah, Annette Aurelie Desmarais, and Nettie Wiebe, eds. 2010. Food Sovereignty: Reconnecting Food, Nature and Community. Oxford: Pambazuka. Woolcock, Michael. 1998. 'Social Capital and Economic Development: Towards a Theoretical Synthesis and Policy Framework'. Theory and Society 27(2):151-208. Yap, Christopher. 2013. Urban Food Sovereignty: Food, Land and Democracy in Kampala. Working Paper no.157. London: Development Planning Unit, UCL.

\section{About the author}

Piyapong Boossabong is Assistant Professor in policy analysis, planning, and governance at the School of Public Policy, Chiang Mai University, Thailand. He also works as the director of the Research Centre for Collaborative Urban Governance Studies. He is a member of 'Smart Growth Thailand' and a consultant for the 'Thai City Farm Programme'. His main focus is on policy and planning to promote urban agriculture, local food systems, and disaster governance. He received a Ph.D. from the Bartlett Development Planning Unit, University College London, UK. 



\title{
5 The Struggle to Create Alternative Urban Spaces
}

\author{
An Attempt by a Theatre Group in Hong Kong
}

Ngai Ming Yip

\begin{abstract}
Hong Kong is exemplary of predatory capitalism. Not only are most of the newly created public spaces being corporatized by the oligarchic land powers in the process of urban growth or gentrification, but the state is also obsessive about sterilizing the city in the attempt to craft Hong Kong into 'Asia's World City'. FM Theatre Power (FMTP), the largest alternate independent theatre group in the city since its establishment in 2001, has incorporated a deep-seated mission of challenging the state hegemony over public space management-particularly the restrictions concerning citizens' freedom of performance in public spaces. Equipped with the craft of public art-impromptu art that involves the audience, performances in public space, and insurgent art that reflects political issues-FMTP began to illegally occupy part of the pedestrian zone in Mong Kok for regular performances. Rounds of verbal warnings, arrests, and prosecution have not deterred their determination; instead, they have expanded their 'sphere of influence' to other tourist areas with flash mob performances. Such actions have successfully attracted copycats that have quickly filled the Mong Kok pedestrian zone with street performers. This has indirectly led the local council to relax restrictions on street performances, and such acts have even been embraced. In this chapter, I investigate the progression of the struggle of FMTP in the creation of alternative urban space by exploring how this public art movement endeavoured to integrate the excluded, linking insurgent art with the lives of ordinary people, cultivating their capabilities in the creative expression of ideas, and scaling up the social resistance that led to policy and finally success reclaiming the lost public space. Yet the contradictions generated by the movement,
\end{abstract}

Cabannes, Yves, Douglass, Michael and Padawangi, Rita, Cities in Asia by and for the People. Amsterdam: Amsterdam University Press, 2018 DOI 10.5117/9789462985223/CHO5 
both within the community and with mainstream society, led to the movement's eventual demise.

Keywords: performance art, public art, social movements, public space, alternate space, Hong Kong

Hong Kong is a highly regulated city. Even large-scale demonstrations organized by civil society groups and with half a million participants are highly orderly. Furious actions like looting, stone-throwing, or arson-which are not uncommon in demonstrations in the West-can only be traced back to a couple of small-scale social unrests in the early 1980 os. And yet Hong Kong's Umbrella Movement in 2014 caught the attention of the world and locals alike because tens of thousands of demonstrators employed more 'militant' means and occupied central city streets to express their political demands. It was also the first time that Hong Kong's civil society groups turned the 'public space' into a Habermasian 'public sphere', in which political thoughts, public policy, and political development were openly debated at a large scale and with persistence. More importantly, such debates were largely self-initiated, with a lack of explicit organizers or hierarchical command chains.

Also, contrary to previous large-scale demonstrations, which were predominantly unilateral articulations of demands using straightforward mottos and symbols, the Umbrella Movement extensively utilized creative and artistic forms of deliberation. Public art was explicitly employed as icons of resistance and defiance. Of course, such forms of expression are not created in one day: there has been a long process of acquisition, experimentation, and consolidation in incorporating art into social actions.

FM Theatre Power (FMTP), the largest alternate independent theatre group in Hong Kong since its establishment in 2001, has a deep-seated mission to challenge state hegemony in the management of public spaceparticularly the restriction of the freedom of performance. Equipped with the craft of public art-impromptu art that involves the audience, performances in public space, and insurgent art reflecting political issues-FMTP began to 'illegally' occupy part of the pedestrian zone in Mong Kok, one of the business retail areas in Hong Kong, for regular performances. FMTP's actions have indirectly led the local council to relax restrictions on street performance. 


\section{Figure 5.1 Maps of (a) Mong Kok District, (b) Hong Kong, and (c) Mong Kok Neighbourhood}
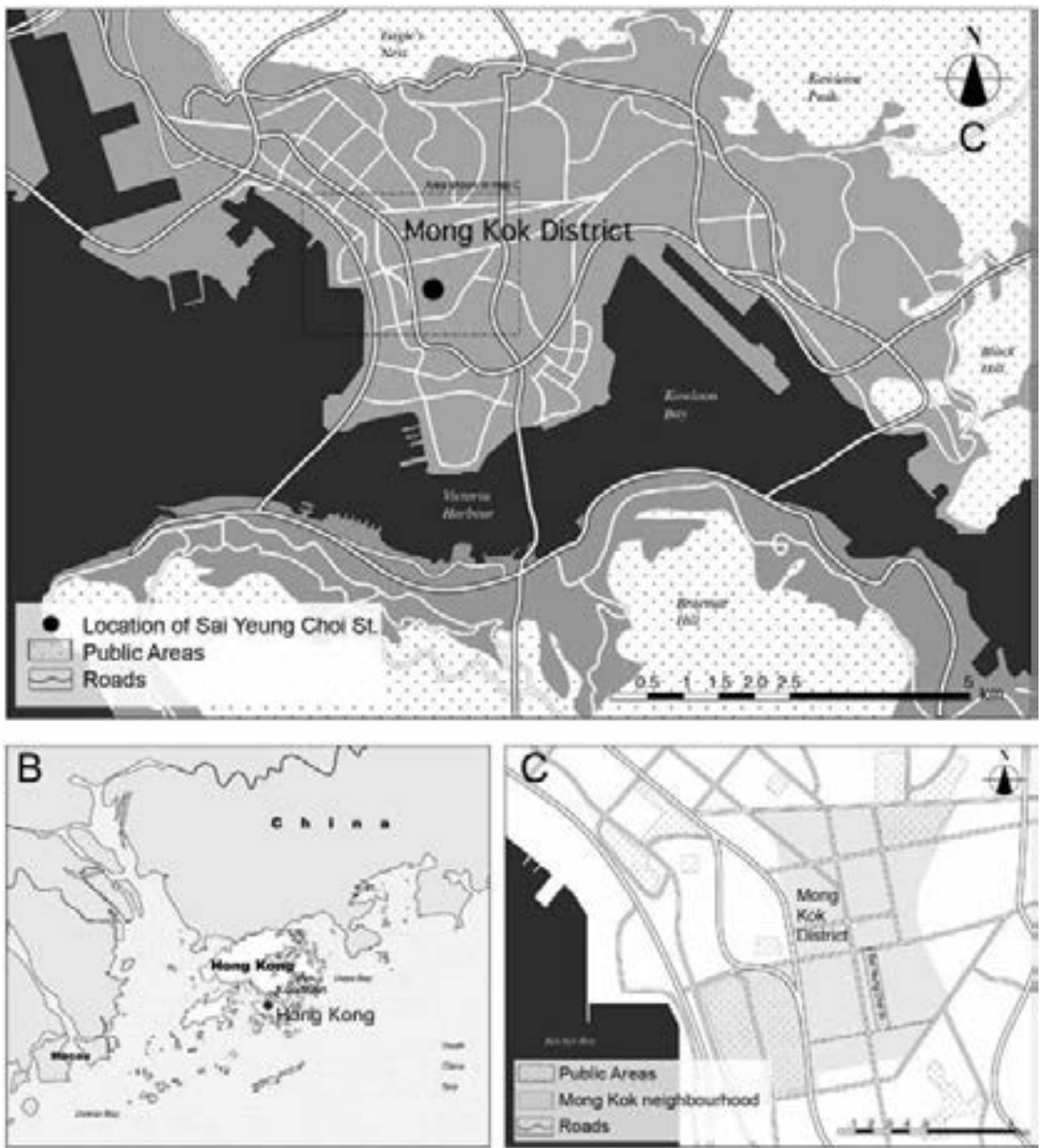

Source: Ariel Shepherd

While FMTP enjoys widespread support from the independent media, political activists, and progressive public intellectuals, there are tensions between them and the community of residents and business proprietors in the neighbourhood, as well as with other performers in the area. A social media group dubbed 'Kicking FMTP out of Mong Kok' was set up in August 2008, accusing FMTP of vulgar artistic forgery and, more importantly, monopolizing public space. The struggle to reclaim public space for performance and entertainment has unfolded into a battle of internal conflict within the artist community 
In 2010, FMTP unexpected made a U-turn, seeking official recognition and refraining (nearly altogether) from street performances. Since then, challenges to the official restrictions on performing in public spaces have proliferated in other districts. To a certain extent, the blossoming of public art during the Umbrella Movement indirectly benefited from such proliferation.

In this chapter, I investigate the struggle of FMTP to create alternative urban spaces by exploring how this public art initiative endeavoured to integrate the excluded, link insurgent art with the lives of ordinary people, cultivate people's ability to creatively express ideas, and scale up social resistance, all of which led to policy changes and finally success in reclaiming the lost public space. This initiative also generated a number of contradictions both within the community and with mainstream society, which eventually led to the initiative's demise.

\section{Social Movement, Cultural Producers, and the Creative Class}

David Harvey (2001) is optimistic about the ability of artistic groups or 'cultural producers' to make an impact on social movements. Harvey argues that cultural producers are able to act as proactive forces to trigger the public awareness of locals and incorporate local people's interest in fighting the tidal wave of global neoliberalization.

However, studies on gentrification and the role of the creative class reveal a more pessimistic picture. More often than not, art in general and artists in particular are merely decorative factors or, even worse, victims of globalization, who are exploited by capitalists in the gentrification process. as Jamie Peck (2005) put it in his paper titled, 'Struggling with the Creative Class'.

Rather than 'civilizing' urban economic development by 'bringing in culture', creativity strategies do the opposite: they commodify the arts and cultural resources, even social tolerance itself, suturing them as putative economic assets to evolving regimes of urban competition (Peck, 2005, $\mathrm{p}_{7} 63$ ).

Such cynicism can be traced back to disillusionment about the artist community being a progressive force. Manuel Castells (1977) considered the struggle around the provision of and access to collectively managed services financed by the state to be one of the three pillars of collective consumption in urban social movements. The artist community, which often struggles 
to get access to such publicly managed space as their production base, spearhead many of such constestations. As sites of cultural and artistic resistance and spaces occupied for autonomous, alternative ways of living have been routinely co-opted by the state, the artistic community has gradually been losing much of its radical political edge (Köhler and Wissen 2003). More detrimental is the demotion of the artist community to an agent of the establishment, when artists are 'used to establish urban-cultural ambiance' and 'displayed by the city as (cultural) locational factors in the competition to attract investors' (Mayer 1993, 161). For these reasons, it is unclear whether the artistic class is able to defend the cultural and social identity and character of places, in particular.

The creative city policies that have become one of the most popular tools in the repertoire of neoliberal globalization have indirectly converted the creative class into a public enemy. As the beneficiary of creative city policies, the artist community is often engaged in the struggle for its own immediate and narrow interests, while the interests of the most deprived groups (who were their partners in previous struggles) have been largely undermined. For this reason, the artistic class is no longer able to mobilize large numbers of people. There are, however, exceptions. Independent creative workers and artists have been successful in fighting for space in Berlin and Hamburg, Germany, and have become 'a strong voice in [the] contestation of the present-day urban order' (Novy and Colomb 2003, 1818). Their success has, to some extent, been attributed to their efficacious exploitation of the contradictions in the neoliberal economy. On the one hand, to be competitive and extract monopoly rent, capital has to 'support a form of differentiation and allow divergent and to some degree uncontrollable local cultural developments that can be antagonistic to its own smooth functioning' (Harvey 2001, 409.). On the other hand, doing so stimulates 'new spaces for political thought and action within which alternatives can be both devised and pursued' and enables 'a segment of the community concerned with cultural matters to side with a politics opposed to multinational capitalism' (Harvey 2001, 410, my italics). Hence, more diversified social and ecological relations emerge from these capitalist relations.

Newer forms of mobilization might be the defence of the status quo by a privileged minority. As a journalist noted regarding the Hamburg case (Novy and Colomb 2003),

Some might ask what exactly gives the artists the right to demand studios more or less for free in a prime downtown location. After all, those who care about social issues-and that describes the core of the 
anti-gentrification movement - might also argue that the buildings could be put to better use accommodating other, needier people than middle class artists for whom squatting is little more than a lifestyle choice. (Oehmke 2010, 4)

Entering the new century, public art is gaining attention in the struggle for artistic citizenship. The concept of 'artistic citizenship' attempts to integrate the public sphere to art, so that public art is no longer produced in enclosed containers, but instead 'the immediate physical world around the work — city, square, building, park, airport, university campus_-becomes its frame' (Campbell and Martin 2006, 3). Gathering and encountering-calling the people together - is one inherent element in the operation of art; it is both the means and ends of art. For many artist communities, the public project of art is their point of departure for their professional trajectory, which is grounded and committed to civic participation. Public art has thus blossomed across the world.

\section{Disappearing Public Space in Hong Kong}

As a densely built-up city, public space has always been a luxury in Hong Kong. However, Hong Kong seems not to have performed too bad in the provision of public space, at least in terms of formal public space. In a comparison between eleven cities across the globe, from Cape Town to Mexico City to Berlin on various aspects of public provisions, Hong Kong scores fairly in the middle (Parkinson 2013). It performs well in the accessibility of public space (because of efficient public transport) and the integration of public and private spaces.

As the population expands and land use is intensified, there has been a concern that public spaces are beginning to 'disappear.' Old buildings and iconic landmarks have been demolished, making way for luxurious apartments for the rich or gigantic tower blocks of offices and retail stores for international capitalists and tourists. At the same time, the neoliberalization of public space has hit Hong Kong the same way as it has hit Western cities (Cuthbert and McKinnell 1997). Public spaces are increasingly being commodified and corporatized as more and larger shopping malls or entertainment spaces are being built. Despite still being largely accessible to the public, such corporatized sites are under intense surveillance and policing. Unnecessary restrictions on the use of public space inevitably limits how the public can enjoy such spaces and may indirectly intensify social exclusion 
and segregation (Low and Smith 2006), although it may very much depend on the exact terms of the contract between the state and the private or social organizations who own and/or manage such space (De Magalhaes 2010).

In addition to this corporatized pseudo-public space, the Hong Kong government has been offering incentives to encourage private developers to provide more 'genuine' public space. This is apparently similar to the thinking of some Western cities in which the expansion of public space is perceived as an important ingredient in recreating a world city (Cochrane and Jonas 1999). Under the 'Public Open Space in Private Developments' initiative, private developers are rewarded with extra floor space if public space is incorporated into their commercial or residential developments. Despite increases to the overall quantity of public space, paradoxically, this initiative further exacerbates the incorporatization problem. If the incorporatized 'private' space mentioned earlier is already problematic, this provision of 'public space in private developments' again places genuine public space under private control. Hence, it is the responsibility of the private management regime, which in the local context most probably means the agents of the powerful real estate sector, to define how 'public' these spaces actually are.

The intention to corporatize public space has been reflected at both the design stage and the management practices. Many privately provided public spaces in gated residential developments have in fact been built in venues that are more accessible to their own residents, while for other members of the public such access is inconvenient. This has apparently removed such space from the public realm. Private management regimes also manage such public space the same way as their corporatized space-and some even make profits from such spaces. For instance, one gated development has put the 'rewarded' public space in the podium garden on the seventh floor of the car park tower, and the only lift accessible to the public was difficult to locate on the ground floor (The Sun 2008).

The disappearance of public space is also fuelled by political considerations. The new government of the Special Administrative Region, eager to get rid of the symbolism of colonial rule, intensified the decolonization drive after the changeover of sovereignty to China in 1997 (Abbas 1997). Icons of colonial rule, which are often precious public space, are among their targets. For instance, the Queen's Pier in the Central District, which was the official landing site of previous governors, has been demolished despite intense protests in support of keeping it.

While formal or institutionalized public space may be on the retreat, the order imposed by the representations of space is always being contested by 
representational space and spatial practice (Lefebvre 1991). In the production and reproduction of public space, power and resistance are constantly interacting to shape and reshape its landscape (Winchester, Kong, and Dunn 2003). The highly regulated city management regime of Hong Kong has placed the city's public spaces under a whole array of rules and regulations. Activities and behaviour in public venues are subject to the bylaws of respective sites, and are often confined to the state's idea of approved usage.

The forces of globalization, diverse local interest factions, and escalating demands for democracy have expanded the spectrum of stakeholders as well as reinforced their quests to redefine public space. For instance, foreign domestic helpers (mainly Filipinos) are perhaps the first group in claiming their right to public space. Exploiting the move to classify the street in front of Statute Square in the Central Business District (CBD) as a pedestrian zone on Sundays (originally proposed by the Jardine Group with the intention of boosting pedestrian flow and their business on holidays), foreign domestic helpers have occupied the area on Sundays as a site for leisure and meeting friends since the mid-1980s. Concerns about the 'abuse' of public space were initially raised, but it was soon tolerated and subsequently routinized (Law 2002).

Besides such static activities, rallies and processions in public spaces have been increasing in recent years and, in fact, Hong Kong is becoming a 'city of protests'. It is estimated that in 2012 alone, over 7000 demonstrations and public processions were launched (HKCSS 2015), with the overwhelming majority held in streets or other public spaces. While the overwhelming majority of such protests are small-scale and on issues concerning the livelihood of a few local people, there have also been a few high-profile political rallies, which embarrassed the Hong Kong and Chinese governments. For example, annual anti-government rallies are held on 1 July in commemoration of the return of Hong Kong to China. Tens of thousands of people routinely turn out for these rallies. Since 1990, vigils have been held on 4 June in Victoria Park on Hong Kong Island to pay tribute to the victims of the Tiananmen suppression in 1989 and demand that the Chinese government take responsibility for it. Similarly, Falun Gong, which was being accused by the Chinese authority as a religious cult and was subsequently outlawed in Mainland China, regularly holds rallies on busy streets in the city to voice their demands.

Under the Public Order Ordinance, it is against the law to have public meetings of more than 30 people without a 'letter of no objection' from the police commissioner. In the application a lot of information has to be disclosed, including the organizers' information, the purposes and routes 
of the procession, the equipment that will be used, and the plans to keeping order amongst the participants. Almost none of the organizers of these public rallies (including Falungong) have attempted to challenge this control of the use of public space.

Despite the rarity of rejections of public rally applications (although there may be negotiations in the rallies' details), this restriction makes similar events held on a regular basis in public spaces, like public performances, inconvenient and creates a high administrative burden. It also curtails the deployment of public space as a Habermasian public sphere and is a restriction on the freedom of speech. This may not be a problem for most civil society groups, which only occasionally employ public space as a venue for expression. FMTP, an amateur theatre group composed of young people, daringly embarked on a deliberate (and successful) effort to contest the hegemony of the state over the regulation of open space.

\section{4}

The Struggle for Alternate Space

FM Theatre Power (FMTP), established in 2001 by a group of amateur university students and graduates, has not only been one of the most vibrant, but also one of the most controversial theatre groups in the city. It has staged dozens of dramas on socially contentious issues and has been successful in attracting regular audiences of young people (Shiu and Wong 2012). Their desire to create an alternate space for performance was inspired by the mass demonstration on 1 July 2003, in which half a million people in Hong Kong marched on the street demanding the resignation of the then-Chief Executive. Dissatisfied with the traditional approach of one-way communication during performances in formal venues, they believed that drama could be a powerful instrument for changing people. Encouraged by the huge rally turnout, it sparked off 'an urge to express ourselves on the street [...] because (we believe) changes start on the street' (Mo Lai, interview by the author, 21 June 2014).

Public space for performance is tightly regulated in twenty-first century Hong Kong. This is in sharp contrast to the 1950s and 1960s, when public performances were part of the city's life. The city's 'sterilized' regime cleaned up street trade, and at the same time killed the street performances that were often associated with street trades (e.g., kung-fu shows to sell herbal medicines, daring snake-slaughtering shows to sell snake gallbladders). Public performances now need a licence from the government, including approval from a number of departments: Food 
Figure 5.2 Banner on the ground to attract attention

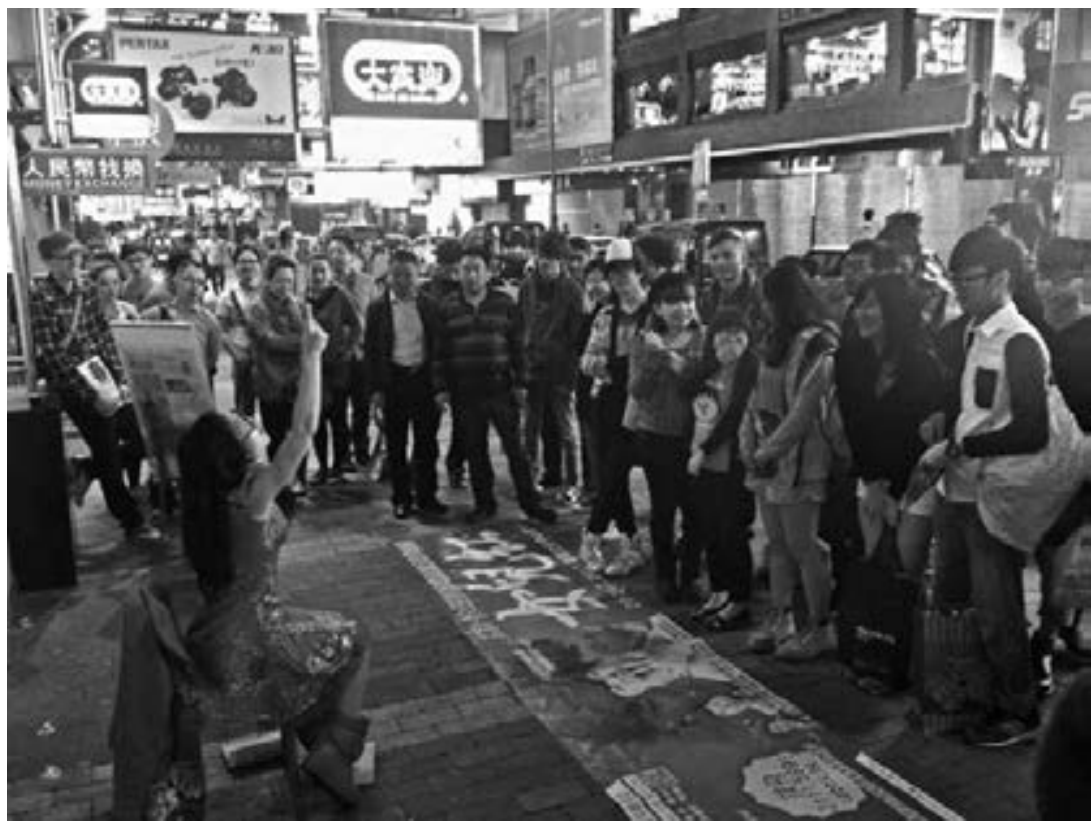

Source: Photograph by FM Theatre Group

and Environmental Hygiene; Cultural and Leisure; Fire Services; Police; Home Affairs; and the department that manages the venue. Even one-off performances in public places require a temporary license for which the application process for approval is tedious. Unlike many other countries, there are no public venues, parks, squares, or plazas that are open for public performances.

Such bureaucratic procedures of approval have made it practically impossible to hold regular performances in public spaces. For this reason, FMTP decided to challenge the managerialist regime by simply ignoring such procedures. The pedestrian zone in Sai Yeung Choi Street in Mong Kok (MK) was logistically the most obvious choice for them, as it is within walking distance from their practice studio in Tai Kok Tsui (TKT). Marketed as the 'West Kowloon Cultural Street Project', a deliberate antithesis to the grand official project of West Kowloon Cultural areas, they began daily performances in the street. Fully acknowledging their spectators, who were people from all walks of life (in sharp contrast to their regular audience of the young and educated), they began to experiment with different forms of performance. 
Inspired by the theatrical concepts of 'theatre of the people, for the people, by the people', 'invisible theatre', 'forum theatre', and 'newspaper theatre', they attempted to involve the audience in interactive performances in the form of 'spec-actor', as pioneered by the Brazilian theatre director and politician Augusto Boal (Banky, interview by the author, 21 June 2014). Adapted to the local context and tied to current popular issues or talks of the town, the performances began to gain popularity. Sometimes the 'Reality Theatre' was so real that passersby, unaware that it was a performance, would even call the police. In response, FMTP began to place a banner on the ground to define their performance space and indicate it was a performance. This banner eventually became a landmark in the pedestrian zone (Winnie, interview by the author, 16 May 2014).

In May 2008, FMTP extended their presence out of Mong Kok by successfully organizing a flash mob titled 'Frozen Times. Square Reborn' in front of the Times Square in Hong Kong. Participants were mobilized by FMTP through social media to go to the venue and hold a frozen position at the same time. This was a direct response to the 'fake public space' debate: 3000 square meters in front of the shopping mall in Times Square had been awarded as an incentive through the 'public space in private developments' policy. While the developer was mandated to open this space to the public, they set harsh rules for its use while openly defying the restrictions and profited from renting it as a venue for commercial marketing activities. It was uncovered by the media that the developer of Time Square had illegally leased a corner of the public space to Starbucks on a long lease and charged as much as HK\$15,000 a day for commercial use of the piazza (Gentle 2008, A1).

The action of 'freezing' was a thought-provoking artistic expression of defiance against the unreasonable rules prohibiting any organized activities or performances in the public space at Time Square. Only static but unorganized activities like strolling or joining a group of friends were allowed. '[E]xcessive lingering' would be cause for intervention by the security guards (Lee 2008). Hence, "no motion" fitted perfectly with their rules' (Mo Lai, interview by the author, June 21, 2014). This flash mob attracted over a hundred participants responding to the appeal on social media and subsequently drew the attention of both traditional and new media. For instance, it attracted over 100,000 views on YouTube. This added momentum to subsequent actions by other social and political groups, as well as a large-scale review by the legislature on the provision of public space in private developments.

However, it was also in 2008 that the group experienced the most difficulties in their struggle for street performance. Antagonism from their 
competitors in the physical, social, and political space began to build, eventually leading them to withdraw from Sai Yeung Choi Street South and launch new initiatives diversifying their performance in other areas and in new venues for street performance. For example, Theatre Everywhere is a 'guerrilla-type performance' in the open space of busy areas around the city. Replicating their performances in Mong Kok, a series of 'One person One story' performances have been held in the shopping centres of public housing estates with the sponsorship of the property management companies. These performances target the (especially old) residents and encourage them to voice their feelings about their lives, lost community, and even negative sentiments towards the gentrified shopping centre where the performances take place.

\section{Challenge the Management Control}

When FMTP started their street performances in Mong Kok, the biggest challenge they faced was catering to their new audience. Regulars in the MK shopping areas were ordinary people from all walks of life, but largely from the poorer spectrum of the city. Very few had ever been to a modern theatrical performance in a formal venue (perhaps with the exception of old people going to traditional Cantonese operas). Constraints on the performances were also significant. For instance, the performance space was cramped, there was a lack of theatrical lighting, and there was no backstage to support the show. More significantly, there was no stage at all on the street. To attract the interest of passersby, they launched short performances that aligned closely with ordinary people's lives, like discussing love on Valentine's Day or family relationships on days close to Chinese festivals. Gradually the shows involved more social elements, like equal opportunities (e.g., the difficulty of pushing a wheelchair on a busy street, during which they even asked a police officer on duty to help) and social discrimination (e.g., people with disabilities facing job interviews). Political issues like universal suffrage also gradually appeared in their shows. In 2008, they openly supported a candidate in the legislative council election and incorporated the campaign in their street performance-though this may have attracted trouble.

When they succeeded in charming a bigger crowd, it touched the nerve of the management regime. Despite the lack of a law that directly prohibits performances in open spaces, such performances are in fact nearly impossible to sustain for long, especially if they are able to attract a crowd. 
Police officers will 'caution and advise' the performers to go; if they do not comply, they risk arrest. Several laws could be invoked to prosecute arrested performers: unlawful assembly, if there is a crowd of more than thirty people; begging, if they accept tips; excessive noise, if loud speakers are used; the obstruction of public space; ${ }^{1}$ and even loitering, if the police cannot find another excuse.

With time and experience, FMTG developed a series of strategies to extend their rights to and opportunities of performing in Mong Kok. This includes intensive research on relevant laws and the limits of their enforcement, including article 34 of the Basic Law (mini-constitution) of Hong Kong, which protects people's freedom to participate in artistic and cultural activities. For instance, they would explicitly ask police officers for the legal basis of intervention and had no reservations about providing them with photocopies of the relevant laws if the officers showed their ignorance. They were also not reluctant to follow them back to the police station for further investigation if asked to do so. They highlighted the photocopies as a way to 'educate' the front-line law enforcement officers on their limits of power. Frequent turnover of the front-line officers made such effort frustrating. They then began to send written notices to the police stations detailing the exact time, location, duration, and scale of their performance, 'with no intention in seeking approval (or objection) but to hint to the officers not to launch unproductive interference [to our performance]' (Mo Lai, interview by the author, 21 June 2014). The intervention of police officers substantively diminished after they started to send written notices.

The risk of being charged for begging was genuine: the FMTP really wanted to collect donations from the audience to ease their financial burdens. To solve this problem, they came up with a mischievous innovation: a living statue show, with a notice in front of the statue saying 'DO NOT give money, if you do, it will sing'. Of course, the curious audience lined up to give money, expecting a song from the statue. They would have used the notice as evidence in their defence if they had been prosecuted, although this did not happen. Winnie said, "They were told at the first instance not to pay, so anything they did was beyond our control' (interview by the author, 12 June 2014).

1 This law about the 'obstruction' of public space seems to imply that public space is not for static use, but only for use as passage for a 'flow.' Take Times Square, for instance, public space is often not a place for staying: security guards politely question whether you have lost your way if you are considered to be stationed in one spot or have been loitering too long. In fact, benches or sitting facilities are rare provisions in public space in Hong Kong, regardless of whether the space is genuinely public or a corporatized one. 
Figure 5.3 Banner on the ground to define the performance area

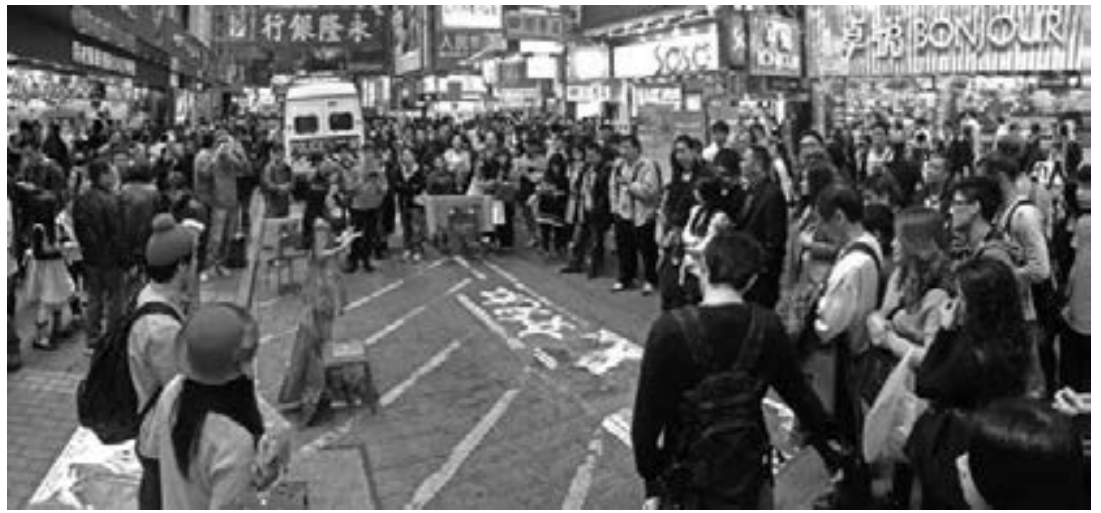

Source: Photograph by FM Theatre Group

The reaction of the shops was an important concern for the theatre group. They worried that they would be unwelcome if they attracted a big crowd in front of a shop and blocked their business. Such worries did not become reality; instead, as their performance became popular it attracted more people and enhanced the businesses of nearby shops. The spot where the theatre group performed even became a landmark of the pedestrian zone. 'They welcomed our presence. They even served us drinks after our show and allowed us to store our equipment in their store overnight and occasionally helped us to earmark the spot (as it was first come, first served basis) for our performance' (Mo Lai, interview by the author, 21 June 2014).

To neutralize the threat of being charged with unlawful assembly, they placed a big banner on the ground to mark the performing area and tried to limit the audience to less than 30 people. If prosecuted, they planned to defend themselves on the grounds that they should not be held responsible for people who watch from outside the defined area. This also eased conflicts with other groups performing in the vicinity.

\section{Landscape of Conflicts and Resistance}

Public space is a landscape for conflicts and resistance (Winchester, Kong, and Dunn 2003). FMTP perceived the major obstacle which prevented them from claiming public space for performances was the urban management regime: the police, the street hygiene regulators, and private security guards acting on behalf of owners of the corporatized or 'privately provided' public 
space. However, despite numerous occasions (particularly in the beginning) where the police intervened and a few incidences where they were taken to the police station, no arrests were made (with the exception which will be described in next paragraph which was not related to their performance) during their five years of performing in Mong Kok (2003-2008).

It seems that as the theatre group was equipped with a better understanding of the law (e.g., both the boundaries and procedure of the enforcement of the laws), explicit interference from the urban management regime was largely neutralized. Of course, tactful strategies of interacting with law enforcers were also crucial for such encounters. The only arrest was made in October 2008, perhaps by accident, when a member of the group engaged in physical contact with an official of the Food and Hygiene Department trying to stop her from selling T-shirts (which was prohibited in the pedestrian zone), and both parties reported being injured (Apple Daily 2008 A6).

While the tactics of resistance was largely successful with the officials, the main source of conflicts was among the people who were competing for use of the public space. Initially, as reported by the theatre group, their foremost concern besides the police was interference from the triad society (local mafia), which had been rooted in Mong Kok for decades. In this, they appear to have been overcautious, as no incident involving the triad society ever occurred (Chow 2015). Instead, when the patrons of the pedestrian zone increased and attracted more street performers and commercial marketing activities, the congested physical space of the pedestrian zone created intense competition. FMTP, which was the most popular performers at that time, unsurprisingly became the target of aggression. As recalled by Banky Yeung, the art director of the theatre group,

Strange things just happened. The group which performed next to us, then turned on their loud speaker unnecessarily to top volume. This forced us to use loud speakers as well (author's remark: they tried to refrain from using loud speakers so as not to break the environmental protection law). This attracted the police and both of us were warned. We tried to convince them that both of us should turn down the noise, but they didn't listen to us. (Banky Yeung, interview by the author, 21 June 2014)

This antagonism gradually built up, both online (e.g., in social media) and offline in the pedestrian zone and traditional news media. The police, which had already accepted the presence of the theatre group in the pedestrian zone as part of the daily routine and no longer bothered paying attention to them, suddenly stepped up their interference, taking action in response 
to alleged complaints about the noise, the obstruction of pathways, and making prohibited commercial sales. Although most such complaints were unfounded, they inevitably created interruptions in the performances and diverted their energies into dealing with police queries.

A new front of attack gradually built up in the pro-Beijing media when FMTP had stepped up the social and political elements of their performances. It became especially severe when the theatre group openly supported a candidate for the Legislative Council from the pan-democracy camp. The theatre group even produced a play as part of the election campaign. This provoked an intensified attack from the pro-Beijing media, which accused them of excessive occupation of public space, use of vulgar language, and creating nuisances for passers-by by forcing them to participate in their shows (Wen Wei Po 2008). This seems to have been a politically motivated attack meant to disgrace the FMTP and indirectly called for tighter control on the freedom of expression in public spaces, as 'performing is a right but it cannot be placed above everything $[. .$.$] and rights and obligations should$ complement each other' (Wen Wei Po 2008).

The most severe raid was not launched directly from social groups that supported the authority, but instead on social media. On 20 August 2008, a Facebook group called 'Kick the FM Theatre Power Out of Mongkok' was set up. It was able to attract over 20,00o followers-nearly 40 times the number of followers on FMTP's official Facebook page (EVCHK 2013). Hundreds of messages were posted on Facebook; according to Chow Lam Fong (2008), most of them focussed on accusing the theatre group of the following:

- Occupying excess public space for their own performance while obstructing passages;

- Forcing passers-by to participate in their show against their will;

- Unfairly earmarking particular spaces and affecting the rights of other performers;

- Rationalizing their self-indulged art form in the name of public art;

- Engaging in commercial activities (e.g., selling T-shirts).

FMTP quickly responded to these accusations and called for an open debate in the pedestrian zone. A marathon forum, lasting six hours, was eventually organized on 24 August 2008, with about 100 participants. However, most of the participants were supporters of the theatre group, and only a few of their opposition expressed their (relatively mild) views openly during the forum. This raised questions about how genuine the size of the Facebook opposition group was (Alone in the Fart 2008). Yet the theatre group's shows were harassed by the opposition in the days following the forum. 
The reaction of FMTP to such accusations was proactive, but their detractors seemed to be unconvinced. Responding to the complaint that they were occupying too much public space, FMTP changed the strategy of their performance by launching over a dozen solo performances on the street, within the same area occupied by broadband service stalls (about $1 \mathrm{~m} \times 1 \mathrm{~m}$ ) (Yeung 2014), but if put together these small performance spaces made up nearly the same area as their earlier performance space. This arrangement was later adapted further into the 'chairperson' show, which featured a solo performer occupying just one chair-an artistic and symbolic defiance of the unfair accusation.

The burst of intense opposition on the Internet and the open forum triggered further deliberations on both sides. The diehard opposition still insisted on 'kicking' FMTP out of Mong Kok, a sentiment that was echoed by the mainstream pro-establishment media's calls for the 'restoration of order' in the pedestrian zone. The District Council, which was responsible for the policy of the pedestrian zones in their jurisdiction, threatened to close the pedestrian zone if local police and government departments did not step up their effort to 'clean' the street. Cultural critics and opposition politicians worried about the administration taking such excuses to 'eliminat [e] the space of differences and an alternate space for expression' (Chan 2008, Do8) and 'put an end to the "democratic street" and democratic debates on the street' (Mo 2008, 10) which would lead to the 'shrinking of [the] public sphere for the civil society' (Fong 2008).

Despite FMTP's compromises on some aspects of their performance, they stood firm on the principle of freedom of expression and the right to perform in public space. However, their momentum and, more importantly, their morale was compromised. This led to their gradual withdrawal from Mong Kok altogether (which was replaced with 'Theatre Everywhere'). Of course, the difficulties they faced in Mong Kok are part of the reason for their withdrawal, but more importantly the public space in Mong Kok has degenerated in their opinion:

As more and more tourists flood in, many of them from Mainland China, shops there are being transformed, gearing towards their taste. Fewer and fewer local patrons come. Yet it is not merely a matter of obstacle in language but a difference in taste, the cultural content, as well as the motivation, to be involved. We have attempted to use Mandarin to involve the Mainland tourists but in vain. They are very different from local Hong Kong people. We are gradually losing our audience, and eventually our impacts. (Banky Yeung, interview by the author, 21 June 2014) 
After their retreat from Mong Kok, FMTP was successful in getting funding from the Arts Development Council (funded by the government), becoming the youngest theatre group to be funded. While this indicates a recognition of their accomplishment in art and empowers them to stage more socially oriented performances, it nevertheless attracts the suspicion from their critics that they have been co-opted by the establishment.

\section{$7 \quad$ Concluding Remarks: Public Space Reborn}

The struggle of FMTP to create an alternate public space may not be regarded as a total success. Despite their initial success in challenging the urban management regime on the restriction of performing in the public space and setting a foot at the pedestrian zone, they eventually withdrew from their 'hard-earned turf.' After they left, the opening hours of the Mong Kok pedestrian zone were greatly reduced from every evening to only weekend evenings. However, their pioneering move has made at least a partial contribution to fundamental changes in the ecology of public space in Hong Kong.

When the MK pedestrian zone was first opened in 2001, it was no more than a buffer area created to ease the congestion of the busy shopping streets. While there was still tight control on unauthorized street vending and direct selling has always been prohibited, the area was quickly exploited as a venue for legal marketing. The FMTP group boldly opened up the possibility of an alternate public space of expression when they started their street performances in 2003. They were not the first street performance group in that area, but most of the other groups had only attempted to slip past the surveillance of the urban management regime; they had no intention of challenging the authorities. FMTP is perhaps the pioneer in daring to challenge the regime to open up a 'space of hope' for open public deliberations.

Their persistence in pressing the limits of the public space management regime was a success, which in turn opened up opportunities for both street performances and more explicit and regular political deliberations in public space. The Mong Kok pedestrian zone became packed with street performances, singing, acrobatics, drama, dances, and kung fu performances that converted the place from a static, commercialized, and lifeless space to a vibrant and expressive cultural venue in the city. The space also became an important venue for political debates: forums with explicit social and political content have been more frequent in the pedestrian zone on weekends. 
Figure 5.4 Performance on issues of political dissent

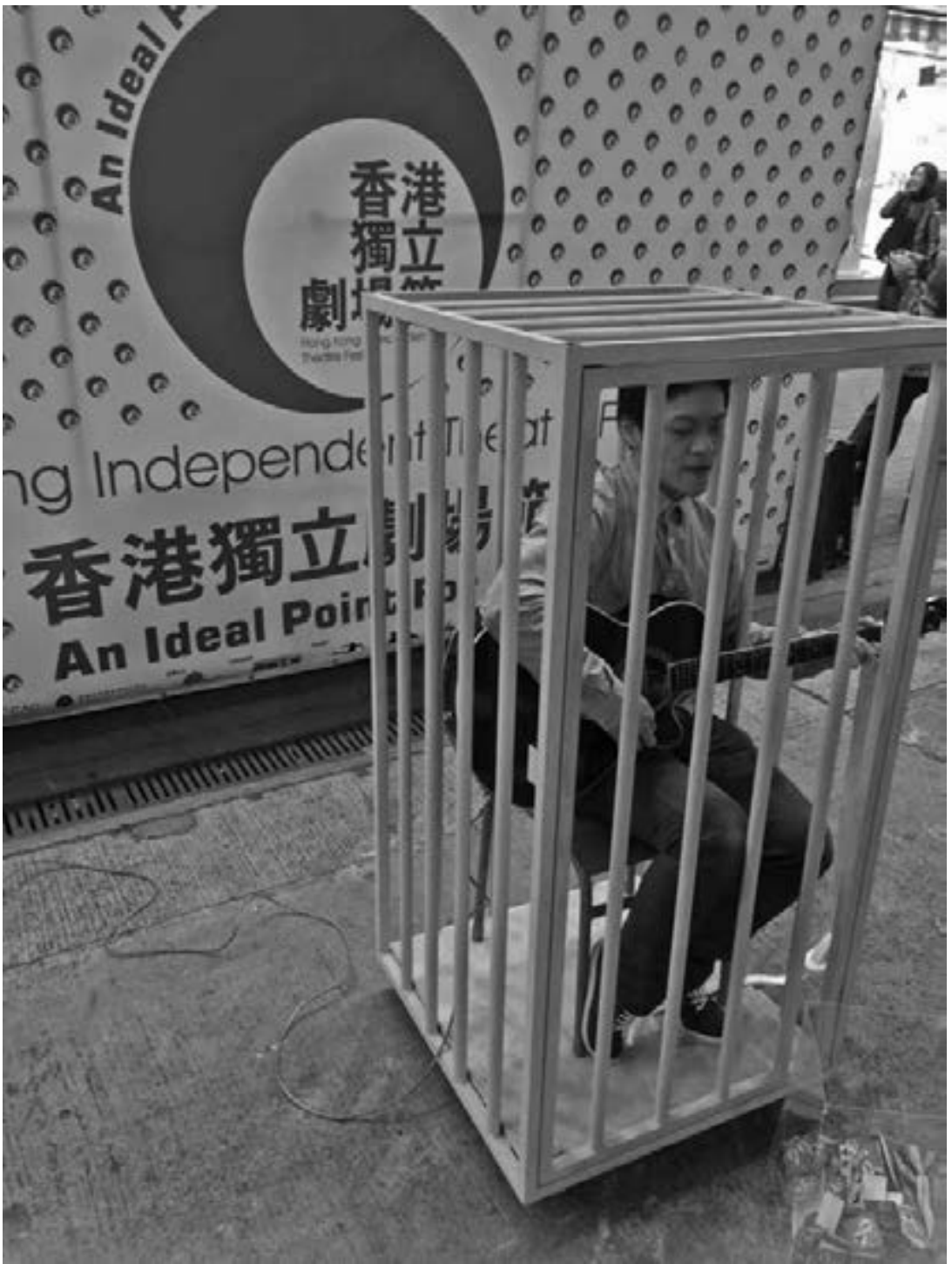

Source: Photograph by FM Theatre Group

This was not limited to Mong Kok. Amateur singers and music groups started to occupy public space everywhere; street music proliferated all over the city. The urban management regime seems to have created new management strategies featuring less control and more tolerance. Unless performances create serious blocks to pedestrian or vehicle traffic, or 
produce excessive noise, they now largely let them continue. The authorities have also tried to imitate 'Music Under NY' in setting up more orderly performances on the street. An 'open stage' project was launched in 2008 in selected public spaces for the approved performances of amateur performing groups. Of course, when the West Kowloon Cultural Project is completed in the early 2020 s, culture as a form of city branding is perhaps a more important underlying driving force of these changes.

Apart from these impacts on the policy of public space use in Hong Kong, FMTP has brought about a more enduring change: an artistic form of expressing social and political demands. This seems to have had an impact on subsequent political movements, including the Umbrella Movement.

However, FMTP's accomplishments are not totally satisfactory from a social movement perspective. Throughout this process, FMTP has only been fighting on its own; there was no attempt to form a wider coalition for the advancement of the common good. In fact, there was no explicit strategy for framing the issues, soliciting social support, or orchestrating action. Hence, it was far from a 'planned movement.' However, given that FMTP is only a theatre group and not a social movement organization, it seems overly harsh to set high demands for them to advance their actions as a social movement. Their mission was art creation. Despite the incorporation of social and political elements into their performances and their clear inspiration for being 'an agent of change' and 'facilitator of social change,' they are not social activists. Therefore, they should not be blamed for not being able to perform as an agent of social movement in scaling up the actions. Banky Yeung said, 'We do street performances hoping that people can be involved in the participatory creation of changing the world [...] Actors need action [...] they are the "activists" who turn thoughts into action' (Yeung 2014).

The group may also be a victim of the neoliberal expansion of space. The financial burden of maintaining an amateur performance group is never small; the relatively affordable rent in an industrial building is perhaps all they can afford. A change in state urban policy has made the conversion of old industrialized buildings easier and offers opportunities for such buildings to release their 'potential' value. The immediate knock-on effect of this is the speculative manoeuvre of increasing the rent-instantaneously increasing FMTP's running costs. It was thus tempting to seek state funding, not just to solve the immediate financial burden but also to open the opportunity for further development. However, this inevitably creates the impression that the theatre has been co-opted, at least among critical artists and social activists. 
Of course, one cannot rule out the possibility that fighting for an alternate space is not entirely altruistic but a selfish act done as a means to boost attendance in their shows. However, this should not dwarf the impact of FMTP's struggle for alternate space for art performances. In their case, the skills of cultural producers, given the appropriate intention, have been demonstrated to be instrumental in raising the consciousness of people in claiming back their public space.

Public space is in fact an 'exclusive space' (Mitchell 2003) that requires active effort to claim the right to its use. Public space is also a landscape of conflicts and resistance (Winchester, Kong, and Dunn 2003) in which struggle and negotiation are necessary to make such claims. The case of FMTP offers a vivid demonstration of this in Hong Kong. The Mong Kok pedestrian zone was turned into a conflicted and contested terrain. This works both ways: the same space is a breeding ground for advocates to express their claims, and yet they do not have the monopoly over their claimed turf. Physical space is the social sphere of expression against the oppression of the state, but it can also be the site of struggles between social actors along the political spectrum. Hence, 'resistance may be the struggle between the powerful and the marginal or the less powerful against the dominant. It may be the continued tension between groups locked in struggle for supremacy and independence' (Winchester, Kong, and Dunn 2003, 125).

\section{Acknowledgements}

I would like to thank my colleague Dr. Jun Wang for sparking the idea of doing this research, her valuable contribution to the literature review, and her comments on an earlier draft of this chapter. The help of Mo Lai, Banky Yeung, and Winnie in providing me with invaluable information on FMTP is also acknowledged.

\section{Works Cited}

Apple Daily. 2008. 好戲量女成員涉阻執法被捕 [Female member of FMTP Group arrested of suspected obtrusion to law enforcement]'. 10 October, page Ao6.

Abbas, Ackbar. 1997. Hong Kong: Culture and the Politics of Disappearance. Hong Kong: Hong Kong University Press. 
Alone in the Fart. 2008. “好戲量事件再思 [The Rethink of the FM Theatre Power Incident]'. Alone in the Fart (blog). 28 September. http://aloneinthefart.blogspot. hk/2008/o8/blog-post_28.html.

Campbell, Mary Schmidt and Randy Martin. 2006. Artistic Citizenship: A Public Voice for the Arts. New York: Routledge.

Castells, Manuel. 1977. The Urban Question: A Marxist Approach. Cambridge: MIT Press.

Chan, King Fai [陳景輝]. 2008. 菜街的空間問題 [Problem of Public Space in Sai Yeung Choi Street]'. 明報[Ming Pao], 3 November, page Do4.

Chow, Wai Ying [周慧盈]. 2015.【街头人物】用十年做好戏量——我们的集体冒 险行动 [Use 10 Years to Improve FM Theatre Power: Our Collective Adventure]'. Street Voice, 7 April. https://streetvoicemsia.wordpress.com/2015/04/o7.

Cochrane, Allan and Andrew Jonas. 1999. 'Reimagining Berlin: World City, National Capital or Ordinary Place?' European Urban and Regional Studies 6(2): 145-64.

Cuthbert, Alexander R. and Keith G. McKinnell. 1997. 'Ambiguous Space, Ambiguous Rights - Corporate Power and Social Control in Hong Kong.' Cities 14(5): 295-311. De Magalhaes, Claudio. 2010. Public Space And The Contracting-Out Of Publicness: A Framework For Analysis, Journal of Urban Design, 15(4): 559-574.

EVCHK (The Encyclopedia of Virtual Communities in Hong Kong [香港網絡大 典]). 2013. ‘好戲 [FM Theatre Power]'. http://evchk.wikia.com/wiki/好戲量.

Fong, Chow Lam. 2008. ‘好戲量」佔用行人專區事件-談公民社會與公共空 [The Incidence of "FM Theatre Power" Occupying the Pedestrian Zone: Discussion on the Civil Society and Public Space]'. Hong Kong Non-profitJournal. http:// ngohk.blogspot.hk/2008/o8/blog-post_3o.html.

Gentle, Nick. 2008. 'Mall sued over public space rents'. South China Morning Post, 18 June, page A1.

Harvey, David. 2001. Spaces of Capital: Towards a Critical Geography. London: Routledge.

HKCSS [Hong Kong Council of Social Services]. 2015. 'Social Indicators of Hong Kong-Political Participation'. October. http://www.socialindicators.org.hk/ en/indicators/political_participation/2.5.

Köhler, Bettina and Markus Wissen. 2003. 'Glocalising Protest: Urban Conflicts and the Global Social Movements'. International Journal of Urban and Regional Research 27(4): 942-51.

Law, Lisa. 2002. 'Defying Disappearance: Cosmopolitan Public Spaces in Hong Kong'. Urban Studies 39(9): 1625-45.

Lee, Diana. 2008. 'Democrats enter fray in Times Square rent row'. The Standard, 6 March. http://www.thestandard.com.hk/news_detail.asp?pp_cat=11\&art_ $\mathrm{id}=62525 \&$ sid $=17904294 \&$ con_type $=1 \& d \_s t r=20080305 \&$ sear_year=2008.

Lefebvre, Henri. 1991. The Production of Space. Oxford: Blackwell. 
Low, Setha M. and Neil Smith. 2006. The Politics of Public Space. New York: Routledge. Mayer, Margit. 1993. 'The career of urban social movements in West Germany'. In Mobilizing the community: Local politics in the era of the global city (Urban Affairs Annual Review 41), edited by Robert Fisher and Joe Kling, 158-167. Sage: London. Mitchell, Don. 2003. The Right to the City: Social Justice and the Fight for Public Space. New York: Guilford Press.

Mo, Claudia [毛孟靜]. 2008. 告別旺角「民主街」? [Farewell to Mongkok “Democratic Street”]'. 信報財經新聞 [Hong Kong Economic Journal], 7 July, page 10.

Novy, Johannes and Claire Colomb. 2013. 'Struggling for the Right to the (Creative) City in Berlin and Hamburg: New Urban Social Movements, New "Spaces of Hope"?' International Journal of Urban and Regional Research 37(5): 1816-38.

Oehmke, Philipp. 2010. 'Squatters Take on the Creative Class: Who Has the Right to Shape the City?' Spiegel Online International, 7 January. http://www.spiegel. de/international/germany/squatters-take-on-the-creative-class-who-has-theright-to-shape-the-city-a-670600-4.html.

Parkinson, John R. 2013. 'How is Space Public? Implications for Spatial Policy and Democracy'. Environment and Planning C: Government and Policy 31(4): 682-99.

Peck, Jamie. 2005. 'Struggling with the Creative Class'. International Journal of Urban and Regional Research 29(4): 740-70.

Shiu, Ka-chun and Wong Yuk Ying. 2012. Emotionalists: A Case of FM Theatre Power. Hong Kong: Red Publishing.

The Sun [太陽報]. 2008. “治安維修誰負責業主公眾慘雙輸公共空間政府亂規 [Who is Responsible for the Security and Maintenance: Owners and the Public All Lost, Chaos in Public Space Planning]'. 31 March. http://the-sun.on.cc / channels/news/20080331/20080331042131_oooo.html.

Wen Wei Po [文匯報]. 2008. 好戲量變「街霸」是阻路還是藝術? [FM Theatre Group turns into 'street tyrants'. Is it traffic disruption or art?]' 10 October, page A28.

Winchester, Hilary, Lily Kong, and Kevin Dunn. 2003. Landscapes: Ways of Imagining the World. Harlow: Pearson/Prentice Hall.

Yeung, Bing Kei [杨秉基]. 2014. 佔領旺角 行人區被「殺」前, 我們做過什麼 [Occupying Mongkok: What Have We Done before the Pedestrian Zone was “Killed”]. 明報 [Mingpao]. 3 January, page Do4.

\section{About the author}

Ngai Ming Yip is Professor in the Department of Public Policy, City University of Hong Kong. He researches on urban and housing issues in Hong Kong, China and other Asian countries. He publishes extensively in international 
academic journals, and his recently published edited books include Neighbourhood Governance in Urban China (2014), Young People and Housing: Transitions, Trajectories and Generational Fractures (2012)(with Ray Forrest), and Housing Markets and the Global Financial Crisis (2011) (with Ray Forrest). He is working on another edited book, The Contested City: Urban activism East and West (with Miguel Martinez and Xiaoyi Sun). 


\title{
$6 \quad$ Making the Music Scene, Making Singapore
}

\author{
Jumping Spatio-Sonic Scales in a Southeast Asian City-State
}

Steve Ferzacca

\begin{abstract}
This paper explores a shift in spatio-sonic scales that occurred with the changing location of a local pub in Singapore featuring live music. Ongoing participatory-ethnographic research has followed a small community of musicians, their families, friends, and various relations as they followed the pub and its music from a renovated shophouse in Chinatown to a mall (Bugis+) in the Bugis arts, culture, learning, and entertainment district of Singapore. This spatial history reveals shifts in ontological structures. Jumping spatio-sonic scales however from shophouse to mall, while extending the "reach" of the assemblage of networks, also extended the affective possibilities important to this community of musicians. Nevertheless, in spite of the jump and the social and cultural change represented by the menu of music and food, this community of musicians and friends continues to patronize the pub as a particularly Singaporean place, but more importantly, as a place to nurture a particularly Singaporean way of apprehending their sonically charged world. In a city-state intent on tight control over the presence of spatio-sonic scales (via the Public Entertainment Act), ethnographic attention to a local pub featuring live music encounters a vernacular community and popular culture made by Singaporeans for themselves.
\end{abstract}

Keywords: spatio-sonic scales, sonic space, music, arts, band, Singapore

Cabannes, Yves, Douglass, Michael and Padawangi, Rita, Cities in Asia by and for the People. Amsterdam: Amsterdam University Press, 2018 DOI 10.5117/9789462985223/CHo6 
Figure 6.1 Maps of (a) Singapore urban areas, (b) Singapore, and (c) Guitar 77, The Hood, and Bugis+

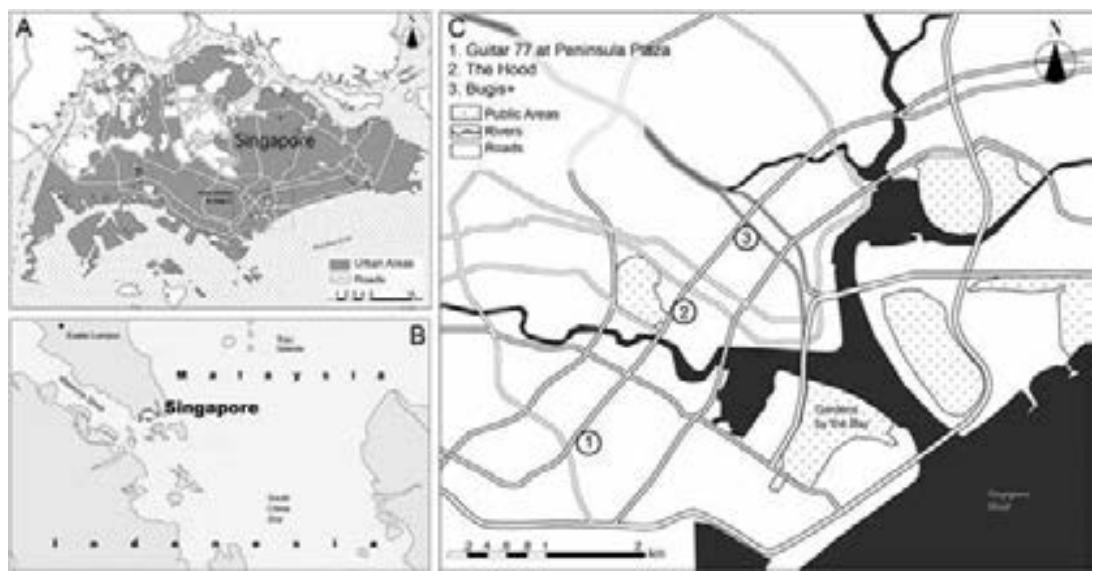

Source: Ariel Shepherd

1

Assembling Sonic Cities By, Of, and For the People

All cities, at all times, in all places, are cosmopolises in both theory and practice. Aidan Southhall's 'universal index' of urban processes highlights the centrality of heterogeneity and dense social role relationships as indicators of the presence of urbanization (Southhall 1973). Southhall emphasizes the 'high spatial density of social interactions' as a distinguishing feature of cities compared to the wider society 'in all times and places.' This necessary 'urban' configuration of heterogeneity and density are the conditions within which 'human and non-human forces' are assembled and reassembled on an everyday basis by urban residents as they make their lives as selves, persons, and groups in cities (Latour 2005). This social dimension-an essential characteristic of cities - can itself become the central motif of the urban experience. Walter Mignolo celebrates this experience as a 'cosmopolitan conviviality' that fuses urban solidarities of both mechanic and organic kinds (Mignolo 200o). This social fact alone - that urbanity is inherently cosmopolitan in effect, and that the experience of a cosmopolis can emphasize local and extra-local densities of social role relationships as well as real and perceived interactions in densely situated forms of social organization-is a basic part of scholarly interrogations of urban projects by and for the people.

One way to conceptualize this social dimension of the cosmopolis effect is the manner in which urban projects by and for the people are governed 
and managed. In other words, the concerns revolve around what 'ensemble of means' is assembled in any place at any time as individuals and groups make cities for themselves. In the process of assemblage, these 'ways of technique' evoke judgments and consciousness-reflexive dispositions in which a way of life, a way of knowing the world, is the 'object' (Ellul 1964). ${ }^{1}$ The assemblage of means, the techniques, the reflexive dispositions in the context of high spatial densities of social interaction can be conceptualized as Lefebvre's 'production of space in the richest sense': an emergent relativity of terrestrial space that Neil Smith refers to as 'deep space.' For Smith, 'deep space is quintessentially social space; it is physical extent fused through social intent.' This social dimension of the cosmopolis effect provides theoretical orientations that are useful for understanding both the presence of and potential for 'alternative spaces in the city' (Smith 2008, 214).

This chapter examines Smith's process of fusion in the context of understanding how city residents, in this case, residents of the Southeast Asian city of Singapore, make plain, homespun, alternate local worlds in this crossroads, global, Asian city. Like all cities, Singapore is a place of limits and possibilities that provide opportunities or impinge upon the intentions and efforts of Singaporeans to make a city, or parts of a city, as a place for and by the people. This chapter explores two concepts to provide insight into the activities of a small group of Singaporeans who come together in various ways, at various times, in particular places, to participate in making music, and in the process, make the city.

The first is the notion of spatial scales. Urban scholars, particularly David Harvey, Neil Smith, Erik Swyngedouw, and Kevin Cox, all note that cityscapes are 'differentiated into complex spatial patterns of human activity, systematically and hierarchically organized as "spatial scales"' (Smith 2008, 181; Harvey 1985; Harvey 2000; Swyngedouw 1997; Cox 1998). Smith proposes a typology of three primary spatial scales: urban space itself; the production of urban space within the nation-state; and its production within global developments. In an article on medical tourism in Southeast Asia, Ara Wilson adds the bodily scale to Smith's formulation (Wilson 2011). Drawing in part from the work of S. A. Marston (2000), Wilson finds "bodily spaces" the most immediate, primary of spatial scales, "nested" in urban, national, and global scales to varying degrees - varying degrees which represent political processes in the "social construction of space" (Wilson 2011, p. 123. ${ }^{3}$

1 I am drawing in haphazard fashion on the work of Jaques Ellul (1964).

2 See Neil Smith's afterword to the second edition of Uneven Development (2008).

3

For Smith (2004), 'home' is the most immediate spatial scale (Wilson 2011, 123; Marston 2000). 
From these perspectives, scale — as simply a relation between proximity and distance - is constantly in question. Harvey, Cox, Smith, and others consider scale and the production of space to be assembled networks of physical space and meaningful human activity, or simply the proximity and distance of human practice (Smith 2008, 107, 229). Such socio-spatial scales, a guitar shop and live music club for example, represent the 'ways of technique' and the 'ensemble of means' that in action are organized as 'technical phenomenon' in which the 'meaning, concepts, and consciousness of space are inseparably linked to its physical production. ${ }^{4}$ Moreover, this assemblage of socio-spatial scales constitutes popular, 'local politics' that operate on interpersonal scales or within the 'hierarchy of scales' identified by Harvey and others (Harvey 1985; Cox 1998). From this vantage point, 'scale' represents a 'relation': a network in action.

Especially in cityscapes, this 'sense of place' emerges in the actions of individuals and groups. In the process, individuals and groups act within and upon various scales in urban landscapes that can "contain' human activity "in space" while demarcating the space or spaces people "take up" or make for themselves (Smith 2008, 229-230). Cox notes that the relationships between these spatial containments of human activity and emergent, assembled spatial engagements are a crucial relationship through which 'localized social relations' realize the interests that are essential to making a city for and by the people (Cox 1998). In this way, particularly in the urban milieu, the state haunts (Derrida 1994) a politics of scale as individuals, communities, and groups secure spaces of dependence within the municipal codes, zoning regulations, rent, and real estate conditions. These mechanisms of governance, and their associated ideological projects that produce physical spaces reveals the city itself as a technical phenomenon made of 'spaces of engagement' in which the politics of securing a 'space for dependence' unfolds (Cox 1998, 2).

The second concept is sound, particularly deep sound. Similar to Smith's notion of 'deep space', deep sound is sound in the richest sense. Deep sound is sonoric extent fused through social intent. Deep sound resounds profoundly: it is soundings from the deepest fathoms of social life. The profound implications and consequences of deep sound are multi-sonorous in affect and meaning, the depth enabled by the milieu in which social lives occur. Michel Foucault described this milieu as 'a certain number of combined, overall

4 I am combining Ellul's (1964) thoughts on how technical functions involve and evoke judgments and consciousness with Smith's (2008) theory of 'uneven geographical development' and the 'politics of scale.' 
effects bearing on all who live in it' $(2007,21)$. This immersion opens up participants experientially to local 'devices of saturation' that are points and moments of the 'intensification' of local experience (Foucault 2007, 21, 45).

The soundscapes that make up Singapore's music scene represent productions of space in which the state is deeply implicated. Sonic existence in Singapore can be challenging. Since its founding by a British colonial administrator, Singapore has been, from some perspectives, governed by one authoritative regime after another. Beginning with British colonialism and continuing into the 'authoritarian capitalism' of present times, the presence of past and present forms of governance not only 'haunt' but actualize the city itself as a nearly totalizing 'space of dependence' for city residents and the multitudes that pass through this southeast Asian crossroads to the world (Tan 2011; Derrida 1994). ${ }^{5}$

Chinese opera performances forced to move to the outskirts of town. Tamil ritual drumming outlawed. The Islamic call to worship confined to the congregation inside the walls of the mosque. Until recently, musicians and bands of all styles and kinds have found extreme limits on opportunities to perform music in public. Public sonics have been a source of concern and a target of social disciplining since Singapore's independence and statehood in 1965. Most recently Bart Barendregt, and Lily Kong specifically with regard to Singapore, have explored the popular music scene of the region, noting the significance of this sonic politics in the various similitudes of modernity (Barendregt 2014; Kong 1999).

State concerns about 'noise pollution' have long been in the books and manifest politically and spatially as the various permits allocated to spaces state authorities designate as educational, recreational, retail, and so forth. Sonic parameters and tolerances translate into spatial dimensions and proximities depending upon the allocation of these designations at any one time, constituting an ontology of 'spaces of dependence' organized through state-sponsored urban planning in a 'politics of scale' in which sound is a crucial determining feature (Harvey 1985; Cox 1998; Judd 1998). Recently, Kelvin Low (2011; 2014), Jim Sykes (2015), and others have explored 'the spatial politics of noise' in this city-state. Their work highlights the role of the state in urban life through legislative and licensing procedures that manage social conflicts between different kinds of sonic activities through the organization of socio-spatial presences and absences. The local live music scene in Singapore assembles spatio-sonic scales within state 'reach', the

5 For an interesting discussion of authoritarianism in Singapore's politics, see Tan (2011). I am echoing Derrida's notion of 'hauntology' (1994) here as well. 
durations of which are responses to the access to public space for live music performances on one hand and the difficulties of establishing, maintaining, and sustaining a live music venue in a challenging business environment on the other. These 'spaces of engagement' are crucial sites 'in which the politics of securing a space of dependence unfolds' (Cox 1998, 2).

In Singapore, the exuberance of the music scene in the heady days of the 1960 s and early 1970 s has recently been restored. The growing numbers of guitar stores, rehearsal spaces, local pubs, and clubs - in addition to venues located in downtown tourist areas-reflect the confluence in Singapore and all over Southeast Asia of a wide-ranging circulation of things and sounds, specifically music and the things to make music with. This confluence is nothing new in this crossroads of world history. What is historically specific in this ongoing long duree of circulation is the increasing access of nearly all Singaporeans to musical gear of all kinds for all purposes that in the past was highly limited by consumer prices, skill and knowledge, local availability, and the number and density of active communities of interest (musicians, listeners). This democratization of access to the many things used to make contemporary music of every genre, local and global, at home and on the stage, is central to the making and assembling of alternative urban spaces in this sonically challenged urban-state. The effect of this sonic democracy is a multitude of spatio-sonic scales scattered around the urban-state, each representing differing degrees of 'coordination' and production, the extent and duration of each to a greater or lesser degree subject to chronic threats (Hendy 2013). ${ }^{6}$

This chapter explores the making of the music scene in Singapore, one of the most urban of all nation-states on the planet. The members of the music community who participated in this research make music and a music scene in a set of nested scales that involve interpersonal networks where the centrality of the presence of the Singaporean state shifts in quality and kind, thinness and thickness in these musical affairs. Participating in the events and social activities of a community of musicians and music lovers who congregate at both a guitar shop and a local live music club demonstrates how, in the process of 'engagement', 'spaces of dependence' produce and are experienced as sometimes competing, sometimes nested affective scales sonically charged by music. The guitar shop, the live music club, and the other musical spaces located around the city clearly represent sonically charged scalar opportunities made by participants in particular city spaces.

6 Hendy (2013) notes that a fundamental, perhaps primordial feature, of the human making of sound is the accompanying making of coordination among things and people. 
Each of these spaces of engagement and dependence is assembled with the presence and absence of scales produced in the process of state governance and rule. Potential spaces of dependence always involve the state.

This chapter associates this reality of the Singaporean production of sonic space with the affective scales assembled along with state-built features of city space, as well as with the wide array of other human and non-human forces that make up the described events and activities. These affective scales are effective in generating sonically produced and spatially transcendent human feelings of self and networked others as a 'sense of place'. For analytical purposes, two locally meaningful affective scales are implicated in the community events at the store and the live music club known as Hood. During the course of this research, the Hood changed location, or 'jumped scale', seeking 'locational advantage' (Harvey 1985; Smith 2008, 176-177). This rupture in the habits of this community of interest revealed the affective scales organized around business and friendship - affective scales that shift the coordination of subtly distinct affective modes in interpersonal relations. These affective scales are assembled into the events and activities of this community of musicians, friends, fans, customers, and family along with the guitars, amplifiers, alcohol, food, cigarettes, and of course city places where networks emerge and are assembled. The affective scale of business and friendship overlap but are not without tension and conflict; These network dynamics built from the associations of people and things comprise the social of this community, and it is in this community of interest that reflexivity occurs.

2 Methodologies

From an ethnographic perspective, this chapter examines the making of sonic communities in urban spaces, and in spaces that can be conceptualized from a number of perspectives — for example, economic and political — as nearly totalizing urban spaces of dependence. This chapter is based on my fieldwork conducted over a three-year period across several urban spaces and among members of a fairly stable community of amateur and semiprofessional musicians, business partners, friends, family, and other varied associates, most of whom were born and raised in Singapore, while others originate from the many who pass through and sometimes find a home in this Southeast Asian port city. None of the community members live near each other in Singapore, much less in a place-based neighbourhood, although some members share place-based memoryscapes in their backgrounds. 
One central gathering spot for this community's 'focused gatherings' is in the basement of a shopping mall in Singapore's central business district among a collection of music stores well known in Singapore for selling vintage and contemporary music gear. One shop in particular-Guitar 77 -is one among several urban spaces where urban projects for and by people in Singapore were observed. Other fieldwork sites included practice studios, performance venues, music schools, churches, and the void decks of apartment complexes where some of the members of this community organized around music interests are active. Some of the performance venues are located in other Southeast Asian cities (Melaka, Malaysia; Ho Chi Minh City, Vietnam). Members of this community travel as a group, either to perform or as members of the entourage, to urban locations in the region - assemblages made increasingly possible by budget airlines and the loosening of visa restrictions among ASEAN countries.

In performance venues this community sonically expresses, and so extends, its interest as a community. Musical performances are one of several techniques involved in reproducing ways of knowing and experiencing the world through sound and performance that Steven Feld refers to as 'acoustemology' in his ethnography of jazz musicians in Ghana (2012). Jam sessions in the guitar shop and musical performances in other venues reactualize—re-entextualize — and so affectively re-assemble this 'community of interest,' this 'vernacular milieu' across the urban milieu in bars and pubs, church events and congregations, music festivals, and so forth (Pickering and Green 1987). The shop, the bar, the city participate as objects in the assembling of 'situated sources of identity' for which affect, generated in part sonically, but also through other 'techniques of the body' (Mauss 1973), becomes scale-able in terms of its presence in place (Pickering and Green $1987,8)$. In these cases of city-making, the social is actualized as spatio-sonic scales both present and heard, but also 'imagined' in networks that may or may not produce actual participation in the sonically charged events and performances. This amalgam of scale-able affect and interest are essential for the making of alternate urban spaces - the 'spaces of engagement' where cities are made by and for people; spaces where the popular culture of cities makes place.

This chapter examines these issues by following a musical community as its 'home' performance venue changes location. In my ongoing participatoryethnographic research, I have followed this small community of musicians, their families, friends, and various other relations, as they followed the pub and its music from a renovated shophouse in Chinatown to a mall (Bugis+) in the old colonial residential area that has since become the Bugis arts, culture, 
Figure 6.2 The Hood, 2011

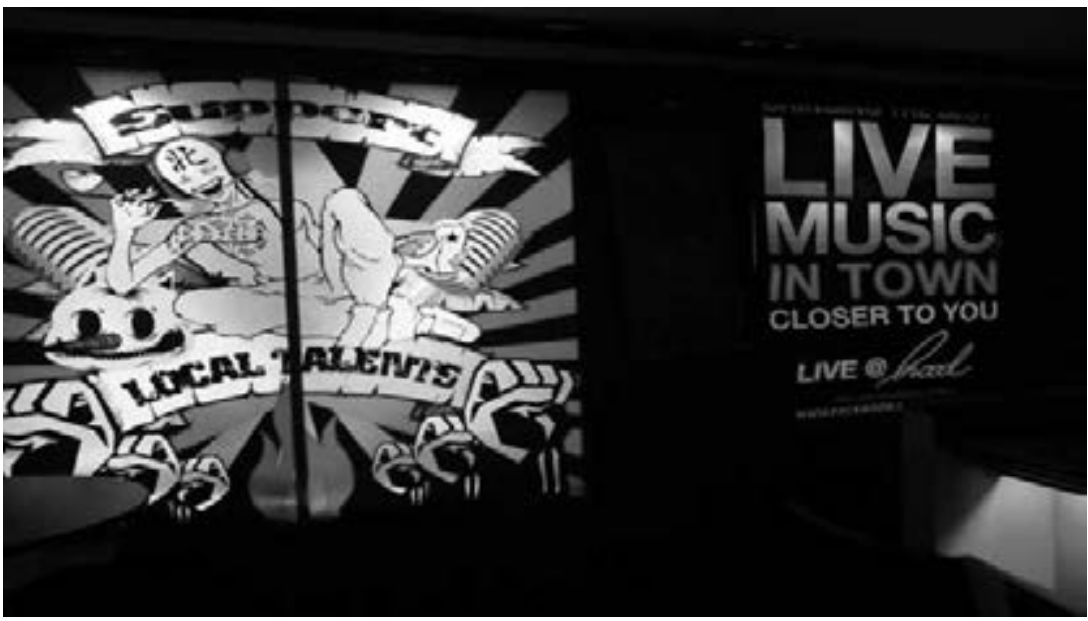

Source: author

learning and entertainment district of Singapore. Jumping spatio-sonic scales from shophouse to mall, while extending the 'reach' of this assemblage of networks, has also extended the sonically-charged affective possibilities of this community. In a 'hierarchy of scales' organized around the Public Entertainment Act (PEA), which provides the process and guidelines for obtaining the required licensing for live music performances in public urban spaces, Harvey's imagined 'struggle for the right to the city' takes place. This participatory-ethnographic project - conducted by a group of musicians, their friends and family, fans, and customers of a local guitar shop and live music club in Singapore and written by an anthropologist - calls attention to those who 'capture' the 'commons' of urban life 'at a variety of scales' through alternative urban spaces (Harvey 1985,78$){ }^{7}$

In spite of radical changes to the live music format and technique, range of musical genre, food and beverages, spatial size, location, staff, and so forth across these varied 'spaces of engagement', this community of musicians and friends continues to patronize the pub as a particularly Singaporean place, but moreover as a place to nurture, to assemble a particularly Singaporean sonically charged way of 'apprehending' their world. In a city-state intent on 
maintaining tight control over the presence of spatio-sonic scales (via the Public Entertainment Act), ethnographic attention to a local pub featuring live music encounters a vernacular community and popular culture made by Singaporeans for themselves. This example of jumping scales reveals the 'nature' of city-making literally embodied in the community's sensorial response, and especially the sonic consequences brought about by this change in spatial location and scale.

Tucked between the elegantly whitewashed and refurbished colonial buildings, museums and art galleries of Singapore's Civic District and the gleaming skyscrapers of the Financial District lies the relatively dated Peninsula Shopping Centre at Coleman Street. Supposedly an upmarket shopping mall when it was built in 1980 with an array of shops from sports accessories and travel agents to tattoo studios and guitar outlets, the place has evolved into an eclectic zone shared as an enclave by youthful punks and skinheads, ethnic Burmese migrant workers, bargain shoppers, and of course music lovers of all kinds. In the basement of the mall where the aromas from the food stalls are mixed into the building's air-conditioning, several rows of shops displaying a range of wooden acoustic and shiny electric guitars can be found. My ethnographic fieldwork was conducted among these music outlets in the mall, including Davis Guitar, Guitar Connections, and Guitar 77, over a three-year period. Conversations with the owners and assistants of these shops as well as customers were facilitated by a global language of guitars and amplifiers. This 'gear talk' is the lingua franca of global popular culture. Reverberating in this global desire for musical commodities, however, are local histories and music scenes vibrating right along with the steel strings.

Kiang is the manager of Guitar 77. I meet him as he stands behind the counter in his shop, glasses hanging on the end of his nose and his long concrete-coloured hair streaked with the blackness of his youth, clearly a man of my age (Figure 4). I ask if I can plug in the shiny black guitar, and I am led to an amplifier with numerous guitar effect pedals attached. Together, the guitar and amp sound beautiful, and I play beginning with some blues riffs from a 'classic' repertoire of mid-2oth century urban, electric American blues_-Howling Wolf, Muddy Waters, Albert King. Peering over the top of his glasses, Kiang loudly exclaims as I crank on another riff, 'A real bluesman.' Now the guitar store's owner and manager, Kiang began his career in music in the 1960 os as a bass player and founding member of 'The Straydogs' - a 
legendary Singaporean band. Kiang describes The Straydogs as a 'beats and blues' group that began playing and later recording in 1966. As our conversations continued, the presence of a 'cosmopolitanism' recognizable for its so-called 'western' features was stunning in its degree of resemblances. Kiang and I had grown up listening and playing the same music, yet living thousands of miles apart and involved in quite different histories. I was struck in the moment by the conjuncture of the 'gestures of similitude' we had both assumed back in the day as our uniquely similar, unsurprisingly distinct entries into "the politics of membership in the "world society".

However, as Kiang and I got to know each other, as I spent more time in the guitar shop becoming acquainted with the music scene of Guitar 77 and the other shops in the mall, and as Kiang and I began to play together, even forming a band named after his shop (Blues 77), my ethnocentric cosmopolitanism that provided a medium through which we could communicate insights into each of our life stories opened up to reveal a historically anchored, rich Southeast Asian cosmopolitanism. Mignolo (2000) has defined cosmopolitanism as a counter-movement to globalization. However, Kiang and The Straydogs reminded me that this island nation has always been at the centre of cosmo-politics immersed in a kind of 'planetary conviviality': a conviviality for the cosmopolitan forged across vast global networks. Feld has also observed this kind of cosmopolitanism in an African musical milieu, and characterizes the cosmopolitan outlook of jazz musicians as an 'acoustemology' which he argues illustrates a 'way of knowing the world through sound' (2012).

This same conviviality - the experience of global popular music embodied in an acoustemology - knowing global forces in lived local circumstances through sound - are central to the lives and livelihoods of these guitar shops. It turns out the people I had met and was going to meet ascribed fully to the 'cosmopolitan commitment' forged from willing, and at times courageous, 'inter-subjective negotiation' that is highly valued and also central to the 'deep hermeneutic engagement' that is one's life. From what I learned, their commitments were always and continue to be framed in an intense loyalty to Singaporean identity, fraught as it is with ethnic politics and crossroads consequences, while forging this loyalty out of a marginal aesthetic footnote in the Singaporean story. Singaporean rock legends like Kiang made commitments to cosmopolitanism years ago, in those mythic times of nation-building and the release from colonial to post-colonial globality. Kiang and many of the others I have come to know and 'jam' with continue to express their cosmopolitan commitments through their music and lifestyle, over and over again, in the context of Singapore's contemporary 
music scene. In the basement of this dingy (by Singaporean standards), aging shopping mall in the heart of the heartland where else would I meet up with the cosmopolitan?

The remainder of this chapter explores the change in location of the live music club associated with the guitar shop named Hood. Hood opened not long after I arrived (in 2011) and recently changed location (in 2013). This change in location is considered here to be 'jumping scales' (Harvey 1985). Rather than exploring the capital involved in the capacity to jump scale in urban commercial settings for the augmentation of economic conditions, this chapter observes the effect on the community of friends who have participated in both assemblages from an ethnographic perspective. In this case, alternative urban space is re-assembled again and again not only from interest but from a habitus that is deeply local and fiercely Singaporean-and so broadly alternative-in spite of the transformations in the live performance experience from one 'space of engagement' to another.

\section{$4 \quad$ Hood on Keong Saik Road}

old hood got a nice feel, people mix around with each other freely, kind of like home pub sort of place and the music is so close to the audience makes it very vibrant. (interview, Kiang Lim, musician, guitar shop manager, February 2015)

Hood, a local live music club, established by the owner of Guitar 77, opened its doors for business on Keong Saik Road in the Chinatown district of Singapore not long after I arrived to take up an appointment at a research institute for my sabbatical. Until the 196os, the area was a prominent and notorious red light district with a high concentration of brothels located in the three-storey shophouses known as examples of the 'transitional, late and art deco styles' (Savage and Yeoh 2004). By the 1990s, the area was transformed by the presence of 'boutique hotels,' shophouses renovated into private residences, coffee shops, restaurants, art galleries, and other shops for commercial use. The Hood's first home was the street-level 'shop' of a shophouse. The Hood features local artists, not quite exclusively, but there is a preference for and concerted effort made to book local artists, mostly popular music from across a variety of genres. Hood opened across the street from a well-known locally known only restaurant specializing in Singaporean Chinese food. Just next door was a small but also highly recommended Malay restaurant. These local establishments signify the effects of structural 
Figure 6.3 Inside the Hood, 2011

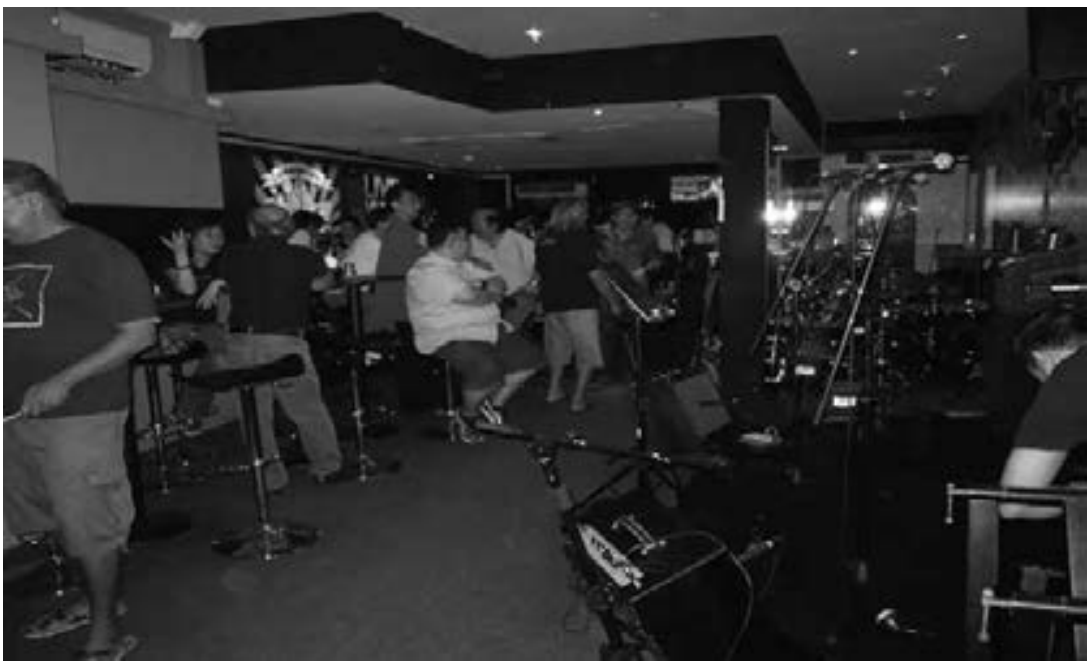

(Source: author)

time, illustrating another feature of scale-duration-which in the case of this neighbourhood stand as monuments saturated in generational depth especially for Chinese Singaporeans. Along with the food establishments, Keong Saik Road is a one-way street with sidewalks, making it an appealing location for a live music club. Located just far enough away from the highrise residences that surround this heritage neighbourhood in Singapore, the Hood renovated the long and narrow street-level storey with a stage, a Plexiglas enclosure to surround the drums, a small bar, a few tables, an open area to stand, some outside tables next to the sidewalk with ash cans for smokers, and toaster ovens and microwaves to prepare a minimal menu. With so many of Singapore's well-known local restaurants, food courts, and hawkers' stalls nearby, the Hood chose to allow food from outside to minimize their own need for an extensive food menu. The most important item on the menu for the live performances I attend with these groups of musicians and their friends is alcohol, mainly scotch whiskey-Dewar's is preferred-consumed by the bottle. However, a wide range of alcohols are consumed; some generational preferences seem to pattern alcohol choices, although as the evening's performances proceed, a general trend towards shots and cheers emerges among the crowd.

On the evenings I was present, the clientele was nearly entirely and nearly always male. Women were present—girlfriends, wives, co-workers, and friends of those who were playing on stage at some point in the evening 
made up the majority—but in small numbers. Women appearing to be out for a night on the town did filter through. The Hood experience for a night on the town could be irregular: one night might be loud and highly charged, while other times the Hood was completely empty. Generally, however, performers brought along family and friends; an audience, even a small one, made performances at the Hood feel like events.

Hood provides opportunities for a wide range of talent, popular music genres, and ages and genders of performers. Local talents in town (as the sign says) is the determining factor in the selection of performers. Genres range from classic rock, contemporary pop, metal, and some blues performed at various levels of amplification to electric instrumentations or some mix of both, by solo performers and bands. One evening I attended an event for high school-aged music students. With each band, a new set of parents and friends came and went.

Each performance generates some degree of the excitement of live music performed before an audience and amplified at levels loud enough to call for nearly complete attention from all present. The only escape from this dense and intense sonic experience is out the front door to the sidewalk tables - amidst the cigarette smoke. The size and layout of the Hood grudgingly held in place a spatio-sonic scale at the very edge of bursting forth with each opening of the front door - a literal spatio-sonic scale more often than not bursting at the seams of containment. Kiang, in his comments that opened this section, describes this sonic experience as 'very vibrant'. John Cage noted that the distinction between silence and sound is not a question of acoustics but one of 'attention'. ${ }^{8}$ Sound, as Nancy $(2007,7)$ argues, is 'made of referrals': '[m]eaning and sound' come to share 'the space of the self, a subject' (8). Sound is 'the ricochet, the repercussion, the reverberation: the echo in a given body' $(2007,40)$.

Straydogs and associates present a 'community of interest' organized around rebellious behaviour and cosmopolitan conviviality. As amateur musicians involved in the music scene, Kiang and the others who form the Guitar 77 entourage, again a community of interest, reproduce community in a 'vernacular milieu' in which the 'rocker' and the rock and roll lifestyle as it existed and was configured in both the past and present, provide a 'specific plane' that becomes a focus for interaction and identity formation. Such communities of interest can be numerous and exist on their own or come together collectively. This happens with the blues jams that occur

8 This well-known quote from John Cage is further discussed with reference to urban existence by James Donald (2011). 
from time to time around Singapore. Local communities like Guitar 77 become involved in such events and encounter other communities that share similar interests. While Guitar 77 represents a 'situated source of identity', it is also a recognizable one among the other situated sources of identity in the community.

The vernacular milieu is the context in which participation in the nonmediated forms and processes of cultural life thrive. To understand the situated sources of identity that are involved and the manner in which these sources of identity are used, it is crucial to identify the technical phenomenon that both helps produce individual and group consciousness of forms of identity and provides the equipment for life that presents identity sources which Kiang and others use to evaluate and perhaps judge the conditions surrounding the maintenance of identity forms that matter to them. In addition to the gear, the stage, the sound, the crucial source, a central source, is alcohol. While the images, activities, and associations that surround the everyday life of this community of amateur musicians are cosmopolitan and include people from many different backgrounds, the nature of most of their activities are characterized by the centrality of masculinity and male bonding. In addition to the constructions of gender that are facilitated by the activities in the store and on the stage, the parochial, and so less cosmopolitan, notions of tolerance for social differences becomes more visible. The afternoon jam sessions in the store, the gigs in Singapore and on the road, follow a similar pattern - referred to by Kiang and others in the community as 'talking cock'. These are the very 'delights' at the centre of many of the activities that Kiang, myself, and our associates find so pleasurable, and meaningful. For these reasons, the old Hood was a 'very vibrant' place.

The activities and events at the Hood on Keong Saik Road embedded urban scales of dependence and engagement that were networked differently over the duration of an evening and from night to night. The live music and all that it involved offered participants an individual, yet at the same time collective, experience in intense, focused ways. These 'focused gatherings' featuring 'messy fluid' bodily scales positioned participants in the capturing of ontological scales around particular renditions of Singaporean masculinity anchored in some generational depth. ${ }^{9}$ For this small group, national scales of dependence were contemporary and historical, rooted in the urban present and past, both fiercely criticized and chastised and

9 Of course I am referring to Erving Goffman and Clifford Geertz's use of this concept. For the bodily scale I am drawing upon Wilson (2011), Parr (2002), Smith (2004), and Marston (2000). 
at the same time fiercely loved and honoured. Hood itself in its technical arrangements - from the design of the space to the execution of formal arrangements with the state-provided a vital place for the 'realization of essential interests' (Cox 1998, 2). As a spatio-sonic scale, Hood assembled networks of 'human and non-human', in durable yet innovatively respondent associations and resemblances in the reproduction of local meaning. The emergent quality of Keong Saik Road was 'an "anthropological," poetic and mythic experience of space' (de Certeau 1984, 92-93). Alternative urban spaces - popular milieus where urban residents engage in practices for themselves by themselves - are the struggle for the city in all its senses.

In 2012, Hood changed locations-jumping scale, partly because the Muslim owner decided to renovate the location for a boutique hotel, or as Harvey might say, for purposes of capital, and he wouldn't be wrong.

\section{$5 \quad$ Hood @ Bugis+: Scale-ability}

The main difference is obviously the size of the place. We chose this place due to the location. It is central, and the shopping mall would be pretty crowded (at the time we signed the lease the mall was not ready). The place is bigger and it is more mass market-oriented. To fill the place (or try to), we had to cater our music selection / decor / Food and Beverages to a larger audience. We couldn't be as niche as we were before. The decor remained the same, just bigger. The Food offering changed quite a bit as we have our own kitchen that is capable of dinner and lunch services. So we redesigned our menu from scratch. Our drink selection also increased because we expected a bigger crowd. (Yang Xi Clement, musician, principal, Hood/ Guitar 77. Personal communication, 11 February 2015)

The move from Keong Saik Road to the Bugis+ Mall was not only a change in the classic features of geographic scale — size, distance, proximity, level—or simply the scale of investment, risk, loss, profit, but also a change in relations and perception. A 'hierarchy of scales' that was purely economic and municipal became more visible. Clement, the principal involved in Hood and Guitar 77 and himself a well-known, excellent musician, noted this increased presence as he spoke of the 'old place' as 'less risky' and 'more cosy', but 'impossible' in terms of scale-ability (i.e., less scale-able).

The old place at Keong Saik definitely was more cosy. It provided a more intimate experience for the customer. The revenue was limited by the size 
and the number of people it could hold. At the new place, the potential to earn more money is more, but we now are dealing with how to make this a cosy drinking environment. We can now hold events that cater for between 50 to 400 people. It would be impossible previously. The new place, being more mass market is also more scale-able. Now we are looking to do more events on top of our usual night business. (Yang Xi Clement, personal communication, 2015)

Scale-ability, disposed as spaces of engagement that are formed within and from spaces of dependence in urban milieus, highlights the capture, or at least the capacity to capture, the urban commons-in this case, contemporary Singaporean experiences and identities at, as Harvey notes, 'a variety of scales'. While spaces of dependence - the state; capitalist and commercial business relations - determine the size and associated physical aspects of both locations as spatio-sonic scales, the spatial features on their own are but minor determinants in their ontological capacities and network reach.

Clement and the newly located Hood jump scales sonically in a continued project that calls attention to localized social relations: local Singaporean talent. The 'old Hood' offered a wide range of contemporary Singaporean popular music. Local talent was selected for and the club presented itself as a live music venue for local Singaporean musicians. Associations with the guitar shop provided significant actualization possibilities for networks around the guitar shop's musicians and clientele to attend and perform at Hood events, jam nights, CD parties, and so forth.

In the new Hood, the performance scale is expanded: there is a bigger stage, a better sound system, and the possibility of visual effects. The spatial location and physical distance of the audience is clearly apparent and demarcated: the stage is raised to just about head level; rows of tables fill the space for audience and clientele; there is a large section of the main room where patrons can be seated away from the music; and there is a smoking section outside on a balcony that can be reached through large glass doors overlooking the city street below.

The most obvious difference is that the new Hood is located inside a mall, with mall parking, mall escalators, and mall shops sparkling here and there on multiple floors in large, vertical, soaring spaces. The Hood is on the fourth floor next to and surrounded by several restaurants serving franchise food. An always-busy steak restaurant is the Hood's neighbour. Unlike the local cuisine offered on Keong Saik Road, the food near the Hood at the Bugis+ location appeals to a different generation. Hood's own menu 
also reflects its proximity to franchise food: it is much expanded and even includes entrees. Parking is certainly more predictable and less of a hassle at the mall location, and there is easy access to nearby mass transit.

From the perspective of some, the Bugis+ location is more 'central'. Located between Queen Street and Victoria Street, the mall is surrounded by a number of churches, business and arts schools; the Singapore Management University is nearby, as is the National Library and several important museums. Bugis+ also borders the Bugis arts and cultural district— the Bras Basah Bugis Precinct. Originally planned by Singapore's European founder for European residences (hence the number of churches), the community quickly reflected Singapore's cosmopolitan foundations afforded by its location in the Asian Maritime trade network. Singapore's elite educational institutions, museums, shops, and eateries exist along with the anchorings in this emerging urban entrepot and its cosmopolitan history. Food and fashion, and also an entire array of thousands of Arabian nights for all the senses can be found.

Compared to Keong Saik Road, the depth of national, regional, and global scales are more clearly palatable, tactile, and visceral in and around Bugis+. Clement considered Keong Saik Road to be 'niche'-limited, in terms of scale-ability. Keong Saik Road as an urban place exists as an urban place forged over structural time through the events of communities, Chinese New Year for example, that reproduce generational depth anchored in a self-conscious community of interest, Chinatown. While this socio-spatial scale feels cosy to the mostly Chinese Singaporean heartlanders who are the core participants in this community of interest, Hood's scale-ability was also limited by the parochial qualities of the Keong Saik Road location. At least, these are my impressions. As Hood jumped scale, the politics of socio-spatial scale in the old Hood finds a new home that retrofits alternative urban spaces in this new location so that the same qualities central to local communities extend and contain experience.

As far as I can tell, the national and regional scales forged in history within which Hood is now emplaced do not seem to have relevance to the owner, performers, or clientele that I have come to know. Clearly apparent in the new location is a particularly local actualization of the contemporary Singaporean sonic experience in which the interactive quality of live music is based upon current and fleeting popular music. In this way, both global and regional sonic scales are tapped. Jam nights are a mix of local talent and hosts who can perform live music of nearly any current popular tune with the aid of iPads and other tablets that can quickly upload lyrics and basic chord structures from online resources while performing. 
Figure 6.4 Having a good time at the new Hood

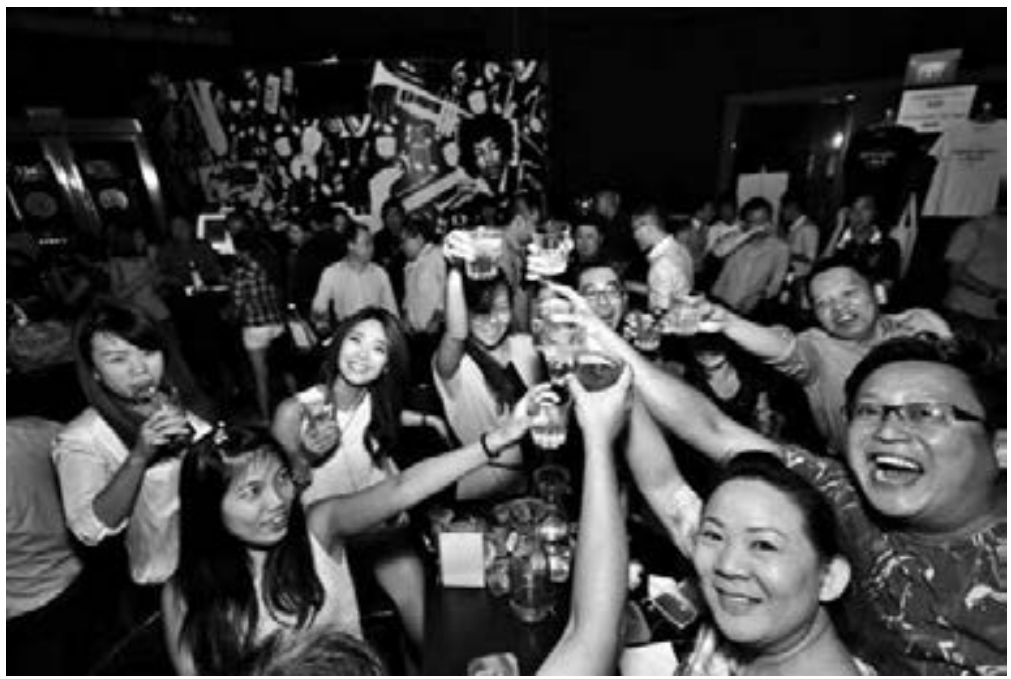

Source: author

This enriched sonic democracy calls for some readjustment among bodies, nations, cosmopolitanisms, and live music experiences. Kiang remarks that the 'new Hood lack the warmth and there is no mingling amongst the people' (personal communication, 10 February 2015). Clement agrees that 'most of the guys prefer the old place [...] It was more of a hole-in-a-wall kind of place while the Bugis+ one is much more commercial' (Yang Xi Clement,. personal communication, 2015).

Ironically, the cosmopolitan commitment in this case is an entirely local affair both historically and in the present. For this group of musicians and friends, cosmopolitanism is central to a fiercely loyal, chauvinistically proud Singaporean self-identification. A 'hole-in-the-wall kind of place' is a likely one for sonically charged cosmopolitan conviviality. Twentieth-century classic sounds like Pink Floyd, Muddy Waters, and Eric Clapton co-mingle with contemporary global popular music of the twenty-first century as Singaporeans assemble in local establishments that offer live music to perform and listen, to make Singapore together. In addition to these more travelled musics are the regionally inspired performances as well as, as in the case of the Hood, an emphasis on 'local talent'. In the Hood and 
many other local clubs, especially those not located in well-defined 'tourist locations' (Clark Quay, for example), this feast of global music is always a local affair, is always a celebration of the cosmopolis even in its most chauvinistic expressions.

Much of this activity is experienced in situ, but it also makes appearances in various forms of social media-further localizing spatio-sonic scales while at the same time extending their reach beyond phenomenological sonic limits. Social media has the capacity to extend spatio-sonic scales limited by space and auditory reach into networks assembled as images, videos, comments, and other tertiary texts available on cell phones, computers, and any other device able to manage social media activity. The community of interest for which the guitar shop and the Hood are actant sites of assembly — sites of the social—is the city; the urban spaces and non-human forces in a network of fragile things, Kiang and others included.

Kiang and others who share in the networks assembled by the nexus of guitar shop-old Hood-new Hood engage show up, eat and drink, perform. Compared to the 'old Hood', the affective scale of this community is not completely diminished, although this seems the effect of jumping scale, at least on the occasions I've been present. Rather, the affective scale of this community in the larger confines of the new Hood, and with the change in food and music menus, is spatio-sonically scaled down. In both space and acoustemology, the way of knowing that was the old Hood has lost some vibrancy in the new location. On the occasions I have been present, the group of friends and musicians whom I have learned from and played music with usually seat themselves as a group at a set of tables to the left side of the stage close to the bar. The remainder, and of course majority, of the tables extend across the front of the stage towards the back of the room, and then off into the extended area furthest from the stage. On the occasions when I have been present and from conversations about the new Hood in many contexts, the general consensus is that a younger, dating crowd has come to populate the Hood in increasingly large numbers. This is good for business, but the sonic effect on the live music is audible: contemporary popular music; taking audience requests; audience participation in performances; the use of hosts to mediate the audience experience; and visual experiences as an alternative to sonic experience, as the entire back wall of the stage is used as a screen to project live soccer matches while live music is being performed. As Clement says, the 'new Hood' is 'commercial.'

Nevertheless, this group of friends continues to show up, eat and drink, and perform from time to time, some members of the group more than others. Opportunities to perform still exist and are extended when slots in 
the performance schedule become available. Local talent is still selected. The Hood continues to strongly endorse its networks and segments of the music community by providing performance opportunities and becoming involved in the production and management of some local groups, musicians, and singer-songwriters. The Hood guitar shop and the Hood are linked in networks of practice spaces, music schools, church programs, musical communities, and venues assembled in various configurations across this spatially located social milieu.

In this urban-nation, this city-state, the Hood jumps scales. As the Hood jumps scales, in the process impacting the continued existence of the guitar shop through diversions of capital, these affective scales that are crucial to the sense of place and the spaces of dependence around which this community assembles become more relevant, more apparent to the social life of the community, and more importantly here for the making of alternative city places. In either case, the Singaporeans involved in this paper, whether associating as friends or as business partners, make the city by and for the people. The friendship emphasizes the cosmopolitan conviviality that the city itself is built from. The business scale emphasizes Singapore as a local cosmopolis. The change in the Hood's location that reverberated across town helped, in part, to bring about the closing of the guitar shop, but also to open new social limits and possibilities with the presence and loss in scales for this sonic urban community. This re-scaling of the Hood did so with a continuing emphasis on live music performed by and for Singaporeans, builds a 'space of engagement' in a hierarchy of scales, political and otherwise, that make such engagements possible. In this way, the 'new Hood' offers an alternative urban space in a music scene where foreign labourers dominate hospitality industry gigs and live music experiences (Filipino musicians) and foreign talent completely dominates the music scene that Singaporeans pay ticket prices to see in concert halls and venues. The consequences have had effect on the spatio-sonic scale identified with the old Hood. The possibility of masculine displays as central to the vibrancy of the space is limited, diminished by the increasing size of the space itself. The space of engagement still exists; it is still possible. It is just another alternative in a sonic democracy.

\section{$7 \quad$ Epilogue}

At the time this paper was presented at the workshop used to organize this volume for publication, the guitar shop closed. Its closure, tied in part to the 
financial conditions involved in launching the new Hood, was described to me as 'cutting costs'. Local politics are in this case scalar politics: an assemblage of personal, national, and global relations. The affective scale used to represent the circumstances was the one of business, easily understood by all members of this community of interest. The week-long clearance sale provided me the opportunity to talk with many in the community, including customers and clerks from other stores, about the closure of the shop. The scale of business - whether the shop was doing business or not, attracting customers or not - or the role of the production of space itself in the shop's existence-for example, attention to the costs of real estate and rents, the ability to compete in an increasingly densely populated market of music retailers, and simply paying the bills to keep the shop open-were local models reflecting the inter-relationships, the nesting of various scales that complicated matters to the point of actually losing a scalar opportunity (the closing of the shop) in this community to 'make' music and so make the city. Judd argues that scales may have 'consequences', but so do their 'absences' - as is clearly indicated in the state's attempt to limit and regulate sonic performances through the Public Entertainment Act. These state sponsored absences in the music community and community at-large ironically provide for the merging social of this community state-designated spaces of dependence (Judd 1998, 30).

The making of the city in this sense is the cosmopolis in which localized identities that are scale-able reflect a bond with a larger scale that is perhaps transcendent of any particular place: the spectre of the multi-cultural city. The old Hood explored this scale, but also provided significant opportunities for sonically charged renditions of a cosmopolitan conviviality from the mid- to late- twentieth century in which local talent not only tapped into global flows but were immersed in them in this global crossroads city-state. In the new Hood, the opportunity for this kind of making the city is reduced, yet the friends who had found so much value in the old location, in its scale of sonically charged affect, continued to show up at the new Hood, even though the affective cohesion sonically saturating their participation was became increasingly silenced. The continuing presence of this community of interest traveling across scales highlights the centrality of the network in the construction of the urban social. One would guess that the significance of affective scales is crucial as well.

It was difficult for everybody to speak of the impact of the closure of the guitar shop on the friendships that help shape the network at any one event, for any one jam session in the afternoon at the guitar shop, for any one performance involving the 'friends' that make up this community at 
the Hood and elsewhere. Kiang's aura of rock and roll heritage, his elder status expressed in kinship terms as an 'uncle' among community members, his embodiment of a cosmopolitan conviviality remain mostly unspoken. After the clearance sale, when the shop had closed its doors for a final time after 12 years in place, at the bottom of the escalator, in the basement of an aging shopping mall, a south Asian Singaporean, a Malay Singaporean, a relocated guitar player/businessman from Japan, Kiang, and myself stood together outside the doors of the shop expressing disbelief at the news of its closure. Kiang opened the bar, mostly for himself. We talked about music, and Kiang stole the show while the other four of us, saturated in our cosmopolitan conviviality, became enchanted as we made this city in this space this way one more time.

\section{Works Cited}

Barendregt, Bart. 2014. Sonic Modernities in the Malay World: A History of Popular Music, Social Distinction and Novel Lifestyles 1930s-20oos. Leiden, Boston: Brill Academic Publishing.

Cabannes, Yves, Mike Douglass, and Rita Padawangi. 2015. 'Concept Note - Urban Knowledge Network Asia. Asia Research Institute Seminar, "Cities by and for the People." April 27-29. National University of Singapore, Singapore.

Cox, Kevin. 1998. 'Spaces of Dependence, Spaces of Engagement and the Politics of Scale or Looking for Local Politics'. Political Geography 17(1): 1-23. doi: 10.1016/ Sog62-6298(97)00048-6.

de Certeau, Michel. 1984. The Practice of Everyday Life. Berkeley: University of California Press.

Derrida, Jacques. 1994. Specters of Marx: The State ofDebt, the Work of Mourning and the New International. Translated by Peggy Kamuf. New York; London: Routledge.

Donald, James. 2011. 'Sounds Like Hell: Beyond Dystopian Noise'. In Noir Urbanisms: Dystopic Images of the Modern City, edited by Gyan Prakash, 31-52. Princeton, NJ: Princeton University Press.

Ellul, Jacques. 1964. The Technological Society. With an introduction by Robert Merton. Translated by John Wilkinson. New York: Vintage Books.

Foucault, Michel. 2007. Security, Territory, Population. Lectures at the Collège de France 1977-1978. Translated by B. Graham. Basingstoke, UK: Palgrave Macmillan. Feld, Steven. 2012. Jazz Cosmopolitanism in Accra: Five Musical Years in Ghana. Durham, NC: Duke University Press.

Harvey, David. 1985. The Urbanization of Capital. Baltimore:John Hopkins University Press. 
Harvey, David. 200o. Spaces of Hope. Los Angeles: University of California Press.

Hendy, David. 2013. Noise: A Human History of Sound and Listening. New York: HarperCollins Publishers.

Nancy, Jean-Luc. 2007. Listening. Translated by Charlotte Mandell. New York: Fordham University Press.

Judd, Dennis R. 1998. 'The Case of the Missing Scales: a Commentary on Cox'. Political Geography 17(1): 29-34. doi:10.1016/Sog62-6298(97)0o050-4.

Kong, Lily. 1999. 'The Invention of Heritage: Popular Music in Singapore'. Asian Studies Review 23(1): 1-25. doi: 10.1080/10357829908713218.

Latour, Bruno. 2005. Reassembling the Social: An Introduction to Actor-NetworkTheory. New York: Oxford University Press.

Low, Kelvin. 2011. 'Sensory Transgressions in Urbanity: Rights, Citizenship, and Sensorial Experiences'. Paper presented at the Sensory Urbanisms Workshop, FASS Cities Cluster, NUS, 11 November.

Low, Kelvin. 2014. 'The Spatial Politics of Noise'. Paper presented at the International Sociological Association 18th World Congress, Yokohama, 13-19 July.

Marston, S.A. 2000. 'The Social Construction of Scale'. Progress in Human Geography 24(2): 219-42. doi:10.1191/030913200674086272.

Mauss, Marcel. 1973. 'Techniques of the Body'. Economy and Society 2(1): 70-88. doi: $10.1080 / 03085147300000003$.

Mignolo Walter D. 2000. 'The Many Faces of Cosmo-polis: Border Thinking and Critical Cosmopolitanism'. Public Culture Fall 12(3): 721-748. doi:10.1215/08992363-12-3-721.

Parr, Hester. 2002. 'Medical Geography: Diagnosing the Body in Medical and Health Geography'. Progress in Human Geography 26(2): 240-51. doi: 10.1191/0309132502ph367pr.

Pickering, Michael and Tony Green. 1987. 'Towards a Cartography of the Vernacular Milieu'. In Everyday Culture: Popular Song and the Vernacular Milieu, edited by Michael Pickering and Tony Green, 1-38. Philadelphia: Open University Press.

Savage, Victor R. and Brenda S.A. Yeoh. 2004.Toponymics - A Study of Singapore Street Names. Singapore: Eastern University Press.

Smith, Neil. 2004. 'Scale Bending and the Fate of the National'. In Scale and Geographic Inquiry: Nature, Society, and Method, edited by E. Sheppard and B. McMaster, 192-212. Malden, MA: Wiley-Blackwell.

Smith, Neil. 2008. Uneven Development: Nature, Capital, and the Production of Space. Athens: The University of Georgia Press.

Southall, Aidan. 1973. 'The Density of Role-Relationships as a Universal Index of Urbanization'. In Urban Anthropology: Cross Cultural Studies of Urbanization, edited by A. Southall, 71-106. New York: Oxford University Press. 
Sykes, Jim. 2015. 'Towards a Malayan Indian Sonic Geography: Sound and Social Relations in Colonial Singapore'.Journal of Southeast Asian Studies 46(3): 485-513. doi:10.1017/Soo22463415000351.

Swyngedouw, Erik. 1997. 'Neither Global nor Local: "Glocalization" and the Politics of Scale'. In Spaces of Globalization: Reasserting the Power of the Local, edited by K. R. Cox, 137-166. New York: Guilford Press.

Tan, Kenneth Paul. 2012. 'The Ideology of Pragmatism: Neo-liberal Globalisation and Political Authoritarianism in Singapore'. Journal of Contemporary Asia 42(1): 67-92. doi: 10.1080/00472336.2012.634644.

Wilson, Ara. 2011. 'Foreign bodies and national scales: Medical tourism in Thailand'. Body and Society 17(2/3): 121-137. doi: 10.1177/1357034X11400923.

\section{About the author}

Steve Ferzacca is Associate Professor in the Department of Anthropology at the University of Lethbridge in Alberta, Canada. He conducts research in the fields of medical anthropology and the anthropology of popular culture with particular attention to urban medicine and health, urban place and space, and urban popular culture in Yogyakarta, Indonesia and Singapore. 



\title{
$7 \quad$ Connecting with Society and People through 'Art Projects' in an Era of Personalization
}

\author{
Motohiro Koizumi
}

\begin{abstract}
This paper examines the current situation of the Art Projects that have been frequently held in Japanese urban communities recently, in order to discuss their significance with respect to these communities. 'Art Projects' refers to cultural movements, art festivals, or exhibitions that do not use museums and art galleries, but rather develop in social spaces such as downtown areas or rural districts, sometimes in old Japanese-style houses or in closed schools and factories. They began to develop around 1990 and have rapidly increased from 2000 onwards. Currently, Art Projects are held all over Japan, numbering more than several hundred annually, with the number of visitors ranging from a few hundred to hundreds of thousands. In recent years, the increasing momentum of Art Projects has replaced the competitive construction of museums, and is the largest movement related to Japan's art spaces in the past quarter century. This paper first considers the increasingly pronounced dilution of relationships among people as one challenge faced by Japanese urban communities, and then considers how Art Projects, which are rooted in the community and developed with the use of cultural resources, have significance as platforms where people can interact. Moreover, this study covers how creative cultural activities contribute to society as a method for facilitating coexistence in an era of personalization, and also indicates its implications and issues.
\end{abstract}

Keywords: art projects, individualization, community, revitalization, Japan

Cabannes, Yves, Douglass, Michael and Padawangi, Rita, Cities in Asia by and for the People. Amsterdam: Amsterdam University Press, 2018 DOI 10.5117/9789462985223/CHO7 
Figure 7.1 Maps of (a) Japan, (b) 3331 Arts Chiyoda, and (c) Tokyo
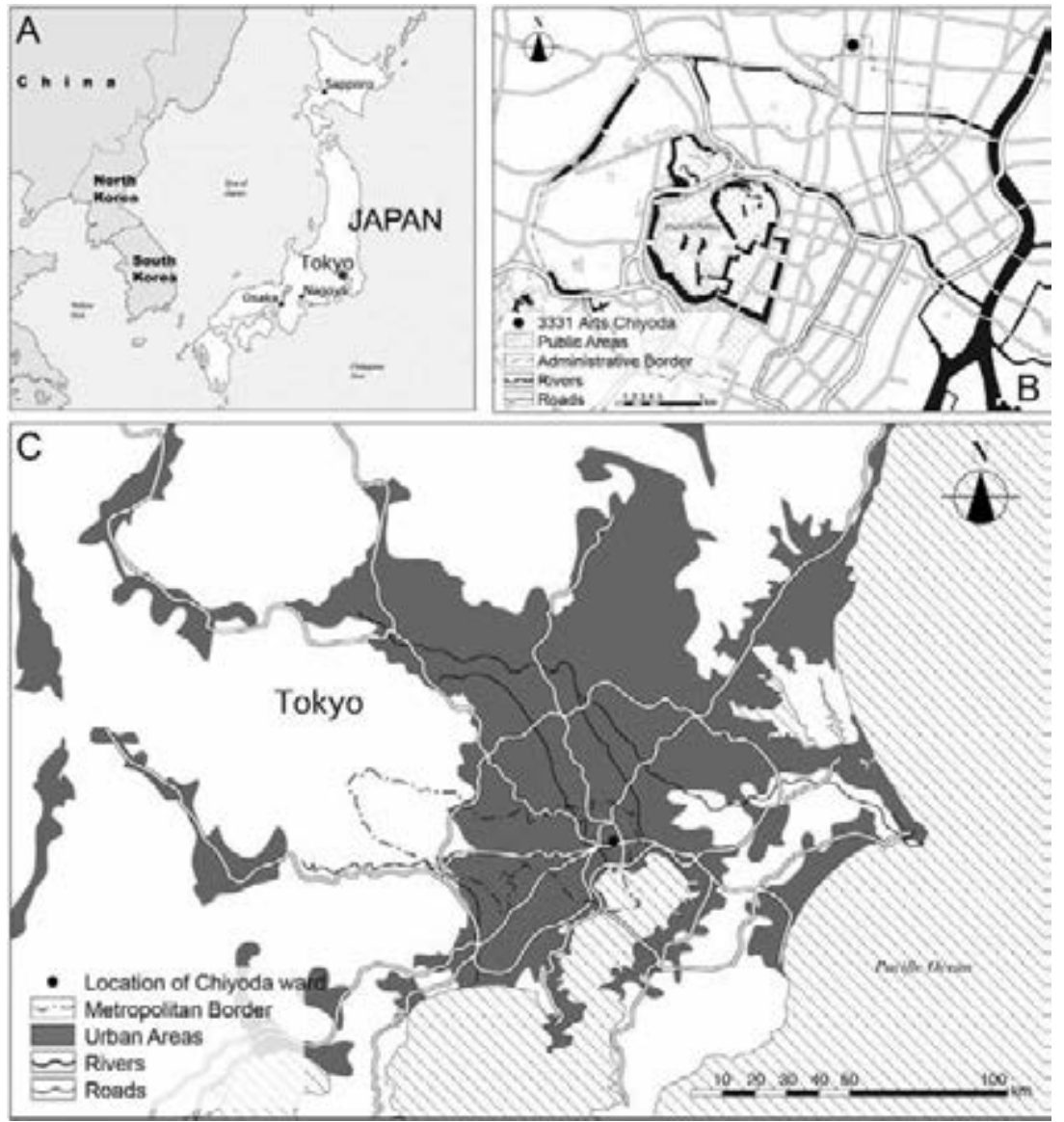

Source: Ariel Shepherd

1

Flourishing of Art Projects in Urban Areas

Akihabara, in Chiyoda Ward, Tokyo, is one of the towns that is considered representative of Japan. It is the world's leading electronics district and is renowned as the center of origin of otaku ('nerd') culture, such as manga, anime, and gaming culture. Walking through the town, one comes across girls in their late teens or twenties dressed in 'maid costumes', distributing pamphlets and announcing, 'Please visit our maid cafes!' with welcoming, smiling faces that seem to have been created from a mould. Street corners are lined with anime and game billboards with colorful and kitsch illustrations and characters. Shops are close to each other, with some 
Figure 7.2 Akihabara, Tokyo

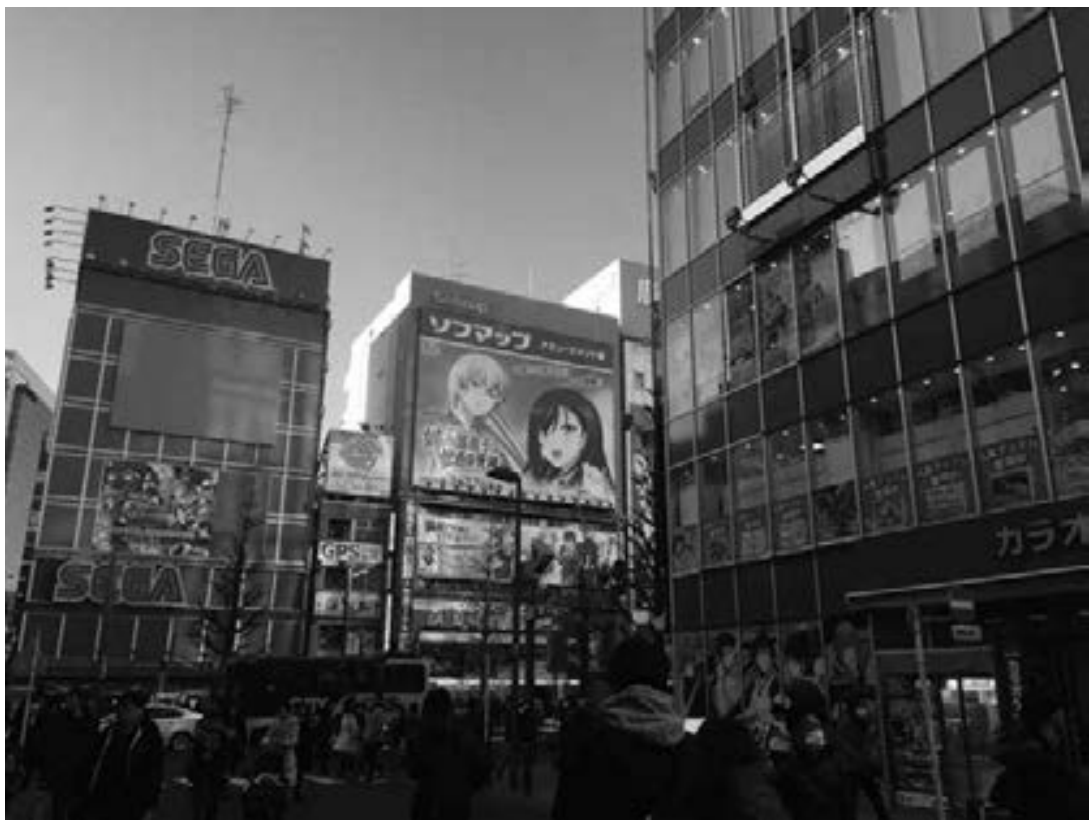

Source: author

stores loudly playing anison ('anime theme songs') or other promotional music (Figure 2).

An art space that focusses on contemporary art-3331 Arts Chiyoda (hereafter, 3331) — is situated in an alley at a short distance from this bustling town (Figure 3). The art center was established by renovating a former middle school. Built in 2010 as part of Chiyoda Ward's cultural policy, 3331 is managed by Command A, an artist-initiative organization. Unlike traditional art spaces in Japan, people from diverse backgrounds frequent this center. The visitors do not necessarily come as spectators to view the exhibitions at 3331; rather, they actively engage in workshops that involve public participation and collaboration. Furthermore, others can enjoy the expansive ambience while, for example, sitting and chatting on benches in the park facing the facilities, pushing a baby carriage, stopping by a café or izakaya ('tavern'), utilizing the free spaces established on the ground floor of the arts center, or-depending on personal preferences - smoking in the smoking zones established in outdoor corners. Here, men and women from different walks of life seem to enjoy the slow pace that strongly contrasts with the restlessness of neighboring districts.

Contrary to the image generated by the mass media, the Akihabara neighborhood is not merely a popular culture center and electronics town 
Figure 7.3 The 3331 Arts Chiyoda

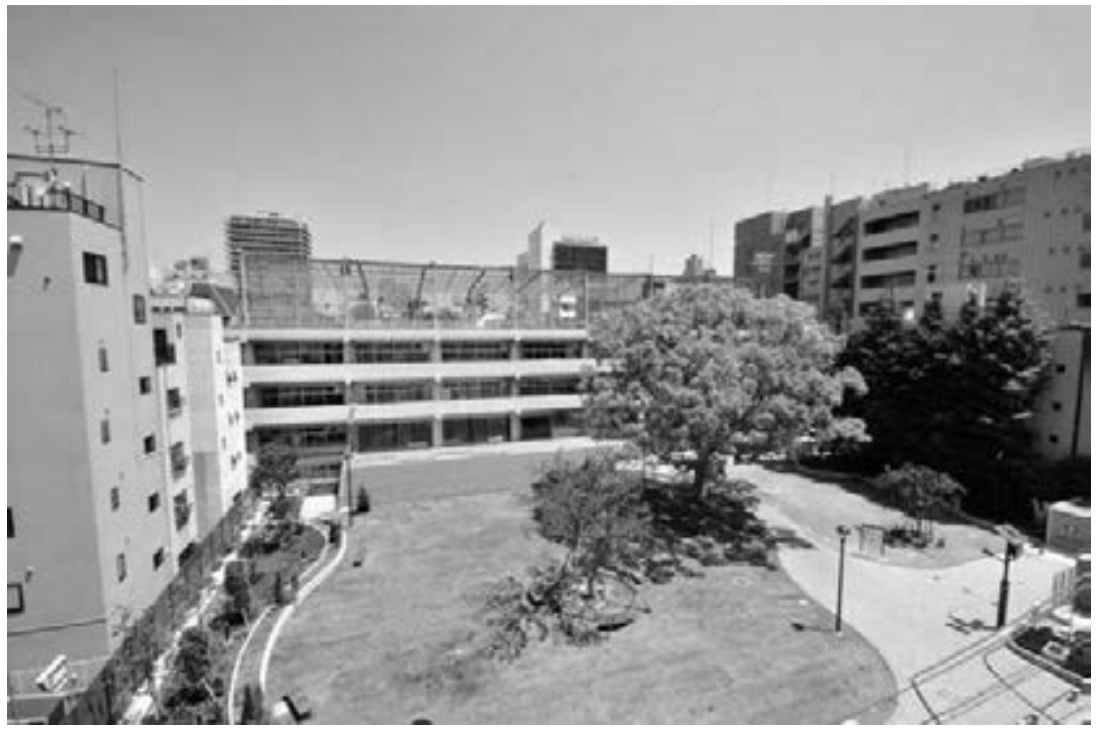

Source: courtesy of 3331 Arts Chiyoda, Tokyo

supported by peoples' hobbies. Rather, it is the residence of various types of people, including those whose families have been residents since the latter half of the nineteenth century or the early twentieth century-from the Meiji or Taisho eras - and the descendants of townspeople and samurais ('warriors') from the seventeenth-century establishment of the Tokugawa shogunate. ${ }^{1}$ In addition to such old and familiar groups, young families and students have recently relocated to this area. Although the number has decreased in recent times because of the trend of exclusion under the name of 'protection', people with no fixed abode also reside in this area. Furthermore, the town is the destination for various businessmen who commute to the neighborhood. Myriad employees pass through every day, including civil servants, restaurant employees, and freelance designers. The district is home to people of various ages and to various social organizations and affiliations. In other words, it is a 'community' within the city in which people of diverse backgrounds live and make a living. At 3331, this heterogeneous mixture of people gathers voluntarily and in a way that pleases them.

1 Tokugawa shogunate (1603-1867), also known as the Edo Bakufu, is the last feudal military government in Japan. At that time, Tokyo was called Edo, and became one of the largest cities in the world. 
3331 is an example of the 'art projects' that have recently been actively developed throughout Japan. While 3331 is an art center for exhibitions, it is also quite consciously a community project rooted in the neighborhood community (Favell 2011). 'Art projects' refers to cultural movements, art festivals, or art exhibitions that are not held in museums and art galleries but developed in social spaces such as downtown areas, old Traditional-style houses, closed schools, and abandoned factories. These projects began to develop around 1990 and rapidly increased in number, popping up at various locations from 2000 onwards in Japan. Since the initiation of Museum City Tenjin (Fukuoka City) in 1990, art projects have been actively held in urban areas at various sites from the 1990s through the 200os. Examples include the Toride Art Project, which was launched in 1999 with a tripartite collaboration among the citizens, the city government, and universities; the Echigo-Tsumari Art Triennial, started in 2000 in a vast, semi-mountainous area; the Beppu Project, which commenced in 2009 in the hot spring tourist city; and the Water and Land Niigata Art Festivals, which began on the Shinano River Basin and along its banks. Currently, several hundred art projects are held annually throughout Japan and are visited by countless people. In recent years, the increasing momentum of art projects has replaced the competitive construction of museums and has become the largest movement concerning Japan's art spaces in the past quarter-century.

A primary characteristic of art projects is that they are frequently connected with the invigoration and development of communities. For this reason, art projects are frequently held in downtown areas. With the rapid ageing of Japanese society and changes to a post-Fordist style of manufacturing, many former community centers, such as schools, factories, and commercial shops, are being closed. Art projects have been initiated in these closed public spaces to re-invigorate communities. Certainly, the relationship between the arts and communities differs for each art project. However, many projects in Japan are expected to invigorate the community using various social spaces and to promote tourism (Kumakura, Kikuchi, and Nagatsu 2014).

Another characteristic of art projects is that their activities frequently include art that involves significant civic involvement. ${ }^{2}$ Citizens from both

2 Many curators and sociologists of art have indicated that in the 1990s a considerable amount of art focussed on the theme of people building relationships. For example, Bourriaud $(2002,14)$ presented the concept of 'relational art' and argued that there had been a recent increase of creative activities with a focus on relations among people. According to Bourriaud, the rapid progress of urbanization in recent years, represented by the spread of a global urban culture and the extension of the urban model, is hampering and restricting the creation of relationships among people. The recent emergence of art trying to find significance in the relationships among people is trying 
within and outside the community might participate in the process of creating works of art in collaboration with the artists. For example, Yoshio Shirakawa created fictional stories based on the popular Yakuza boss, Chuji Kunisada (the local government has kept distance from him because he was an outlaw), and a well-known poet, Sakutaro Hagiwara (who abandoned his own town, thus it is sometimes difficult to use him as a local hero for the local municipalities). Shirakawa further created a festival based on these stories with citizens at the Umaya-no-Mokuba-Matsuri ('The Wooden Horse of Umaya Festival') in cooperation with Arts Maebashi in Maebashi City. At the Breaker Project in Osaka and at the Guruguru ya $\rightarrow \mathrm{mi} \rightarrow$ project in Tokyo, Kimura Toshiro Jin-jin operated a mobile café called 'Nodate', where he dressed like a drag queen and fired teacups that the participants painted on the spot so that they would enjoy Japanese tea in their own teacups. Takayuki Yamamoto held workshops that predicted people's futures through various fortune-telling scenarios that were invented by children, and he further created artistic footage based on the workshops at the Artist-in-Jidokan ('Artist-in-Children's House') Project in Tokyo and at the Hospital Project in Tottori City. Japanese art projects feature a diverse group of aesthetic trends mainly centered on contemporary art. Examples include art installations, architectural art, music, and dance. However, considering the expectation of community invigoration, a significant characteristic of art projects is the development of various art forms that incorporate creating a relationship with the citizens, in addition to using social spaces in the local community. Considering these characteristics, Japanese art projects could be called 'community-based art projects' (Koizumi 2012).

2

\section{Problem Awareness}

Traditionally, research on the relationship between art and society has considered art to be a special area within society; thus, this relationship has not been given significant attention from the social science perspective. Especially, an adequate examination of the roles of art in building a society had yet to be conducted. Of course, there has been some classic research regarding the

to bridge the gap (sometimes in a symbolic manner) and rebuilding ties between people in the modern, computerized, and mechanized society (Bourriaud, 2002). Kester (2004) and Foster (2008) have proposed similar arguments. On the other hand, Rancière $(2004 ; 2008)$ questioned the recent 'relational art' — attempts to 're-politicize' art, since they lessen this discontinuity and gap between the work and viewer. Bishop (2006) has also expressed discontent with 'socially engaged art' that has an interest in the relationships between people, and suspects that art critics judge a work as good or bad depending on whether the work conformed to ethical standards. 
relationship between art and society. For example, Walter Benjamin (1936) explained that the unique 'aura' of artworks had been lost due to printing technologies, but that this had given birth to an 'exhibition value'. Through this theory, he suggestively commented on the significance of the masses' primary participation in the production of art. This is an indicative observation on the relationship between art and people, but his theory did not mention the role of art in building a society. In addition, other researchers who were also members of the Frankfurt school; Theodor Adorno and Max Horkheimer (1944) expressed concern about the risk of standardization of people's perceptions due to the culture industry, noticing the flourishing of jazz in America. Obviously, they considered art to be a specialized field within society. Even after World War II, Baumol and Bowen indicated — taking the example of performing arts - that professions like arts are not 'productive' compared to other industries such as manufacturing (Baumol and Bowen 1966). This theory is called as Baoumol's cost disease. Later, Pierre Bourdieu (1984) stated that people's tastes are defined by 'cultural capital', which is formed through 'cultural reproduction'. Likewise, some other researchers also mentioned the relationship between art and society, but many of them considered art to be independent from society and did not discuss its societal impact.

However, recently, art has been the object of intense social focus, mainly stemming from a strong interest in 'creativity' as a way to differentiate one's nation, city, or products from those of others. This interest has risen both from within the economies of advanced consumer societies in an effort to evoke differences in people's tastes and from the escalating competition between nations and cities due to the 'time-space compression' (Harvey 1990, 240) of advancing globalization. For example, Tessa Morris-Suzuki (2004) has indicated that cultural and various social spheres (themselves made of political and economic spheres) are becoming more closely tied together and overlapping. She states that there is an intense emphasis on the differentiation of cultures in the political and economic spheres during this time of globalization. The truth of this assertion is demonstrated by the increased focus on and awareness of the importance of 'soft power', which can be observed in nations' recent cultural policies, such as the Korean Wave Promotion Policy ${ }^{3}$ and the Cool Japan strategy. ${ }^{4}$ Moreover, a strong interest

3 After the Asian currency crisis in 1997, the Korean Government has been embarking on a nationwide effort to strengthen and globally expand cultural industries such as drama and popular music.

4 Since around 2010, the Japanese government has been focusing on expanding creative industries such as anime and fashion overseas and is planning to strengthen overseas public relations and further develop human resources. 
in 'creativity' is reflected in the focus of social actors on creative industries directly, as well as on their influence on other industries (Hartley 2005; Iwabuchi 2007; Nye 2004). Furthermore, as the social focus on creativity continues to increase, creative people (referred to as the 'creative class') are considered the key to invigorating the industry. This 'creative class' includes prominent artists, who form part of the 'super-creative core' (Florida 2002, 4; Florida 2012). Creative talents, then, are considered the definitive source for the stimulation of the economic and political areas of society.

Despite the optimism regarding creativity's role in forming an appealing nation or city and its importance as a source of industry's competitive power, the influence of creative work on the development of human communities has been inadequately discussed. Except for the focus on industrial development, few investigations have been conducted on the actions of the creative class in society and how these actions could cause changes in the community. Moreover, little research has been undertaken on the importance of citizens' creativity for community development. With awareness of this problem, this chapter examines the influence of creativity on the development of communities using the example of Japanese art projects, which frequently include art demonstrating significant civic involvement. This study covers how creative cultural activities contribute to society as a method for facilitating coexistence in an era of personalization, and also indicates its implications and issues. ${ }^{5}$

\section{An Era of Personalization}

As has been noted by Zygmunt Bauman with the term liquid modernity', today, our society is characterized by individualization (Bauman 2000). The same is true of Japanese society within the framework of neoliberal competition in a social structure that is based on the post-Fordist mode of production. For example, this tendency can be seen in Japan in the trend of consuming towards personalization, such as the 'solitary meal', called 'Koshoku' - 'to eat meal alone', and 'personalized electric appliances', called 'Koden', geared towards the individual rather than the family. This tendency can bring us the possibility of choice and 'freedom', and more importantly, different viewpoints, diversity.

However, this personalization trend sometimes also triggers social problems. Yoshinori Hiroi (2009) asserted that, along with the outflow of human resources from rural areas to cities after World War II, the closed

5 This paper used the results of interviews and participant observation conducted in Chiyoda Ward, Tokyo, from April 2010 to January 2015. 
nature of the traditionally strong rural communities was transferred to Japan's cities. This led to the formation of villages within the cities, in the form of companies and the nuclear family. Since the 1970s-1980s, there has been a complete collapse of these villages within the city caused by changes in the structure of industry and the movement of people from place to place during the transition to post-Fordist production styles. Consequently, people have lost their sense of belonging, which in turn has led to individualization. Further, even rural areas that previously featured strong community connections have transformed into urban suburbs due to the blurring of the boundaries between urban and rural areas by transportation networks and technological advancements. Regional towns and cities are gradually facing challenges similar to those faced by larger urban areas. Furthermore, the current social structure of Japan is heading towards the increasing isolation of individuals, spurred in part by the world's most quickly aging and declining population, and the aggressive erosion of urban communities. As society ages, birth rates decline, and the trend towards individualization continues, existing social foundations are in the process of being lost. Although, as Osawa (2008) indicates, people - the base element of communities - want to form relationships with others; they find forming such relationships extremely challenging (Osawa 2008).

Under these circumstances, it is reasonable to predict that communities based on interests and hobbies rooted in shared tastes and cultural values could develop into relatively stable communities. Recently, the advancement of Internet technology has encouraged the formation of communities based on interests and hobbies that extend beyond nations and regions. Examples of such communities are those created on the web by people interested in manga, anime, or game culture. As stated by Bourdieu (1984, 173), 'Taste, the propensity and capacity to appropriate (materially or symbolically) a given class of classified, classifying objects or practices, is the generative formula of life-style', therefore, communities based on shared tastes may develop comparatively close relationships.

Although isolating communities can create stability, excessive exclusion of diversity that extends across nationalities, occupations, religions, and sexualities, can be harmful. As Richard Florida indicates, diversity creates energy and attracts people who possess creativity in abundance (Florida 2002; Florida 2012), thereby stimulating renewed creativity within the community.

Yet, how can individualized and diverse people interact and be interdependent - or, in other words, how can society with diversity be realized? In Japan, interest in community development—known as Machizukuri- has also 
increased since the collapse of the bubble economy in the early 199os. Such community development has spurred interest in the re-formation of relationships among people and has assumed forms such as neighborhood building (Sorensen, Koizumi, and Miyamoto 2008). However, the potential for reforming communities with multicultural relationships has been inadequately examined (Iwabuchi 2007). This argument asserts the importance of the role of art in this realization. This is because art, which evaluates people's 'alternative ideas,' or respects the imaginative power derived from 'different points of view,' is a form of cultural expression based on diversity, and therefore can play a significant role in creating relationships with 'others' in this individualized society.

Art projects in Japan have been flourishing since the 1990s, and particularly since the early 2000s. Initially, they took the shape of biennial or triennial festivals that lasted for limited periods of time. However, many of these events became deeply connected with the communities as their activities developed; gradually, these events and activities began to be organized throughout the year. From approximately 2010, there has been a remarkable trend of year-round events (for example, the activities of the Echigo-Tsumari Art Triennale and the Setouchi Triennale).

Since 2010, '3331 Arts Chiyoda' has also established itself as a permanent art project through various activities involving diverse groups of people. The incentive for establishing 3331 emerged when the Rensei Middle School was closed in 2005. The Chiyoda district government — which had established and managed the middle school-formulated a policy for its reutilization and decided that the closed school, which contained many memories connected to the community, would be utilized for important projects in the Chiyoda Culture and Arts plan. Thereafter, it was decided that the operations would be managed by the Non-Profit Organization (NPO) named 'Command A'. After renovation, the former school was re-opened in 2010 and given the name '3331 Arts Chiyoda'. The name ' 3331 ' stems from the clapping pattern of the traditional Edo Ippon Tejime handclap, used when people want to share their happiness and encourage each other. The former school building houses the central facility, which has a basement, three floors, and a rooftop. In addition to spaces for exhibitions and artist activities, it also contains offices of design companies, shared offices for NPOs and small-scale businesses, commercial art galleries, and small- to medium-size spaces used by businesses to develop activities emphasizing the creation of relationships within the community. 
The initial renovation cost of slightly less than two hundred million Japanese Yen was taken on by the district. While independent financial resources shoulder the burden of slightly less than 50 million Yen, over 9o per cent of the current annual operating expenses of 1.3 hundred million Yen are paid primarily by business revenue, such as income from rent.

3331 conducts cultural activities, such as exhibitions, workshops, and lectures, throughout the year, in addition to art activities that focus on community relationships-both foreign and domestic. An example of these activities is the development of exhibitions via an exchange project with areas not only in Japan but also in other countries (for example, the Artistin-residence program 'AIR3331' and the 'open residence' program, in which visiting artists - while living in the community — conduct creative activities with the help of the community that utilize community resources). In addition, they provide various opportunities to exhibit arts by citizens. Examples of this are, creating spaces for exhibitions of the creative works of a diverse group of citizens, such as one that gathers artwork by both able-bodied citizens and those with disabilities (e.g., the POCORART public exhibition), and the 'independent' exhibition, which is often participated in by people from within and without the community (e.g., Chiyoda Art Festival - an open submission art event). It had as many as 565,000 visitors in 2012 and this number has a tendency to increase annually. The common age group of the visitors is people in their 30 to $40 \mathrm{~s}$ ( $45 \%$ of the all visitors), but there is also a significant number of visitors in their $10 \mathrm{~s}$ to $20 \mathrm{~s}(31 \%)$, and 50 s to $60 \mathrm{~s}(20 \%)$ as well. The female percentage is 60 per cent, and male is 40 per cent. Also, visitors come from various professions, such as company employees (33\%), students $(16 \%)$, community planners and others ( $15 \%)$, artists and others (11\%), designers and others $(9 \%)$, and public servants $(7 \%)$. These visitors are not only from Tokyo (56\%), but also from other parts of the Kanto area (33\%) and the Kinki area (such as Osaka and Kyoto, 4\%), and the Chubu area (such as Nagoya, $3 \%$ ). Some people are from overseas such as China (3331 Arts Chiyoda 2014).

Another important aspect of 3331 is that activities are conducted, in cooperation with the community residents (Figure 4). Many local events and groups are conducted by 3331 including: the community neighborhood association; cooperative activities with the Kanda Matsuri Festival; ${ }^{6}$ a screening of footage from Kanda Matsuri Festival edited by creators from 3331; and mochitsuki ('rice cake pounding') events for the local residents. In addition, an organic

6 The Kanda Matsuri Festival is the festival of the Kanda Myojin Shrine, and has a history of more than 400 years. It is known as one of three major festivals in Japan along with Tenjin Matsuri Festival held in Osaka, and Gion Matsuri Festival held in Kyoto. 
Figure 7.4 The 3331 Arts Chiyoda, 'Kirigami workshop'

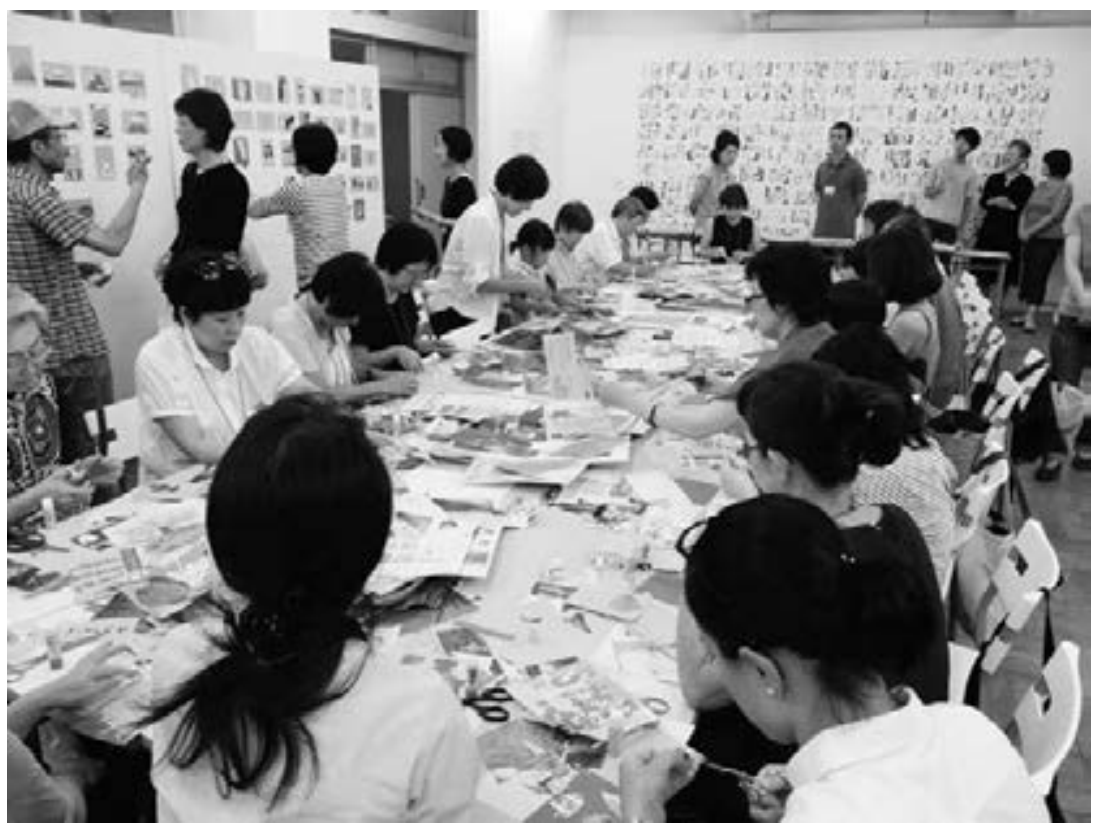

Source: courtesy of 3331 Arts Chiyoda, Tokyo

vegetable garden has been opened on the facility's roof, and it is also the site of reunions by the elderly. All of these cultural and social activities involve the participation and cooperation of diverse groups of neighbouring people of all ages. A cafe and an izakaya ('tavern') are also situated in 3331 which further raise the potential for social interaction. A space has also been established in the complex that can be used by anyone without charge to encourage social activities. 3331 is more than a place where citizens are involved in the exhibition and appreciation of art; it is also a place for the development of diverse activities involving the participation of local citizens (Favell 2011).

\section{Effects of Art Projects in Urban Communities}

What do community-based art projects accomplish? Firstly, art projects are significant because they provide cultural experiences for the citizens. Experiencing art in familiar places, such as closed schools and factories that previously formed communities' centers, has a greater mass appeal than the top-down approach followed in Japanese public museums. As 
Hideharu Matsumiya $(2003,267)$ has indicated, public museums in Japan have tended to superficially imitate the Western system. As a result, the scope of the term 'public' institution is limited; it does not mean that the institution is serving the public, but rather that it has been provided by the government. Matsumiya argues that these museums are filled with works of art that inspire feelings of 'awe' similar to religious sentiments, instead of providing more general public engagement. In contrast, art projects are significant because they are related to a community's cultural resources and provide a novel perspective on the community to people both inside and outside the community. Furthermore, art projects are also meaningful because they provide opportunities for many young artists to associate with one another, and they nurture the next generation's creativity (Koizumi 2012).

Moreover, art projects are now places that many local citizens casually visit frequently. As a result of their activities, 3331 has become a place where various people spend their time, either visiting or participating. The interviews conducted as part of this study and the quantitative survey conducted by an external think tank both show this tendency. For instance, one of the 3331 visitors who is in her 3o's said: 'I live nearby, so I can just drop in. I look forward to my holidays now'. Her comment indicates that 3331 has become a community hub where people can come and go in a casual manner. Also of importance is that this project is linking with local community memories. A man in his 40's said: 'I am a graduate of the [closed] junior high school. I was really happy to see that it is being re-used - not just as a museum but also in such different ways. Thank you so much for using it and not destroying it'. 3331 is intentionally retaining and using the old facilities of the school. This project provides the place where cultural resources are connected to community memories and are starting to function as new places for people to visit in addition to their workplace or home.

Ray Oldenburg $(1989,16)$ once stated that Americans are losing their informal public lives; therefore, having a 'third place' that is neither home (the first place) nor the workplace (the second place) and that serves as 'the great good place' is essential for community development and invigoration. The Japanese translation version of his book cover used the picture of the Izakaya ('tavern') as the 'third place'. The picture described the scene where people comingle in the street in front of the Izakaya shop. Certainly, they were a good example of a Japanese third place at that time. However, since the 1980 s, an increasing number of Izakaya chains characterized by separated or individual seats, and also sometimes situated in shopping malls, have begun to appear in the country, and the former third place-type Izakaya has been 
in decline. Also, people gathering in the shopping arcade like during the 1980 s has been restricted recently. Machimura (2017) used the example of Japanese shopping streets to point out the recent development of managed pseudo-public spaces from a social engineering viewpoint. He compared the degree of comfort of clean, safe mall-style spaces that are more privatized and controlled to that of conventional public shopping street-style spaces. He argued that in the recent mall-style spaces, the somewhat neglected spaces that generate a variety of 'noise' (present in the shopping street-style spaces) were excluded. Thus, the loss of informal public lives is a noticeable trend in Japan as well, where communities are becoming more isolated. It is therefore important for residents to have a place that they can aimlessly frequent.

More importantly, art projects constitute a setting that encourages people to create new cultural and social activities. As previously mentioned, various points of entry to art projects have been provided for different types of lifestyles. This feature makes art projects places where people from different locations and occupations can come to appreciate art, participate in workshops and events, in addition to simply visiting without any specific purpose (Figure 5).

Let us consider the example of the functions of 3331's 'Commissioned Artists' in activities performed in cooperation with local residents. These artists have become incorporated into the local community and are working on art exchanges with community members, workers, and visitors. One such project is the Asatte Asagao Project, in which artists and community citizens collaborate to cultivate Japanese morning glory plants. The principal aims of this project are as follows: (a) to 'foster communication among people, communication between people and the community and communication among different communities, and strengthen the relationship between people and the community in modern society;' and (b) to 'evaluate the diversity and functionality of art in society by taking the forms derived from

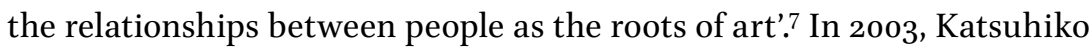
Hibino launched this project during the Echigo-Tsumari Art Triennale; as of 2013, 25 communities, including 3331, were participating in it. Notably, beyond solely the activity of the artist, this project has resulted in cooperation among people who would not otherwise have had the opportunity to meet each other and collaborate; such as community citizens, the 3331 staff, and elementary school students. These people from different communities are able to exchange their feelings using visual and performing arts through

7 'Asatte Asagao Project,' Day After Tomorrow Newspaper Cultural Department, http://www. asatte.jp/asatteasagaoproject/about.html. 2015, translation by author. 
Figure 7.5 The 3331 Arts Chiyoda, 'Free Space'

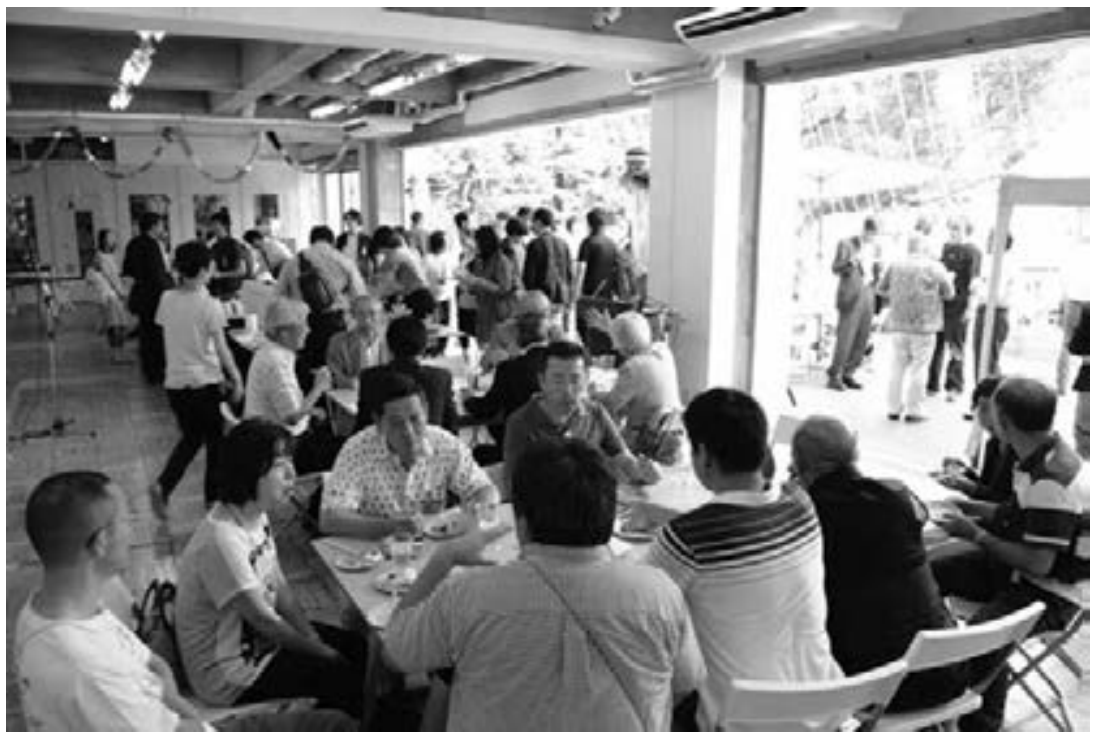

Source: courtesy of 3331 Arts Chiyoda, Tokyo

the project, in addition to directly exchanging their opinions through conversations concerning Japanese morning glory seeds and seedlings at the exchange meetings.

In addition, inspired by these activities, participation in projects at 3331 provide a new opportunity for local community council meetings, which have become somewhat routine and uninspired. For example, at the neighborhood association's New Year's party (itself significant in the formation of Japanese communities), the art projects with the local community from the preceding year are reviewed with newcomers to 3331's activities. It becomes part of the enjoyment, as people excitedly discuss the upcoming New Year while looking back over the preceding year. In the case of 3331's citizen projects, this result occurred from the simple task of working with others using day to day knowledge, such as the cultivation of Japanese morning glory plants. It is simple and relatively familiar situations for citizens like these that allow for the continuous maintenance (primarily by local citizens) of a place where people can interact with each other as well as form new connections. Besides 3331, examples of civic activities conducted through the collaboration between people's day to day knowledge and art activities can be observed in other art projects, such as the Echigo-Tsumari Art Triennale (Koizumi 2010; Koizumi 2012). 
From the community development perspective, art projects are in the process of becoming co-created civic spaces. Mike Douglass, K.C. Ho, and Giok Ling Ooi defined civic spaces as 'those spaces in which people of different origins and walks of life can mingle without overt control by government, commercial or other private interests or de facto dominance by one group over another' $(2008,5)$. They defined the term 'civic spaces' from terms with similar meaning such as 'public space' as managed and administered primarily by the government (or the private sector in cases of coffee shops and pubs), and 'civic society space' that which entails a broader definition. That is, 'civic space' especially refers to a social and spacious place wherein people can interact while maintaining a definite distance from specific power relationships. Today, art projects function as a new type of civic space and provide opportunities for cooperative activities. They stimulate important social connections between diverse groups of people and occasionally provide opportunities to undertake other activities. In other words, they can be seen as 'civic spaces that accompany co-creation'.

There is an insufficient number of civic spaces for democratic cultural practices in Modern Japan (Mōri 2009). For example, as Douglass, Ho, and Ooi (2008) indicated, during the bubble economy in the latter half of the 1980s, bathhouses - which were previously important civic spaces in Japan - became the targets of land developers and were subsequently commercialized. Also, between the 2000s and the 2010s, spaces for people's expression has also been limited; encompassing such areas as Miyashita Park in Shibuya City, which has essentially become the fee-accessed 'Nike Park' surrounded by fencing, Ikebukuro Nishiguchi Park, where art was used to drive off unlicensed performers, and Yoyogi Park, where there has been a severe crackdown on raves and other free parties. For these reasons, new civic spaces such as 3331-in which people can visit and escape from strong authority and interference without needing to be a member-are important for forming relationships and offering opportunities and activities that can trigger cultural and social interaction.

In civic spaces that are open to all, what can be done to connect people without using forced rules? The important thing is, art serves as a platform where people may 'inadvertently' collaborate. At art projects, the interactions among people through art and activities are not a form of pre-planned harmony. Rather, dramatic changes gradually occur as activities progress or members encounter each other (or share their thoughts or art). Cooperation frequently becomes necessary during a project; new members are added to the project by simply asking people to help out. This mechanism can result in 
chance encounters. This type of accidental co-creation (which is unexpected even by the artists) is accomplished through different artistic activities.

Certainly, there are limits to this line of reasoning: not all people involved with or mediating at art projects are active participants. However, the act of going to 3331's garden to meet others, or to the free space or smoking area to relax, helps create relationships among people and provides opportunities to create more relationships. These acts facilitate the exchange of opinions among people with the art project as a catalyst, and these encounters may prompt further interactions. Irrespective of whether participation is active or passive, permitting diverse viewpoints on activities is important for art projects to be able to function as a co-created civic space.

\section{$6 \quad$ Implications of Art Projects}

What are the implications of art projects for developing communities? Further, what are the important factors that enable artists and people in the community to co-create a space? This section presents two reasons why the art developed at these community-based art projects facilitates the formation of relationships among people in urban communities.

First, art projects serve as a place connecting the artists with people within and outside the community. Florida $(2002 ; 2012)$ noted that everyone has the potential for creativity but argued that people of the creative class are especially situated at the center of development. Moreover, he posited that the key to creating an energetic, attractive town lies not in attracting businesses but in providing an environment that attracts diverse human resources, particularly the creative class. However, he argued this in relation to the importance of creative talents particularly for economic growth. Conversely, from the viewpoint of social formation, art projects suggest the importance of places where artists can meet and connect with diverse citizens, to encourage community revitalization. Such places are essential for allowing artists to manifest their strengths in the community. Even if there are artists adept in community focused art, there is nowhere for them to connect with the people (e.g., a place that appropriately provides contact with society), their creativity cannot be fully manifested in society and they are unable to encourage people's creative potential for community development.

As noted by Sarah Thornton (2008), art has generally been composed and produced by the social systems associated with art, including auction houses, art markets, art schools, and media such as art magazines. Accordingly, the places concerned with art were developed within the small incubator 
of art-related social systems. The community-based art projects that are currently flourishing have departed from this incubator and garnered significance as places concerned with art that are making their way to everyday civil society. The supervising director of 3331 and artist Masato Nakamura has stated the following: 'When one goes to a modern art museum, there is a feeling that there is only one acceptable standard [...] but art projects have the feeling of having diverse possibilities [...]. "3331 Arts Chiyoda" itself can have the awareness of being a project because it has taken on varied senses of values' (Kumakura, Kikutchi, and Nagatsu 2014, 212, my translation). Thus, art projects are different from the existing places related to art, such as modern art museums: they are starting to function as places that attract diverse groups of people with different standards of value and where artists can work through a type of trial-and-error method. Here, the artists' role is like a 'social designer' or 'community curator' not only creating works of art, but also 'inadvertently' creating the relationship between people and community.

In addition, related to this, from the point of view of cultural policy, the example of 3331 shows the importance of having a vision for future culture creation. Initially, 3331's initiatives-which are centered on experimental areas of contemporary art- did not appear to significantly contribute direct (particularly economic) benefits to the community when considering the expenditures for subsidizing the project. However, this initiative has been designated one of two high priority projects in the Chiyoda district to predict the positive influence of this type of project. This is because the Chiyoda local government considered the importance of the artists and the local citizens' creativities for the coming generations in addition to focusing on traditional cultures. This attitude towards future culture creation is significant for cultural policies in any period, including Japan's current rapidly ageing society. When confronted with the decline of local cultures, governments tend to prioritize cultural preservation and protection. A typical example is the preservation of precious local cultures such as local 'chosen' cultures in museums. However, when confronted with vanishing local cultures, simply preserving and protecting them is not adequate, because these activities can turn into a requiem for a living culture.

Also, from an art management perspective, it shows the importance of public-private partnerships including those involving artists or curators, in the form of sharing opinions regarding the management and organization of the project in its early stages. The administrative manager of 3331 and artist Koichi Sasaki has stated: 'Being able to collaborate in this way before the local government decides on a single plan is very beneficial for us. The architects and people from the Ministry of Land, Infrastructure, Transport 
and Tourism said that it would receive a failing grade architecturally, but this place could also be called an example of success as a place for artists and the people who use it' (Koichi Sasaki, interview by author, 12 January 2015). In the case of 3331, it is significant that 'Command N' (an organization primarily led by artists) was involved in the construction from the start: the administrators who would be responsible for 3331's activities were able to help design the space from a user perspective. Demands for a similar partnership are frequently heard on the sites of other art projects as well. To help artists perform to the best of their potential as 'social designers' or 'community curators', we have to create an environment able to accommodate the active initiatives of the artists.

\section{$7 \quad$ Issues Related to Art Projects}

On the other hand, it is important to give sufficient attention to the inherent challenges of building a place for co-creation. This is because, although in the case of 3331, not a great amount of open political and economic intervention occurs in the civic space of co-creation, art projects are connected to various social authorities.

The historian and cultural anthropologist James Clifford $(1997,192)$ has indicated that museums are 'contact zones' constructed from historic, political, and ethical relationships and using the organizational structure of the collections as their intermediaries. The concept of contact zones was originally proposed by Mary Louise Pratt $(1992,7)$, who defined it as 'an attempt to invoke the spatial and temporal co-presence of subjects previously separated by geographic and historical disjunctures, and whose trajectories now intersect'. Pratt used this term in her arguments on how the asymmetrical relationships between non-colonial areas and colonies were intertwined during the mid-eighteenth century, when the European imperial order was established. Clifford (1997) adopted Pratt's awareness of these issues and applied them to museums. He indicated that many museums are situated in metropolitan cities, and they often diligently rescue, store, and interpret objects that originate from peripheral areas. In this way, they exist on the overlapping historical, political, and moral relationships exchanged. Museums are located in the relationship between colonization and decolonization, between nation formation and minority assertions, capitalist market expansion and consumer strategies.

Of course, this social structure of powers can be seen not only in museums but in all social organizations. However, Clifford's assertion can be 
considered to be critical since he questioned the strong power structure of museums as they confront 'others' and exclude the 'inauthentic'. He proposed that this would not be 'a democratic politics that would challenge the hierarchical valuing of different places of crossing' (Clifford 1997, 214).

In light of these theories, it is appropriate to call art projects 'true contact zones' (Koizumi 2012). The artistic activities in these projects are calm on the surface, but even if they seem to be at ease, there is a mixture of historical, political, and moral influences that underlie them. The social art project must be planned and developed among the mixing and polarities of various external power relationships. These relationships involve economic and political participation by different social actors, such as the administration, supporting businesses, and support groups. The art project also includes the power relationships of participants that the art projects are involved in, brought about by the differences between occupations, residential areas, residential history, and family structures.

Considering this perspective, we should be cautious of the overemphasis on art projects being used for specific social goals, such as revitalization of local industries, cultural tourism, or the enhancement of national interest. In the recent post-fordist society, perspectives on how to use cultural areas for creating differences from other social actors have gained strength (Iwabuchi 2007; Morris-Suzuki 2004; Mōri 2014). According to George Yúdice (2003), nations, businesses, and even Non-Governmental Organizations (NGOs) have tended to inconsiderately utilize various cultures for their expediency. As globalization progresses, culture is used more as a socio-political or economic resource by social actors as well as the state, who place its usefulness to their causes at the center of attention. Yúdice $(2003,9)$ termed this 'the expediency of culture'. Because of the closer relationship between these cultural and social areas in the current age, there is a risk that art projects will become excessively geared towards a specific purpose. This causes 'unsuitable' people and things (for example, art and people that at first glance are considered unnecessary for the reinvigoration of communities) to be eliminated from art projects. This causes the diversity included within art projects-and consequently its use as a civil space - to decrease. Koichi Sasaki of $333^{1}$ stated the following: 'There are times when opinions of the government district surface [regarding the activities at 3331]. Opinions like "this is too much stimulus for children." With regards to the first period [of the five-year operating contract for the building], it was tentative, so we do not know if there will be a second term. If we have confrontations with the district, we must tread carefully' (interview by author, 12 January 2015). This quotation partially illustrates the difficulty in forming a balanced relationship with 
other social groups in the operation of community-based art projects, which focus on activities rooted in the diversity of the citizens. In other words, art projects are facing a situation in which they must consider the views of, and avoid things that will be rejected by the local government and community. This has occurred at 3331 and is a latent possibility in any art project.

Crucially, art projects have meaning because community development is occurring alongside the diverse and disjointed subjectivity that exists within art projects. A group of strangers can participate actively or casually and transcend the differences in their viewpoints. Art focused on creativity in community-based art projects exists to set up a place that encourages this type of diversity. However, what would happen if the artistic activities of art projects were restricted and some activities and people were excluded? This would make them merely communities supported by similar tastes. Art projects have meaning because they can encompass various walks of life (including those who do not have a direct interest in cultivating Japanese morning glory plants, for example) and enable them to participate in or casually observe activities. This diversity is connected to the forming of new communities from individualized societies. Therefore, it is important to be conscious of the expediency of culture, and also of the asymmetrical powers from the outside (such as nations, businesses, NGOs, and even artists and participants) in art projects that encourage community relations.

\section{Moving Towards Community-based Art Projects of Co-creation}

This paper has discussed observations on art projects that have proliferated in recent years and their effects on the surrounding urban communities. First, using the example of ' 3331 Arts Chiyoda' in Tokyo, some features of art projects have been identified. Art projects can use art for co-creating civic spaces that make connections between people amidst the personalization observed in today's society. Art projects have become a place visited by diverse people, and they help these people connect incidentally through artistic activities. Occasionally, art projects have also 'inadvertently' facilitated the creation of new cultural activities and the development of social activities. Thus, they are new places where artists and citizens can form new creations together. The emphasis on future culture creation and systems to help artists perform to the best of their potential for revitalizing community is significant, even with the rapid ageing of society and its tendency towards the preservation of old traditions. 
Nonetheless, art projects face certain challenges. They are always surrounded by social actors; and if art projects cater too much to the demands of any particular social actor, the democratic nature of their activities might be hindered. This study's primary purpose is not to form judgments or condemn the control exercised by the government and various social authorities. Social actors, such as the government and commercial enterprises, are not monolithic organizations, and the people who visit art projects are not subservient slaves who will blindly follow all instructions. This study also does not advocate for the excessive separation of art from society. However, it should still be emphasized that art projects constitute places where the diverse and disjointed subjectivities of the participants are connected through artistic activities. It is significant to avoid losing this diversity by being vigilant against any alterations to the function of art projects because of the agenda of any social actor (nations, businesses, NGOs, artists, and participants). Such an alteration would result in the loss of the inherent meaning conveyed by art projects, and people would lose one important opportunity to reform important social foundations in their communities where an isolated lifestyle is becoming more common.

Community-based art projects are places of co-creation, where the subjective opinions of a diverse group of people 'intersect'. The activities conducted by artists can bridge the gap of an individualized society. In order to realise 'cities by and for the people', the focus must be shifted to the creativity that contributes to community development, and the significance of the interaction of diverse groups of people.

\section{Acknowledgments}

This work was supported by Japan Society for the Promotion of Science (JSPS) KAKENHI Grant Numbers 24730419, 15K21169.

\section{Works Cited}

Adorno, Theodor W. and Max Horkheimer. 1944. Dialectic of Enlightenment. Translated by John Cumming. New York: Herder and Herder.

Bauman, Zygmunt. 2000. Liquid Modernity. Cambridge: Polity.

Baumol, William J. and William G. Bowen. 1966. Performing Arts, the Economic Dilemma: A Study of Problems Common to Theater Opera, Music and Dance. New York: Twentieth Century Fund. 
Benjamin, Walter. 1936. Das Kunstwerk im Zeitalter Seiner Technischen Reproduzierbarkeit. Berlin: Suhrkamp Verlag.

Bishop, Claire. 2006. 'The Social Turn: Collaboration and Its Discontents'. Artforum International 44(6): 179-85.

Bourdieu, Pierre. 1984. La Distinction. Translated by Richard Nice. Cambridge: Massachusetts.

Bourriaud, Nicolas. 2002. L'esthétique relationnelle. Translated by Simon Pleasance and Fronza Woods. Dijon: les presses du réel.

Clifford, James. 1997. Routes. Cambridge, MA: Harvard University Press.

Douglass, Mike, K. C. Ho, and Giok Ling Ooi. 2002. 'Civic Spaces, Globalisation and Pacific Asia Cities'. International Development Planning Review 24(4): 345-61.

Douglass, Mike, K. C. Ho, and Giok Ling Ooi, ed. 2008. Globalization, the City and Civil Society in Pacific Asia. New York: Routledge.

Favell, Adrian. 2011. Before and After Superflat: A Short History ofJapanese Contemporary Art, 1990-2011. Hong Kong: Blue Kingfisher.

Florida, Richard. 2002. The Rise of the Creative Class. New York: Basic Books.

Florida, Richard. 2012. The Rise of the Creative Class: Revisited. New York: Basic Books.

Foster, Hal. 2008. '(Dis)engaged Art'. In Right about Now: Art and Theory Since the 199os, edited by Margriet Schavemaker and Mischa Rakier, 73-85. Amsterdam: Valiz.

Hartley, John, ed. 2005. Creative Industries. Oxford: Wiley-Blackwell.

Harvey, David. 1990. The Condition of Postmodernity: An Enquiry into the Origins of Cultural Change. Cambridge, MA: Wiley-Blackwell.

Hiroi, Yoshinori. 2009. Komyuniti o toinaosu: Tsunagari, toshi, Nihon shakai no mirai. Tokyo: Suiyosha.

Iwabuchi, Koichi. 2007. Bunka no Taiwaryoku: Sofuto pawa to burando nashonarizumu o koete. Tokyo: Nikkei.

Kester, Grant. 2004. Conversation Pieces. Berkeley, CA: University of California Press. Koizumi, Motohiro. 2010. 'Who Creates Arts?' Annual Review of Sociology 23:35-46. Koizumi, Motohiro. 2012. 'Is “Art Project" Necessary in the Local Community?' Journal of the Faculty of Regional Sciences 9(2): 77-93.

Kumakura, S., T. Kikuchi, and I.Y. Nagatsu. 2014. Art Project. Tokyo: Suiyosha.

Machimura, Takashi. 2017. "Noise' Creates Complexity and Sociability: Shopping Streets as an Imperfect but Livable Public Space in the Era of 'Space Wars'.' The Annual Review of Sociology 30: 3-15.

Matsumiya, Hideharu. 2003. Museum no Shisou. Tokyo: Hakusuisha.

Morris-Suzuki, Tessa. 2004. 'Globalisation and the New Cultural Economy'. In Gurobarizeshon no bunka seiji, edited by Tessa Morris-Suzuki and Shunya Yoshimi, 86-117. Tokyo: Heibonsha. 
Mōri, Yoshitaka. 2009. Sutoriito no Shiso: Tenkanki to shite no 1990 nendai. [Street

Thought: The 199os as Turning Point]. Tokyo: NHK Publishing.

Mōri, Yoshitaka. 2014. Hihyouteki Crieitibu-sangyouron-e. Tokyo: Serika Shobo.

Nye, Joseph S. 2004. Soft Power: The Means to Success in World Politics. Cambridge,

MA: Perseus Books Group.

Oldenburg, Ray. 1989. The Great Good Place. New York: Paragon Books.

Osawa, Masachi. 2008. Fukanousei no Jidai. Tokyo: Iwanami Shoten.

Pratt, Mary Louise. 1992. Imperial Eyes: Travel Writing and Transculturation. London: Routledge.

Rancière, Jacques. 2004. Malaise dans l'esthetique. Paris: Galilée.

Rancière, Jacques. 2008. Le spectateur émancipé. Paris: La Fabrique.

Sorensen, Andre, Hideki Koizumi, and Ai Miyamoto. 2008. 'Machizukuri, Civil

Society, and Community Space in Japan'. In The Politics of Civic Space in Asia:

Building Urban Communities, edited by Amrita Daniere and Mike Douglass, 33-50. London: Routledge.

Thornton, Sarah. 2008. Seven Days in Art World. London: Granta Books.

Williams, Raymond. 1966. Communications. Harmondsworth: Penguins book.

Yúdice, George. 2003. The Expediency of Culture: Uses of Culture in the Global Era.

Durham: Duke University Press.

3331 Arts Chiyoda. 2014.3331 Arts Chiyoda Annual Report 2013. Tokyo: Arts Chiyoda.

\section{About the author}

Motohiro Koizumi is Associate Professor of art and sociology at Rikkyo University, Tokyo, Japan. He received his B.A. from the International Christian University (ICU) and his M.A. in music and Ph.D. in sociology from Tokyo University of the Arts in 2009. He was a Research Fellow of the Japan Society for the Promotion of Science (JSPS, 2008-2011); a Research Fellow at the Centre for Transnational Art, Identity and Nation (TrAIN) at the University of the Arts London (2009-2010); a Research Fellow at CLIC-ON (Cooperation toward Leadership in Innovative Creation - Open-innovation Network) of Osaka University (2011-present); a Researcher at Birkbeck, University of London (2011); and an Associate Professor in cultural policy at Tottori University (2011-2016). Koizumi is also actively engaged in teaching courses in music management at the International Christian University (2013-present). 


\title{
8 Activating Alternatives in Public Market Trade
}

The Resilience of Urban Fresh Food Provisioning in Baguio, the Philippines

B. Lynne Milgram

\begin{abstract}
Throughout the Global South, governments have responded to rapid urban growth by embracing visions of 'modernity' that favour constructing large-scale infrastructure projects (e.g., supermarkets) while discouraging or even destroying what they view as the remnants of 'traditional' entrepreneurial trade (e.g., public marketplaces). Such policies disrupt long-standing livelihoods and provisioning networks on which urbanites have depended for decades. This chapter engages this issue by using the retail vegetable trade in the Baguio City Public Market (BCPM) in the northern Philippines, to argue that marketers innovatively combine public 'advocacy' and under-the-radar 'everyday' politics to sustain the diversity of their urban livelihood options despite the development challenges they face. To protest the Baguio government's 1995 privatization of the public market, marketers launched civil lawsuits and appeals that continue to thwart municipal action today. Given delays in court decisions, marketers simultaneously operationalize social capital networks and everyday politics of 'gray spacing' to achieve short-term gains that secure their enterprises (e.g., expanding displays into market aisles). That BCPM officials allow merchants to pay rent for such market guideline infractions highlights governments' complicity in formalizing informal and illegal practices as urban organizing logics when it is to their advantage. Although Baguio's supermarket sector is expanding, public marketers have developed a complementary rather than singularly competitive relationship with supermarket venues. I argue that BCPM retailers' advocacy materializes how civic engagement
\end{abstract}

Cabannes, Yves, Douglass, Michael and Padawangi, Rita, Cities in Asia by and for the People. Amsterdam: Amsterdam University Press, 2018 DOI 10.5117/9789462985223/CHO8 
can be effectively negotiated when competing ideologies clash over livelihood rights, and how to structure the quality of urban life for and by its residents.

Keywords: the Philippines, public markets, vegetable commodity flows, everyday politics, urbanization

Building upon their historic roles as household financial managers and the country's foremost public market traders, Filipino women continue to be the main fresh produce retailers and wholesalers in the country - the work sector in which women tend to predominate throughout Southeast Asia (Chant 1996; Lloyd-Evans 2008). In Baguio, the Philippines, for example, 58-year-old Evelyn de Leon, ${ }^{1}$ who has two years of college education, has been operating her public market vegetable business for twelve years after inheriting the lease of the store from her parents. Evelyn sells fresh local upland Baguio vegetables (e.g., broccoli, cauliflower, carrots, cabbage, green beans, and potatoes) in the Vegetable Section of the Baguio City Public Market (BCPM). Since 1995, when the Baguio government announced its plan to redevelop or 'modernize' the public market, Evelyn and other small-scale marketers have felt uncertain about the future viability of their businesses - an insecurity augmented by the recent proliferation of newly constructed supermarkets. In response to both of these developments, Evelyn has diversified her business by offering specially sourced products that appeal to a rising middle class looking to experiment with different cooking ingredients and to city residents' general concerns about food safety. Evelyn's new products include bean sprouts, ginger, sweet peas, basil, shiitake mushrooms, and tofu - the latter product made by her sister and delivered fresh to the store each morning. As Evelyn explains, 'Currently, only two Baguio public market retailers in my section sell this specific mix of vegetables which are combined for particular Filipino dishes. By always topping up my display with fresh produce, customers can see I ensure the high quality of my goods' (interviews by author, 13 May 2014, 5 February 2015) (see Figure 2).

Urban public marketplaces that host dynamic businesses such as that of Evelyn de Leon are bustling constellations of economic, social, and political 
Figure 8.1 Maps of (a) the Philippines, (b) Baguio City, (c) Central Business District and (d) Baguio City Public Market
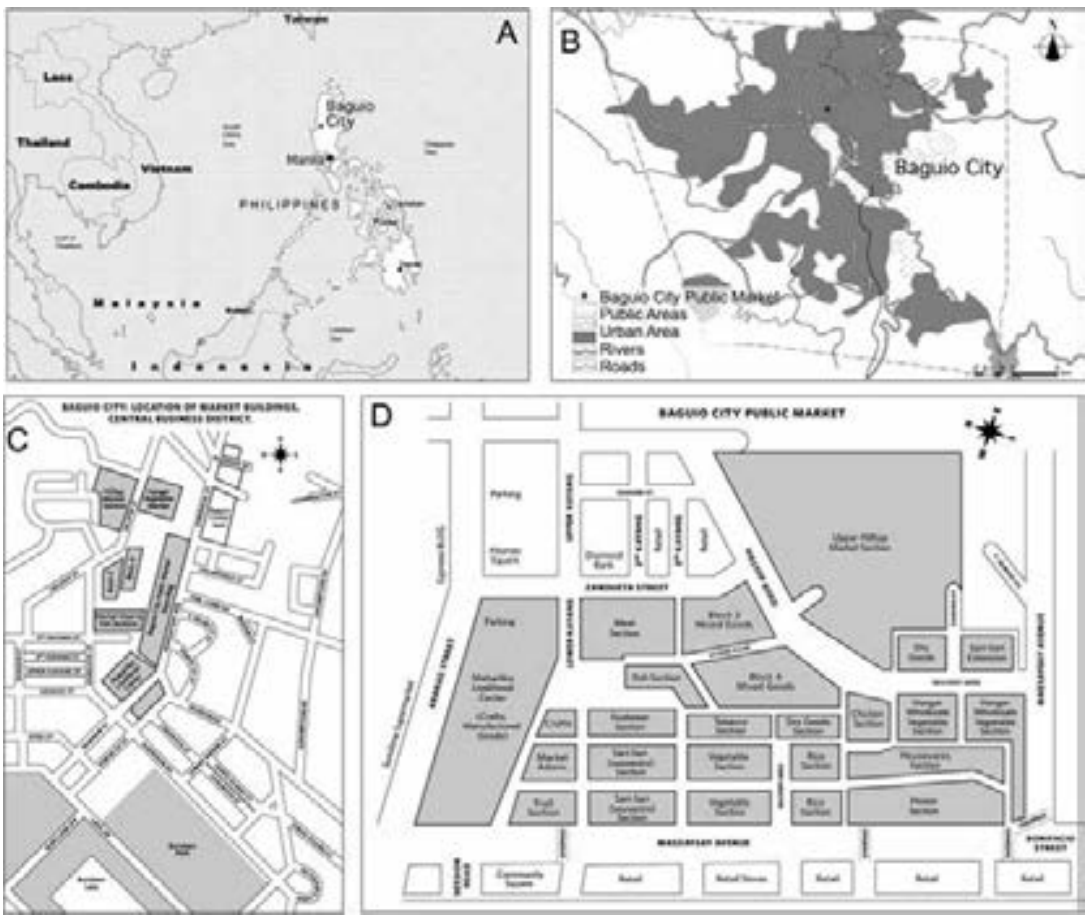

Source: Ariel Shepherd (a, b), author (c, d)

life. Throughout the Global South, however, the explosive growth of cities has prompted local and national governments to embrace visions of 'modernity' and development that favour the construction of large-scale infrastructure projects (e.g., shopping malls) while discouraging or even destroying what governments view as the 'traditional' remnants of entrepreneurial trade, such as public marketplaces, ad hoc stalls, and street vending (Douglass, Ho, and Ooi 2008, 17; see also Cohen 2004; Dannhaeuser 1997; Matjeowsky 2000 and 2008; Perera and Tang 2013). Such market modernization projects limit the livelihood opportunities available to small-to-medium size businesses and the consumption options accessible to city residents. As a result, one might expect the demise of the so-called 'traditional' fresh food provisioning networks and their replacement by those linked to more capital-intensive operations. Yet, my ongoing research on the redevelopment of the Baguio City Public Market in the northern Philippines suggests otherwise.

Long-standing provisioning sites such as the Baguio City Public Market are, in fact, thriving. Here, fresh produce marketers working in retail and 
Figure 8.2 A Baguio City Public Market retailer selling upland Baguio vegetables

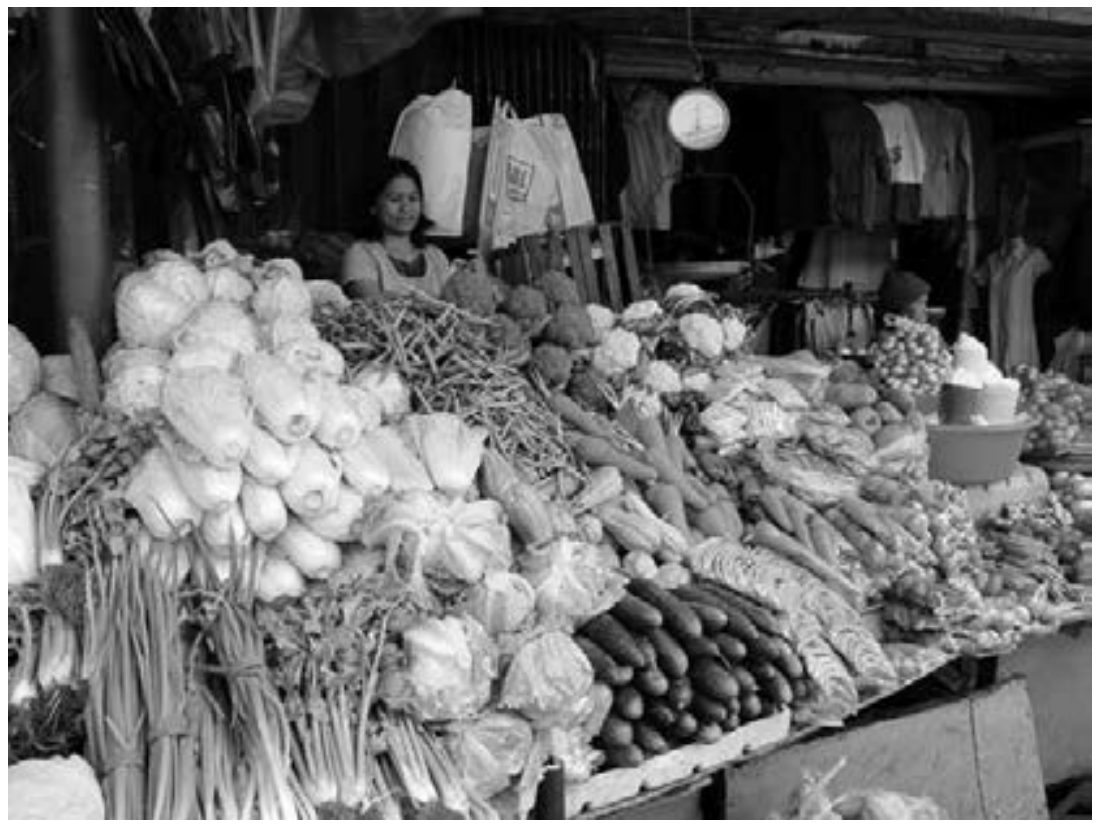

Source: author

wholesale businesses (e.g., fruits and vegetables) refashion practices to meet the demands of peri-urban farmers, on the one hand, and the changing consumption needs of urbanites, on the other. Tracing the channels through which merchants such as Evelyn navigate the shifting dynamics of their trade highlights the finely tuned trading-scape marketers activate to challenge the government's framing of their enterprises as 'pre-modern' and 'inefficient' (Milgram 2011, 262; see also Clark 1994; Seligmann 2004; Solomon 2006).

This chapter engages these issues by analyzing the mainstream channels and edgy side roads through which Baguio's public market retail vegetable sellers - of both upland and lowland products — sustain their provisioning livelihoods despite the city government's policies that have repeatedly threatened their businesses' viability. I argue that within a contested context that privileges the 'city beautiful' (Brown 2006, 3), vegetable retailers innovatively use 'everyday politics' (e.g., negotiating individual rental agreements, offering bribes, and expanding store premises into market aisles) (Kerkvliet 2009,227 ) to maintain the commodity chains and personalized networks they have used for decades to supply city residents with fresh produce. Vegetable retailers, for example, create new interstitial economic spaces within old ones by consigning produce to mobile vendors. They diversify 
their enterprises by sleuthing out unique products, and they expand their social capital by fostering individualized ties with farmers, wholesalers, porters, and customers. Indeed, to encourage shoppers' loyalty, some public market retailers develop initiatives that transform food provisioning - a daily activity—into a memorable encounter (e.g., sampling new types of produce). Creating such in-between or 'gray spaces' (Yiftachel 2012, 24) within which they can supply special shopping experiences, vegetable retailers market their enterprises through what Joseph Pine and James Gilmore $(1998,97)$ term the 'experience economy'.

Baguio City Public Market retailers explain that they ultimately have had little choice but to engage in such everyday politics. In 1995, the municipal government awarded the market redevelopment contract to a private, Manila-based shopping mall developer (Baguio Midland Courier 1995, 8). Marketers immediately challenged this outsourced initiative by launching a series of civil lawsuits and appeals that continue, over twenty years later, to thwart city action (Agoot 2009, B26-27, B52; Borja 2010, 1, 13; Caluza 2013; Castro 2009, 1, 22; Refuerzo 2009, 1, 43). Baguio City councillors frustrated with delays to their development agenda increasingly launch market cleanup exercises and more stringently enforce minor trade infractions, both of which can constrain marketers' businesses (Fontanilla 2014, 2, 4). At the same time, and particularly since 2000, small-to-medium size supermarkets, as well as the large-scale shopping mall Shoe Mart (SM) Baguio City, have been constructed across the city, each offering residents multiple food shopping options.

Such city government and private development initiatives, however, do not mean that public market vegetable retailers necessarily lose out to new market players or to government constraints. Rather, customers variably shop in both locales, depending upon their immediate needs, loyalty, and convenience. I suggest that, by maintaining important social capital and the type of hands-on food access ordinary urbanites across all classes still seek, Baguio vegetable marketers' practices engage with and challenge the 'unreal reality of the modern city' to materialize a diverse 'cityness' by, and more relevant to, urban residents (Robinson 2006, 10).

To conceptually situate the shifting trajectories of trade within the Baguio City Public Market, I first review studies arguing that how governments choose to frame their city's identity has important implications for the sustainability of diverse urban livelihoods. I then explore the concepts and practices of social capital and everyday politics, subsequently demonstrating the extent to which retail vegetable marketers can operationalize these 
actions to secure their food provisioning systems despite the development challenges they face.

With growing urbanization in Global South cities and the unpredictability of global financial markets, municipal governments have privileged development projects designed to enhance their city's public cultural and economic positioning - its world-class status - rather than implementing livelihood options that address the everyday subsistence needs of most urbanites (Brenner, Marcuse, and Mayer 2012; Douglass, Ho, and Ooi 2008; Perera and Tang 2013). Such a development agenda-clearly evident in Baguio's aim to become the regional industry, education, and tourist centre-has had devastating consequences for low- to middle-income residents in terms of equality in service access and provision and the redistribution of goods (Douglass 1998, 111). Rather than governments imposing a vision of 'cityness' in which one aspect represents an entire urban identity (e.g., sports stadiums, communication towers), Jennifer Robinson $(2006,10)$ encourages policies to adopt an 'ordinary city' perspective - an approach that 'considers the city as a whole in all its diversity and complexity'. Such a perspective implies a stronger, locally-oriented 'reterritorialization' of the individual city or city-region rather than an outward-looking emphasis that gauges global status- the degree to which a city is immersed in transnational flows (Robinson 2006, 10).

By considering all cities as 'coeval' - as existing in the same time, rather than along a developing-developed continuum - we can more integrally understand the diversity of city economies and thereby effectively respond to urbanites' on-the-ground subsistence needs (Robinson 2006, 85; Douglass and Daniere 2009). Work such as street vending or public market trade, rather than indicating activities of 'underdevelopment', provide evidence of how sellers use proximity to foster relations of trust between individuals and organizations in economic interactions and thus create a more responsive and reflexive city (see Smith and McQuarrie 2012). As Mike Douglass, K. C. Ho, and Giok Ling Ooi (2008) remind us, in situations of limited infrastructural development such as that in Baguio (e.g., poor housing, social service provision, and employment options), the street, public markets, and other public spaces become crucial settings for inventing ways of being sociable, earning a living, and gaining recognition. Finding ways of being modern in cities worldwide is not only realized in the built environment, but also 
in flexible private and public spaces and enacted in personal performances and innovative socioeconomic practices.

For urbanites to challenge the largely exclusionary effects of modernism imposed from above, they need to be able to access rights that gives them power over the city's socioeconomic and political resources. This demand for the right to the city is 'a right not only in the legal sense of a right to specific benefits [and ...] to a set of rights to justice within the existing legal system, but a right on a higher moral plane that demands a better system in which the potential benefits of an urban life can be fully and entirely realized' by the majority of residents (Marcuse 2012, 34). Peter Marcuse $(2012,36)$ argues that the right to the city — which may at first seem like 'a right of consumption - a right to consume what the city, and city life, has to offer' - should also include the 'integrally linked' right to produce the city to meet one's particular needs. Rather than simply having the right to choose 'what is produced after it is produced', urbanites should be able 'to determine what is produced and how it is produced and to participate in its production' (Marcuse 2012, 36). Baguio's market vendors favour market improvements as long as they are part of the planning process-part of determining the rules of the game that enables them to instrumentalize city resources on more of their own terms. ${ }^{2}$

\section{Activating Everyday Politics, Social Capital, and 'Gray Spacing'}

Given that the public market vendors' umbrella association, the Baguio Market Vendors Association (BAMARVA Inc.), continues its court challenge of the city government's market redevelopment plan, and given that a legal resolution will take years to achieve, public marketers use 'everyday politics'

2 Holston's $(1999,169)$ discussion of cultural citizenship similarly addresses this issue, as he argues that simply having the legal status of 'citizen' does not guarantee effective access to the rights and protections offered by the nation state. He suggests that, 'although in theory full access to rights depends on [national] membership, in practice that which constitutes citizenship substantively (rights and duties) is often independent of its formal status. Indeed, it is often inaccessible to those who are formal citizens (e.g., the native poor), yet available to those who are not (e.g., [well-off] legally resident "aliens")' (Holston 1999, 169). In the Philippines, this difference between formal and substantive citizenship is, at least in part, mapped according to one's type of employment. Despite the nationalist rhetoric that guarantees all Philippine citizens basic social, economic, and political rights, in practice the livelihoods of public market merchants, for example, consistently place them outside national and globalized standards of modernity, progress, and appropriate urban development (see also Guarnizo 2012). 
to secure their livelihoods in the short term. Benedict Kerkvliet's (2009, 232) concept of 'everyday politics' provides a framework for analyzing how disenfranchized individuals assert their rights to livelihood given the wider political system within which they function. For Kerkvliet, everyday politics involves 'people embracing, complying with, adjusting, and contesting norms and rules regarding authority over, production of, or allocation of resources and doing so in quiet, mundane, and subtle expressions and acts that are rarely organized or direct'. Everyday politics involve 'little or no organization, [are] usually low profile and private behaviour, and [are] done by people who probably do not regard their actions as political' (Kerkvliet 2009, 232). Within everyday politics Kerkvliet identifies four forums of action: 'support, compliance, modifications and evasions, and resistance' (2009, 233). To secure and diversify the commodity chain flows that sustain their enterprises, Baguio's public market vegetable retailers activate these everyday tactics by, for example, respecting market code guidelines in some instances while respatializing market zones (e.g., occupying public market aisles) in others.

\subsection{Social Capital}

In the Philippines, as is customary throughout the Global South, the strength of one's social networks is integral to the success of one's economic pursuits. To overcome situations in which formal financial and legal infrastructures are not well developed or not easily accessed, most Filipinos form suki ('favoured relationships') to reduce risk in economic transactions. These customary trade relationships involve trust and reciprocal favours, such as being able to purchase goods on credit, pay a debt in installments with little or no interest, and (for producers) to receive a fair price for their goods from traders (Davis 1973, 211; see also Dannhaeuser 1983; Lin 2001). As Gina Porter et al. (2010, 31) note about Nigerian markets, 'social networks and small acts of human agency have been used to build trust, to diffuse tension, and to effect reconciliation.' Given that Baguio's public marketers' work falls outside the state's vision of appropriate urban development, merchants depend on their social capital to access new business options and garner support when unexpected challenges arise.

Early scholarship on social capital focussed on positive outcomes and paid inadequate attention to the 'dark side' of this practice. Because social networks can isolate non-members and frustrate efforts to build a unified front against top-down development initiatives, analyses must also consider the differing power relations and inequality among people who seemingly 
hold common goals (Narotzky and Moreno 2002). To this end, Alejandro Portes and Patricia Landolt (2000, 532) identify four negative consequences of social capital, namely 'exclusion of outsiders, excess claims on group members, restrictions on individual freedoms, and downward levelling norms'-all of which can challenge new sellers seeking entry into the public market's fresh food provisioning network, for example.

\section{2. 'Gray Spacing'}

'Gray spaces', Oren Yiftachel $(2012,153)$ argues, 'have become a dominant feature of contemporary urbanism' created both 'from above" by powerful groups linked to the centers of power', and more commonly from below by city residents whose rights have been marginalized. The latter, rather than 'being powerless recipients of [unfavourable] urban policies, [...] generate new mobilizations and insurgent identities' by using 'gray spacing' to create 'bases for self-organization, negotiation, and empowerment' (Yiftachel 2012, 153). Gray spaces thus emerge as 'developments, enclaves, populations, and transactions positioned between the "lightness" of legality/approval/ safety, and the "darkness" of eviction/destruction/death' (Yiftachel 2012, 153). Baguio's public market retailers use everyday politics to create such in-between 'gray spaces' by, for example, expanding their product displays into public market aisles and thereby contravening market guidelines. Although such 'gray spaces' are rarely fully 'integrated' into or 'eliminated' from contemporary urban regions, they persist partially outside of the knowledge of or are tolerated by state authorities when the latter feel they can gain some benefit from looking the other way (Smart and Zerilli 2014, 229; Yiftachel 2012,154). Understanding that 'gray spacing' is a quiet ongoing process of refashioning socioeconomic spatial relations (Yiftachel 2012, 153) dissolves the modernist dichotomy between legal and illegal to yield a more inclusive sphere that Alan Smart and Filippo Zerilli $(2014,222)$ term 'extralegality'.

These approaches thus provide critical lenses for charting marketers' strategies to mitigate the 'hypercommodification' (Robinson 2006, 2) that is currently steamrolling Baguio's urban life.

\section{$4 \quad$ Baguio City Public Market}

In the early twentieth century, the American colonial government in the Philippines established Baguio as its mountain summer resort to escape 
the hotter lowland temperatures. Baguio, an urban centre of 300,000 , is the government, educational, and administrative hub for northern Luzon's five mountain provinces; its extensive public market offers wholesale and retail sales of fresh produce, manufactured goods, and crafts, supporting businesses throughout the region. The city is home to a wide range of colleges and universities that, along with the city's government services, retail stores, and new shopping malls, provide the customer base sought by prospective entrepreneurs. Across commercial sectors, however, individuals must negotiate personalized strategies to realize the potential of this urban market. Although Philippine government policies continue to put forward anti-poverty programs for urban and rural renewal, many initiatives have fallen short of achieving long-term economic and political reforms (e.g., more work opportunities, accessible financial infrastructure) that can effectively benefit anyone other than well-off Filipinos-a situation common to urbanizing centres throughout the Global South (Hutchcroft and Rocamora 2012, 98-99; see also Balisacan 1995; Bello et al. 2005).

As the altitude of much of Benguet province, where Baguio is located, is above $1,500 \mathrm{~m}$, the cool temperatures enable farmers to grow temperateclimate vegetables that those in the hotter lowlands cannot produce. For this reason, Benguet province markets have emerged as the country's key collection and distribution hubs for upland vegetables such as broccoli, cauliflower, beans, potatoes, carrots, cabbage, tomatoes, and lettuce. These upland vegetables, as well as vegetables transported daily to Baguio from neighbouring lowland provinces, are available locally to urban consumers in public market stores, in neighbourhood satellite or roadside markets, from itinerant street vendors, and as noted, in new supermarket venues scattered across the city.

The Baguio City Public Market (BCPM) is located in the heart of the city's Central Business District and was formally established in 1913, shortly after the 1909 founding of Baguio (Agoot 2009, B26). The market is the regional hub for the wholesale and retail trade of a variety of local and imported fresh products, dry goods, and selected services (barber shops, women's hair salons, shoe stores, and cosmetic care salons). Market buildings Blocks 1 and 2 , which house wide aisles and product-specific zones for fruit, vegetables, rice, housewares, cut flowers, souvenirs, meat, fish, and tobacco, remain the showcase of the market for local residents as well as for tourists. In the late-1970s, the Maharlika Livelihood Center was constructed to house regional crafts and prepared food outlets, and from 2011 to 2014, the city renovated two smaller mixed-use buildings, Block 3 and Block 4 (Agoot 2009, B26-27; Milgram 2015). 
The Hanger Wholesale Vegetable Section at the far end of Block 2, past the Rice Section, handles a major part of the region's extensive wholesale trade in upland Baguio vegetables. Wholesale produce from Benguet's intensive cultivation is also funnelled through the La Trinidad Vegetable Trading Post and the Benguet Agri Pinoy Trading Center both located in neighbouring La Trinidad, Benguet's capital city. Each wholesale market supports trading networks that distribute upland produce to local retailers and wholesalers throughout northern and southern Luzon and the central Philippine islands. While the overall parameters of the wholesale upland vegetable trade are beyond the scope of this paper, the fact that Baguio's upland vegetable retailers first source their goods at the Hanger Wholesale Vegetable Section of the public market means this site is a key node in the vertical commodity flow from producer to consumer.

The guidelines for trade within the BCPM and its surrounding streets where itinerant vendors are active are outlined in the Market Code, which stipulates rental rates, lease terms, and locations for and types of permitted trade (City of Baguio 2000-2001). The implementation of the Market Code is administered by the municipal government's umbrella department for city-wide trade, the Committee on Marketing, Trade, and Commerce, and for everyday affairs by the Baguio City Market Authority. The latter consists of a market manager, market office staff, and guards who are all municipal employees. Market officials allocate market stalls, collect market fees, and enforce the market's general security and business guidelines. Despite being administered by the city government, the market management allows trade to take place fairly freely and, as described by the majority of BCPM merchants, primarily focusses on efficient administration. The market management does not undertake trade negotiations and only intervenes in vendor conflicts if called upon by the merchants themselves. The task of settling disputes is usually handled by the traders' umbrella organization, BAMARVA, Inc., which, in turn, comprises smaller product-specific associations (e.g., BCPM Vegetable Vendors Association, BCPM Tobacco Traders Association, etc.). As Julie Batton, one vegetable retailer, explains, 'We want to police ourselves such that we retain some business flexibility and maintain the power to penalize or benefit our association members on a case-by-case basis' (interview by author, 23 May 2014, 9 February 2015).

This customary ‘arms-length' pattern of public market trade can, however, shift with a change in mayoral leadership. Throughout the early 2ooos, for example, some Baguio councillors sought to emulate the modernizing development initiatives of Manila's Marikina City government. The 
then-Marikina mayor passed controversial legislation to clean up the city's public market by regularizing store size, restricting sales to specific types of goods, and banning itinerant vendors from the surrounding streets. The resulting sanitized market was achieved only by officials resorting to extreme punitive measures such as repeatedly destroying vendors' goods, dismantling stalls that violated size and product guidelines, imposing large fines, and installing permanent camera surveillance in the market office (Koki 2010; Viliran 2008). At times when a majority of Baguio councillors favour a similar urban vision, municipal authorities are less tolerant of market trader infractions, imposing fines and more stringent clean-up initiatives. At such times, marketers regain their hard-won trade rights only through persistent lobbying and everyday politics.

The fact that Baguio's current food provisioning landscape supports more shopping options does not mean that urbanites have abandoned the BCPM - a so-called traditional consumption site. Instead, and not surprisingly, most residents across classes shop in different retail venues depending upon the products they need for a particular purpose, the time they have to shop, and the convenience of the store location. Many consumers explain that they continue to shop for fresh produce (e.g., fruit, vegetables, fish) at the public market and at supermarkets for their bulk dry goods, although some continue to frequent the public market section specializing in the latter products, which are often sold at discounted prices. More well-off consumers, part of the Philippines' rising middle class, explain that they still visit public market stalls. As one shopper states, 'If I can, I will always return to my favourite BCPM retailer to secure specific fresh produce. I rely on my suki to most consistently sell me the best quality and safest food' (interview by author, 26 May 2014). Consumers who have nurtured long-term provisioning relationships with specific market retailers want to maintain these links grounded in trust, as Karen Monteban, another middle-class shopper, confirms: 'My neighbours and I visited the new SM Supermarket when it first opened to experience this large facility and the wide range of goods it offers. And I return to SM to shop when I am in the area. But I prefer to go to the public market where I can find the freshest and most varied produce' (interview by author, 2 June 2014). As such personal accounts suggest BCPM retailers remain competitive players despite the city's top-down efforts to minimize diversity in urban consumption options. Vegetable marketers, in particular, have effectively activated everyday tactics to successfully refashion their trade's ongoing relevance to shoppers and its preservation, as the following case studies demonstrate. 


\section{5 Upland and Lowland Vegetable Commodity Flows}

\subsection{Upland Vegetable Commodity Chains}

Upland vegetable retailer Julie Batton, who is 38 -years-old with two years of college and three children, took over her aunt's vegetable store in 2008 after working with her in this business since 2004. Julie's husband works as a night security guard. Julie's family connection, her 'bonding social capital', (links among tightly associated groups such as kin and community members) (Putnam 2000, 22-24) enabled her to secure this rental agreement amid keen competition for public market stalls. Julie's business is similar to that of other vegetable retailers who specialize in upland produce. Julie sells what she calls 'vegetable sets', namely, vegetables that are commonly used together in customary dishes; this sales tactic enables consumers to purchase, in one place, the ingredients they need for specific recipes (Figure 2). As one shopper explains: 'When I was purchasing produce in the supermarket, I found camote ['sweet potatoes'] next to calmunsi ['limes']; this product arrangement makes no sense to me? When I shop at my market suki I am certain I will obtain all the ingredients I need for a particular dish, as my suki organizes her vegetables more logically. I do not want to start cooking at home only to realize that I forgot one item' (interview by author, 5 June 2014). With a rotating capital of approximately $5,000-8,000$ pesos (US \$110-180), 3 typical of most small-scale businesses, Julie purchases the majority of her upland vegetables from the public market's Hanger Wholesale Vegetable Section, visiting her favourite wholesalers each day at 5.30 a.m. As each wholesaler usually specializes in only a few types of upland vegetables, Julie builds 'bridging social capital' relationships (links with non-kin heterogeneous groups) (Putnam 2000, 22-24) with four to six key sukis to obtain the variety of produce she needs. Once Julie makes her purchases, she obtains a receipt from each wholesaler and gives these to her porter, who subsequently collects and delivers her goods to her store. To collect his payment from Julie at the end of the day, the porter totals the number and route of his deliveries and is paid according to this delivery schedule.

BCPM porters belong to their own member association, the Baguio City Public Market Porters Association, which has established standard rates of pay depending upon the weight of each delivery and the distance it is carried (e.g., 0.50 pesos per kilo, or 50 pesos per $100 \mathrm{kilos})$. To equitably share 
employment among market porters, association guidelines stipulate the specific market areas within which each porter is permitted to work. For example, some porters transport produce only within the Hanger Wholesale Vegetable Section and between this wholesale area and the outside unloading and loading facilities reserved for traders and farmers; other porters' routes operate between the Hanger Section and either the Block 2 retail Vegetable Section proper or the upper retail Hilltop Section, while others carry goods between Hanger and off-site storage warehouses. The movement of both upland and lowland vegetables into, out of, and within the public market thus goes nowhere without the essential service of market porters-a key node in the multi-sited flow of these commodities and a main forum of employment for unskilled labourers and new immigrants.

Relations of trust anchor the negotiations among porters, retailers, and wholesalers. Julie pays the Hanger wholesalers cash for her vegetables, but she most often pays in instalments by making a down-payment when she orders her goods and giving the balance due at the end of that business day. When sales have been slow, Julie carries over her interest-free credit to the following day. If she needs to restock her produce but cannot leave her store, Julie reorders by sending a text to her wholesaler and subsequently contacting her porter to pick up and deliver her goods. In such instances when Julie does not personally choose her produce, she explains, 'I trust my wholesaler will supply good quality produce and that my porter will correctly total the receipts. I have been in business for over eight years and my sukis know that if they include spoiled goods, I will take my business to other dealers. We have a good understanding' (interviews by author, 23 May 2014, 9 February 2015).

Similar negotiations that maintain allegiances occur in retailers' everyday buying and selling practices with one another. Given that market store displays are located very close to one another and that upland vegetable retailers generally sell the same type of produce, at times it is difficult for consumers to discern where one shop's products end and another's begin. Julie explains that when customers, in error, choose goods belonging to a neighbouring vendor, 'I just sell the products for my neighbour and give her the payment; she would do the same for me' (interviews by author, 23 May 2014, 9 February 2015). In addition, if a customer needs an item that Julie does not stock, she personally visits a fellow vendor's stall to purchase the required vegetable for her client. Julie does not earn a commission on this sale, nor does she mark up the price; rather, her gesture earns her bridging social capital with her fellow vendor and the consumer. I witnessed such a transaction while visiting Julie one morning when she disappeared for a 
few moments only to reappear with mushrooms she had purchased for a customer from a trader who specializes in this product.

In an effort to distinguish her upland vegetables from those of her neighbouring sellers, Julie develops additional vertical producer-to-consumer commodity chain flows by negotiating agreements with independent farmers to purchase their seasonally harvested produce - vegetables and herbs, such as parsley, watercress, basil, spinach, and cherry tomatoes. Leveraging her bonding social capital with relatives who are farmers, Julie is able to purchase the latter two vegetables at very competitive prices. She has also started to carry different types of lettuce (e.g., iceberg, red, and green curly lettuce) and shorter, thicker white radishes to meet the food preferences of the city's growing Korean and Vietnamese residents while also cleaning and cutting local gabi leaves and stems to facilitate customers' food preparation at home.

To further ensure that she can supply customers with most of the ingredients they need for specific dishes, Julie currently sells what she calls 'spices'. These include garlic, different types of onions, ginger, and chilies. She purchases these goods from viaheras - lowland wholesalers - who bring their regional produce to Baguio from the neighbouring lowland provinces each day, an hour and a half trip by road.

Other upland vegetable retailers have activated additional tactics to distinguish their enterprises. Patricia Tayad, for example, who is 54 years old with one year of college and adult children, has been selling upland vegetables in the market for over twenty years, inheriting her store lease from her mother. In 2011, Patricia established an edgy business strategy by building a wood and metal table to extend her store premises into the market aisle. Patricia's store extension-her 'gray spacing' (Yiftachel 2012, 153) of public market space - is technically 'illegal'. However, with the support of her neighbouring vendors, Patricia has been able to negotiate an unofficial agreement with the market superintendent in which retailers can pay twenty pesos extra rent per day to erect similar store expansions (see also Milgram 2013, 85-86). Patricia uses this space not only to display her produce, but also to mount customer service events such as offering shoppers tea stored in her thermos or free samples of new products. As Patricia explains, 'I want customers to linger at my store to enjoy a personalized experience and, of course, I hope they will return to purchase additional vegetables' (interviews by author, 26 May 2014, 10 February 2015). Patricia's initiative can be understood as simply offering good service, but I suggest that this tactic also creates a memorable participatory interaction that enables consumers to engage the vibrancy — sights, sounds, smells—of the market in what Pine and Gilmore $(1998,97)$ term the 'experience economy'. 
As these authors note, 'Commodities are fungible [...] services intangible, and experiences memorable' (1998, 98, original emphasis). Although Patricia has 'wrapp[ed]' an experience around her commodity transactions, such 'inherently personal' interactions, in which customers actively perform and participate to co-create the shopping experience (Pine and Gilmore 1998, 98-100), link consumers and retailers in the long term and distinguish face-to-face public market shopping from more disengaged supermarket encounters.

\subsection{Lowland Vegetable Commodity Chains}

Down the row from Julie Batton's store, Heidi Montelo, 43 years old with two children and a college degree in communication, has been operating her lowland vegetable business for seven years while her husband does contract wage labour (Figure 3). After working for another lowland vegetable dealer for four years, Heidi was able to rent a neighbouring store when the former owner died and the family decided to rent out the site. Heidi's

Figure 8.3 A Baguio City Public Market retailer stocks her display with vegetables grown in the neighbouring lowland provinces

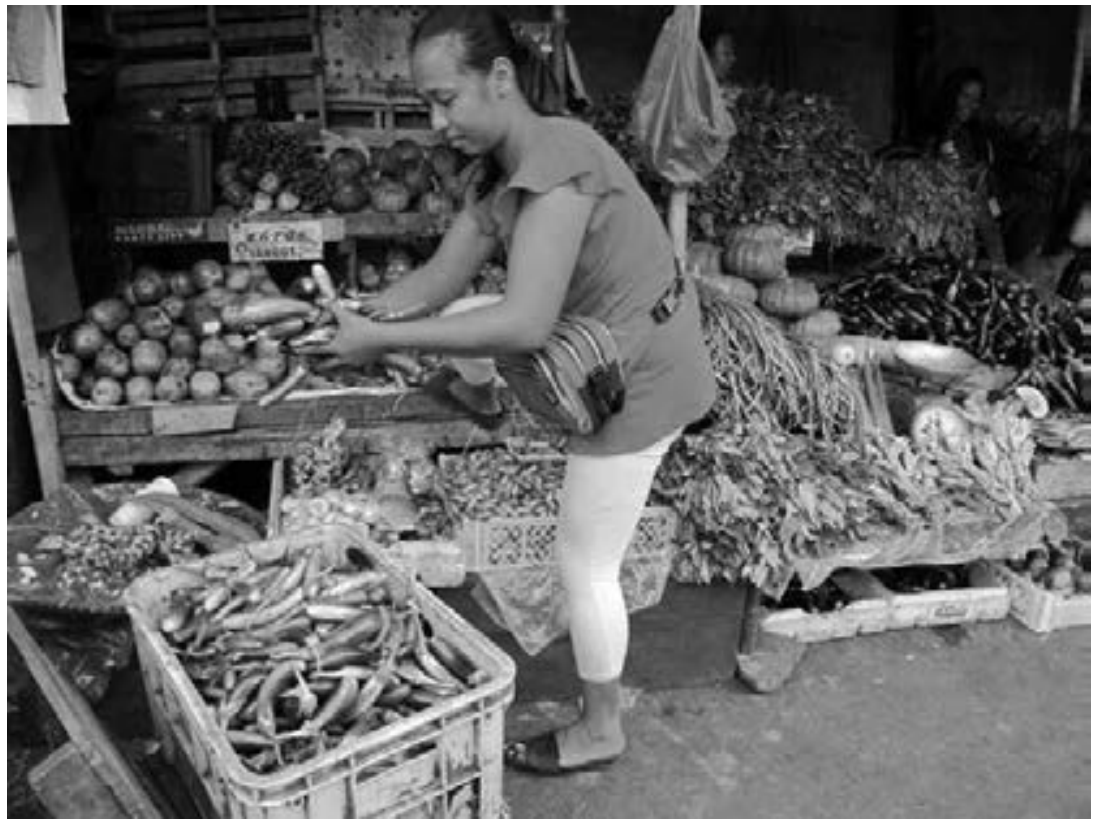

Source: author 
small-to-medium size business, with a typical rotating capital of 8,000-10,000 pesos (US \$180-225) is similar to that of other lowland vegetable retailers. Like Julie, Heidi sells produce that is combined in customary dishes, including eggplant, squash, assorted greens, square and long string beans, banana hearts, and okra. Heidi purchases her produce each morning at about 5.00 a.m. from her five favoured suki suppliers who, along with other viahera from the neighbouring lowland provinces (e.g., La Union, Pangasinan) unload their regional produce in the Hilltop Section of the market. As Heidi can gauge the volume of produce she requires each day, she sends a text with her order to her viahera the night before the morning delivery. If she requires further items, Heidi purchases these from the extra goods the viaheras usually bring with them. Each morning, Heidi checks the orders she has placed with different suppliers, leaving her porter to collect and deliver her purchases. Heidi explains, 'It is up to you to choose and train your porter. My porter knows my purchasing patterns and he knows the viaheras with whom I conduct business. I do not need to give him receipts; he simply visits each viahera to ask "What has Heidi purchased today?" Our negotiations are based on trust' (interviews by author, 4June 2014, 23 February 2015).

In a business strategy similar to that of upland vegetable retailers, each morning Heidi tops up the produce she has on hand with newly purchased vegetables to ensure her display tells consumers they are purchasing the freshest goods. Shopping at the public market enables consumers to personally inspect the produce they buy and to purchase the specific volume they require. As one shopper explains, 'Much of the fresh produce at supermarkets is already packaged and thus I have to buy pre-determined amounts. The products in the plastic and Styrofoam packages often look good from the top, but what does the underside look like?' (interview by author, 14 May 2013). According to Heidi, 'Customers carefully examine the quality of the vegetables I display to choose what they think are the freshest. For my regular customers, I will even divide into smaller amounts the larger volumes of produce I have bundled together. This helps those who need to shop each day because they have limited refrigeration facilities at home. I have to offer personalized service in such a competitive field' (interviews by author, 4 June 2014, 23 February 2015). In an initiative similar to that of Julie's trade in upland vegetables, Heidi also diversifies her sourcing by purchasing selected seasonal produce directly from farmers who go store-to-store offering their recently harvested vegetables and herbs.

Given Baguio's growing population, independent lowland vegetable wholesalers have increasingly started operating businesses on speculation. These new traders canvas lowland farmers to find produce that has not 
been previously promised to other buyers and after purchasing the most in-demand types of lowland vegetables (e.g., eggplant, beans, assorted greens), they resell these to BCPM retailers on a store-by-store basis. Unlike the lowland viaheras who have more established suki arrangements with producers and retailers, these new businesspeople do not take advance orders, but simply sell whatever lowland produce they have been able to secure on a particular day. Their lack of local social connections and the fact that their trade competes with the trade of more established viaheras precludes these new lowland sellers from renting a public market store, even if they had the funds to do so. Their businesses thus remain irregular-illustrating the dark, exclusionary side of social capital. The ongoing, albeit fluctuating, demand for these interloper sellers' services, however, evidences an additional channel through which lowland vegetable retailers can diversify the vertical commodity flow of their produce and thus the horizontal variability in the lowland vegetable trade across vertical chains (e.g., alternative commodity flows for the same goods) (Bush 2004, 39; see also Fine 2002, 118-121; Leslie and Reimer 2003, 428).

In another everyday political action that realizes the multiplicity of commodity chains for lowland vegetables, Heidi sells small amounts of vegetables (about $3-5$ kilos) on a consignment basis to itinerant street vendors who sell in the public market aisles and on the surrounding public streets-sales that are prohibited in the Market Code (City of Baguio 2000-2001, 54) (Figure 4). When these ambulant vendors have sold their consigned goods, they return to Heidi to pay her for their sales and replenish their stock. In this way, Heidi conducts business as both a retailer and a wholesaler. Selling lowland vegetables is a particularly opportune business option for periodic sellers because obtaining this particular produce at wholesale prices is possible only through personal connections with lowland viaheras and volume purchases - both of which preclude periodic vendors' access to these goods. Itinerant vendors selling upland vegetables do not have this challenge, as they can purchase upland vegetables without a personal introduction and in amounts as small as 1 kilo in the market's Hanger Wholesale Vegetable Section.

Ambulant market vendors working on consignment and the new lowland vegetable entrepreneurs working on speculation both lack Baguio municipal business licenses and hence their trade is technically 'illegal', as is marketers' tactic of extending their store displays into public market aisles. The armslength administration style of the BCPM officials, however, enables vegetable retailers to engage in the everyday politics of 'evading' and 'modifying' the market guidelines that prohibit such unauthorized actions (City of Baguio 
Figure 8.4 Itinerant vendors obtain vegetables on consignment from store retailers and sell their produce in the aisles and streets of the Baguio City Public Market

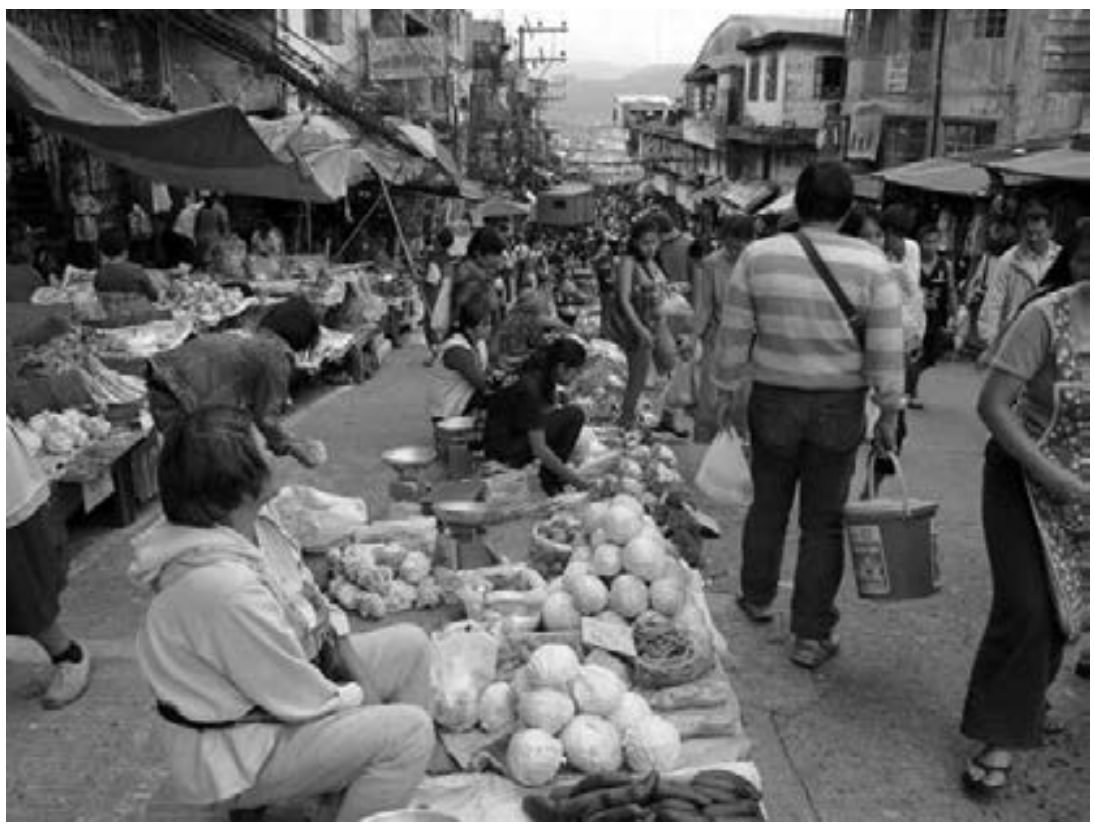

Source: author

2000-2001, 54-55; Kerkvliet 2009, 232). Although public market retailers have been able to institute these practices to facilitate their generally autonomous trade, their apparent successes have not been protected by new laws and thus are inevitably precarious, temporary ones that the city can remove at will (Brenner, Marcuse, and Mayer 2012, 4). Tolerance and informally agreed upon regulations are always 'concessions rather than rights', and these can change when the city feels that these tolerated systems no longer meet its interests or when new strategies for the control of market activities emerge (Smart and Zerilli 2014, 229).

$6 \quad$ Persistence of the Public Market Vegetable Trade and Food Safety

Amid ongoing urbanization and a market redevelopment plan that could threaten the viability of public marketers' businesses, Baguio's upland 
and lowland vegetable retailers have engaged in everyday politics to (thus far) stymie any stark 'spatial polarization' (Douglass, Ho, and Ooi 2008, 17) between 'traditional' public market and 'modern' supermarket shopping patterns. While some consumers prefer the prescriptive order of supermarket venues, most explain that they shop in both venues depending upon the goods they need, their purpose, and the convenience of the location. As one consumer, Kathy de Guzman, explained about shopping at the new SM Supermarket, 'I prefer this option of one-stop shopping in the supermarket rather than ten-stop shopping in the public market although we often have to wait in long supermarket check-out lines' (interview by author, 6 June 2013). Indeed, many consumers who agree with Kathy added that they are additionally attracted to supermarkets that are housed within a larger shopping mall, as occurs in the SM Baguio City complex. Other consumers strongly voice their preference for shopping in the public market as Nel Nunag outlined: 'Baguio residents seeking convenience or those with large families may prefer bulk-style supermarket shopping as prices can be lower. But I like to personally choose my vegetables to ensure I obtain the freshest and safest items. And who is there at the supermarket to ask about these concerns? The young staff who only stock the shelves do not have the product knowledge I seek' (interview by author, 6 June 2013). As another shopper noted about supermarket shopping, 'Since we now divide our trash into solid waste and compostable materials, the extra plastic and Styrofoam packaging from supermarkets contributes to our household trash accumulation and this added material may cause us to exceed our collection limit' (interview by author, 9 June 2014). Maia Green's $(2015,301)$ research in urban Tanzania reveals a similar pattern of cross-sector shopping: 'supermarket-style stores [...] are not the preferred retail-destination for low- and average-income Tanzanian citizens, who buy unpackaged foods [...] by volume from market traders and small shops that sell basic, low-price products in small quantities.'

Food safety is another important issue among local consumers, as Nel explained above. Although private sector and government agricultural reports—which to date have not been effectively acted upon—acknowledge that Benguet province's intensive upland vegetable cultivation, as well as much lowland vegetable farming, depend upon using high concentrations of pesticides (Lu 2009; Reyes and Laurean 2006 and 2007; Reyes-Boquiren 1989), the fear of food safety has not precipitated a move away from public markets towards supermarkets (Matejowsky 2008; Moustier et al. 2005; Reardon et al. 2003). As the head agriculturalist in Benguet province explained, 'Few Baguio shoppers trust supermarkets to be the best source of safe produce. 
All consumers believe that produce procured from any source contains chemicals and is therefore potentially unsafe' (interview by author, 10 March 2015). With no conclusive way to know the origin of produce unless one purchases it directly from the farmer, consumers stated that their best recourse is to purchase from individual vendors who they trust are procuring the safest possible produce (see also Gerber, Turner, and Milgram 2014, 58 ). Another shopper, Aileen Munoz, commented: 'If I purchase my vegetables at a particular retailer's store and the quality is consistently good, then I trust this vendor and she becomes my suki' (interview by author, 7 June 2013).

Trust, then, emerges as the closest thing to a guarantee that consumers have regarding the safety and origin of their goods (see also Gerber, Turner, and Milgram 2014, 57-8). Once retailers have earned the trust of their customers through ongoing transactions, the latter tend to purchase the majority of a specific type of produce from the same retailer, or will at least visit that merchant first to check the quality of his or her stock. As upland vegetable retailer, Julie explained, 'I try to deal directly with individual farmers and wholesalers on a continuing basis so I can have confidence in the safety of their produce as well as obtain a good variety of products' (interviews by author, 23 May 2014, 9 February 2015). Lowland vegetable retailer Heidi described an incident last year in which some of the vegetables she had purchased from one of the new entrepreneurs selling on speculation spoiled quickly, resulting in customers returning to her with complaints. Losing the trust of some of her regular clients—a decline in her social capital—represented a challenging financial loss for her small-scale business.

Although the supermarket sector is expanding throughout Southeast Asia, 'sales of fresh food - fruits, vegetables, meat, and fish — are still a stronghold of the traditional retail markets and itinerant retailers' (Cadilhon et al. 2006, 31; see also Goldman, Krider, and Ramaswami 1999; Green 2015; Manalili 2005). In Baguio, as in much of the Philippines, supermarkets have tended to develop a complementary rather than a singularly competitive relationship with the public market and street vending sectors (Matejowsky 2008). In this light, in a provocative marketing initiative, SM Supermarket in Baguio currently sets up specialty product displays in the supermarket aisles and in the foyer of its main entrance. This potpourri of kiosks offering regional baked goods, prepared foods, fresh produce, and crafts in a spectacle market atmosphere simulates the vibrancy of the Baguio City Public Market located at the other end of the street—in effect, materializing an 'experience economy' similar to that initiated by Patricia Tayad, the BCPM vegetable retailer (Pine and Gilmore 1998). 


\section{$7 \quad$ Conclusions}

Baguio's rapid economic growth in the late-199os and early new millennium means that consumers can currently access a growing number of food provisioning options for their everyday subsistence needs. Yet, shopping at the Baguio City Public Market remains an essential part of the Baguio experience for local urbanites across classes, as well as for visitors. Upland and lowland vegetable retailers, including Julie Batton, Patricia Tayad, and Heidi Montelo, have ensured the ongoing relevance and perseverance of public market trade by activating a modernism 'from below' (Ribeiro 2009, 298). These vegetable marketers have closely coordinated their initiatives with the social and economic interests of the other market players on whose allegiance they depend for livelihood survival — wholesalers, porters, peri-urban farmers, retailers, and consumers - thereby innovatively reconfiguring long-held commodity flows to secure their contribution to, and integration into, the city's economy. Taking advantage of newly opened wholesale and local producer networks while flexing to the specific, informed demands of their changing consumer base, vegetable retailers have thus largely mitigated the challenge of supermarket expansion and government constraints (see also Cadilhon et al. 2006; Green 2015).

Baguio City Public Market retailers' struggles to secure the commodity chain flows that anchor their livelihoods rarely entail heroic confrontations with government authorities; nor do they produce large-scale, collaborative strategic actions. Rather, marketers use everyday politics in 'a quiet encroachment' to access their rights to the necessities of daily life (e.g., business opportunities, consumption choices) (Bayat 2004, 81). By familiarizing themselves with the fissures in the city government's power, they continuously activate small-scale initiatives to create 'gray spaces' of survival and innovation that are 'neither fully coordinated, nor fully articulated, but cumulatively significant to upset the prevailing urban order' (Yiftachel 2012, 152).

The resulting complexity of food provisioning systems in Baguio thus highlights the futility of characterizing urban centres by having one part of a city stand for the whole (Robinson 2006, 10). Understanding cities as 'multiplex' and 'internally differentiated' spaces encompassing relations that span 'interaction and disconnection, sociability and alienation' foregrounds the diversity of ordinary cities and the 'diversity of ways of living in [ordinary] cities' (Robinson 2006, 171-72). That Baguio City Public Market vegetable retailers have effectively sustained and diversified patterns of fresh food provisioning in the face of government constraints evidences 
how conflict and reconciliation, civic engagement and everyday politics can be effectively negotiated when competing ideologies clash over rights to livelihood, marketplace modernization, and the best way to facilitate a city's quality of life for and by its residents.

\section{Acknowledgements}

The fieldwork for this paper was conducted in yearly research field trips in the Philippines from 2010 to 2015. Financial support has been provided by the Social Sciences and Humanities Research Council of Canada (SSHRC) (2008-2011, 2012-2016) and by OCAD University. In the Philippines, I am affiliated with the Cordillera Studies Center (CSC), University of the Philippines Baguio. I thank my CSC colleagues for their support and I thank my research assistant, Corinna Villanueva, who assists me in the Philippines and informs me of events during the year. I also want to thank the volume editors for their thoughtful comments on earlier versions of this chapter. To the Baguio City Public Market merchants who have answered my numerous questions I owe a debt of gratitude.

\section{Works Cited}

Agoot, Liza. 2009. 'Remembering the Lessons of the Past for the Future: The Baguio City Public Market'. Baguio Midland Courier, 30 August, pp. B26-B27, B52.

Baguio Midland Courier. 1995. 'City Market to be Developed into Modern Leisure Complex'. Baguio Midland Courier, 28 May, p. 8.

Balisacan, Arsenio M. 1995. 'Anatomy of Poverty during Adjustment: The Case of the Philippines'. Economic Development and Cultural Change 44(1): 33-62.

Bello, Walden F., Marissa de Guzman, Mary Lou Malig, and Herbert Docena. 2005. The Anti-Development State: The Political Economy of Permanent Crisis in the Philippines. New York and London: Zed Books.

Bayat, Asef. 2004. 'Globalization and the Politics of the Informals in the Global South'. In Urban Informality: Transnational Perspectives from the Middle East, Latin America, and South Asia, edited by Ananya Roy and Nezar AlSayyad, 79-104. Lanham, MD: Lexington Books.

Borja, Adam. 2010. 'Uniwide's Market Plan Probed Anew'. Baguio Chronicle, 23 January.

Brenner, Neil, Peter Marcuse, and Margit Mayer. 2012. 'Cities for People, Not for Profit: An Introduction'. In Cities for People Not for Profit: Critical Urban Theory 
and the Right to the City, edited by Neil Brenner, Peter Marcuse, and Margit Mayer, 1-11. London: Routledge.

Brown, Alison, ed. 2006. Contested Space: Street Trading, Public Space, and Livelihoods in Developing Cities. Warwickshire, UK: ITDG Publishing.

Bush, Simon R. 2004. 'Scales and Sales: Changing Social and Spatial Fish Trading Networks in the Siiphandone Fishery, Lao PDR'. Singapore Journal of Tropical Geography 25(1): $3^{2-50 .}$

Cadilhon, Jean-Joseph, Paule Moustier, Nigel D. Poole, Phan Thi Giac Tam, and Andrew P. Fearne. 2006. 'Traditional vs. Modern Food Systems? Insights from Vegetable Supply Chains in Ho Chi Minh City (Vietnam)'. Development Policy Review 24(1): 31-49.

Caluza, Desiree. 2013. 'Building to Replace 105-yr-old Baguio Market'. Philippine Daily Inquirer, 3 March. http://newsinfo.inquirer.net/368019/ building-to-replace-105-yr-old-baguio-market.

Castro, Leia. 2009. 'BAMARVA Regroups, Hopes to Preserve Baguio Market'. Baguio Midland Courier, 15 November, pp. 1, 15 .

Chant, Sylvia. 1996. 'Women's Roles in Recession and Economic Restructuring in Mexico and the Philippines'. Geoforum 27(3): 297-327.

City of Baguio. 2000-2001. Tax Ordinance Number 2000-oo1. Baguio City, Philippines: Office of the City Treasurer.

Clark, Gracia. 1994. Onions are My Husband: Survival and Accumulation by West African Market Women. Chicago, IL: University of Chicago Press.

Cohen, Margaret. 2004. 'Mighty Malls'. Far Eastern Economic Review, 1 July, pp. 5, 38. Dannhaeuser, Norbett. 1983. Contemporary Trade Strategies in the Philippines: A Study in Marketing Anthropology. New Brunswick, NJ: Rutgers University Press. Dannhaeuser, Norbett. 1997. 'The Malling of Dagupan'. Philippine Studies 45(2): 151-73.

Davis, William G. 1973. Social Relations in a Philippine Market: Self-Interest and Subjectivity. Berkeley, CA: University of California Press.

Douglass, Mike. 1998. 'World City Formation in the Asia Pacific Rim: Poverty, "Everyday" Forms of Civil Society and Environmental Management'. In Cities for Citizens, edited by Mike Douglass and Jonathan Friedman, 107-37. Chichester, UK: John Wiley.

Douglass, Mike and Amrita Daniere. 2009. 'Urbanization and Civic Space in Asia'. In The Politics of Civic Space in Asia: Building Urban Communities, edited by Amrita Daniere and Mike Douglass, 1-18. London: Routledge.

Douglass, Mike, K.C. Ho, and Giok Ling Ooi. 2008. 'Globalization, the City and Civil Society in Pacific Asia'. In Globalization, the City and Civil Society in Pacific Asia: The Social Production of Civic Spaces, edited by Mike Douglass, K. C. Ho, and Giok Ling Ooi, 1-26. London: Routledge. 
Fine, Ben. 2002. The World of Consumption: The Material and Cultural Revisited. London: Routledge.

Fontanilla, Giovani. 2014. 'Baguio Mayor Orders Continued Market Clearing'. Sun Star Baguio, 17 July, pp. 2, 4.

Gerber, Jonathan, Sarah Turner, and B. Lynne Milgram. 2014. 'Food Provisioning and Wholesale Agricultural Commodity Chains in Northern Vietnam'. Human Organisation 73(1):50-61.

Goldman, Arieh, Robert Krider, and S. Ramaswami. 1999. 'The Persistent Competitive Advantage of Traditional Food Retailers in Asia: Wet Markets' Continued Dominance in Hong Kong'.Journal of Macromarketing 19(2):126-39.

Green, Maia. 2015. 'Making Africa Middle Class: From Poverty Reduction to the Production of Inequality in Tanzania'. Economic Anthropology 2(2): 295-309.

Guarnizo, Luis E. 2012. 'The Fluid, Multi-scalar, and Contradictory Construction of Citizenship'. In Remaking Urban Citizenship: Organizations, Institutions, and the Right to the City, edited by Michael Peter Smith and Michael McQuarrie, 11-38. New Brunswick, NJ: Transaction Publishers.

Holston, James. 1999. 'Spaces of Insurgent Citizenship'. In Cities and Citizenship, edited by James Holston, 155-73. Durham, NC: Duke University Press.

Hutchcroft, Paul D. and Joel Rocamora. 2012. 'Patronage Based Parties and the Democratic Deficit in the Philippines: Origins, Evolution and the Imperatives of Reform'. In Handbook of Southeast Asian Politics, edited by Richard Robinson, 97-119. London: Routledge.

Kerkvliet, Benedict J. Tria. 2009. 'Everyday Politics in Peasant Societies (and Ours)'. Journal of Peasant Studies 36(1): 227-43.

Koki, Seki. 2010. 'Governing Through Extension: The Un/Making of "Citizen” and "Community" through Neoliberal Urban Development in Metro Manila, Philippines'. Japanese Review of Cultural Anthropology 11: 67-101.

Leslie, Deborah and Suzanne Reimer. 2003. 'Fashioning Furniture: Restructuring the Furniture Commodity Chain'. Area 35(4): 427-37.

Lin, Nan. 2001. Social Capital: A Theory of Social Structure and Action. Cambridge: Cambridge University Press.

Lu, Jinky Leilanie. 2009. 'Total Pesticide Exposure Calculation among Vegetable Farmers in Benguet, Philippines'. Journal of Environmental and Public Health: 1-5. DOI:10 1155/2009/412054.

Lloyd-Evans, Sally. 2008. 'Geographies of the Contemporary Informal Sector in the Global South: Gender, Employment Relationships and Social Protection'. Geography Compass 2(6): 1885-906.

Manalili, Nerlita. 2005. Regoverning Markets: Securing Small Producer Participation in Restructured National and Regional Agri-Food Systems, South East Asia. London: International Institute for Environment and Development. 
Marcuse, Peter. 2012. 'Whose Right(s) to What City?' In Cities for People Not for Profit: Critical Urban Theory and the Right to the City, edited by Neil Brenner, Peter Marcuse, and Margit Mayer, 24-41. London: Routledge.

Matejowsky, T. 200o. 'The Privatization of the Public Plaza in the Philippines. Three Cases from Pangasinan'. Philippine Quarterly of Culture and Society 28: 263-300. Matejowsky, T. 2008. 'The Commercial Transformation of a Philippine Cityscape: A Case from San Fernando City, La Union'. In Economies and the Transformation of Landscape, edited by Lisa Cliggett and Christopher A. Poole, 291-310. Lanham, MD: Altamira Press.

Milgram, B. Lynne. 2011. 'Centering Urban Margins, Mobilizing Livelihoods: Women and Street Vending in the Northern Philippines'.Journal of Developing Societies 27(3-4): 261-93.

Milgram, B. Lynne. 2013. 'Taking the Street into the Market: The Politics of Space and Work in Baguio City, Philippines'. In Street Economies in the Urban Global South, edited by Karen Tranberg Hansen, Walter E. Little, and B. Lynne Milgram, 71-92. Sante Fe, NM: SAR Press.

Milgram, B. Lynne. 2015. 'Unsettling Urban Marketplace Redevelopment in Baguio City, Philippines'. Economic Anthropology 2(1): 22-41.

Moustier, Paule, Dao The Anh, Hoang Bang An, Vu Trong Binh, Muriel Figuie, Nguyen Thi Tan Loc, and Phan T. G. T. 2005. 'The Participation of the Poor in Supermarkets and other Distribution Value Chains: Making Markets Work Better for the Poor'. Discussion Paper 11. Manila: Asian Development Bank.

Narotzky, Susana and Felix Paz Moreno. 2002. 'Reciprocity's Dark Side: Negative Reciprocity, Morality and Social Reproduction'. Anthropological Theory 2(3): 281-305.

Perera, Nihal and Wing-Shing Tang. 2013. Transforming Asian Cities: Intellectual Impasse, Asianizing Space and Emerging Translocalities. London: Routledge.

Pine, B. Joseph and James H. Gilmore. 1998. 'Welcome to the Experience Economy'. Harvard Business Review 76: 97-105.

Porter, Gina, Fergus Lyon, Fatima Adamu, and Lanre Obafemi. 2010. 'Conflict and Cooperation in Market Spaces: Learning from the Operation of Local Networks of Civic Engagement in African Market Trade'. Human Organization 69(1): 31-42.

Portes, Alejandro, and Patricia Landolt. 200o. 'Social Capital: Promise and Pitfalls of its Role in Development'. Journal of Latin American Studies 32: 529-47.

Putnam, Robert D. 2000. Bowling Alone: The Collapse and Revival of American Community. New York: Simon and Schuster.

Reardon, Thomas, C. Peter Timmer, Christopher B. Barrett, and Julio Berdegue. 2003. 'The Rise of Supermarkets in Africa, Asia and Latin America'. American Journal of Agriculture Economics 85(5):1140-46. 
Refuerzo, Alicendro. 2009. 'Court Verdict Validating Uniwide Contract UpheldMarket Vendors Appeal'. Baguio Midland Courier, 11 January, pp. 1, 43.

Reyes, Gaudelia A. and Carlito P. Laurean. 2006. 'Pesticide Residues in Soil, Water and Vegetables from Selected Barangays in a Benguet Municipality: Assessing Potential Concern for Human Health'. St. Louis University Research Journal 37(1): $35^{-51 .}$

Reyes, Gaudelia A. and Carlito P. Laurean. 2007. 'A Comprehensive Assessment of Pesticide Residues in Two Vegetable-Farming'. Northern Luzon Research Journal 1: 39-54.

Reyes-Boquiren, Rowena. 1989. 'The History and Political Economy of the Vegetable Industry in Benguet'. CSC Working Paper Series, Cordillera Studies Centre, University of the Philippines, Baguio.

Ribeiro, Gustavo Lins. 2009. 'Non-Hegemonic Globalizations: Alter-Native Transnational Processes and Agents'. Anthropological Theory 9(3): 297-329.

Robinson, Jennifer. 2006. Ordinary Cities: Between Modernity and Development. London: Routledge.

Seligmann, Linda J. 2004. Peruvian Street Lives: Culture, Power, and Economy among Market Women in Cuzco. Urbana, IL: University of Illinois Press.

Smart, Alan and Filippo Zerilli. 2014. 'Extralegality'. In A Companion to Urban Anthropology, edited by Donald M. Nonini, 222-38. New York: John Wiley.

Smith, Michael P. and Michael McQuarrie. 2012. 'Remaking Urban Citizenship'. In Remaking Urban Citizenship: Organizations, Institutions, and the Right to the City, edited by Michael P. Smith and Michael McQuarrie, 3-11. New Brunswick, NJ: Transaction Publishers.

Solomon, Christiana. 2006. 'The Role of Women in Economic Transformation: Market Women in Sierra Leone'. Conflict, Security and Development 6(3): 411-23. Viliran, Ramonito. 2008. The Healthiest Market in NCR: Marikina Public Market. Marikina City, Philippines: Marikina Public Market Office.

Yiftachel, Oren. 2012. 'Critical Theory and "Gray Space": Mobilization of the Colonized'. In Cities for People Not for Profit: Critical Urban Theory and the Right to the City, edited by Neil Brenner, Peter Marcuse, and Margit Mayer, 24-41. London: Routledge.

\section{About the author}

B. Lynne Milgram is Professor of Anthropology at OCAD University, Toronto, Canada. Her research on gender and development in the northern Philippines has analysed the cultural politics of social change with regard to microfinance and women's work in crafts and in the transnational Hong 
Kong-Philippine second-hand clothing trade. Milgram's current research investigates transformations of urban public space, governmentality, and issues of formal/informal and legal/illegal work regarding street vending and public market redevelopment that alter food security and provisioning systems. She has co-edited (2000, with K.M. Grimes), Artisans and Cooperatives: Developing Alternative Trade for the Global Economy; (2007, with R. Hamilton) Material Choices: Refashioning Bast and Leaf Fibers in Asia and the Pacific; (2009, with K.E. Browne) Economics and Morality: Anthropological Approaches; and (2013, with K.T. Hansen and W.E. Little) Street Economies in the Urban Global South. 


\title{
$9 \quad$ From Street Hawkers to Public Markets
}

\author{
Modernity and Sanitization Made in Hong Kong
}

\author{
Maurizio Marinelli
}

\begin{abstract}
Historically, street hawkers and street markets originated, all over the world, as the real first form of retailing. Today we still use the term 'street markets' to refer to outdoor spaces that are made up of a set of implicit and explicit traditions and cultural practices, but these are also spaces of sociality and connection (Watson 2009; Watson and Studdert 2006). Although street markets are primarily studied as sites for the exchange of economic goods and tradable products, they play a crucial role in the policies of urban regeneration, tangible and intangible heritage, placemaking, healthy eating, social sustainability, environmental impact, social and community cohesion, and economic innovation (Shepherd 2009; Stillerman 2006; Watson and Wells 2005). Based on the premise that street hawking and street markets are part of a wider socioeconomic and political system, this essay concentrates on the transition from street hawkers to public markets in Hong Kong, and analyses this historical transformation and their consequences within the framework of Hong Kong Government's strategy to create a modern and sanitized city.
\end{abstract}

Keywords: hawkers, public market, urban regeneration, neighbourhood, Hong Kong

1 The Semantics of Marketplaces

This chapter concentrates on the socio-spatial politics of land redevelopment and displacement in Hong Kong's Western and Central Districts, with

Cabannes, Yves, Douglass, Michael and Padawangi, Rita, Cities in Asia by and for the People. Amsterdam: Amsterdam University Press, 2018 DOI 10.5117/9789462985223/CHO9 
Figure 9.1 Maps of (a) Hong Kong, (b) location of markets, (c) Smithfield, Shek Tong Tsui, Sai Ying Pun, and Sheung Wan markets, (d) Bridge Street, Western and Central Markets
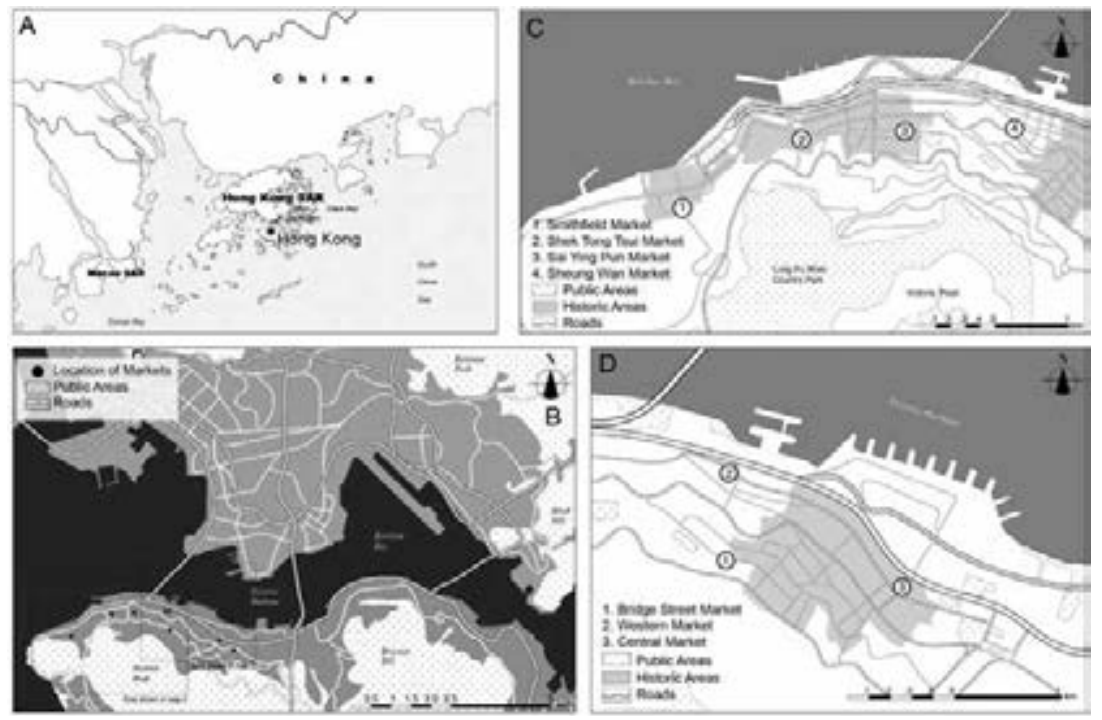

Source: Ariel Shepherd

particular attention to the transition of street hawkers and street markets to indoor public markets. This piece of writing is part of a larger research project focusing on the crucial role that street hawkers and street markets play in the policies of urban regeneration, living heritage, place- and peoplemaking, healthy eating, sustainability from below, environmental impact, social and community cohesion, and economic innovation. I argue that the rationale for the transformation of street markets into indoor public markets derives from Hong Kong Government's hegemonic discourse of sanitizing public space, maximizing land's exchange value, and therefore privileging ultra-modern shopping complexes. The collateral damage is the progressive annihilation of street community living in the name of 'modernity' and 'urban regeneration', deliberately forgetting that the vibrancy of the street markets is a constitutive element of Hong Kong's historical development, and street markets offer alternative spaces in the city, which contribute to human flourishing and collective well-being, since they reflect a city by and for the people as opposed to a city just for profit.

The concept of the marketplace is often associated with the idea of people coming together in a specific space. In Greek, the marketplace is called laiki

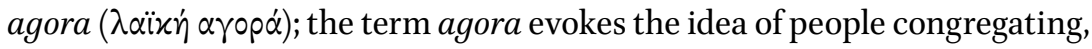


often in a square. For centuries, the association of these two elements has been the main characteristic of marketplaces in many cities and towns all over the world: a community of people in a public space. (Shepherd 2009, Stillerman, 2006) In Hong Kong, the need to modernize and sanitize the global city has implied a persistent tendency to move outdoor hawkers into indoor public markets.

Etymologically, the essence of the Chinese term shichăng (市场, 'market') is merely economic, although its juxtaposition with other words makes it possible to appreciate a broader semantic range that intersects with social forms of common life. In Hong Kong, markets are traditionally called 街市 街市; the same two characters are pronounced jiēshi in Mandarin and gaai si in Cantonese. This is actually a very literal translation of 'street market'. This essay concentrates on two pivotal forms of historical, socio-political, and semantic structure of markets in Hong Kong: hawkers, and gōnggòng shichǎng (公共市场, 'indoor public markets'). The complexity of the human, socioeconomic, and legal status of the street hawkers is embedded in the multiple Chinese translations of the term 'hawker'. The simplest is xiăofàn (小贩小贩), which indicates a small business. Also common is the English loan word term hawker as huòkè (霍克). However, there are two more terms which that more explicitly refer to reveal, more explicitly, the legal and social nature of this profession. One of them is wúzhèng xiăofàn (无证 小贩无证小贩), which literally means 'unlicensed hawker', and the other one is huòláng (货郎货郎), which means 'itinerant peddler'.

\section{Public Markets in Hong Kong}

Outdoor street markets and indoor public markets in Hong Kong have played an integral part in shaping the landscape for population growth and urban development. Not only do they serve as localized and more cost-effective alternatives to supermarkets for fresh produce, but they also provide their local customers with the chance to interact directly with producers and distributors. In this sense, markets are spaces of social inclusion and, I would argue, testing grounds for collective experiences of public space-and in some cases bottom-up practices of democratization.

In a city-state like the Hong Kong Special Administrative Region (HKSAR), where locals have grown accustomed to having access to everything from clothing retailers and restaurants to community centres within a ten-minute walk, and where families practically live on top of each other due to the scarcity of land ( $\mathrm{Ng} \mathrm{2014}$ ) and the high property prices and rents, public 
markets maintain this tradition of close proximity to the most fundamental of life's necessities. But this necessary, community-serving business has gone through a significant change over the last half century, as the government takes an active role in controlling public markets for the sake of public health and the development of modern and more hygienic urban spaces. The traditional profession of hawking wares on the street fell out of favour as Hong Kong's aim of becoming a 'global city' began to take shape, starting with more restrictive public policies in the 196os. The partial restrictions on hawkers' activities were followed, during the following decade, by the government's final decision to curb this traditional business from further expansion (Ho 1991, 3). By doing so, the British Colonial Government set a mandate for Hong Kong's wildly variant and constricted terrain to become a more orderly and cleaner city that would be more accessible to vehicles and the general public. This was part of the colonial global ${ }^{1}$ project of urban governmentality and modernity: mapping and re-ordering the urban space to guarantee social stability and economic expansion (cf. Foucault 1997, 2007 and 2008). The Hong Kong government's solution for modernizing the street markets was to expand the public works project that was already under way to include the development of designated market buildings. These market spaces became a way for the government to control hawking and improve public health concerns, while still providing the communities of the city-state with accessible produce at the local level.

This essay's main objectives are: first, to provide an analytical survey of the indoor public markets in the Central and Western districts of Hong Kong Island; and second, to evaluate how these public markets have responded to the Government's intention of modernizing and sanitizing the areas where the street markets were originally located, while also meeting the local demand for fresh produce. The study will also engage with the ongoing annihilation of street-hawking and the government's attempts to control the practice.

From the 1970s through the 1980s, the scholarly literature reveals a strong interest in hawkers and street markets in Hong Kong (e.g., McGee 1973; Smart 1989). As Josephine Smart $\left(1989,5^{2}\right)$ poignantly observed:

With the advent of industrialization and increased urbanization since 1950, the conflict between the government and street hawkers over the use of public space has deepened, the government has intensified its intervention in street hawking in an attempt to gain greater control over 
the management of public space. It is now widely recognized within the government apparatus that any attempt at eradicating street hawking is unrealistic; instead, increased enforcement actions are channelled into controlling street hawkers' access to public space for economic activity.

Smart emphasizes the connection between the government's intentions of controlling street hawkers (normativizing their activities and modus operandi) and gaining full control of public space. This intuition seems to echo David Harvey's $(1978,21)$ remark on capitalist accumulation by dispossession: 'the urban process implies the creation of a material physical infrastructure for production, circulation, exchange and consumption. [...] Capital represents itself in the form of a physical landscape created in its own image.' Hong Kong has one of the highest Gini coefficients (a measure of income disparity and therefore socioeconomic inequality based on household income) in the world (Chiu and Lui 2004; Forrest, La Grange, and Yip 2004).

One of the first systematic studies on the relevance of street markets in relation to urban planning was done by Chiu Fan Ho, a Hong Kong University Master's student in Urban Planning (1991). The thesis concentrates on the planning of market complexes, and discusses whether there were enough stalls, and more importantly, occupied stalls, within the various public markets to meet the demands and needs of the local residents. Ho offered recommendations on preserving street hawking, making existing markets more efficient, and guaranteeing better forms of development in future projects (1991). Building on the previous studies, one of the objectives of this chapter is to shed light on the current situation of Hong Kong's governmentrun public markets and evaluate whether those recommendations have been partially and/or completely implemented - and to what extent they have been successful.

\section{Street Hawkers: The Fulcrum of the Public Markets}

At first glance, street markets in Hong Kong can easily be regarded as nothing more than a place to buy food, cooked or uncooked. However, when carefully studied, they hold a number of significant socio-economic aspects that can contribute to the future development of Hong Kong, while preserving a centuries-old tradition of sociality and community living.

In Hong Kong, government-recognized hawkers have operated in public street markets for over two centuries. By legal definition, hawkers are 
licensed (as opposed to unlicensed) individuals or families who have the right to sell various products in open stalls on public streets. These products include everything from raw meat, live animals, vegetables, and cooked foods to clothes, toys, appliances, and newspapers. Both historically and from the point of view of the public policy development, the latter group of goods - classified as 'dry goods' — has never been much of a problem compared to fresh food, which is an essential component of Hong Kong culture and livelihoods. One of the key issues is that raw meat and fish, in particular, are highly susceptible to spoiling quickly and spreading diseases in public street markets. Without the aid of proper refrigeration and defined hygienic measures, such markets can quickly become hazardous zones. In addition to these public health concerns, public street markets that sell these goods have been accused of causing severe disturbances to public works (Ho 1991, 1-4). Specifically, hawkers have been blamed for the obstruction and deterioration of the public roads they occupy.

The Cantonese term gaai si ('street market') is commonly associated with 'wet markets', which are extremely popular in Hong Kong. Therefore, gaai $s i$ is used to describe these types of public markets that sell fresh produce, a practice which derives from the hawking profession. The use of the qualifying adjective 'wet' refers to the extensive use of water, which is used to keep the fruit and vegetables fresh, the fish and shellfish alive, and to wash excess animal parts, blood, and other waste from the streets (Wordie 2002). ${ }^{2}$

In 1969, after lengthy study and debate, the Urban Council (the government body in charge of monitoring hawkers at the time) proposed stopping the issuance of new hawker licenses within the territory. In 1971, the government officially endorsed this policy, and it became law. This ordinance had no effect on pre-existing licenses, and made sure that licenses could be transferred from one generation to the next within the same family. However, it signified the end of any possible expansion of the number of hawkers, while clearly aiming at the progressive reduction, if not disappearance, of the profession due to the complexities of the intergenerational transfer of the licenses. Controversial as it was, the ordinance was clearly an initial step towards controlling hawking practices

2 Recently, wet markets have witnessed a radical transformation of end-users: traditionally used by the lower-income, older generation of Hong Kongers and their domestic helpers, they have recently become an attraction for tourists who want to experience the 'real' old Hong Kong. Property investment companies have stepped in and now own the wet market buildings, renting out stalls to the retailers who sell their products (cf. PD 2009). 
in Hong Kong. The next steps were building facilities that could house some of the traditional hawker stalls and thereby remove them from the public streets. In reality, such facilities already existed in several areas across the territory in the Central, Sheung Wan, Wan Chai, and Mong Kok districts prior to the ordinance. Terry McGee $(1973,176-82)$ observed that Hong Kong's policies towards street hawkers had been geared towards four main outcomes: stabilizing their business in a fixed area; relocating them to allegedly more suitable areas; implementing structural measures aimed at controlling every aspect of the trade; and creating situations and incentives that would reduce the number of hawkers. I would add that these measures, implemented in the name of food safety, public hygiene, and modernity, were in line with the city-state's priority of ordering the society for economic development and expansion. Significantly, McGee and Yeung $(1973,1977)$ came to the conclusion that, while the Government considered hawkers to be hindrances to economic development, in reality, hawkers played an important role in contributing to urban economic growth. The fact that the hawkers were occupying the lower circuit economic model, which consisted of non-capital-intensive industrial activities, services, and trading, does not necessarily lead to the conclusion that this occupational sector is less productive than others. On the contrary, one could argue that hawkers are complementary to other economic activities, and this is a good reason for them to be adequately supported by the government policies.

Street markets are barometers of social change and well-being. In her work on street markets in the United Kingdom, Sophie Watson (2009, 1584) has poignantly argued that the marketplace represents 'a significant public and social space for different groups in the locality as a site of vibrant social encounters, for social inclusion and the care of others, for "rubbing along" and for mediating differences.' From an economic point of view, hawkers offer the possibility of providing cheaper goods to local residents, helping to lower their living expenses and maintain sociality, thus avoiding the withering away of what is common to the community (Rancière 2009). Hawking also offers the possibility of 'absorb[ing] excess labour during uncertain employment conditions and hon[ing] entrepreneurial skills useful for economic development' (McGee and Yeung 1977, 47). McGee and Yeung advocated the adoption of indigenous planning policies that could provide support (as opposed to obstacles) for the co-existence of the hawking profession with the progressive development of the city, since - in their opinion-economic advancement and hawking could actually complement each other and 
Figure 9.2 Number of unlicensed hawkers, 1990-2011

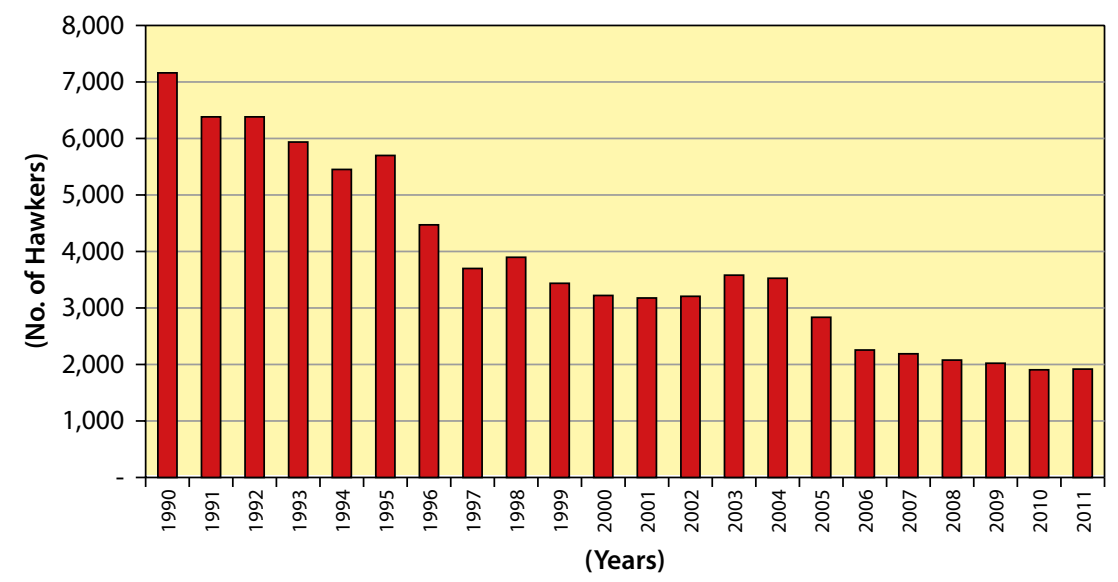

Source: FEHD n.d.

encourage greater productivity. Smart also emphasized that Hong Kong's stable and strong economic performance in the 1980s demonstrated that the persistence of street hawking was actually disconnected from unemployment and underdevelopment.

Rather, Smart (1989) argued, street hawking had a crucial functional importance vis-à-vis the overall retailing structure. Due to the relatively slow growth of wages in the 1980 s (which were pegged to the supply and demand mechanisms of the labour market), the more flexible hawking profession had the potential to become a high-income profession in some cases. There were also personal advantages, such as the possibility of being one's own boss and carrying on the family business, combining the historical tradition with the economic basis for self-sustainment. Depending on their specific location, some hawkers were also able to establish contacts and mutual dependence networks with the adjacent shops: a strategy which allowed them to survive in spite of the competition that modern shopping complexes have created for them. The scholars working on this topic in the period between 1970 and 1989 concluded that the persistence of the hawking profession, which determined changes in the traditional economy, complemented the rapid economic modernization processes ongoing in the society at large. This raises questions about the necessity of a government-led strategy to control public space and create a modern city. In the following sections, I analyse some specific examples of marketplaces located in Hong Kong Central and Western Districts. 


\section{4 Three Historical Markets}

Over the last three decades, Hong Kong's Central and Western Districts have undergone a dramatic rise in property values and the concomitant displacement of long-term low-income residents. These two districts contain three historical markets: two that originated in the late nineteenth century, and one that was developed after World War II. The current buildings of the Western, Central, and Bridges Street Markets were built in 1906, 1939, and 1953, respectively.

In 1858 , to facilitate the growing population of Sheung Wan and greater Hong Kong Island, the government built the Western Market on the site of a former street market that had first been established in 1844 on Queen's Road Central. Over the next 40 years, as demand grew with an expanding population, the government formulated plans to extend the market into a second building. The North Block—originally constructed as the government's Harbour Office-became the second market facility. Des Voeux Road, Morrison Street, and Connaught Road Central physically bound the building. Historical information on North Block is very limited. ${ }^{3}$ Built in 1906 in the grand Edwardian style, the North Block building features a combination of red bricks and granite for the base and the band. With over $2240 \mathrm{~m}^{2}$ of internal space located on two floors, the building operated as a successful public market for fresh produce, dry goods, and cooked food for 83 years, until 1989. The North Block seems to have operated alongside the South Block: the two buildings were actually known as 'The Western Market'. In 1981, the government decided to demolish the South Block and, on the same site, built a temporary facility that became known as the Sheung Wan Complex, leaving the North Block to carry the title of Western Market by itself. By 1989, the Land Development Corporation (LDC) and the Urban Council completed the construction of a permanent structure at the Sheung Wan complex, which incorporated the public market within the municipal services building complex at 345 Queen's Road. At that point, the government seemed to have lost interest in the socio-economic function of the Western Market. However, the North Block building, now identified as the Western Market, was declared a monument with preservation status soon after by the LDC and the Urban Council.

3 Cf. in particular: 'Research File Western Market (North Block) = 舊上環街市 (北座), AM770025, Hong Kong: Heritage Discovery Centre Library of the Antiquity and Monuments Office; Land Development Corporation, Western Market. Hong Kong: Land Development Corporation, 1991. 
After it was given preservation status, the LDC spent the next two years conducting a full renovation and preservation project of the site. In 1991, after spending approximately $\mathrm{HK} \$ 55$ million, the Western Market was reopened as a centre for arts and crafts merchants and various local dry goods businesses (URA 1991). In 2002, The Lifestyle Group - a firm established in 1981 and focussing on lifestyle, hospitality, and leisure businesses in Hong Kong-bought the rights to open a banquet hall in the Western Market's top floor, as well as manage the entire building. In 2003, the Lifestyle Group set out to renovate the building and attract a more diverse array of business owners. Currently, the market is divided into four levels. The ground floor is home to nineteen merchants, while the first floor houses only textile shops. The remaining second and third floors are home to the Lifestyle Group's Grand Stage restaurant. The demographics of Western Market's customers has changed greatly with the renovations. With the emphasis more on upscale dry goods merchants, the market now primarily serves tourists rather than the local residents and could fall under the category of reconfigured heritage (Staiff 2013, 42).

The history of the Central Market is very different. It was built in 1939 with over 200 stalls across three levels of floor space. In 1967, during the governorship of Sir David Trench (1964-1971), it was dubbed the largest meat market in Southeast Asia. In a city like Hong Kong, where land is scarce, particularly on the island, the Central Market's space encompasses a large portion of the associated district. The market is surrounded by Queen's Road Central, Des Voeux Road Central, Jubilee, and Queen Victoria Streets, and occupies $4150 \mathrm{~m}^{2}$ of land. A team of British architects utilized the popular Bauhaus design form of the time to build the market; this architectural style was guided by the idea that 'form follows function', which essentially meant that the design of the building had to be guided by the nature of its intended use. By incorporating a linear curtain wall of windows and an open atrium of approximately 10x54 $\mathrm{m}$ in the centre of the building, the market intended to make maximum use of daylight to provide interior illumination. During the 1960s-1980s, when the majority of the Central district was populated by working-class Chinese families and the adjoining neighbourhood of mid-levels was home to most of Hong Kong's expatriate community, the Central Market was home to a wide range of hawkers. These hawkers sold their wares not only to local residents, but also to the many restaurants and catering businesses within the area. As the Central district's landscape began to change in the mid-1970s, however, the government decided that it was time to change this historic market. 
In 1976, the Hong Kong Legislative Council (LegCo) decided that a change to the urban planning of the neighbourhood was required to deal with the rapid commercialization of the Central district. Hundreds of residential properties across Queen's Road Central, Des Voeux Road Central, and neighbouring side streets were re-zoned as commercial property. The public bus system was boosted with new routes to accommodate the new influx of workers commuting to the Central district. With the onset of a larger public transport system, a need for facilities to house the vehicles and act as a final drop-off point for passengers emerged. Due to its location, the Central Market was chosen as the ideal spot to house both a new bus terminal and a commercial office building. Unlike residential property - which only had one major hurdle for the government to worry about (e.g., the landlords) - the Central Market had an entire bureaucratic arm of Hong Kong's government to ensure its best interests (Kwok 1999).

The Urban Council was a 100 year old government department that was responsible for the development and maintenance of public facilities and outdoor venues across Hong Kong Island and Kowloon. The council was founded in 1883 , with the declared objective of championing arts, culture, and public health initiatives aimed at improving the living conditions of the Hong Kong community. It was also responsible for overseeing public market facilities and public street markets. All government policies on public market development, reconstruction, or demolishment had to be approved by the council in order to proceed.

When the LegCo decided in 1976 to demolish the Central Market to modernize the Central district, the Urban Council refused to approve the plan. Their reasoning was that the government could not demolish the Central Market without providing equally acceptable facilities for the hawkers, who were currently operating inside the market, to be able to work within the same vicinity. Begrudgingly, the LegCo agreed and decided to reconvene at a later date. Over the following 20 years, the government did little to nothing in pushing forward the relocation of the Central Market. However, in the 1980 s, as property prices climbed to astronomic heights in Hong Kong, various corporate groups, including property developers and retail business owners, advocated for the government to put the Central Market's land up for sale, which meant privatization. The lucrative potential of the Central Market became even more apparent in 1987 when the old Central Fire Station, occupying $2,200 \mathrm{~m}^{2}$ of land and located directly across the street from the Central Market on Des Voeux Road Central, was sold to Hang Seng Bank for HK\$ 840 million (Kwok 1999). 
During the two decade-long heated discussion between the Urban Council and the LegCo, the business activities at the market began to change dramatically (Fellman 1995; Hughes 1996; Moy 1996). Due to the relocation of residents away from Central and the parallel growth of supermarkets within the district, the Central Market changed from a retail centre to a wholesale market. Hawkers within the market increasingly started to sell their goods to local restaurants and catering companies within the area.

By the mid-199os LegCo's demand for the 'regeneration' of the Central Market grew stronger. To accommodate the stall owners who still wanted to operate within the area, LegCo offered to convert a section of the former Central Police Station headquarters on Hollywood Road into a market space. However, this proposal was met by strong opposition from the Urban Council due to the accessibility of the site. The Urban Council demanded the guarantee of thirty or more parking spaces to be built in the area to accommodate delivery vehicles, as well as a pedestrian link to Central. LegCo rejected these improvements and offered an alternative with only a handful of parking spaces and minimal public access, which the Urban Council immediately rejected (Cheung 1997). Negotiations with the Urban Council continued well past the handover of Hong Kong to the People's Republic of China on 1 July 1997.

By 1998, LegCo was demanding that the Urban Council remove all stall owners at Central Market by May 1999 and relocate them to the old Police Headquarters on Hollywood Road (Lannin 1998). This led to a stalemate and, due to stubbornness on both sides, the hawkers within the market were never relocated to Hollywood Road. What happened instead was that the businesses inside the Central Market either closed for good or relocated to outdoor spaces or indoor public markets within the vicinity, primarily the Lockhart Road Market in Wan Chai and the Sheung Wan Market. LegCo subsequently dissolved the Urban Council in 1999, with the declared aim of diversifying the Council's responsibilities for better efficiency (Loo 1999). In its place, the Food and Environmental Hygiene Department was created to manage public markets. By March 2003, the Central Market was officially shut down. LegCo again considered its initial plans to demolish Central Market and sell the area, but by 2009 the government's tone changed from commercialization to conservation. LegCo entrusted the Urban Renewal Authority (URA ${ }^{4}$ with redeveloping the building into a recreational space

4 The URA was created in May 2001 by the Urban Renewal Authority Ordinance. URA is the government department tasked with the development and revitalization of various streets and buildings across Hong Kong. Therefore, it is often presented as the 'heritage arm' of the LDC. 
for the public and a new home for retails businesses, working with the building's historic façade. The Central Market, which currently operates as a passageway to and from Central Escalator, was slated to reopen in 2015, but this did not happen.

The third important historical market is the Bridges Street Market. As Hong Kong's population grew after World War II, public markets were progressively built across neighbourhoods within the Central and Western districts according to the Urban Council's development plan. The Bridge Street market was the first of the seven markets built within the district (FEHD 2013).

The majority of wet markets across the streets of Caine, Robinson, Conduit, and Hollywood roads were destroyed during the Japanese occupation of Hong Kong during World War II. Bridges Street Market was constructed in 1953 to replace the old markets and meet the demands of the rising population in this area. The market sits on the corner of Bridges Street and Shing Wong Street. Like the Central Market, Bridges Street Market was built according to the Bauhaus style. The two markets' asymmetrical styles play on the use of natural sunlight to illuminate the entire space during the day-a feature that is hard to grasp these days with so many high-rises encircling and literally suffocating the two market buildings. The interior of Bridges Street market contains $950 \mathrm{~m}^{2}$ of floor space, separated into three stories. The ground and second floors contain 26 stalls each, varying in size from $5.2 \mathrm{~m}^{2}$ to $9.36 \mathrm{~m}^{2}$. The first floor-which originally contained 33 stalls for the sale of meat, fruits, and vegetables - was converted into an indoor children's playground in 1969 to combat the lack of public spaces for children in the neighbourhood. Once converted, the first floor's access was separated from the rest of the market via a walking bridge behind the building on Wing Lee Street, parallel to Bridges Street. While the official business hours of the market and public space are 6 a.m.-9 p.m., the market is now only in operation between 6 a.m. and 9 a.m. for fish, poultry, and vegetable hawkers. This is similar to Beijing and other major Chinese cities, where the street markets have progressively disappeared but the zaoshi (早市, 'morning markets') can still operate between 6 a.m. and 9 a.m. This restriction is meant to satisfy local residents' needs for fresh produce, while guaranteeing the showcase of a modern and sanitized image of the cityscape.

Because of its historic status, Bridges Street Market is completely different from other public markets within the Central and Western districts. The building does not serve any purpose other than the indoor public playground and morning market. Its location in an increasingly expensive residential neighbourhood has rendered this limited use a serious issue for both the 
residents and the government, especially compared with the more modern public markets that are housed in multi-purpose buildings and occupied by municipal services and recreational centres for the locals.

In 2008, the URA announced that the Bridges Street Market and the Chinese tenement houses located behind the market on Wing Lee Street, would be earmarked for preservation (Chen 2008). This decision was a result of demands from the local community to prevent the redevelopment of the area with skyscraper residences and was aimed at preserving the historical significance of the area. An important part of this decision was the history of the site before the market's development in 1953, when it was partially occupied by the American Congregational Preaching Hall where one of China's most prominent historical figures - the Father of the Republic, Sun Yat-sen—was baptized (CRHKH 2012).

The new plans call for all new buildings within the surrounding area to be no taller than twenty-five storeys (DB 2011). As of 2012, when I conducted my ethnographic work, plans were still being considered for the future use of Bridges Street Market. I asked a few local residents if they had any idea about the possible uses of the building. Mr. Lee, the 81-year-old owner of the Bridges Street Market shop Wai Che Printing Co.—a business he had started in the mid-1950s, soon after the market opened - was very eager to share his views, both on the history of the market and its possible future use. Mr. Lee remembered that when he started the printing company the local area was very diverse: 'Expatriates occupied the main street-ways [Caine, Robinson, Seymour Road, Conduit] of mid-levels, while mostly local Chinese and new immigrants from the mainland lived in tong la ${ }^{5}$ along the side streets and Hollywood road' (interview by the author, 10 May 2012). He also remembered how lively the market was, providing the locals with easier access to fresh produce than Central Market could, but then he added: 'By the 1970s, when supermarkets like Wellcome and Park n' Shop began to open across the neighbourhood, the Bridges Street Market started becoming less and less popular'. One reason for this was the lack of air-conditioning: 'One had to avoid products like fish by the end of the day, if it was a hot and humid summer day'. With regard to heritage preservation, Mr. Lee believed that the government was doing 'a good job by protecting the building and the local area'. He added: 'There is so much history here. I

5 The term tong lau (or tang lou in pinyin, 唐楼) refers to the 2-4 storey tenement buildings which were built from the late-nineteenth century until 1964 to accommodate the Chinese residents of Hong Kong. They were designed for both residential (upper floors) and commercial uses (ground floor, mostly for food vendors). 
think one way to make good use of the space is to turn it into an historical exhibition centre, so they can provide information to tourists and locals about the area's history. Then the government should convert some of the old residential buildings into commercial shops like coffee and souvenir shops'. Other proposals for the repurposing of the market building are as follows: 1) the creation of an information centre focussing on the Central and Western districts; 2) conversion into a recreational facility for live performances; and 3) functional adaptation into retail shops and visitors' information centre ( $\mathrm{Ng} 2012)$.

While the future of Bridges Street Market is an object of debate, most nearby residents have all but forgotten the market space. During my fieldwork in 2012, both children and the elderly frequented the communal playground during the day-but with modern supermarkets just a block or two away, the morning-hour market primarily catered to restaurants in the vicinity and had become a wholesale business.

5

\section{Modern Day Public Markets in Central and Western Districts}

In this section, I present the results of my ethnographic work in the following contemporary public market complexes: the Sheung Wan, Sai Ying Pun, and Shek Tong Tsui public markets, and the Smithfield market in Kennedy Town.

After the demolition of the temporary Sheung Wan Complex, the permanent structure of the Sheung Wan Market was built, opening to the public in 1989. This market is still one of the most successful uses of public space by the Hong Kong government. The market is housed within the government's municipal services building. In a total of thirteen floors, the building houses a range of government services, including the Food and Hygiene Department's offices for the Central and Western district, a sport and leisure entertainment facility, and a number of other social welfare services for the local community. The public market on the first three floors of the building is set up in typical Hong Kong fashion: fish and poultry stalls on the ground floor; meat, vegetable, and dry goods sellers on the first; and a cooked food centre on the second floor. According to the Food and Hygiene Department, there are a total of 226 stalls in the market, ranging in size from $3.6 \mathrm{~m}^{2}$ to $13.65 \mathrm{~m}^{2}$, including 20 stalls for cooked food vendors on the top floor. Twenty of the fresh produce stalls were vacant in 2013 (FEHD n.d.b). The Queens Street Cooked Food Centre was built as an extension of Sheung Wan Market's cooked food floor. Demand was so high 
for food stalls from both vendors and local residents that the government decided to provide an additional space. The centre is located on Des Voeux Road, just a few blocks from Sheung Wan Market. Currently, all thirteen stalls at this market are occupied by restaurants, with an average size of $15.1 \mathrm{~m}^{2}$ per stall.

During my visits to the market, I conducted a few interviews. Mr. Chip Lee-Mok, who has owned and operated a poultry stall in the market for nearly ten years, shared his experiences with me. He emphasized, in particular, the significant changes that have occurred in the distribution-consumption network: 'Business has considerably changed. It is very different from the time when I started. At that time, I would say that 70 per cent of the business was directed to local residents and 30 per cent to restaurants and catering companies at wholesale. Nowadays, I would say that I do more wholesale business than retail' (interview by the author, 15 May 2012). One reason for this was the competition: 'Most vendors at the market source their chickens, ducks, and geese from the same sources now, with just about the same quality. Therefore, it is impossible to offer very competitive prices, compared to the other vendors'. Fierce competition also comes from the supermarkets that have been built in the area. There are also specific historical circumstances that affect the businesses. Mr. Chip told me:

I started getting into the poultry business around 2002, right after the bird flu outbreak in Hong Kong. Most people thought I was totally crazy! But I inherited this business from my family and did not have many other options. When the bird flu was finally brought under control and the government sanctioned central slaughterhouses to control meat distribution in the city, people started trusting supermarkets more since a lot of them worked closely with the government's slaughterhouses. (interview by the author, 15 May 2012) $^{6}$

One of the most controversial topics of debate both among the urban planners and the vendors is the necessity, or likelihood, of future expansion of the Sheung Wan Market. In the same interview, Mr. Chip argued against it, saying: 'the market is already very well developed. The government did a good job with building the market. And there is no real need to expand since Sai Ying Pun Market is so close by'. Other vendors who joined our conversation seemed to agree with Mr. Chip. On the contrary, most vendors believed that local residents would use the market less in the coming years. Mr. Yip, 
another vendor, added: 'I do not think Sheung Wan Market will become like Central Market though. The reason that place went out of business was because the neighbourhood became more and more gentrified and became a white-collar commercial district. Sheung Wan as a neighbourhood is changing too, but it is just becoming more upscale' (interview by the author, 15 May 2012). Other vendors agreed with Mr. Chip and Mr. Yip that the area continues to be both residential and administrative, but the type of people who live there are changing very fast. Mr. Chip added:

Significantly, the kind of customers one usually finds in Sheung Wan Market are housewives, grandmothers, and housekeepers; all looking for a bargain because they either do not trust the quality at the supermarkets and prefer fresh produce, or they think supermarkets' food is too expensive. However, that group of people, including their families, are finding it harder and harder to live in this neighbourhood and are moving more west of Hong Kong Island or over to the Kowloon/New Territories area. So, I think that in the future, Sheung Wan Market will become more of a wholesale market since we stand a chance to compete with the bigger wholesalers who are primarily located in Kowloon and the New Territories.

During my last visit to Sheung Wan in 2017, a major redevelopment was under way on Des Voeux Road Central and many small shops were closing down. The progressive gentrification of the neighbourhood will most certainly have an impact on the Sheung Wan Market.

Continuing to the west of Sheung Wan, the neighbourhood of Sai Ying Pun is technically home to one of the largest public markets in Hong Kong, or, more precisely, two public markets that are connected via a public bridge: Centre Street Market and Sai Ying Pun Market, built in 1976 and 1999 respectively. The Centre Street Market is the closest to the harbour and contains 47 stalls, ranging in size from $5.4 \mathrm{~m}^{2}$ to $21 \mathrm{~m}^{2}$. For over twenty years, the market housed fresh produce stalls on the ground floor and a range of dry goods and cooked food stalls on the first floor. However, by the end of the 199os all fresh produce operators were relocated to the newly built Sai Ying Pun Market. This new market was built due to the rapid increase of Sai Yin Pun's population. Upon completion, Sai Ying Pun market added 102 stalls to the neighbourhood's available market business. Compared to the other public markets in the Central and Western District, Sai Ying Pun and Centre Street markets have one of the lowest levels of stall vacancies-only 10 stalls across the 149-stall complex are unoccupied. 
I interviewed a few vendors as well as some frequent visitors about their experiences. Vegetable hawker Ms. Louisa Tsang told me that she had previously operated out of the Centre Street Market before moving to Sai Ying Pun Market. Her family has been involved in vending since 1991. She recalled: 'I was a teenager at the time and would come to manage the two stalls we operated near each other at the original Centre Street Market' (interview by the author, 20 May 2012). When the government completed Sai Ying Pun market in 1999, they were relocated to the new building: 'By that year [1999], our business grew since we started a family farm on Lamma Island, allowing us to set our own prices on produce and gain more profits. When my parents retired, my brother did not have any interest in continuing the business, but I did not want the family to lose it. So I hired a few full-time farmers for the Lamma Island land and continued with the business we currently have'. She also emphasized the changes she had experienced: 'When we first started at the Centre Street Market in 1991, business was thriving mainly because, at the time, many working-class families were relocating further west from Central'. The population of Sai Ying Pun exploded in the 1990s: where there used to be maybe 1000 or so families in the 1980 s, by the 1990 s it had increased to 10,000 or more. When asked about her business now (2012), Ms. Tsang stated:

These days, business is still very good for us. The government has spent a lot of resources in the new market hall, and it shows. We have a quality facility for business and residents still come here frequently. I think when they finish the new outdoor escalator to connect Queens Road West and Bonham Road via Centre Street, business will continue to do well since people will be more willing to stop by the market.

According to Ms. Tsang, the Sai Ying Pun Market complex is the busiest of all markets in the Central and Western districts. This is due, in part, to the local demographic: most of the Sai Ying Pun area's residents are working class Chinese families. All the vendors that I interviewed shared the same positive opinion about the government's intention to complete a new public escalator, which will connect the Centre Street Market to the mid-levels on Bonham Road, providing even easier access to the neighbourhood and the market. ${ }^{7}$ In response to my question about her own personal future, Ms. Tsang added: 
I do not think I will stay until retirement. I live in Sai Ying Pun, but I have become very tired from all the years of working as a fruit and vegetable seller. My kids are growing up and they do not seem interested in continuing the business at the market. What I want to do is move to Lamma Island and work more on managing the farm. I think that is what I will do in a few years' time. This way, I can still keep the family business alive by only selling our produce to other hawkers at the market.

The interconnectedness between production and distribution, which characterises the activities of many old vendors of fruit and vegetables in particular, and contributes to the investment in a collective sense of community living and well-being will be progressively lost.

Shek Tong Tsui market, located at the mid-point between Sai Ying Pun and Kennedy Town, was built in 1991 to serve a relatively small neighbourhood and provide easier access than the Sai Ying Market complexes. The market is located towards the end of Queen's Road West and is modelled in a similar fashion to the Sheung Wan Market complex. With the market occupying the lower four storeys of the building, the government built a public library and sporting facility on the upper four floors. There are 153 stalls within the market, ranging in size from $5 \mathrm{~m}^{2}$ to $30 \mathrm{~m}^{2}$. The dry goods stalls are located on the ground floor and the meat stalls are on the mezzanine, while the vegetable and fish stalls are on the first floor. Of 153 total stalls, fifteen are reserved for a cooked food centre on the top floor of the market.

When I visited in May 2012, one instantly noticeable characteristic of Shek Tong Tsui market was the number of vacant market stalls: 40 in total. I asked the director of the Food and Hygiene Department, Mr. Wesley Y. $\mathrm{H}$. Tang (interview by the author, 15 May 2012), why such a large number of stalls were vacant. His response was that there was just not enough demand from vendors: the government had made efforts to price vacant stalls at competitive rates, but there was little to no interest. When I spoke to some current vendors in the market, they offered more insight into the reasons for the vacancies. Ms. Sarwa Mookjai, who along with her husband immigrated to Hong Kong many years ago, has owned and operated a Thai restaurant within the cooked food hall for more than eight years. Ms. Mookjai argued:

There are a lot of vacant stalls at the market because there is a lack of business when compared to Sai Ying Pun Market and Kennedy Town's Smithfield Market. It does not really make sense to have so many hawkers in this market. The cooked food hall does excellent business, but I think that's because so many people who live in the neighbourhood eat out for 
at least two of their meals every day. I think the government is better off blocking off a whole section of the market and converting it into some other kind of public space. Leaving so many stalls vacant for so long does not make sense. (interview by the author, 20 May 2012)

When asked about the Shek Tong Tsui public market's future, she added:

I think the market will definitely stay around for a while. Like the Sai Ying Pun area, Shek Tong Tsui is a working-class neighbourhood; it is also located directly at the bottom of the hill from Hong Kong University. Therefore, the residents still need this market. But I think that the government should cut the number of fresh produce markets, and maybe convert them into cooked food stalls. Business is very good for all the cooked food vendors. I think more vendors would help the market, but I am sure it will also force current businesses like mine to be more competitive.

Another important market in this area is the Smithfield Market, located in Kennedy Town on Smithfield Street. The Smithfield Market was opened in 1996, at the time when the residents of Hong Kong Island began moving westward in search of cheaper rents. Kennedy Town, whose name derives from Hong Kong's seventh British governor Arthur Edward Kennedy (1872-1877), was a working-class neighbourhood. ${ }^{8}$ Like the Sheung Wan and Shek Tong Tsui markets, this market is housed in a multi-purpose municipal services building. There are 218 stalls in total, with sizes ranging from $3.5 \mathrm{~m}^{2}$ to $37.5 \mathrm{~m}^{2}$. In May 2012, at the time of my fieldwork, there were fewer than ten vacant stalls in the building. Similar to the Sai Ying Pun and Centre Street markets, Smithfield Market's low vacancy is due to the neighbourhood's demographics: Kennedy Town is primarily a residential neighbourhood for middle-class to lower middle-class workers.

I interviewed a few Filipina housekeepers, who represent a significant number of the customers of the market. One, Gloria, ${ }^{9}$ had been living in Hong Kong for ten years. For eight of those years she was with the same employer, a mid-3o's Chinese couple with two grade-school children. Her main reasons

8 Things have changed in the last few years, especially after the $\mathrm{HK} \$ 18.5$ billion Mass Transit Railway (MTR) project was launched in 2010. The MTR was completed and opened on 28 December 2014, with mixed reactions from both old-time residents and businesses (cf. Sung and Cheung 2014).

9 Gloria declined to provide her last name. 
to shop at the Smithfield Market, as opposed to chain supermarkets, relate to her current employers:

They are a family of four, and both the mother and father work all day. The reason for coming to the market is mainly because of my budget. The family gives me between $\mathrm{HK} \$ 100-150$ a day to buy food to cook lunch and/ or dinner for the whole day. I prepare lunch for the kids on occasion, and I usually cook dinner for the whole family, but sometimes I simply buy groceries for the mother to cook dinner for the family. The market is still cheaper than the supermarkets. I usually only go to the supermarket if I am looking for a particular spice or seasoning, or anything else imported. (interview by the author, 21 May 2012)

Gloria explained that she visited the market twice every day, and the customers were different in the morning and afternoon:

In the morning, one finds more elderly people at the market, together with some restaurant owners. Usually, the elderly like to go in the morning, because they can get the grocery shopping out of the way early in the day. The restaurant owners go at that time to buy their various goods for their dinner hours. In the afternoon, one usually sees housekeepers and stay-at-home mothers. I personally prefer to go in the afternoon, since I have a chance to see a lot of my old friends.

When asked about the products she purchases, Gloria added: 'I buy everything from pork to chicken, as well as vegetables and fruits. Sometimes in the afternoon, when I have finished most of the house chores early, I will meet my friends for lunch at the cooked food centre on the top floor'.

My ethnographic exploration of these markets reinforces Watson's conceptualization of the market as a space of sociality and a place of 'rubbing along' (Watson, 2009). This indicates that the market is not only 'a form of limited encounter between social subjects where recognition of different others through a glance or a gaze, seeing and being seen, sharing embodied spaces, in talk or silence, has the potential to militate against the withdrawal into the self or the private realm' (Watson 2009, 1581), but also a space where a collective identity is negotiated and emerges (Watson and Studdert 2006, Watson and Wells 2005).

When asked about her personal future, Gloria stated: 'My employer treats me well. I like the work, but I am becoming tired of Hong Kong. I think I will stay for 3-4 more years until the children are in college. Then I will go 
back to the Philippines to be with my own family full-time. Hong Kong is nice, but it is a very expensive city' (interview by the author, 25 May 2012). Gloria's final thoughts were that she firmly believed the Smithfield Market would stay around for a long time. The fact that fewer than ten stalls were vacant in the market seemed to support her belief.

Other Filipina housekeepers responded with worry when I asked them, 'What do they think would happen if Smithfield Market ever closed?' Maria ${ }^{10}$ immediately stated:

It would be a serious problem for the neighbourhood. I know Central Market was very popular many years ago, and it is no longer in business, and that's because the neighbourhood changed. I do not think the government will close down this [Smithfield] market until that [commercialization] happens to Kennedy Town. There are too many poor and middle-class families in the area that need this market. (interview by the author, 25 May 2012)

\section{$6 \quad$ Concluding Remarks}

As previously mentioned, Hong Kong has one of the highest Gini coefficients in the world (Chiu and Lui 2004). Something that went unnoticed in the 2014 autumn of discontent, when the eyes of the world were attracted by the media on the streets of Hong Kong where the 'Occupy Hong Kong with Peace and Love' movement was unravelling, is that that movement was not only about the request for universal suffrage. In recent years Hong Kong residents have faced increasing socioeconomic inequality. Income disparities has widened and quality of life has declined for the city of seven million residents: the top 1 per cent is getting richer, while 1.3 million residents (20 per cent of the population) live below the poverty line. The situation has deteriorated even more since 2007, ten years after the handover of Hong Kong from the British rule back to the 'embrace of the motherland' (Chu 2013, 2).

The study of the transition from street markets to public market complexes offers an angle for analysing the human stories of adaptation, resistance, survival, and metamorphosis. These stories are inscribed within the framework of Hong Kong's project of urban governmentality, sanitization, and modernity: the re-ordering of urban space to guarantee social stability and 
economic expansion is inevitably intertwined with gentrification-induced displacement and marginalization (Forrest, La Grange, and Yip, 2004).

The first conclusion to be drawn from the markets analysed in this essay is that, although hawkers have often moved into public markets, they have simultaneously resisted the normativization of their behaviour. Instead, the hawkers have reproduced in the public market the same kind of apparently chaotic appearance that the government bodies would have liked to control and normativize.

The second conclusion is that public markets still play a pivotal role in the lives of the local residents. Especially for lower- and middle-class families, public markets provide not only a cheaper option for daily food needs, but also offer them a sense of community in daily life. In this sense, markets play a prominent role as spaces of social inclusion and contribute to the group cohesion in a specific neighbourhood.

The main objectives of this study were to analyse the transformation of street hawkers and street markets into public marketplaces, and to evaluate the efficiency of the public markets and cooked-food centres on the Hong Kong Island. Individually, markets meet the needs of the individuals who frequent them. But statistically, as a whole, the available data tells a different story. Hong Kong contains a total of 77 public markets and 25 independently operated cooked-food centres. On Hong Kong Island alone, there are 29 markets and cooked-food centres. The following table graphs have been created based on population density and the operations of public markets at the district level:

Table 9.1 Population and Market Stalls: Demand, Supply and Shortage

\begin{tabular}{lccccc}
\hline District & $\begin{array}{c}\text { Population } \\
\text { estimate (a) }\end{array}$ & $\begin{array}{c}\text { Demand } \\
\text { of Market } \\
\text { Stalls (b) }\end{array}$ & $\begin{array}{c}\text { Supply of } \\
\text { Market } \\
\text { Stalls (c) }\end{array}$ & $\begin{array}{c}\text { Shortage } \\
\text { of stalls (d) }\end{array}$ & $\begin{array}{c}\text { Percentage } \\
\text { of stalls } \\
\text { shortage (e) }\end{array}$ \\
\hline Central \& Western & 251,519 & 1,131 & 786 & 345 & $30.50 \%$ \\
Wanchai & 152,608 & 686 & 615 & 71 & $10.35 \%$ \\
Eastern & 588,094 & 2,646 & 1,482 & 1,164 & $44 \%$ \\
Southern & $\mathbf{2 7 8 , 6 5 5}$ & $\mathbf{1 , 2 5 4}$ & 806 & 448 & $35.50 \%$ \\
Total & $\underline{\mathbf{1 , 2 7 0 , 8 7 6}}$ & $\underline{\mathbf{5 , 7 1 7}}$ & $\underline{\mathbf{3 , 6 8 9}}$ & $\underline{\mathbf{2 , 0 2 5}}$ & $\underline{\mathbf{3 5 . 4 2} \%}$ \\
\hline
\end{tabular}
(a) Population data by district from Hong Kong 2011 Census
(b) Demand of market stalls based on Hong Kong Planning Standard \& Guidelines 1989 (Note: the guidelines have not been updated by the government) of 45 stalls for every 10,000 members of population
(c) Supply of market stalls based on data from the Food and Environmental Hygiene Department
$(\mathrm{d})=(\mathrm{b})-(\mathrm{c})$
(e) $=($ d) $\div$ (b) $\times 100 \%$ 
Table 9.2 Population and Market Stalls: Change in Demand

\begin{tabular}{lccccc}
\hline District & $\begin{array}{c}\text { Popula- } \\
\text { tion in } \\
\text { 2001 (a) }\end{array}$ & $\begin{array}{c}\text { Popula- } \\
\text { tion in } \\
\mathbf{2 0 1 1} \text { (b) }\end{array}$ & $\begin{array}{c}\text { \% of } \\
\text { Population } \\
\text { change (c) }\end{array}$ & $\begin{array}{c}\text { Net change } \\
\text { demand of } \\
\text { market stalls } \\
\text { due to popula- } \\
\text { tion change (d) }\end{array}$ & $\begin{array}{c}\text { (d) in \% } \\
\text { of stall } \\
\text { demand in } \\
\mathbf{2 0 1 1}(\mathbf{e})\end{array}$ \\
\hline Central \& Western & 261,884 & 251,519 & $-4.0 \%$ & -46 & $-13.33 \%$ \\
Wanchai & 167,146 & 152,608 & $-8.7 \%$ & -65 & $-91.54 \%$ \\
Eastern & 616,199 & 588,094 & $-4.6 \%$ & -126 & $-10.82 \%$ \\
Southern & $\mathbf{2 9 0 , 2 4 0}$ & 278,655 & $-4.0 \%$ & -52 & $-11.60 \%$ \\
Total & $\mathbf{1 , 3 3 5 , 4 6 9}$ & $\mathbf{1 , 2 7 0 , 8 7 6}$ & $\underline{-4.84 \%}$ & $\underline{-289}$ & $\underline{\mathbf{- 1 4 . 2 7 \%}}$ \\
\hline
\end{tabular}

(a), (b) Population data by district from Hong Kong 2001 and 2011 Census

(c) $=$ (b) - (a) / (a) $100 \%$

(d) $=$ (b) - (a) $/ 10,000 \times 45$ stalls

(e) $=($ d) $\div$ (d) of table $1 \times 100 \%$

Tables 1 and 2 demonstrate that there is a significant shortfall in the ratio of public stalls compared to the population in all four official districts of Hong Kong Island (PDCD 2001; 2006; 2011). The issue partially found a physiological solution: the pressure was relieved in the past decade, as the population of each district on Hong Kong Island has decreased. However, even with the decrease, there is still a deficiency in the number of public markets required to meet local demand. According to the statistical data of all official districts within Hong Kong, the majority of districts within Kowloon and the New Territories have increased while Hong Kong Island decreased in population. One could argue that this occurred because more individuals and families moved to the outer areas of the city. The displacement of long-term lowincome residents is strictly associated with the dramatic rise in property value and rent in the Central and Western districts. On the other hand, one could argue that the influx of supermarkets across Hong Kong more than makes up for the amount of public markets necessary for the population. There are several supermarket brands within Hong Kong. The two most popular and abundant ones though are Wellcome and Park N' Shop.

Table 3 shows how many markets are present in each district.

The most scientific method for calculating the effectiveness of each market would be to measure the average square footage of the supermarkets and compare to the average size of the stalls within public markets to arrive at an approximate amount of stalls that could fit within a supermarket's usable space. However, obtaining such a number is nearly impossible. This is due to the fact that supermarkets in Hong Kong range in size from $55^{\circ} \mathrm{m}^{2}$ to as high as $4,000 \mathrm{~m}^{2}$. As one can see from the information about the 
Table 9.3 Number of supermarkets

\begin{tabular}{lccc}
\hline District & $\begin{array}{c}\text { Wellcome } \\
\text { Supermarket }\end{array}$ & $\begin{array}{c}\text { Park N' Shop } \\
\text { Supermarket }\end{array}$ & Total supermarkets \\
\hline Central \& Western & 15 & 11 & 27 \\
Wanchai & 6 & 4 & 10 \\
Eastern & 18 & 20 & 38 \\
Southern & 10 & 11 & 21 \\
Total & $\underline{\mathbf{4 9}}$ & $\underline{\mathbf{4 6}}$ & $\underline{\mathbf{9 6}}$ \\
\hline
\end{tabular}

Source: author

public markets provided above, every public market has a different range of stall sizes.

Even with all of these analytical limitations, one can still infer from the number of available supermarkets that they do fill a large portion of the gap between the local population and the amount of markets necessary. With the increasing infiltration of quality supermarkets, ranging in items from the basic necessities to the higher-end versions that provide all imported goods, the daily grocery needs of Hong Kong's residents seem to be well met. Public markets and even the hawkers who operate in street markets have modernized to meet the needs of today's residents of Hong Kong. From the young to the old, the markets and associated municipal service buildings provide greater access to government services to the local residents. The government is still adamant about decreasing the number of street hawkers with licenses, and the laws set forth decades ago to prevent the issuance of new licenses are still in effect.

According to the Food and Hygiene Department, hawkers who seem to be the biggest concern-since they are fresh produce sellers-have for the most part been resettled to the various public markets on Hong Kong Island. This analysis of Hong Kong's public market system seems to reveal that the system, as it stands today, is not so dramatically different, from a functional point of view, from the one that goes back to the nineteenth century. At the core, markets today still serve the same purpose as they did more than hundred years ago: they offer a cheap and central location for working-class residents to gain access to fresh produce. The individuals interviewed for this essay all believed their respective markets were there to stay in their neighbourhoods for quite some time. The price of property rapidly increases as one moves west on Hong Kong Island, but even if prices were to reach astronomical heights the residents believe that the public markets would still remain open. Unlike Central and to a lesser extent 
Sheung Wan, Sai Ying Pun, Shek Tong Tsui, and Kennedy Town are all primarily residential neighbourhoods. As residents like Gloria explained, public markets offer a range of products and services that make life easier for residents. Without them, life for Hong Kong's residents, the majority of whom live on an average of HK $\$ 10,382-14,354^{11}$ (i.e., US \$1337-1848), would become much more challenging.

\section{Acknowledgments}

The author would like to express his grateful thanks to the editors for their insightful suggestions.

\section{Works Cited}

Anon. 1991. 'Research File Western Market (North Block) = 舊上環街市 (北座), AM77-0025, Hong Kong: Heritage Discovery Centre Library of the Antiquity and Monuments Office; Land Development Corporation, Western Market. Hong Kong: Land Development Corporation.

Chen, Bonnie. 2008. 'Historic Sites to Escape Wreckers'. The Standard, 8 April. http://www.thestandard.com.hk/news_detail.asp?pp_cat=11\&art_ $\mathrm{id}=64071 \& \operatorname{sid}=18389961 \&$ con_type $=1 \&$ d_str $=20080408 \&$ isSearch $=1 \&$ sear year=2008.

Cheung, Carmen. 1997. 'Council Suspends Central Market Talks'. The Standard, 3 September. http://www.thestandard.com.hk/news_detail.asp?pp_cat=\&art_ $\mathrm{id}=36875 \&$ sid=\&con_type=1\&d_str=19970903\&isSearch=1\&sear_year=1997 $>$.

Chiu, Stephen W.K. and Tai-lok Lui. 2004. 'Testing the Global City-Social Polarisation Thesis: Hong Kong since the 1990s'. Urban Studies 41(10): 1863-88.

Chu, Yiu-Wai. 2013. Lost in Transition: Hong Kong Culture in the Age of China. Albany: State University of New York.

CRHKH [Conserve and Revitalise Hong Kong Heritage]. 2012. 'Background Information'. Batch III Revitalisation Scheme, 5 January. http://www.heritage.gov.hk/en/ bsm/background.htm.

DB [Development Bureau]. 2011. 'Public Engagement Days on Bridges Street Market Revitalisation'. 8June.http://www.devb.gov.hk/en/publications_and_press_releases/press/t_index_id_6620.html. 
FEHD [Food and Environmental Hygiene Department]. N.d.a. 'Number of Unlicensed Hawkers in 1990-2011'. Hawker. http://www.fehd.gov.hk/english/ pleasant_environment/hawker/images/201003_chart.jpg.

FEHD [Food and Environmental Hygiene Department]. N.d.b. 'Sheung Wan Market'. Tidy Public Markets. http://www.fehd.gov.hk/english/pleasant_environment/ tidy_market/markets/Sheung\%2oWan\%2oMarket.html.

FEHD [Food and Environmental Hygiene Department]. 2013. 'List of FEHD Public Markets and Cooked Food Markets/Centres'. Public Markets, 1 October. http://www.fehd.gov.hk/english/pleasant_environment/tidy_market/Markets_CFC_list.html.

Fellman, Joshua. 1995. 'New Bid to Push Central Market Redevelopment'. The Standard, 25 July. http://www.thestandard.com.hk/news_detail.asp?pp_cat=\&art_ id=16416\&sid=\&con_type=1\&d_str=19950725\&isSearch=1\&sear_year=1995.

Forrest, Ray, Adrienne La Grange, and Ngai-ming Yip. 2004. 'Hong Kong as a Global City? Social Distance and Spatial Differentiation'. Urban Studies 41(1): 207-27.

Foucault, Michel. 1997. Il faut défendre la société, Cours au Collège de France [Society Must be Defended. Lectures at the College de France]. Paris: Seuil.

Foucault, Michel. 2007. Security, Territory, Population: Lectures at the Collège de France, 1977-1978. Translated by Graham Burchell. Basingstoke: Palgrave Macmillan.

Foucault, Michel. 2008. The Birth of Biopolitics: Lectures at the Collège de France, 1978-1979. Translated by Graham Burchell. Basingstoke: Palgrave Macmillan. Harvey, David. 1978. 'The Urban Process under Capitalism: A Framework for Analysis'. International Journal of Urban and Regional Research 2(1-4): 101-31. Ho, Chiu Fan. 1991. 'Planning of Market Complexes in Urban Areas'. MA thesis, University of Hong Kong.

Hughes, Duncan. 1996. 'Shun Shing Wins 109m Market Contract'. The Standard, 18 October. http://www.thestandard.com.hk/news_detail.asp?pp_cat=\&art_ $\mathrm{id}=32913 \&$ sid=\&con_type $=1 \& d$ _str=19961018\&isSearch=1\&sear_year=1996.

King, Anthony D., ed. 20oo. Culture, Globalization and the World-system: Contemporary Conditions for the Representation of Identity. Minneapolis: University of Minnesota Press.

Kwok, Lilian. 1999. 'Uncertainty Hangs over Central Market'. The Standard, 21 March. http://www.thestandard.com.hk/news_detail.asp?pp_cat=\&art_ $\mathrm{id}=25648 \&$ sid=\&con_type $=1 \& d \_$_str=19990321\&isSearch=1\&sear_year=1999.

Lannin, Susan. 1998. 'Council Review "not Tied to Market Row”. The Standard, 8 June. http://www.thestandard.com.hk/news_detail.asp?pp_cat=\&art_ id=36481\&sid=\&con_type=1\&d_str=199806o8\&isSearch=1\&sear_year=1998. 
Li, Joyce. 2001. 'Old Markets Face Closure in Wake of Bird-flu Outbreak'. The Standard, 19 June. http://www.thestandard.com.hk/news_detail.asp?pp_cat=\&art_ $\mathrm{id}=11659 \&$ sid $=\&$ con_type=1\&d_str=20010619\&isSearch=1\&suar_year=2001.

Loo, Grace. 1999. 'Councils Put in Dust Bins'. The Standard, 3 December. http:// www.thestandard.com.hk/news_detail.asp?pp_cat=\&art_id=41147\& 8 sid=\&con_ type=1\&d_str=19991203\&isSearch=1\&sear_year=1999.

McGee, Terry. 1973. Hawkers in Hong Kong. Hong Kong: University of Hong Kong. McGee, Terry and Y.M. Yeung. 1977. Hawkers in South-East Asian Cities. Ottawa: IDRC. Moy, Patsy. 1996. 'Council Challenges Market Plan'. The Standard, 7 February. http:// www.thestandard.com.hk/news_detail.asp?pp_cat=\&art_id=22854\&sid=\&con_ type $=1 \&$ d_str=19960207\&isSearch=1\&sear_year=1996.

Ng, Joyce. 2012. 'Two Proposals on Shortlist for Bridges Street Market Project'. South China Morning Post, 13 November. http://www.scmp.com/news/hong-kong/ article/1081012/two-proposals-shortlist-bridges-street-market-project.

Ng, Mee Kam. 2014. 'The State Planning Rights in Hong Kong: A Case Study of “Wall-Like Building”'. Town Planning Reviews 85(4): 489-511.

PD [Planning Department: The Government of the Hong Kong Special Administrative Region]. 2009. 'Chapter 6: Retail Facilities'. April. http://www.pland.gov.hk/ pland_en/tech_doc/hkpsg/full/ch6/ch6_text.htm.

PDCD [Population by District Council District]. 2001, 2006, and 2011. http://www. census2011.gov.hk/en/main-table/A201.html.

Rancière, Jacques. 2009. The Politics of Aesthetics: The Distribution of the Sensible. London: Continuum.

Shepherd, Robert J. 2009. When Culture Goes to Market: Space, Place, and Identity in an Urban Marketplace. New York: Peter Lang.

Smart, Josephine. 1989. The Political Economy of Street Hawkers in Hong Kong. Hong Kong: University of Hong Kong.

Staiff, Russell. 2014. Re-imagining Heritage Interpretation: Enchanting the PastFuture. Farnham: Ashgate.

Stillerman, Joel. 2006. 'The Politics of Space and Culture in Santiago, Chile's Street Markets'. Qualitative Sociology 29(4): 507-30.

Sung, Timmy and Tony Cheung. 2014. 'Kennedy Town MTR Station Opens but Not Everyone is Happy with the Pace of Change'. South China Morning Post, 29 December. http://www.scmp.com/news/hong-kong/article/1670332/ kennedy-town-mtr-station-opens-not-everyone-happy-pace-change.

Trading Economics. 2015. 'Hong Kong Average Monthly Salaries'. http://www. tradingeconomics.com/hong-kong/wages.

URA [Urban Renewal Authority]. 2011. 'Urban Renewal Authority-Western Market'. 1o September. http://www.ura.org.hk/en/projects/heritage-preservation-andrevitalisation/central/western-market.aspx. 
Watson, Sophie. 2009. 'The Magic of the Marketplace: Sociality in a Neglected Public Space'. Urban Studies 46(8): 1577-91.

Watson, Sophie and David Studdert. 2006. Markets as Sites of Social Interaction: Spaces of Diversity. London: Joseph Rowntree Foundation.

Watson, Sophie and Karen Wells. 2005. 'Spaces of Nostalgia: The Hollowing Out of a London Market'.Journal of Social and Cultural Geography 6(1): 17-30.

Wordie, Jason. 2002. Streets: Exploring Hong Kong Island. Hong Kong: Hong Kong University Press.

\section{About the author}

Maurizio Marinelli is Associate Professor in East Asian History and CoDirector of the Asia Centre at Sussex University. He is also a Visiting Senior Research Associate at the UCL Institute for Global Prosperity. The focus of his research is located at the crossroads of Chinese history, politics, and society, connecting socio-spatial transformations in China to wider themes of colonialism and globalization, territoriality, identity formation, citizenship construction, and the impact of gentrification. Marinelli has worked for a number of years on the port city of Tianjin, from the foreign concessions era (1860-1945) to the present. On this topic, he has recently co-edited a volume titled China: An Historical Geography of the Urban (2017, Palgrave). He is now writing a single-author manuscript entitled Hong Kong: Markets, Street Hawkers and the Fight against Gentrification (2019, Zed Books). 



\title{
10 Street Vending from the Right to the City Approach
}

\author{
The Appropriation of Bhadra Plaza
}

\author{
Lila Oriard Colin
}

\begin{abstract}
This chapter explores the kinds of spaces that street vending informally produces. Street vendors use space, but they also change it in a strategic way so that it better serves their commercial needs. By doing so, they generate efficient (market) spaces that might alter the nature and values of public space - a process not without tensions between the different stakeholders and users of the space. The chapter highlights the dialectic relation between street vending and public space. Bhadra Plaza in Ahmedabad's Old City is used as a case study to look at how street vendors have re-appropriated a space that was originally designed as a public plaza in the heart of the city's historical area, which obtained in 2017 a UNESCO World Heritage Site Nomination. The chapter considers two aspects: first, the political empowerment of certain groups of street vendors, especially the political threads that ensure their re-appropriation of the space. Second, it highlights the relationship between the groups' political power, the spatial patterns that drove the re-appropriation of space, and the process of codification to unveil the logic of the rules enforced by powerful groups and the benefits they receive from doing this. The central argument is that street vending is able to appropriate and shape space according to vendors' commercial interests. Henri Lefebvre's 'right to the city' and 'production of space' theory $(1968,1974)$ was used to examine the connections between the organization, empowerment and mobilization of street vendors' groups and the process of appropriation of public space from a grounded approach.
\end{abstract}

Keywords: street vendors, right to the city, appropriation, Bhadra Plaza, Ahmedabad

Cabannes, Yves, Douglass, Michael and Padawangi, Rita, Cities in Asia by and for the People. Amsterdam: Amsterdam University Press, 2018 DOI $10.5117 / 9789462985223 / \mathrm{CH} 10$ 
Figure 10.1 Maps of (a) India and (b) urban area of Ahmedabad
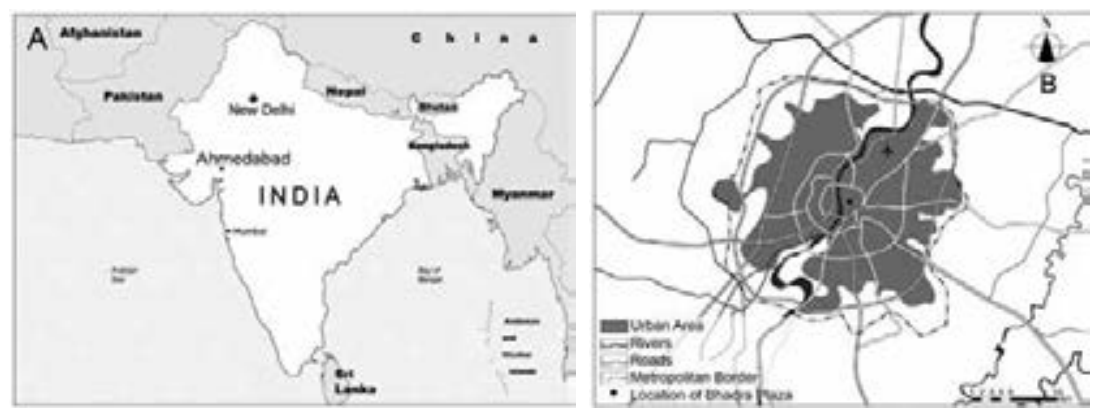

Source: Ariel Shepherd

1

\section{Introduction}

Street vending is a widespread activity in Global South cities despite its lack of formal regulation. It contributes in a positive way to alleviating poverty, supplying goods and services for low income groups, and creating employment and business opportunities for vulnerable social groups (Brown 2006). Street vendors are able to make attractive commercial places such as food markets, which function as places for social interaction, or specialized street markets that offer a great diversity of commodities within the same business line. In its different modalities, street vending is part of the social and economic life of cities, an element that contributes to making the city a collective construct.

The integration of street vending into the city is, however, problematic. This chapter explores how public space changes when groups related to street vending take control and enforce their rules (codes) in favour of the market's interests. I explore two of the main challenges to integrating street vendors into public spaces. First is the allocation of vending spaces by city authorities in the context of the renovation of the city centre; the second, more theoretical, challenge is the alienation of the 'public' nature of space, especially when it is dominated by powerful groups of vendors who rent out or sell valuable vending spots to other vendors. I use the renovation of Bhadra Plaza in Ahmedabad, India as a case study to demonstrate how street vending may evolve and alter the values of space over time.

To develop this argument, I use Henri Lefebvre's concepts of the right to the city and the production of space $(1968 ; 1974)$. When applied to street vending, the right to the city approach highlights who is able to make decisions on the uses of a public space, which role is played by each of the actors, and how the interplay of power and interests shapes the physical 
and social form of space (Mitchell 2003). Street vendors occupy public spaces but, are usually not considered a group that has a right to decide about the city and or to receive allocated spaces in public areas. However, they take an informal place in the city-making process and are able to deter authorities' decisions and instead enforce their own codes according to their commercial interests. Moreover, they are able to arrange space to enhance the attractiveness of the market areas; thus, street vendors do participate in the organization of the cities.

Following Lefebvre's theoretical framework, this paper explores two interrelated concerns. First, the conflicts that are generated between the exchange value and the use value of a public space. Exchange value of space emerges when it is appropriated and altered to fit the business purposes of the street vendors. ${ }^{1}$ Vending space is valuable for street vendors, as it is essential for running their business. In prime locations, where potential clients are abundant, space can be sold or rented out by the vendor who originally appropriated that space; this is a widespread practice in certain locations. The exploitation of space for commercial purposes requires an individual or group to gain control over that space-a process that creates tensions and open conflicts between local groups and authorities. The use value of a space, such as children playing on the streets or spontaneous gatherings between locals, is excluded or marginalized from spaces dominated by powerful groups of street vendors.

Second, I describe the mechanisms that allow specific groups of street vendors to build their capacity to appropriate and codify space. I look at this process in the context of the renovation of the Bhadra Plaza. Space appropriation by street vendors takes place through informal arrangements and customary codes. This occurs as streets and open spaces tend to be places that can be appropriated spontaneously which is part of the way they work on a daily basis, especially in the Global South. However, the absence of frameworks to establish the ways space is appropriated becomes problematic as the activity expands.

The case is interesting as India is one of the first countries to recognize the positive contribution of street vending by enacting the Street Vendors Protection of Livelihood and Regulation of Street Vending Act nationwide (Ministry of Law and Justice 2014). This law forces Indian cities to develop a strategy for integrating vendors into the city planning process in two specific

1 Exchange value and use value are concepts developed in Marxist theory applied to raw materials and labour used as means of production. H. Lefebvre applied these concepts to urban space and its making process (Lefebvre 1974). 
ways. First, cities must recognize street vendors' right to participate in the decision-making process through the creation of Town Vending Committees, which include different stakeholders, experts, city authorities, and street vendors' representatives. Second, cities are called upon to allocate specific areas to street vendors so that they can carry out their activities without being harassed. Authorities identify street vendors and grant them a license that allows them and their family members to sell in a specific area, which was based on guidelines developed in 2009 (AMC 2010). The main objective of this policy is recognizing street vending as part of the current functioning of Indian cities and its role in poverty alleviation (Ministry of Housing and Urban Poverty Alleviation 2013). This law recognises the importance of protecting vulnerable street vendors from evictions in principle. However, the law overlooks the power relations between different groups of street vendors at the local level and the value that vending spots acquire, especially in prime locations.

This chapter is based on six months of field research in Ahmedabad, in which I studied street vendors' integration into Bhadra Plaza after its renovation in 2013, a project in the heart of Ahmedabad's city centre. I used mapping and in-depth interviews with key community members and authorities as research methods. The case demonstrates a spectrum of power among street vendors' groups and how the more powerful ones dominated the reorganization and valuation of the plaza despite the will of the authorities to get control of the allocation of spaces.

\section{$2 \quad$ The Right to the City as a Theoretical Approach}

One of Henri Lefebvre's major contributions to urban theory was the explanation of how political and economic processes relate to the dynamics of space (Lefebvre 1968; 1974). As a result of the interplay of forces, dominant groups can codify space to fit their specific interests. In my research, this was evident in how powerful groups of street vendors dominated the uses of a public space and changed it into a kind of commodity, an object used for individual commercial purposes. In fact, Lefebvre proposed that modern societies tend to make of urban spaces a commodity that serves capitalistic purposes, by doing so, they enter into contradiction with their original use value. For example, social housing units are produced, as any other market items, to be sold rather than to create adequate social environments for the inhabitants. The case of city centres is similar, they are not new urban settings but they are appropriated and changed to 
promote a culture of consumption (Lefebvre 1968). A culture of consumption refers to buying goods, food and similar services in space but also to the symbolic consumption of the spaces themselves. In the capitalistic societies a branded bag, to give an example, is not bought only to carry things, which is its original use value, but rather, as it might become a sign of social status, the bag is consumed symbolically in this way. From Lefebvre's perspective, a similar process occurs with urban spaces, they are created or appropriated not to become social environments, its original use value, but to become objects used for commercial, capitalistic purposes (Lefebvre 1991).

The use value of a public space is expressed through the diversity of ways it is appropriated by different groups creating a social environment. Streets, for example, are made for transit and gathering, for children to play in, and for social interaction. Commercial uses and street vending might be part of the diversity of uses of public spaces. As suggested by Lefebvre, the change towards a different set of values is unveiled when spaces are appropriated by a few dominant groups preventing others to use them, they become subordinated spaces. In the case of street vending, selling spots in the streets and open spaces become valuable assets as the street markets gain recognition and attractiveness, and thus tend to be appropriated to make a business out of them, preventing other noncommercial uses of space.

I use Lefebvre's concept of 'space codification', which refers to the codes that regulate space and define the uses of the place: who can use it and for what purposes (Lefebvre 1974). In some cultures, these codes are established by legal frameworks and authorities, while in others they emerge from daily negotiations among users of the space or are framed by customary practices. Examining vendors' appropriation of the streets also requires an examination into the codification of the space.

Diversity of use is an indication of the balance between the use value and exchange value of a space. For example, a square called Manek Chowk in Old Ahmedabad City is used for diverse functions throughout the day. In the morning, it is used to feed cows; in the afternoon, it is a parking area; at night, it becomes an attractive street-food area visited by locals from different social classes and from different city areas. Street vendors in Manek Chowk play a role in creating a hub of social interaction, a meaningful place for the citizens, in co-existence with a multiplicity of other social and commercial activities. In this case, a balance of values is reflected in the fact that the Chowk is not dominated exclusively by the street vendors' group. 
A clear expression of the street vendors' domination of streets is when vending spots are illegally rented out or sold by more powerful groups to street vendors in the area. Street space rentals show how a vending place (i.e., space) can become a very tangible asset, associated with a monetary value and, depending on demand and supply, generating an economy of street space. ${ }^{2}$ In these cases, the commercialization of vending spots, related directly to the exchange value of space, contradicts the other noncommercial uses, generating conflicts among different social groups. The Bhadra Plaza case is no exception. The recent renovation has changed the characteristics of the place rendering it more attractive for commercial purposes, a business opportunity that street vendors did not easily let go.

I used Lefebvre's above mentioned ideas to examine two aspects of the Bhadra Plaza case: on one hand the plaza renovation process led by city authorities; and on the other hand, the capacity of powerful groups of street vendors to appropriate space and enforce informal codes to set the organization of the street vendors in the plaza.

\section{The Bhadra Plaza Case}

The case of Bhadra Plaza provides an example of how a city planning failure can be used by local groups to extend market's activities. Bhadra Plaza is located in the heart of the Old City, a symbolic place for citizens as it is strongly attached to the origin, history, and identity of Ahmedabad. Before the renovation project, the plaza had around goo vendors; after the renovation finished in 2014, the number of street vendors had doubled - far beyond the expectations of the city authorities and plans. Before the renovation, the Old City commercial area had approximately 5500 street vendors: 3500 between Bhadra Fort and Teen Darwaja, and 2000 towards Manek Chowk in 2013 (Centre for Urban Equity 2014). ${ }^{3}$ Now, Bhadra Plaza is one of the city's prime vending locations and is dominated by market activities. To sell in Bhadra, vendors pay INR 200 (3 USD) per day to local leaders; in nearby streets and other city areas, they pay INR $5^{\circ}$ (o.74 USD).

2 I explored in-depth the domination of streets and open spaces by street vendors in the Tepito case in Mexico City (Oriard 2015). In this case the market area had expanded and deeply transformed the low income neighbourhood into a globally connected market place of around 12,000 street stalls dominating the economy of the place, and exploited by the local families.

3 The Bhadra-Manek Chowk market area sells a wide diversity of goods in specialized commercial streets. The specialized market areas include: a shoes street, a sari street, a book area, a cloth market, a second-hand clothes market, a cooking utensils area, and an eateries area. 
The case study also shows that street vendors have a good understanding of space and how to arrange it to maximize their businesses. They use strategies such as occupying corners to expand their market facade, creating pathways, displaying their goods in vertical structures to make them more visible, and creating specialized business line hubs to create a commercial identity. By doing so, street vendors are able to transform the plaza into a highly organized marketplace. However, the expansion of street vending generates problems with other social groups that are excluded from the place. Nearby apartments have been transformed into storage places; residents complain about noise and difficulties with access to their house entrances. Local shops have become more specialized with a focus on external visitors, with a reduction in the number of general stores for residents. People looking for a place to sit and relax find only residual market spaces with limited views of the plaza. Street vending maximizes the commercial value of the plaza but disincentivizes other uses.

Most of the population welcomed the plaza's renovation project. One of the reasons for this public support was the lack of well-designed public spaces in the city. Interviews I conducted when the plaza opened discovered people's appreciation of the city's provision of space for them to rest, sit, and admire a beautiful setting: the Old City. Some interviewees explained that before the renovation they had no space to take a break because the whole space had been used intensively for market activities, parking, and the movement of cars. ${ }^{4}$ In fact, in the nineteenth century, the plaza had been converted into a road intersection connecting the city's two main bridges (Nehru Bridge and Ellis Bridge) with two main roads (Gandhi Road and Relief Road) (see Figure 10.3 (a)).

The area's easy access by cars and two-wheel vehicles was an important condition for increase in the commercial activities along the roads. Figure 10.2 shows the organization of street vending along the roads and the Bhadra Kali Temple. Different elements such as traffic, parking hubs, numerous clients visiting the place, temples, and public buildings, just to name a few have played a role in creating the perfect conditions for commercial activities to expand, see Figure 10.2 (b). All of these elements formed an ecosystem in the area; traffic and congestion are favourable conditions for street vending.

4 Five people were interviewed in the plaza. Most were happy with the result; they told me about the activities they usually do in the plaza. Most of them came to sit, chat, rest, and observe, while others came to purchase goods. Interviews were held on the 21 February 2014, when the plaza was partially opened after the renovation. 
Figure 10.2 Organization of street vending in the plaza before the renovation
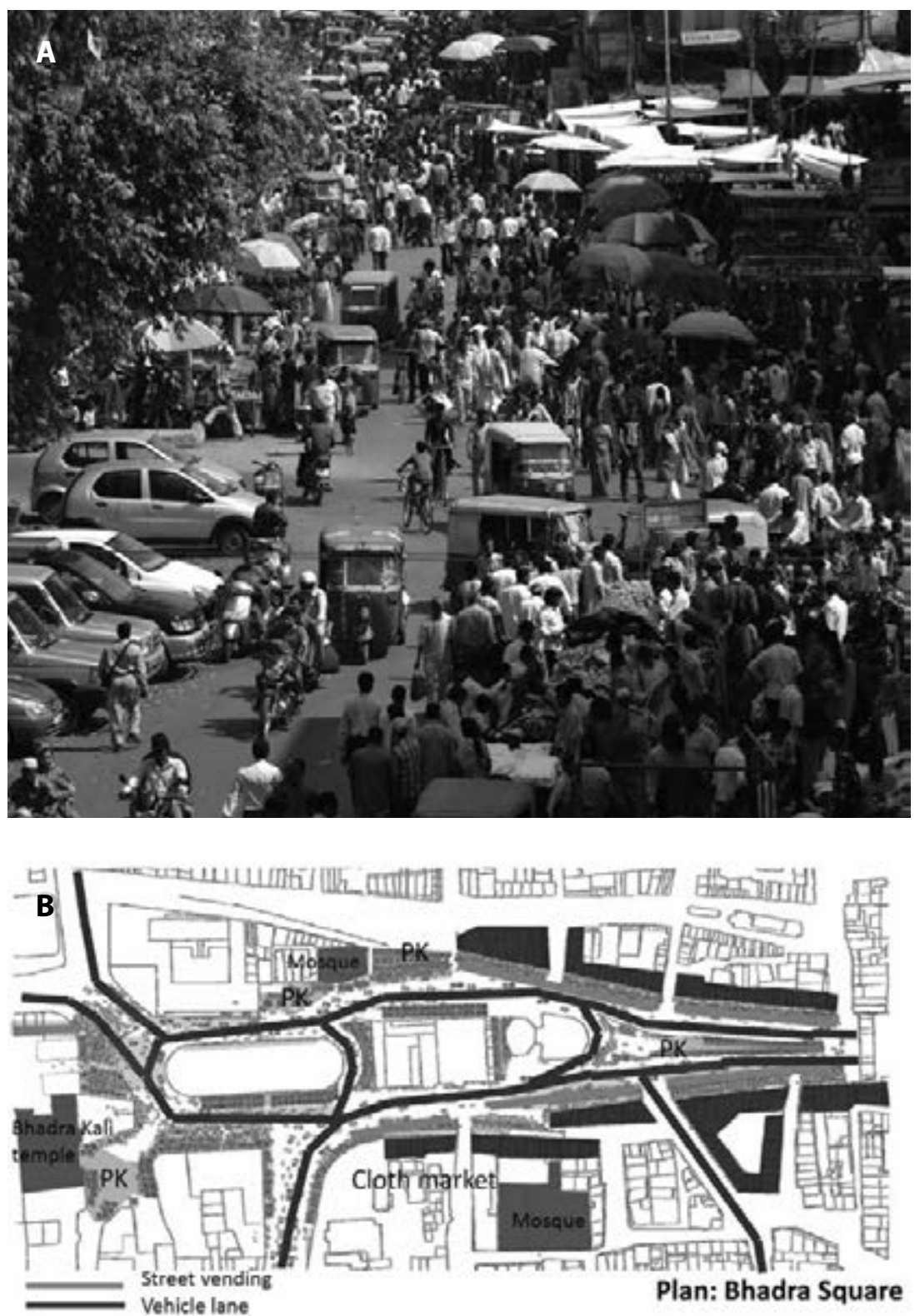

Source: Rocio Conesa 2011 (a) and Lila Oriard (b) ${ }^{5}$

5 Special acknowledgments are given to CEPT University students who shared the background images of the area used to do the maps in Figure 10.2 (b) and Figure 10.3 (a and b). 
Figure 10.3 Bhadra Plaza transformed into a pedestrian area
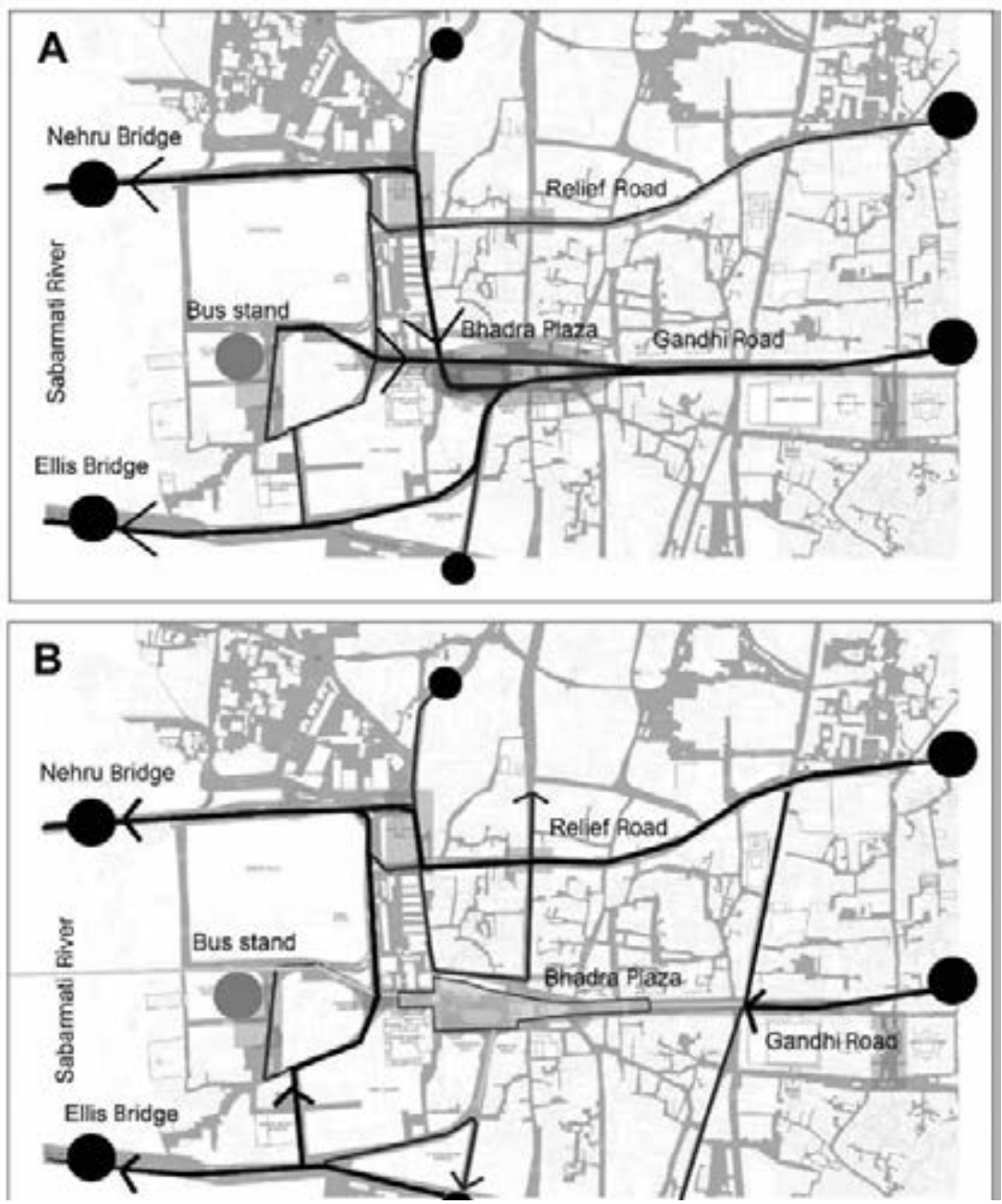

Source: Lila Oriard 2013 (a) and (b)

Bhadra Plaza's renovation was done by the Ahmedabad Municipal Corporation (AMC) with the intention of 'giv[ing] the place back to the city' as an accessible space for all to walk, sit, and enjoy the place by creating an area for pedestrians. ${ }^{6}$ Figure 10.3 (a) and (b) shows Bhadra Plaza's conversion into a pedestrian area, a radical change made by the reorganization of vehicle

6 The project's information was sourced from in-depth interview with the private-sector architect in charge of the plaza's design and execution; the same information was confirmed by 
traffic in the area before and after the renovation, and which also changed the conditions for street vending.

The Bhadra Plaza redevelopment project intended to highlight the value of the historical area. In fact, for at least the past decade the AMC's Heritage Department has been trying to obtain a UNESCO World Heritage Site nomination for the Old City, which was obtained in 2017. Ahmedabad is the only Indian city included in the heritage list. 7 The plaza's renovation would have enhanced the aesthetic value of a core area surrounded by historical monuments. Two officials whom I interviewed ${ }^{8}$ mentioned that the project was inspired by the renovation of European historical centres and public spaces. However, the Bhadra historical area was not a post-industrial area, as is the case of historical cities in Europe. On the contrary, the area already hosted one of the most vibrant, informal, and historical markets in the city.

The cloth market, for example, located at the south end of the plaza, had been around since the city was founded and had been part of the city's entrepreneurial spirit and history. When the cotton mills closed in the 1980 s many people lost their employment, and during this crisis period, the market started expanding and shifted from selling raw materials (fabrics) to distributing manufactured garments. After the violent riots between Hindu and Muslim communities in 2002, ${ }^{9}$ the clothes market welcomed many vendors with Muslim origins, who encountered difficulties in finding job opportunities in other parts of the city (Breman 2004, 132). Since then, street vending has generated employment opportunities for local families and minorities, which can be considered its important contribution to the city. This market, although part of the plaza and its vending dynamics, was ignored in the renovation project's design.

AMC officials. The Bhadra project was co-financed by the JNNURM (Jawaharlal Nehru National Urban Renewal Mission) National programme and to a lesser degree by the city (AMC).

7 The historic centre of Ahmedabad has a unique organization of space based on community units called pols; this feature merited consideration for the UNESCO nomination. The old city resembles a labyrinth connecting one pol to another. The community system in the old city has almost disappeared due to changes in the society and the introduction of 'modern' lifestyles. Local families, especially the middle- and upper-income groups, tend to move to other parts of the city looking for more comfort. Important efforts have been made to restore some traditional wooden houses and to create some heritage promenades for tourists.

8 The interview was conducted on 15 February 2014 at the AMC offices with Mr. P.V.K. Nair DGM (Deputy General Manager), Heritage Department, and his assistant.

9 In 2002, a train with Hindu pilgrims was set on fire, presumably on purpose. It is unclear how this occurred and who did it, but Muslims were massively condemned for this atrocity. Hindu citizens went out and killed many Muslims, who reacted with the same violence. The Ahmedabad city government remained silent for two days before protecting the Muslim population; this behaviour by the government was widely questioned. 
Figure 10.4 Expansion of the Bhadra Plaza street market

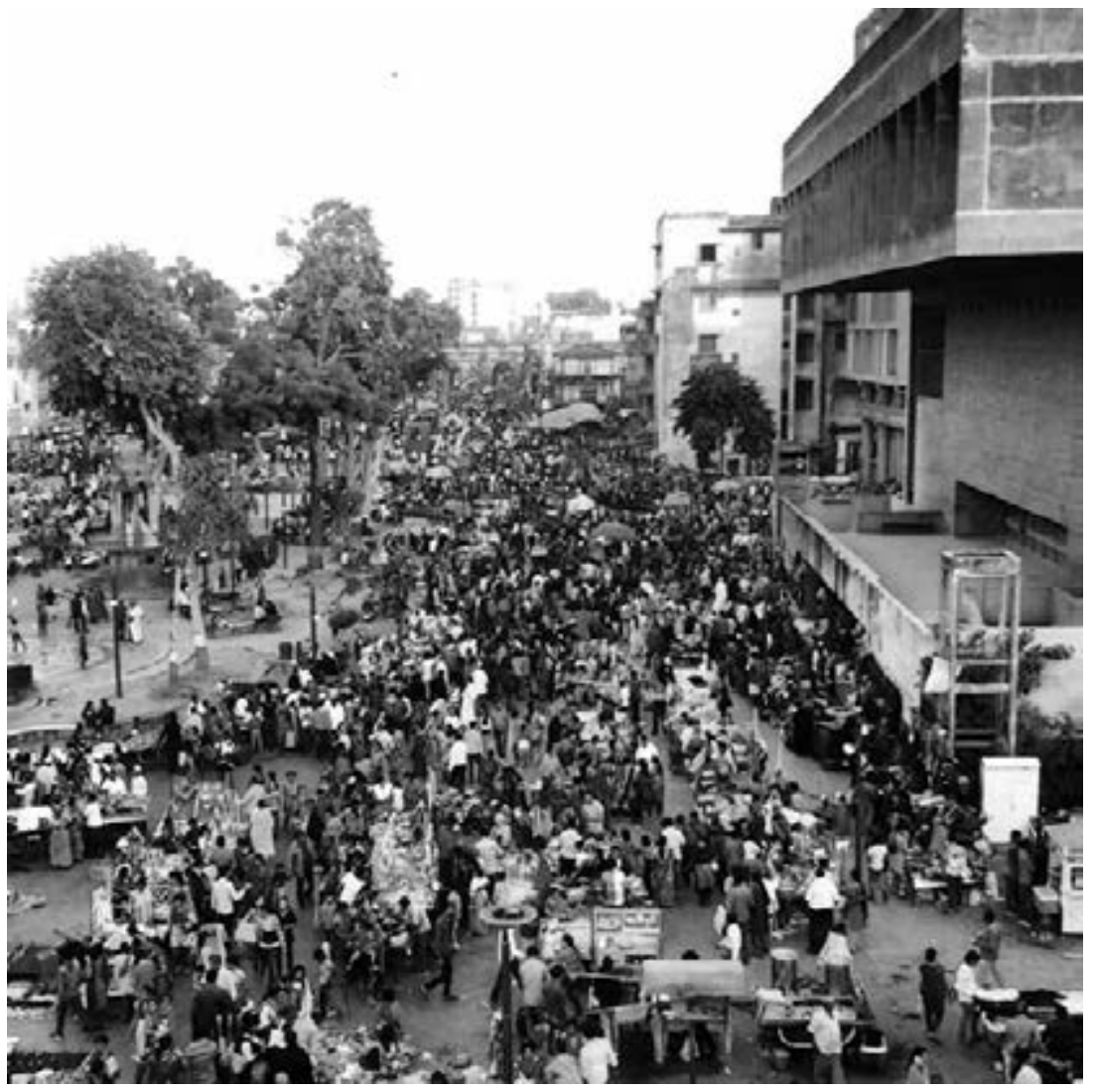

Source: Rocio Conesa 2014

The new design for the plaza involved creating a large, open perspective from the Bhadra Fort to Teen Darwaja. Two buildings were demolished to clear the area, and an existing group of trees that used to be in an enclosed green were integrated into the plaza. The design featured amenities such as a fountain in the middle of the plaza and a sitting area under the shade of trees. Spaces on the edges of the plaza were allocated for street vendors. However, the design of the plaza overlooked the vendors' commercial needs and their interests in vending space.

The AMC allocated 600 vending spaces for existing vendors in the renovated plaza, but this process was never enforced because the local vendors considered it unfair. The architects and city planners had planned for the post-renovation vendor spaces to be in the same exact locations as vendors had occupied before, but did not consider that the new condition of the 
plaza would lead to new street market configurations. According to the project manager, there were around goo street vendors in the area before the renovation..$^{10}$ In the months following the completion of the plaza, the number of street vendors increased rapidly; in 2015, a year after the opening of the plaza, there were a total of 1200 street vendors illegally using most of the pedestrian-designated areas for market activities. The designers had overlooked the business opportunity that space represents for street vendors to create new businesses and expand their present ones. The renovation of the plaza increased the quality of public space which in turn increased the demand for vending spaces in the area. The form of the plaza changed as two buildings at the centre of the area were demolished to enlarge public space and clear the view to create a direct perspective from the Bhadra Fort to Teen Darwaja monument. The design of the plaza was pedestrian friendly, the use of natural materials such as granite enhanced the quality of space. As the demand for vending spots increased, many vendors were willing to pay a higher daily amount to run their businesses in the plaza. Paradoxically, the plaza's design created an economy of vending spaces, causing the street market to expand. Figure 10.4 shows the new distribution of the market's activities in the plaza as of 2014.The vendors now occupy the public plaza entirely, extending the market into the areas that were planned for pedestrians and changing distribution patterns according to pedestrian flows in the plaza. Consequently, a public plaza designed for a diversity of (especially leisure) activities was converted into a marketplace-a result different from what was expected in the original design.

\subsection{Difficulties allocating spaces for the street vendors}

After the completion of the plaza, the AMC was unable to implement the allocation of vending space. The planning tools concerning street vending at city level were limited and presented serious implementation problems, especially in contested locations like Bhadra Plaza (AMC 2010). Some organized groups of vendors mobilized in February 2014 asking for recognition from the city authorities and allocation of vending spaces for all the members of the organizations within the plaza, following the national Street Vendors Act that was finally approved some weeks before the demonstrations took place.

10 An interview was conducted with Mr. U. Sharma, Director of the CEPT Research and Development Foundation at CEPT University in March 2013. He was in charge of the Bhadra Plaza project, and his team kindly provided information about the on-going project. 
In this process, two important space codes were neglected. First, vending space is highly important for vendors. As their businesses depend on access to the streets and other public spaces, relocation would seriously impact their livelihoods. Some vendors had regular clients who came to their stalls; others had formed complementary commercial hubs by associating business lines with areas of stalls (shoes, clothes, socks, and accessories, for example). For this reason, one of the main concerns of the street vendors was to have specific areas assigned to them, individually, and should appear as such in the plan. The authorities reacted with silence and ambiguity to this specific demand. City authorities could not designate an area of public space with a name as if it was a private property, but some mechanisms to secure the vendors' assets could have been taken into account.

Second, the AMC overlooked the organizational capacities of some vendor groups and their ability to establish political networks, especially the Muslim groups that felt particularly vulnerable in this situation. After the 2002 riots, there are continued tensions between the different ethnic groups in Ahmedabad. AMC's passivity and silence regarding space allocation during the construction phase also created tensions between different vendor groups. The Bhadra historical area includes a range of local communities, many of Muslim origin. In this case, Muslim groups have shown an important capacity for organizing, mobilizing, and appropriating the plaza as a reaction to the threat of eviction. This shows how distrust of and marginalization in the planning process can trigger the development of communities' capabilities.

An in-depth interview with leaders of the Self-Labour Organization (SLO), an association that was created in 2013 from a previous organization, ${ }^{11}$ revealed how the AMC did the survey to define which vendors had the right to a place in the plaza. According to them, two people from the AMC went to the plaza to do a survey in 2011, before the new plaza layout was designed. They had a computer and used a few different locations to interview street vendors individually and register them in a database. The vendors claimed that the surveyors had never conveyed that this was the official AMC survey, nor did they mention how critical it was for the vendors to register in order to get space allocations some years later. Furthermore, other institutions,

11 The interview was held at the office of the Self-Labour Organization (SLO) behind Bhadra Plaza on 12th January 2015. The Gujarati-English translation was done by the street vendors themselves. It is worth mention that as a female, foreign researcher it was easier to obtain sensitive political information by myself, rather than in the presence of local researchers. Two of the leaders were there during the interview, and a small group of street vendors gathered around us and shared a few comments. 
including the architects in charge of the design, some students, and some researchers, were conducting surveys at the same time. Consequently, street vendors were confused and did not know which survey was the official one. This created a lot of confusion and a feeling of distrust in the AMC procedure. One street vendor who got official registration after the plaza renovation, explained that he used to be a mobile vendor. On one fine day while passing by the plaza he registered with the AMC by chance and eventually managed to secure a place to sell in Bhadra Plaza. He said he felt very lucky and happy, and afterwards he had joined the SLO to help other vendors, especially those who were not registered officially by AMC and had been selling in that area before.

In fact, many Muslim vendors who had long occupied spaces in the plaza were not recognized by the AMC survey, despite strong evidence of their occupation. This was the case for vendors who used to have places behind the Fort, near the Lal Darwaja bus stop. This group had been selling backpacks and luggage items, and they had confiscation receipts issued by the police when they had been evicted previously. In the receipts individual names appeared, effectively demonstrating that they had been vendors in the plaza at the time. Indeed, the length of time that a vendor had occupied space for business is a very important factor for legitimating his or her appropriation of the space. Even with this strong evidence, the AMC did not include this group in the official survey, resulting in a lack of allocated space for them. However, they were still using their spaces as before, and other local groups considered them legitimate users based on familiarity.

The street vendors were removed from the area during the construction of the plaza between 2013 and 2014. The authorities did not offer the vendors an alternative solution for keeping their businesses in operation during this time. They were allowed, however, to discreetly occupy other streets in the nearby area if they were able to find a place on their own. The vendors used their social networks to find places to sell and displayed a capacity for finding temporary solutions. Some found vending places near the mosque or in front of their relatives' houses. It is customary for a shop front to be considered an extension of the shop or residence; in some cases, street vendors ask permission to use these spaces or directly rent them from the so-called owners.

The vending space-related confusion and speculation during the plaza's renovation attracted new street vendors to the area. In December 2014, street vendors asked the AMC to accommodate 2000 vendors in the completed plaza (Times of India 2014). A letter send to the Municipal Commissioner, shown to me during an interview in January 2015, states the following: 'The 
municipal officials have removed 887 self-employed vendors of the 1500 vendors in the area without providing us with an alternative place to carry out our vending activities, violating thus the Honourable Supreme Court guidelines and provision set forth in the Vendors' Policy by depriving us from our livelihood'. A verification process was carried out by the AMC after the completion of the plaza to identify the local street vendors who were to be allocated a place in the plaza, based on the 2011 survey. However, many registered vendors were excluded because their fingerprints or position in the plaza did not correspond to the previous survey. After the verification process, the AMC identified approximately 700 street traders to be allocated space in the plaza, although the previous survey by the plaza designer office had listed 900 vendors.

This process was contested by the local street traders, causing political pressure to keep the vendors in the plaza. The vendors described how the AMC had quickly held a drawing to allocate the spaces to the street vendors and relieve political pressure. However, the allocation based on this drawing was eventually not enforced. This situation shows the difficulties for authorities to deal with the allocation of limited spaces in the context of growing demand for vending space. 'The vendors complained because the drawing was conducted when most original vendors were not at the location. The vendors alleged that nearly $75 \%$ of the vendors who figured on the list were outsiders' (Times of India 2014).

The AMC's management of this situation created confusion and the fear of eviction among the street vendors. As a result, Muslim groups organized demonstrations to contest the registration process and ask for transparency from the city authorities. They brought together unregistered vendors, who were claiming that they have been vending in the area before the renovation with those who were lucky to coincidentally get the registration. Vendors mobilized politically, simultaneously increasing their numbers and extending the limits of the market area. The AMC was unable to distribute space as per the plaza's original design, and the lack of clarity in the process of registration of the vendors resulted in discontent. Some vending places were considered in the design of the plaza, without taking into account to whom, individuals or groups, they will be allocated. The plaza design was not followed by a process that takes into account the street vendors' situation, needs and socio-spatial dynamics, it also lacked political agreements with local groups on how to do the allocation of spaces from a participatory, democratic perspective. Street vendors were considered in the plaza design plans but not as officially recognised actors of the city making process. 


\subsection{Groups' Resistance and Appropriation Strategies}

The street vendors I interviewed in the plaza agreed that the area should accommodate as many vendors as possible, as it is a very good place for vending activities. This reflected street vendors' interests and representation of space. The AMC had a very different idea: the plaza would be a public space for the city that highlights the beauty of the monuments. Although a garden was integrated into the original design, after the plaza's completion this space degraded rapidly and was eventually converted into a two-wheeler parking area for market customers. This shows how the representations and practices of space contribute to the production of spaces, in this case transforming a garden into a parking area.

Among the many groups in Bhadra Plaza, I worked with two groups: the Self-Labour Organization (SLO) and the Self-Employed Women Association (SEWA). Both organizations are different, and both have very strong ethnic characters: SLO incorporated mostly Muslim men, while the SEWA street vendors in Bhadra were mostly Hindu.

SEWA is a powerful non-governmental organization (NGO) with almost two million members across India. ${ }^{12}$ It is part of the National Alliance of Street Vendors in India (NASVI), and it is an internationally known organization. SEWA was established in 1972, when some women vendors were evicted from the Manek Chowk vegetable market area in Ahmedabad Old City and afterwards fought for recognition. For the past four decades, SEWA has been fighting for the legal rights of street vendors, especially women vendors. SEWA has won important cases at the High Supreme Court. In fact, it was after they won a case in 2009 that the Indian Government recognized the importance of integrating street vendors into the city, which eventually led to the issuance of the Street Vendors Act in 2014.

As in many countries of the Global South, in India planning tools are frequently inoperative at the local level because codes and rules that regulate street practices are constructed through the practice of customary codes or negotiated in informal arrangements with local leaders. This way of producing space creates an important gap between legislation and what actually happens at ground level. This is evident in the case of Bhadra; for example, a fruit stall owner who had been vending for ten years outside Bhadra Plaza was registered by the AMC and assigned a place inside the plaza, as per the drawing. However, after the new assignment of places, the local organizations did not allow him to occupy his new place, as it was located at the intersection of two paths 
that had previously been occupied by the clothes market vendors. This was a valuable spot that was already occupied by local leaders, who rented out the street spaces in front of their shop. The street vendors' law is supposed to protect more vulnerable vendors such as this fruit vendor, but in this case it is protecting the businesses of powerful local leaders. The local people did not recognize the fairness of the drawing and established their own codes based on how previous organizations had operated. The fruit vendor kept selling at his usual place outside the plaza's gate. Hence, the actual allocation of the vending spaces took place outside of the formal planning process and was enforced by power relations, namely local powerful leaders.

SEWA vendors got official recognition by the authorities almost without problems. During an interview in a slum in Navrangpura where some vendors live, ${ }^{13}$ the SEWA members said that they were not interested in obtaining a license or official recognition; they only wanted to have vending space. SEWA has political power and could secure this access, so the vendors could rely on the NGO to do the negotiations for them. There were no mobilizations of SEWA members, as they did not claim their rights by themselves without SEWA's mediation. Indeed, SEWA membership provided some level of protection for the vendors. One vendor woman who was interviewed showed some documents that proved she had been a SEWA member for a long time. ${ }^{14}$ The documents served as evidence that she had been selling in the plaza before and legitimized her appropriation of space. This confirms that customary codes are very relevant in the appropriation and codification of the plaza.

SEWA vendors did, however, face conflicts with Muslim groups. Most of the women vendors keep selling, but some have lost their privileged positions. For example, one vendor was displaced from the Bhadra Kali temple to a different location in front of the Zila Panchyat Bhawan - an effect of 'muscle power', as she described it. A fruit vendor in the area who was not involved in local conflicts said that the SEWA members sometimes increased their numbers by inviting family members to join, which increases the number of street vendors in the area. Vendors from other groups complained about this as vending spaces are limited and highly contested. ${ }^{15}$ Local groups of

13 The interview was conducted on 7 th January 2015 with a group of local street vendors in Navrangpura, the settlement is known as 'Hollywood'. The translation from Gujarati was done by the research assistant.

14 This vendor woman was reluctant to talk to us and decided to call other traders and family members so she would feel more comfortable. It was clear that they were reluctant to talk and were worried about misinforming others.

15 The interview was conducted on 2 January 2015 in Bhadra Plaza, translation from Gujarati was done by the research assistant. 
street vendors were competing among themselves to get as much space as possible, as space was a valuable resource for all of them. Power relations were important in understanding who was getting the better places and for which purpose.

SEWA vendors seemed to keep using the same spaces and did not extend their vending spaces to the plaza central areas. However, some variations were identified. For example, one vendor I interviewed rented out four stalls selling women's accessories near the Bhadra Kali temple area, as well as a storage location in a building; to have control on the area, he run a small stall but his family business was to rent out space to other vendors. This information was verified in a second interview. ${ }^{16}$ The family appropriation of vending spaces for rentals was prevalent among other groups as well. The mother of this interviewee had gotten the stalls because she belonged to SEWA and she had kept them for the same reason; and yet, she rarely goes to the stalls because of her advanced age. Her sons continue the businesses. The ways street vending evolves and how space was inherited by family members merit consideration. As mentioned before, changing from vendors to space lenders is a common move, especially in valuable locations; this quickly spreading practice promotes public space to become a commodity, an exchange value, that benefits individuals and families but prevents others to use space. In fact, local leaders tend to get control of spaces just to rent them out - thereby contributing to the alienation of the nature of the public space as a community asset.

SLO had a different political strategy to carry out the appropriation of space: they relied on political relations. ${ }^{17}$ The clothes market street vendors were one of the most powerful groups, and used to have their own organization before the founding of SLO. Historically, Members of the Legislative Assembly (MLAs) from the Congress Party had given their support to these community leaders; currently, three MLAs from the Congress Party support the street vendors. Since 2012, a new MLA from the Bharatiya Janata Party (BJP) has also provided partial support to the vendors in Bhadra.

In an interview, SLO leaders stated that they were able to secure access to space through political connections. These connections were visually

16 The interview was conducted on 19 February 2014 in Bhadra Plaza, translation from Gujarati was done by a CEPT Faculty member.

17 The interview was conducted on 6th January 2014 in the SLO office with the leaders; a second interview on the 8th January in Bhadra Plaza was done with a local leader. I first got in contact with him in 2014 during my first interviews and keep in touch with him to verify information, as he spoke openly and gave precise information. The translation from Gujarati was done by the research assistant. 
displayed in the area through images of political leaders from both the Congress Party and the BJP. One of the shop owners in the clothes market had been able to secure fifty vending places in Bhadra for his people (i.e., street vendors under his protection), to whom he rented out the spaces. This person, who was highly respected in the area, owned ten formal shops and was a local community leader. After the plaza's renovation, he continued to rent out the same places, so the distribution of space was maintained. Street vendors considered this situation legitimate because they were using the same places that they had occupied before. This practice represented control over resources (i.e. vending spaces) by local leaders.

One of the most important leaders is H.bhai. He has 10 formal shops in the area; 50 of his people (street vendors under his protection) got space in the Bhadra Plaza. He earns around 10 ooo Rs per day (100£). He has good connections with politicians. He is an old leader in the area, an umbrella guy. Y.bhai has 5 stalls, Ib.bhai has 7 stalls, but they didn't get a place in the plaza. (notes taken during the interview, names are changed to ensure privacy of informant, 2014)

SLO interviewees ${ }^{18}$ explained that their main problem was the new leaders who had no connections to the local community but had powerful political connections that supported their appropriation of street spaces. More information about the new leaders was not available; however, during several interviews, it was confirmed that the number of vendors had increased considerably. Organizations that relied on political relations, such as SLO, sought to increase the number of their members, as their power of negotiation was related to the number of street vendors in the organization. Interviewees from SLO said that street vendors felt used by the political parties, who offered their support in obtaining spaces in exchange for political support, a phenomenon that exists not only in India, but in other countries as Mexico as shown by Cross (1988).

SEWA and SLO both ensured their members' access to space, but through different means. SEWA members relied on this NGO to defend their selling places. Most of the vendors from this group were able to keep their places, and only a few displacements were confirmed. In contrast, SLO relies on the political connections of local leaders. Their fear about being displaced played a major role in motivating the vendors to organize and mobilize. Because of their organizational capacity, SLO members appropriated important 
areas in the plaza, expanded market activities, ensured control of space, and established new codes regulating access to vending spaces that were enforced by powerful local leaders.

The Bhadra Plaza case shows that the AMC had little control of the groups that were appropriating public space for commercial uses and the market activities in the plaza. This gap was used by local powerful groups to transform the intended public plaza into a street market area. This happened for at least three reasons: first, the architects' plan was inspired by European designs for public space that had little to do with the Indian context; second, the plan did not consider the street vendors' interests, especially their attachment to space as a valuable resource for running their businesses; third, the survey of original vendors was done in a way that generated feelings of distrust and fear of eviction, which motivated the vendors to mobilize and protect their interests. The street vendors showed great capacity to mobilize and secure their most important asset: vending spaces. The domination of market activities in the plaza alters the value of the space, as its becomes a business asset for the benefit of specific interest groups.

\section{$4 \quad$ Conclusions}

The right to the city was used by the street vendors in Bhadra Plaza to claim their right to vending spaces after the renovation of the place, as per India's recent enaction of a law protecting street vendors. In fact, this concept is widely used to point out that marginalized groups are excluded from city planning and design processes. However, the theoretical concept of the right to the city does not intend to defend the interests of specific groups, but instead looks at the qualities (and values) of space from a wider perspective. The street vendors certainly have the right to take part in the city-making process and to have their interests expressed in the physical form of space-just as much as the other actors who express different views and uses of space. Indeed, when street vendors dominate a public space to get individual profits from its commercial exploitation, preventing other uses, their attempt to obtain the right to the city alters the quality of space as a collective construct characterized by its diversity of use values.

An interesting lesson from the Bhadra Plaza case is that the way the AMC managed the process of identifying vendors and allocating space produced fears of eviction, which in turn played an important role in 
motivating street vendors, especially Muslim groups, to mobilize to keep their places in the plaza. This shows that the value of space in the plaza for street vending was becoming more valuable as it became more suitable for running profitable businesses. Vulnerable vendors were protected by powerful groups and leaders mobilized to protect their own interests. After the opening of the plaza and the official allocation of spaces, the street vendors reorganized according to the groups who have appropriated certain territories. This was true in the case of the fruit vendor who was displaced from his officially allocated vending space, which was controlled by the clothes market leaders.

The Street Vendors Act was used by powerful groups and organizations to defend their interests and those of the market, but it was not useful for empowering vulnerable vendors directly. Women vendors, for example, are still struggling to keep their spaces against the 'muscle power' of other groups. This situation highlights a limitation of the law at the ground level. Marginalized vendors are still dependent on powerful structures and leaders; some are displaced, and some continue to be harassed. This situation unveils a deep disconnection between the law and the complex reality taking place on the ground.

The right to the city approach is useful for identifying some of the limitations in the implementation of the street vendors' protection law at the local level. The municipal corporation lacked reliable information on the different groups operating in the plaza, their relations of power, and their capacity to mobilize. When the allocation of spaces was contested, the AMC faced difficulties in proposing an alternative and re-taking control of the process. In spatial terms, the municipal corporation did not expect that the renovation of the plaza would create a demand for street vending space due to its commercial value. The result is that the design for a public plaza resulted in a dysfunctional marketplace where gardens are used as parking spaces, some pedestrian spaces are used by the vendors' vehicles or their clients, and the planned view of the Teen Darwaja is completely blocked by street stalls.

This emerging arrangement of the uses of this plaza is the result of a complex process of the production of space, including its recodification. When the street vendors were able to appropriate and give a commercial form to spaces through informal practices and establish their own rules through the exercise of power, the qualities of the public space changed. Now the use of the space is clearly unbalanced and many other actors, such as the plaza's visitors, are clearly excluded. 


\section{Acknowledgements}

All my gratitude to Prof. Yves Cabannes for his support and valuable feedback. The in-depth interviews with local street vendors and leaders would not have been possible without the kind help of Madhu Bharti, faculty member at CEPT University, and Aseem Mishra, research assistant at the Centre for Urban Equity, CEPT University.

\section{Works Cited}

Ahmedabad Municipal Corporation. 2010. Street Vendors Scheme 2010. Ahmedabad: Ahmedabad Municipal Corporation.

Breman, Jan. 2004. The Making and Unmaking of an Industrial working Class: Sliding Down the Labour Hierarchy in Ahmedabad. Oxford: Oxford University Press.

Brown, Alison, ed.20o6. Contested Space: Street Trading, Public Space, and Livelihoods in Developing Cities. Warwickshire, UK: ITDG Publishing.

Centre for Urban Equity. 2014. Inclusive Design for Street Vendors in India. Ahmedabad: Centre for Urban Equity and Cardiff University. http://portfolio.cept. ac.in/wp-content/uploads/2014/o2/Inclusive-Design-for-Street-CUE-02-12-14.pdf.

Cross, John. 1998. Informal Politics: Street Vendors and the State in Mexico City. Stanford: Stanford University Press.

Ministry of Housing and Urban Poverty Alleviation, Government of India. 2013. Support to Urban Street Vendors (Operational Guidelines). National Urban Livelihoods Mission.

Lefebvre, Henri. 1968. Le Droit à la Ville. Paris: Anthropos.

Lefebvre, Henri. 1974. La Production de l'Espace. Paris: Anthropos.

Lefebvre, Henri. 1991. The Production of Space. Translated by Donald Nicholson. Oxford: Blackwell Publishing.

Mitchell, Dom. 2003.The Right to the City, Social Justice and the Fight for Public Space. New York: The Guilford Press.

Oriard, Lila. 2015. 'Street Vending and its Ability to Produce Space'. Ph.D. thesis, University College London.

Purcell, Mark. 2002. 'Excavating Lefebvre: The Right to the City and its Urban Politics of the Inhabitant'. GeoJournal 58(2-3): 99-108.

Mirror Ahmedabad.2014. 'Bhadra area dumpyard, once again'. Times of India group e-paper, 5 December 2014. http://epaperbeta.timesofindia.com/Article. aspx?eid=31819\&articlexml=Bhadra-area-dumpyard-once-again-05122014009006 
Ministry of Law and Justice. 2014. 'The Street Vendors (Protection of Livelihood and Regulation of Street Vending) Act, 2014'.The Gazette of India, Extraordinary. New Delhi, 5 March.http://www.indiacode.nic.in/acts2014/7\%20of\%202014.pdf.

\section{About the author}

Lila Oriard Colin did her Ph.D. at the Development Planning Unit (DPU), University College London (2015). Her thesis concerned street trading and its ability to produce space in Tepito, a neighbourhood in downtown Mexico City; in this work, she argues that street trading changes the public spaces it occupies, which then become valuable commercial assets. Lila is an architect with two master's degrees in urban planning. She has several years of experience as an urban planner in France. In 2013-2014 she was a research associate at the DPU Urban Knowledge Network Asia hosted by the Centre for Environmental Planning and Technology in Ahmedabad, India. Recent publications include The right to the city, learning from the Tepito experience (2013); Contra la ciudad museo: el papel del comercio callejero para la conservación de los barrios tradicionales (2011); and Conservation in Developing Countries: Patan World Heritage Site in the UNESCO List in Danger (2006, co-authored). 



\title{
11 Surviving Existence through a Built Form
}

\author{
The Advent of the Daseng Sario \\ Cynthia R. Susilo and Bruno De Meulder
}

\begin{abstract}
This chapter explores how an excluded group of fishermen employs a built form as a tactic to deliver their actions of resistance and survive against the oppressive presence of the Boulevard Commercial Project (BCP) in Manado, Indonesia. Employing the rhetoric of 'delivering Jakarta lifestyle to Manado', a consortium of six private investors built the BCP on 70 hectares of land reclamation along the coast of Manado with the support of the local government. Despite its 'success', the BCP has transformed Manado into a stage for discontent. The remaining Sario fishing community suffers from marginalization caused by the city's denial of their existence and rights to the lands and sea, their social fragmentation from their former neighbours who have accepted the BCP, and the transformation of their neighbourhoods. All of these are the results of aggressive physical expansion by the BCP. With the backdrop of the physical built environment of the $\mathrm{BCP}$, the visual contrast among the dominant wealthy image of the BCP, the deteriorating settlement of the remaining Sario fishermen and the physical improvements in the settlement of their (ex-) fisherman neighbours looks very prominent. This chapter explores the acceptance, resistance, and meaning of the BCP from the local perspective through interviews and questionnaires distributed among the nearby residents, both groups of (ex-)fishermen, investors, and the key persons in local government during our ethnographic fieldwork conducted from 2009 to 2012. It reveals how the marginalized community has built their own spaces to defend their existence in urban space. It also shows that there is still a place where the marginalized group could reverse their power relationship with the oppressive development project, since the
\end{abstract}

Cabannes, Yves, Douglass, Michael and Padawangi, Rita, Cities in Asia by and for the People. Amsterdam: Amsterdam University Press, 2018 DOI 10.5117/9789462985223/CH11 
people have the capacity and tactics to deal with the situation. Physical development and built forms can mirror the tension and counter-reactions among the oppositional stakeholders in the urban space. However, built forms can also serve as a medium through which to express and manifest protests in the material world. For these struggling fishermen, the physical space of their built forms, their permanency and visibility contribute to underscoring their resistance, establishing their presence in the urban space, and defending their rights to the space.

Keywords: marginal community, urban transformation, built form, power and resistance, Manado, Boulevard Commercial Project

\section{1 \\ The Daseng Sario Phenomenon: A Brief Introduction}

Indonesia's new decentralization policy, which began in 2001, granted each of its 480 local cities the right to manage their own fiscal and development policies (Miller 2013, 838; Patunru, McCulloch, and von Luebke 2009, 6; Sondakh and Jones 2003, 296). Among other things, this new policy targeted the acceleration of urban development in eastern Indonesia to overcome the long-standing retardation of physical, economic, and social developments that the region had suffered under the unequal 'developmental' version of the New Order regime (Silver, Azis, and Schroeder 2001; URDI 2005; Vickers 2005). Many city governments, including that of Manado, have begun to aggressively promote their city's image, inspired by Jakarta's model of a Central Business District (CBD) and mixed-use commercial developments. Jakarta itself carries the proud label of a 'service city for the global economy'. The local Indonesian version of mega-scale commercial projects are the most favourable means of becoming a new centre in the inter-urban competition at both the national and regional levels, thereby encouraging cities to become more entrepreneurial in their approach to development, representation, and consumption (Miller 2013; Salim and Kombaitan 2009).

This trend of commercial mega-project development coincides with coastal Indonesian cities' increasing interest in expanding their lands toward the sea through land reclamation. Although land conversion practices in the coastal area are not a new phenomenon in postcolonial urban Indonesia, the coastal development of Indonesian cities has only recently been described as a feature of capitalist values (Kusno 2013, 99). Indonesian developers see beaches and coastal areas as an opportunity for privatized 
Figure 11.1 Maps of (a) Indonesia, (b) the location of the BCP along the coast of Manado, (c) the location of the (ex-)fishermen-influenced areas, (d) contrast conditions between Wenang and Sario areas: Map 1 (above right): the Wenang (ex-)fishermen's dwellings with direct access to neighbourhood streets, Map 2 (below right): the Sario fishermen's dwellings with lack of direct access to neighbourhood streets
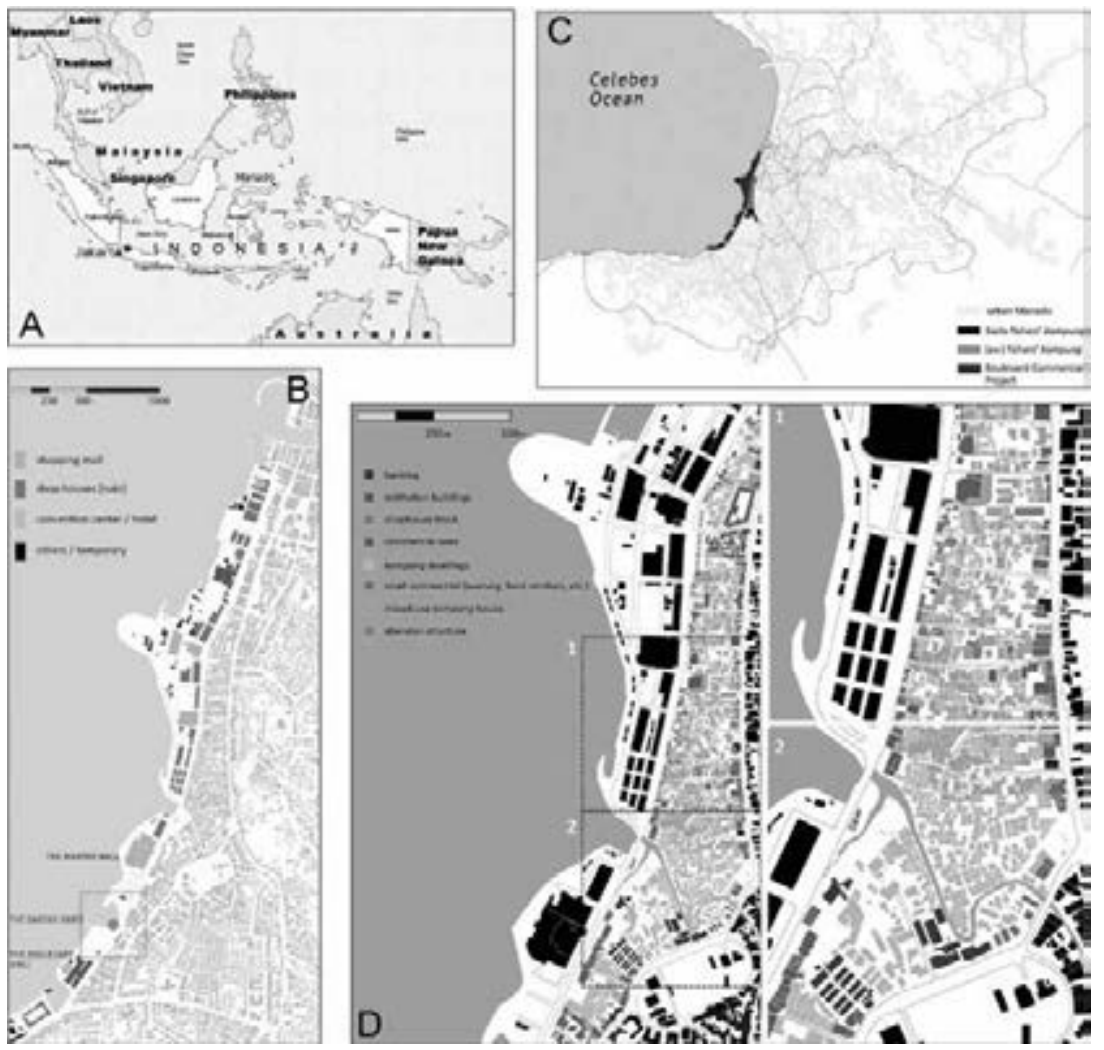

Source: Ariel Shepherd (a), author (b, c, d), Kumurur 2012 (image map 2)

physical development ${ }^{1}$ due to the potential for extending land territory, creating tourist recreation spaces (Firman 1997), and showing national and local globalization efforts since the late-New Order regime (Kusno 2013). The application of capitalist values to Indonesian coastal areas exposes

1 As recorded by Firman and Kusno, the exploration of coastal reclamation development projects by private developers was already taking place during the New Order regime along the northern coast of Jakarta despite numerous environmental protests against their realization (Firman 1997, 1038; Kusno 2013, 100). 
traditional agricultural and coastal lifestyles to large (foreign) capital and uneven distributions of power, resulting in the sudden and massive physical transformation of these areas into urban space.

The marrying of coastal land reclamation and commercial mega project development in Indonesian cities is done by maintaining exclusive relationships with particular business parties while ignoring the broader community (McCulloch, Patunru, and von Luebke 2009; Patunru, McCulloch, and von Luebke 2009). This reality reveals an important side effect of decentralization: local city administrations have suddenly received unprecedented control over their own administrative, fiscal, and political powers, placing them in the liberating position to manage their own power in governance (Firman 2009; Miller 2013). However, these city governments may not have the capacity to exercise accountable and responsible administration, in addition to Indonesia's lack of experience with democratic governance due to its former control by a centralized authoritarian regime (Miller 2013). As a result, local governments have frequently been criticized for their insensitivity to poverty and marginal communities and for their ignorance in incorporating bottom-up needs and initiatives required by their communities and citizens (Firman 2009).

Moreover, cities' marked preference for commercial mega projects triggers the over-exploitation and abuse of the natural landscape. In the past, Indonesian cities were frequently described as well-embedded and coexisting within or alongside nature (De Meulder and Shannon 2010). Before the advent of the Boulevard Commercial Project (BCP), descriptions of Manado were always framed by its harmonious coexistence with the natural beauty of its surrounding landscape (Leirissa 1995; Makkelo 2010; Mawikere 2005; Nas 1995). However, the reclamation of Manado's beach area by the BCP and the massive construction work on the reclaimed land are considered disruptive of the splendid orchestration between the picturesque natural landscape and the city. For this reason, both local non-governmental organization (NGO) activists and local academics have consistently voiced concerns about the BCP's endangerment of Manado's aquatic biodiversity. They raise question on the sustainable quality of the $\mathrm{BCP}$, while questioning the impact of this project on the local society and to the future environment of Manado in general.

Indonesian cities' commercial mega development projects regularly exclude certain groups of people (Firman 1997; Leaf 1994; Kusno 2000, 2010, and 2013), including the project in Manado. Manado is well known for the frequent legalization of oppressive acts meant to further diminish poor neighbourhoods and their various types of informal economy (Niessen 
1999). ${ }^{2}$ The top priority of Manado's development campaign, repeatedly followed by every mayoral administration and proudly maintained by the current mayor of Manado, is that 'Manado must be the role model of an orderly, clean, and pleasant city' (Lalenoh 2014). ${ }^{3}$ As a result, the image of poverty presented by poor neighbourhoods and economic informality has frequently been regarded as a threat to the progress and development of Manado - or the existence of poverty has simply been ignored. The arrival of the BCP has only strengthened this tendency.

Although many groups, communities, and individuals welcome the BCP by appropriating its spaces for their own public spaces, the BCP has also caused discontent in its immediate (ex-)fishermen neighbourhoods (Figure 1). Despite the generally euphoric acceptance of the BCP as the new centre of Manadonese urban activities, a resistance against the spectacular collective space of the BCP has also emerged. The Sario fishermen are one community who suffer from the denial of their access and rights to the land and sea, divisions with their fellow (ex-)fishermen, transformation of their neighbourhoods, and the oppressive physical expansion of the BCP. Their marginalization exemplifies the city's ignorance of the existing poor community while providing priority rights to the BCP. Veronica Kumurur (2010) provocatively describes the obvious contradiction between their exclusion and the vibrant 'public' activities along the BCP: 'Along the coast of Manado today, only a few traditional boats of fishermen with their catches can be found. Loud and soft music of Clayderman and Usher from the outdoor cafes along the Boulevard now replaces them. Manado's modernization has tossed aside its local fishermen'.

Nevertheless, the Sario community continues to use spontaneous responses and resistance efforts to deal with the physical pressures of the BCP's profit-oriented development (Block 2001; Polanyi 2001). This article aims to describe the manifold responses of these (ex-)fishermen survivors to the consequences of living right across from the BCP.

2 Niessen describes an example of oppressive action by the Manado local authorities during the New Order regime: an old kampung in the city centre, namely kampung Texas, was burnt down to create a gardening beautification project. In the end, the site was handed over to a private developer for a more profitable re-development. Similarly, Maody Gerungan, the North Sulawesi branch director of Walhi, has highlighted the repeated forceful approaches taken by the local government during E.E. Mangindaan's and A.J. Sondakh's administrations when relocating fishermen settlements from the Strand Boulevard for the BCP (Luhukay 2001).

3 Mayor Vicky Lumentut used this argument during the razia pedagang kaki lima ('raiding operation of street vendors in Manado') (Lalenoh 2014). 
A mere 40 metres of unreclaimed beach located between the Mantos and Boulevard Malls of the BCP was designated for the remaining traditional fishing activities - and only after a long negotiation process between the Sario fishing community, the Manado local authorities, and the developer of the Mantos Mall, PT Gerbang Nusa Perkasa (GNP). To secure their right to this open space, the Sario community constructed the Daseng Sario in October 2010. Due to the limited financial capacity of the fishermen, this humble shelter was built from cheap local materials such as bamboo, recycled waste timber, and dried leaves. The result is the traditional, 'ordinary' image of the Daseng Sario, which stands in stark contrast to the glamorous appearance of the BCP buildings. The backdrop of the physical built environments - of the BCP, the improved settlements of the ex-fishing neighbourhoods, and the deteriorated slum settlement of the remaining Sario fishermen-has played a significant role in the escalation of these conflicts.

In Manadonese, daseng refers to an ordinary shelter surrounded by an open space where fishermen keep their traditional boats and prepare for fishing activities. The role of the Daseng Sario is extended beyond this traditional function, since it plays the additional role of a communal space for the Sario fishermen and their wider group members. Since physical space and its usage can be instrumental in conveying symbolic meaning and creating a medium for displaying group identity and emotions (Colombijn and Erdentug 2002, 240), the Sario fishermen community employs the spatial and instrumental potentiality of this Daseng to emphasize its protest against the BCP's land expansion. This act produces a different form of collective space, one representing a community's claim to urban space.

This article unravels the production of the Daseng Sario: a collective space that expresses protest, resistance, and defensive actions against the BCP. By focussing on the physical and lived spaces of the Daseng Sario, this article examines the role of a built environment in representing the existence of contradictions and discontent in the urban space near the BCP, and analyses the influence of this space of protest on the BCP's collective space. Interviews were conducted and questionnaires distributed among nearby residents, both groups of (ex-)fishermen and key persons of the local government, in order to assess locals' perspectives on this contradiction.

The first part of this chapter presents the history of the Daseng Sario, the process of displacement, and the resistance movement of the Sario fishermen. The second section addresses the condition and roles of the Daseng Sario today. It unravels the structure's symbolic meaning, its role as a space of defence, its activities and social role, and its influence in broadcasting the protests of the Sario fishermen community to a wider 
public. The final section describes the contradicting views about the $\mathrm{BCP}$ and the Daseng Sario that are circulating among various sections of Manado's urban population.

2 Situating the Context: The Establishment of the Daseng
Sario

2.1 The Displacement of the Fishermen: Adaptation, appropriation, and marginalization

With its total coastline of $18.7 \mathrm{~km}$, coastal fishing activities and fishing communities have historically formed half of Manado and the North Sulawesi region in general, hand-in-hand and co-present with the inland agricultural societies and the farmers from the mountainous Minahasa region (Schefold 1995, 1). Influenced by Manado's role as a port city since the colonial era, traditional fishing communities and coastal trade activities have been equally important to the formation of Manado and its daily life (Makkelo 2010; Mawikere 2005; Nas 1995; Parengkuan et al. 1986). Fishery makes a substantial contribution to the economy of North Sulawesi and Manado; these regions are well-known for the production of seafood, particularly as the country's main exporters of tuna. Moreover, the seafood-based cuisine of Manado has been regarded as one of the tourist attractions of the region.

However, the absence of a comprehensive urban vision (particularly in reference to the $\mathrm{BCP}$ ) has interrupted this long-standing balance and raised the question of a potential fragmentation of Manado's social and material fabrics. The statistical data demonstrates that the coastal communities, most particularly the fishermen communities, have constituted the very poor $(10 \%)$, poor $(28 \%)$, and almost poor $(62 \%)$ communities of Manado. ${ }^{4}$ This reality shows that the substantial economic production of these fishermen communities remains unable to guarantee their economic and social position in the urban space of Manado. On the contrary, the tendency to sacrifice the existence of local fishermen communities for the sake of development is only getting stronger.

The success of the BCP in transforming the coastal landscape of Manado into a modern, pulsating urban centre has resulted in the forced relocation of fishing settlements from the area (Patunru, McCulloch, and von Luebke 2009, 26). Few (ex-)fishermen neighbourhoods from the BCP area remain, 
because the project's occupation of the beach has already mostly destroyed the fishing environment and shrunk the availability of the open space needed for daily fishing preparation activities. Therefore, the construction of the Daseng Sario is closely linked to that of the BCP and its impacts on the transformation of the remaining neighbourhoods.

After the advent of the BCP, a strong sense of image gap appears between the 'semi-village' image of Manado's urban landscape and the 'modern' appearance of the BCP. 5 The physical format and modern image of the BCP reinforces the urban 'city' image of Manado; however, a drastic change in the traditional lifestyle along the area adjacent to the BCP was an inevitable by-product of this development. The increasing mobility of capital and new lifestyle patterns of a commercial urban environment have replaced the remaining (ex-)fishermen neighbourhoods and their distinct atmosphere. Adjusting from the traditional pattern of communal living to the individual urban one, and to a new occupation, are the major challenges facing the (ex-)fishermen. All these processes affect the degree of their acceptance of the BCP.

Spatial changes along this reclaimed coast have created new class-identity divisions and reconfigurations of urban space, and these are reflected in the contradictory responses from two different groups of (ex-)fishermen: the (ex-)fishermen of the Wenang neighbourhoods accept the BCP and have adjusted to the ongoing transformation of their living area; those living along the Sario dike, on the other hand, reject the BCP altogether. The social tension between these two groups and the drastic decline of fishing space along the $\mathrm{BCP}$ area have increased the marginalization of the Sario group and decreased its right to urban space.

The first group, which accepts the BCP, consists of former fishermen who have given up their traditional profession and the remaining active fishermen from the Wenang neighbourhoods, which have built a beneficial relationship with the BCP. This first group initially rejected any offers and propaganda on the good life launched by the $\mathrm{BCP}$, including rejecting an

5 According to Evers and Korff (2005, 25-27), Indonesian (coastal) cities other than the capital have a weak base of urban tradition due in part to the absence of a cultural concept of 'city' before the arrival of Dutch colonialism. Although the colonial administration established Indonesia's coastal cities, including Manado, the urban lifestyle and its physical form were not accompanied by profound structural changes or drastic physical development (Evers and Korff 2005,31 ). Consequently, the physical development of most Indonesian cities moved forward at a slow pace, much behind the capital city. Unequal development of Javanese and other islands' cities during the thirty-two years of the centralized New Order regime only emphasized this developmental gap. 
unfair offer of compensation. After being pushed further by the hard life caused by declining fishing catches and changes in their living environment, however, this group were able to find alternative income sources as they adapted to their new living environment. Aware of the economic potential of their new living environment, a number of ex-fishermen started to provide accommodations and services for the BCP business environment. The rising commercial value of their settlements and the arrival of new migrant workers for the BCP have created new income sources that provide income higher than their previous income from fishing. Economic improvement from providing services like renting out rooms and opening cost-effective eating stalls and kiosks has supported their capacity to maintain and adjust the physical quality of their settlements. For these families, the BCP produces a positive memory. An interview with Ventje - a former fishermen leader who had previously rejected the establishment of the BCP but now supports it-and his wife reflects the view of the families that now accept the BCP:

Since the BCP, we have a better life. Our younger generations can work in those malls. Our families have a more relaxed life compared to the previous times when we were fishermen, because we now find a better way to earn money. We can rent out our rooms to the migrant workers. My wife earns an additional income by opening a food stall. We can support our daughters to study in a good university in Java. It would not have been possible for us to have this quality of life had we remained fishermen. Of course, we also rejected the Boulevard at the beginning because we were afraid of our future. But now, we see it differently. (interview by Cynthia Susilo, 12 April 2012, Manado) ${ }^{6}$

The remaining active fishermen from the Wenang area who accept the $\mathrm{BCP}$ have also gained an increased income due to the creative combining of their in-group daily fishing jobs with other activities. They nurture creative efforts, such as assertively and initiatively requesting and negotiating a claim of use on acquisitioning a small vacant space from the BCP to establish a restaurant or food stall for visitors, or supplying the restaurants and food

6 The authors selected this conversation with Ventje to show how the immediate residents affected by the presence of the BCP chose to adapt. As reflected in Ventje's opinion, he, who previously was one of the strong opponents of the BCP, gradually changed his view on this project after seeing the new financial opportunities. His view represents the views of the majority of the Wenang neighbourhoods' residents. 
vendors along the $\mathrm{BCP}$ area with fresh fish, to fully utilize the potential of their new living environment.

The second group, which rejects the BCP, is known as the Sario fishermen community. On the one hand, their rejection is conditioned by their limited ability to grab the new opportunities offered by the BCP's development wave. On the other hand, it is also motivated by their strong cultural identity: they want to conserve the fishing traditions and skill sets that they inherited from their ancestors. For the Sario fishermen community, the entire BCP area symbolizes agony and uncertainty due in part to the incremental economic pressure that residents experience. A group interview with the members of the Sario fishermen community captured this feeling, represented by the statement of Yongky, a 53-year-old Sario fisherman:

The Boulevard is for us a place of misery. We were the native owners of this land, but others did not count our existence. Our government and those investors have forgotten what they promised us a long time ago, that is, our rights to this land. No matter how many events are organized in the BCP, those are not for us. We feel bitter. However, we don't want to leave this place. This is the land where we were born, and we grew up with many memories. Our life is tied to this place. (Yongky, interview by the author, 10 May 2012, Manado)

\section{$2.2 \quad$ Fragmented (Ex-)Fishermen Neighbourhoods}

A new construction mechanism planned by architects and developers as the agents of change was introduced to Manado through the establishment of the BCP. Following the pattern of development in Jakarta (Firman 1997; Kusno 2013), huge capital-city developers have established a dominant role in converting and re-purposing communal lands into private and individual commodities (Patunru, McCulloch, and von Luebke 2009, 17). This new mode of development interrupts the common acceptance of informal urban patterns and has escalated the growing dichotomy of formal and informal settlements in Manado. Before the arrival of the BCP, unclear plot divisions, unclear legitimate property deeds, and communal mechanisms that regulate relationships between citizens were widely recognized by the city as the norm for local life. Organically patterned settlements, self-built mechanisms, and kalakeran ('communal land ownership') in 'informal' settlements have all been commonplace in Manado. Extra-legal tenure recognition from the city secured the existence of these settlements within 
the urban space, including the fishermen's informal settlements along the Sario and Wenang areas.

After the BCP's development, however, the local authority of Manado has started to consider this informality embarrassing. The image of 'modern' (attached to 'formal') settlement emerged as the desirable model, designating the 'informal' settlements as less desirable (Kusno 2000, 122, 124). As a result, these 'informal' settlements have faced the threat of losing their extra-legal tenure - confirming Kim Dovey and Wiryono Raharjo's (2010, 83) description of the perception of informal settlements in Indonesian cities as 'negative symbolic capital, signifiers of failure and lack of state control', and socially unwanted urban systems.

A residential division has sprung from the economic and physical improvements to the neighbourhoods that have accepted the $\mathrm{BCP}$, on the one hand, and the deteriorating economic and physical conditions of the neighbourhoods of the Sario fishing community on the other. This division carries the potential of creating unequal access to and provision of development (Colombijn and Erdentug 2002). Although these groups live next to each other, barriers to social interaction have developed from the visual contrast between the conditions of the two settlements. Each neighbourhood, the Wenang and Sario, treats its own quality of settlement differently from its counterpart. As Bruno De Meulder and Hilde Heynen (2006, 159-6o) have maintained, some spatial environments lend themselves to the formation of exclusion within urban space much more than others. These factors include: location; morphology features typifying spaces of exclusion; the mode of development, such as settlements' regulation deficit; transformation mode supporting de-development and/or lack of maintenance capacity and/or accessibility; and quality of typology.

Incremental physical changes are taking place in Wenang where the groups that accept the BCP live. More permanent houses and buildings are replacing the previously predominant shacks and temporary structures. Two-way streets run along these neighbourhoods, giving them direct access to both the BCP and the previous main street of Manado. This wide accessibility has also attracted local businesses to take over some plots and invest in these neighbourhoods. Since the local residents have become aware of the increasing economic potential of their neighbourhoods, they have come to co-exist with businesses, and together they bring about area transformations. These neighbourhoods are transforming from predominantly residential areas for families into a mixed-use area of low-price accommodations supporting the BCP environment (inexpensive food vendors called warung, rental rooms, etc.,) and small- and medium-sized commercial facilities 
(e.g., small cafés, restaurants, and hotels). Furthermore, a new pattern of heterogeneous social interactions is replacing the previously homogeneous interactions of fishing kampungs, following changes in the demographic profiles of these residents and the system of land ownership (namely, from communal to individual land).

The Sario fishermen community settlement, on the other hand, is trapped in a squatter-and-slum environment along the Sario dike. The conversion of communal lands into individual ones in the adjacent Wenang neighbourhoods has diminished the permeability and accessibility of the Sario fishermen neighbourhoods and trapped them at the back side of the Wenang area. Lack of direct access to either the BCP or the streets has made their neighbourhood an unattractive, peripheral pocket guarded against the incoming waves of economic opportunity. Higher economic pressures, lack of access to proper public and infrastructural services, and restriction restricted participation in decision-making all serve to keep the fishermen community at a disadvantage - a scenario comparable to what other vulnerable groups in poor urban communities suffer (Madanipour 2003, 2010a). Moreover, the occupation of the beach area by BCP developers has significantly contributed to decreasing catches and, consequently, to their dire financial state. Economic difficulties have further degraded their settlements' physical quality due, in part, to their limited economic ability to maintain adequate living quarters.

Class divisions have emerged out of growing differences and increasing tension between the Wenang (ex-)fishermen and the Sario fishermen. This class division contributes to the formation of residential fragmentation in this ethnically integrated society (Colombijn and Erdentug 2002, 227). Although living next to each other, different social groups may form and communication difficulties arise due to different modes of income, consumption preferences, languages, and frameworks of life (Madanipour 2010a). Moreover, the favouritism shown by the local authorities to the wealthier groups and the BCP leaves the Sario fishermen with feelings of oppression and exclusion from the ongoing development of the city. All this has led the Sario fishermen community to regard the BCP as a symbol of oppressive power.

\section{3}

\section{The Resistance Movement}

Land reclamation carries complex and contradictory land tenure change. It lies on the margin of transition and ambiguity concerning the land's 
uses, claims, and identity (Desfor and Laidley 2011, 8). The small parcel of remaining beach where the Daseng Sario now stands represents the states of ambiguity and transition that characterize liminal spaces, reflected in the area's contested claims of use from fishermen as authentic users, and from the developers and local authorities. For the Sario fishermen, this parcel of beach is a place of survival and for maintaining their lifeways, as well as a nostalgic place tied to their identity as fishermen. For the local authorities, however, it is a marginal and underused piece of land, a space whose image of poverty is undesirable: an unprocessed image in need of development. ${ }^{7}$ For this reason, the BCP developers regard this space as a potential source of additional profit. When an urban space belonging to a marginal group offers the potential for profit, it frequently attracts a battle over claims to land ownership (Madanipour 2010b).

The lack of a comprehensive urban vision during the planning and development stages of the BCP caused the exclusion of less-powerful groups from the competition over this limited space. From the Sario fishermen's perspective, the BCP's land reclamation constitutes the destruction of their living space. However, prior to the BCP's construction, the local authorities of Manado and the BCP developers signed an agreement obliging the developers to accommodate the activities of the remaining fishermen and their fishing environment. This agreement states that some of the remaining open beach areas should be conserved for the fishermen, and any expansion of the reclaimed land should be approved by both the local authorities and the affected fishermen community. ${ }^{8}$ In reality though, the developers and the local authorities have frequently and secretively determined land reclamation expansions between themselves, and then intimidated the fishing community into accepting their already fixed decisions.

The frequent oppression experienced by the Sario fishermen pushed the National Human Rights Commission (Komisi Nasional Hak Asasi Manusia/ Komnas HAM) to take over the mediation process between the Sario fishermen community, the Manado local authorities, and the GNP (owner of the BCP's Mantos Mall) in 2009, after receiving a number of intense complaints from Antra, the local NGO supporting the Sario community. Finally, an agreement was made to secure the 200 metre parcel of beach for fishing activities; however, the GNP constantly trespassed on this secured open

7 Ronny Kumurur, Deputy of the Manado Planning Authority Office, interview by Cynthia Susilo, 1 June 2012, Manado.

8 Vicky Lopulalang, Secretary of the Manado Planning Authority Office, interview by Cynthia Susilo, 15 May 2012, Manado. 
Figure 11.2 The Sario fishermen's protest against the BCP expansion

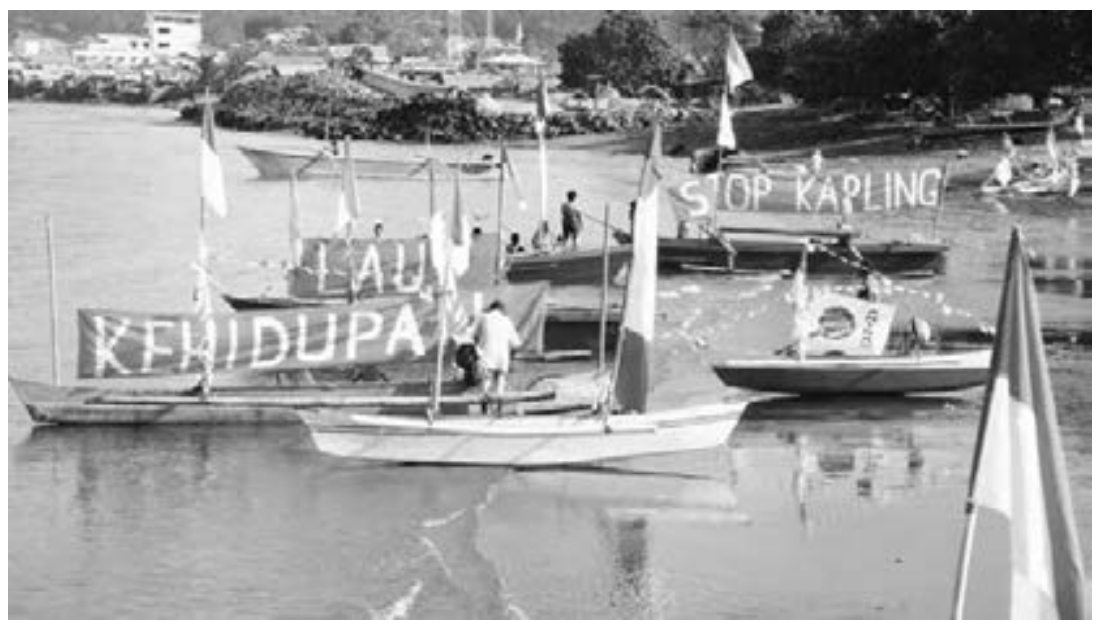

Source: Hartanto for ANTRA 2012

space in attempts to expand its land claims, an act noticed by the city authorities. By 2010, only 40 out of the 200 metres of secured open space remained to the Sario fishermen.

After more dialogues ended in deadlock, 500 group members protested against this agreement violation. Seeking a medium to enhance their protests, the Sario fishermen transformed land and sea into spaces of civic manifestation. Tikala Square, the civic square of the city hall, and the streets between Sario and the square were occupied and transformed into stages, through which protesters even carried their fishing boats in demonstration. By carrying out the protest with their fishing boats in hand, the sea next to the remaining beach was also transformed into an extraordinary space of civic action (Figure 11.2). These actions led the Komnas HAM to urge the GNP and local authorities to stop expanding the reclamation of the remaining land.

Since the GNP frequently threatened the survival of the Sario fishermen through construction aimed at reclaiming land, the fishermen used a similar tactic and constructed the Daseng Sario as a manifestation of their protests, aiming to secure the remaining open space. They built the Daseng Sario with self-funding. Although protests using spatial appropriation and physical forms are less direct than regular demonstrations, these protests enhance the visibility of a group's existence and resistance to a larger public (Low 2000). The establishment of this Daseng materializes the contradiction of the BCP area in a more obvious way. 


\subsection{Selection of the Site}

Choosing the right place for public protests is important for the Sario fishermen. Protests need to attract the attention of the local authority, the developers, and the wider public, and the location itself is highly significant for guaranteeing that the message reaches its intended destination (Padawangi 2013; Smith and Low 2006). Tikala Square, Manado's main civic square since colonial times, has been a common space for the Sario fishermen's protests against the local authorities. However, protesting in Tikala Square is, by itself, not very effective for halting the developers' aggressive land expansion. In an interview, Djamalludin, the leader of the Sario fishermen, expressed the need for a different tactic to send messages of protest directly to the developers: 'We need to deliver our protest right in front of the GNP. They don't hear our voice, and they don't see us in Tikala. So a spot next to their project is the best place for launching our rejection' (Rignolda Djamalludin, interview by Cynthia Susilo, 25 May 2012, Manado). ${ }^{9}$

Choosing the right setting within an urban space holds another key to garnering effective support for a demonstration (Padawangi 2013), and in this case the fishermen chose one of the two dasengs in the Sario area. The first, located next to the fishermen's settlement area at the estuary of the Sario dike, is less visible and would not attract much public attention. Instead, the Sario fishermen placed the new Daseng Sario at the centre of the mega projects and their activities, between the two massive buildings of the Mantos and Boulevard Malls (Figure 11.3). This location is much more observable by the public, and it sets a scene that effectively enhances the contrasting images of the Daseng and the BCP. The background of the 'modern' built forms of the BCP effectively functions as a symbolic icon of the capitalistic power encircling the Daseng Sario. Placing the protest at the new Daseng Sario 'practically and symbolically imbricates with the ongoing conflicts' (Irazabal and Foley 2008, 164), extending the protest across urban space to include the BCP buildings. The contrast between the built forms of the Daseng Sario and the rest of the BCP highlights the sharp delineation between the wealth of the BCP and the poverty of the fishing community. The aim of the protest - to expose social inequalities and discontent resulting from the $\mathrm{BCP}$ - has found a dramatic medium for expression.

9 The authors quote three statements from Djamalludin in this paper due to his influential role of keeping the spirit of the Sario fishermen community alive, as well as leading the communications and negotiations of the group with the local authority, developers, and the public. 
Figure 11.3 Location of the Daseng Sario between the Mantos Mall and the Boulevard Mall, and the image of Daseng Sario
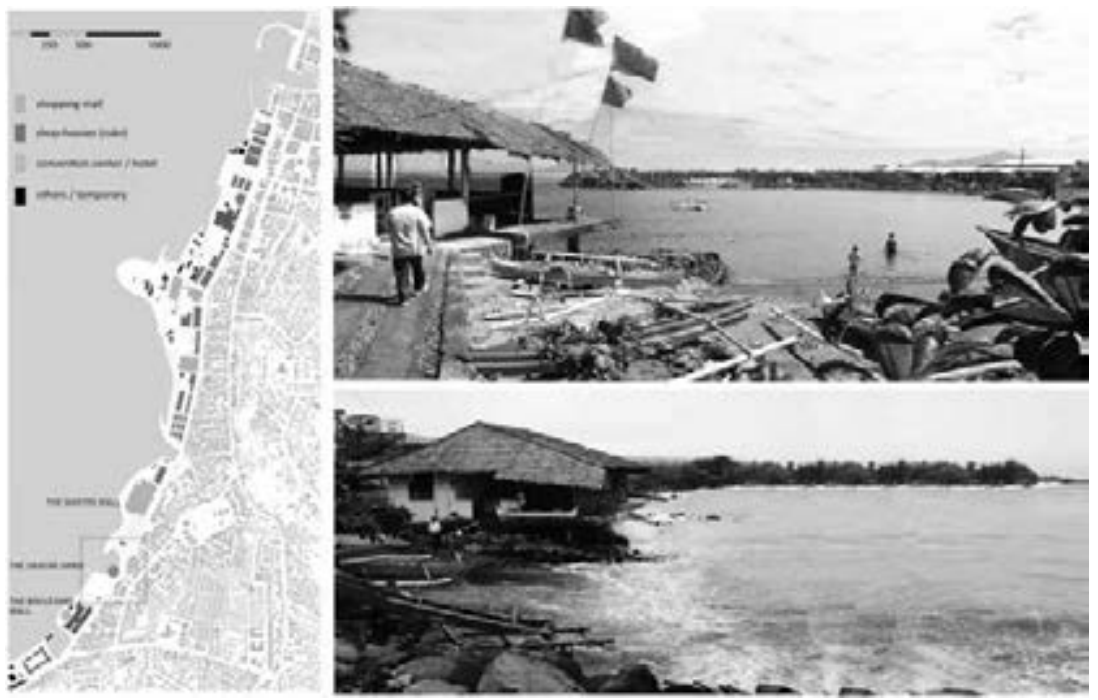

Sources: Map image: author; Daseng Sario images: Harsono for Mongabay Indonesia 2013 (above); and Nugraha for Komunitas Pasir 2013 (below)

\section{2. $\quad$ The Daseng Sario Today}

a. Symbolic Meaning

Today, the Sario fishermen community regards the Daseng Sario as the symbol of their identity and struggle. The contrast between the glamorous image of the BCP's Mantos Mall and the ordinary, humble, and traditional qualities of the Daseng produce a strong symbolic visual for the identity of this group of fishermen. Overlapped with the Sario fishermen's memories of struggles in defence of their rights to this open space and to fund and construct the Daseng, its built form has begun to 'shape a representational world [for the Sario fishermen] stabilizing and authorizing certain forms of identity and place' (Dovey 2010, 39). As a result, today the Sario fishermen consider the Daseng Sario to be the physical image of their settlement. The statement of Noel, a 55-year-old member of the Sario fishermen community, represents the prevailing opinion of the group: 'Whenever we see this Daseng, we feel like we see our poor kampung settlement that is as poor as we are. Although this Daseng also looks poor like our houses, we are proud of building it ourselves. Even though the city forgets us, at least people will recognize 
our existence through this Daseng' (interview by Cynthia Susilo, 13 May 2012, Manado).

b. Space of Defence

The key actors in physical development projects often regard the space and territory of marginal communities as an empty site (Dovey 2010, 97). BCP developers and local authorities' denial of the Sario fishermen's social, spatial, and economic practices in urban space demonstrates this attitude. The blindness of the developers and local authorities to the reality of these fishermen is expressed in the statements of both the developers' management and the management of the local authority: 'No one uses the open space between the Mantos Mall and the site of the ex-Boulevard Mall', ${ }^{10}$ or 'The site located between the Mantos Mall and the ex-Boulevard Mall is empty and underused'. ${ }^{11}$

However, the construction of the Daseng Sario in the centre of the $\mathrm{BCP}$ has brought forth a strong wave of support in response to its visibility. Unlike most marginal communities, who prefer to be invisible in order to secure their existence in urban space (Dovey and Raharjo 2010), the Sario fishermen prefer to be visible, as they believe it will strengthen their efforts to gain acknowledgement from the city officials. As the leader of the Sario fishermen said, 'Without having a physical space, we will be staying invisible. The authority will keep denying their responsibility to us. Therefore, we must build this daseng.12 The Daseng Sario works as expected: that is, it helps invert the power relations of this marginal community in relation to the local authorities and BCP developers. Before the establishment of the Daseng Sario, negotiations about the future of the remaining fishing environment and the expansion of the BCP always took place in government offices or the offices of one of the developers. After the Daseng Sario was established, the Sario fishermen have been able to use it as an instrument for strengthening their bargaining power by requesting that further negotiation meetings be held there (Figure 11.4).

10 Susilo, General Manager of the Mantos Mall, interview by Cynthia Susilo, 5 March 2012, Manado.

11 Vicky Lopulalang, Secretary of the Manado Planning Authority, interview by Cynthia Susilo, 27 March 2011, Manado.

12 Rignolda Djamalludin, interview by Cynthia Susilo, 3o May 2012, Manado. 
Nevertheless, a stand-alone built form has a limited capacity for defending a cause. Although a physical space is present, the absence of activities and users can weaken its existence. Threats on the Daseng Sario come in various forms. One night, Mantos Mall security cut all the ropes that tied the fishing boats in the open space of the Daseng. At other times, it has been damaged by vandals. ${ }^{13}$ On the other hand, the continuous presence of activities and users surrounding a built form strengthens the existence of the space. To prevent vandalism and maintain the existence of the Daseng Sario, the fishing community keeps members and their activities present in the Daseng day and night.

\section{c. Inserting Activities, Establishing Attachment, Defining Territory}

The establishment of the Daseng Sario reflects the construction of territory, with the physical built space of the Daseng at the centre. The placement of the fishing boats in the surrounding open space of the Daseng marks the boundary. But the daily fishing preparations and the bustle of social activities are the main factors that strengthen and stabilize its spatial definition as fishing territory. Through these activities, the influence of the fishing territory expands beyond the physical boundary of the Daseng.

The role of the Daseng Sario in sheltering the fishermen's social activities transforms the space into something exceptional. Like common dasengs, the main function of the Daseng Sario is as a place to tie fishing boats, keep fishing equipment, and prepare for fishing activities. More particularly, the space of the Daseng Sario increasingly plays a significant role as a stage and theatre where interactions, social activities, and processes of community empowerment take place. Setting up group activities within the physical space of a disadvantaged community can enhance a sense of community emancipation, help fight the negative stigmas of being 'poor' and 'marginalized', and foster the community's confidence and empowerment (Madanipour 2010a). Every late afternoon, philanthropists and volunteers regularly conduct learning activities for children and teenagers in this space. External supporters and outside institutions also participate by giving regular training sessions and workshops on skills improvement, human rights, and law. Furthermore,

13 On-site interviews conducted by the authors with fifteen members of the Sario fishermen. Interviews were held in Manado, 5-7 May 2012. These acts of vandalism took place several times in 2012, and no one claimed responsibility. However, members of the Sario fishing group believed that the vandals were people from the developers' party. 
Figure 11.4 The Daseng Sario with and without activities. Upper: the Daseng Sario when there was no activity. Below left: the Daseng-held negotiation among Komnas HAM, Sario fishermen, the local government, and the developer. Below right: daily educational activities for children at the Daseng
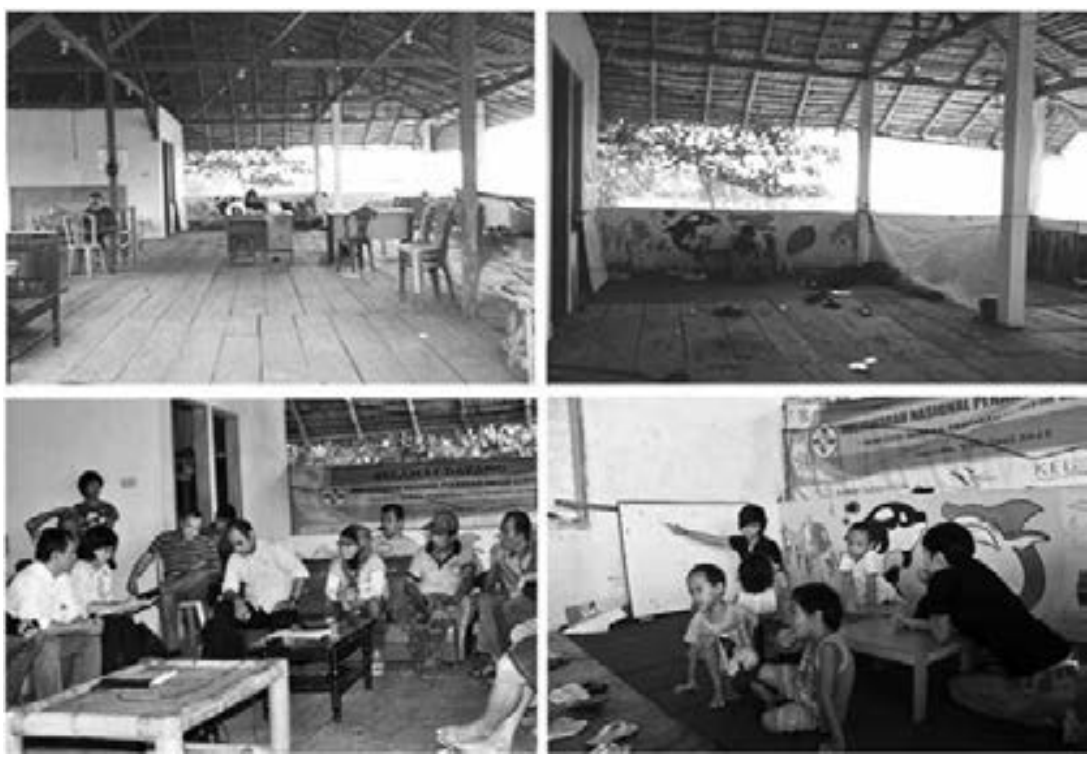

Source: Mamahit 2013 (above), Doaly for Mongabay Indonesia, 2013 (below left), Nugraha for Komunitas Pasir, 2012 (below right)

discussions and negotiations with other stakeholders of the BCP have begun to frequently take place in the Daseng Sario, helping to materialize and visualize the community's existence and pride (Figure 11.4).

The Daseng Sario has developed into a collective place of and for the Sario fishermen on the 'public' land designated for this community. It is a collective space that was self-created out of the feeling of being excluded from the BCP space. Community members move various activities and important events from the neighbourhood to this Daseng, including: a modest birthday party for the daughter of Noel, a 44-year-old fisherman; the weekly gathering of fishermen's wives; and the weekly activities of a local youth organization named karang taruna. These communal activities strengthen the collective memory of the community and construct a meaning of place attached to the Daseng. At the same time, the existence of this once-forgotten community becomes more visible to the public. 
d. Enlarging the Influence on the Public, Reaching beyond Territorial Boundaries

A centre of urban activities generally becomes a centre of circulating networks and information, which places it as a centre of media attention (Padawangi 2013). As a new centre of Manado's urban activities, the BCP's frequent staging of the city's major events has lead it to be the most popular place for local media coverage. The social inequality reflected in the setting of the Daseng Sario and its visible contrast with Mantos Mall and the rest of the BCP area creates an interesting frame for stories that especially attracts the local media. Previously, the public largely ignored the activities of these fishermen. After the Daseng Sario was built, however, the local media more frequently report the community's struggle. The media plays a significant role in spreading the movement and messages of social protests and disseminating the symbols and ideas that are cultivated and staged within urban spaces (Padawangi 2013). In this case, a 'megaphonic effect' (Padawangi 2013, 855) is created through the interactions between the built form of the Daseng Sario, its contained activities, the wider BCP environment, and the media coverage. The frequent coverage of the Daseng Sario and its activities facilitates public awareness. Prior to the existence of the Daseng, only one NGO had paid attention to the Sario fishermen; today, five NGOs consistently support their struggle. ${ }^{14}$ Some of the responses we received from supporters during our interviews are: 'We support the struggle of the Sario fishermen after reading the reports from Tribun Manado',15 'I was touched to volunteer here after I read a story about these fishermen in Berita Manado',; 'I knew about the story of the Daseng Sario and the fishermen from the website of ANTRA NGO'. ${ }^{17}$ Through these media and NGO networks, more parties have begun to give support and attention to the struggle of the fishing community, thereby enhancing and broadcasting their message.

14 Yessi Mekeng, member of the Sario fishermen community, interview by Cynthia Susilo, 1 May 2012, Manado.

15 Aditya Nugraha, counselling volunteer for the Sario fishermen community from Yayasan Kelola (one of the local environmental NGOs), interview by Cynthia Susilo, 21 April 2012, Manado. 16 Magdalena Pontoh, teaching volunteer in the Daseng Sario, interview by Cynthia Susilo, 26 May 2012, Manado.

17 Fernando Lomban, a local evangelist pastor, interview by Cynthia Susilo, 12 May 2012, Manado. 


\section{4 Contradicting Views on the BCP}

The BCP also triggers several contrasting opinions among the citizens of Manado. While the marginalization of the Sario fishermen raises critiques about its existence, other people enthusiastically accept the new experiences it offers. This division cannot be simply categorized based on the dichotomies of upper and lower classes or rich and poor communities; much more complex and heterogeneous groups make up the contemporary urbanity of Manado.

Sixty out of 75 respondents ${ }^{18}$ from various social classes outside the Sario community expressed feelings of satisfaction with the BCP. For these respondents, the BCP's role went beyond that of a commercial place: it has become the popular destination for all kinds of social interaction. 'We like to have family lunch in Mantos Mall every Sunday after the church service', said Yurike, a 45-year-old housewife from another poor fishermen community, Tuminting, that is further away from the BCP. 'My family prefers to spend weekends relaxing in the Mega Mall rather than in the Pasar 45', said Abenedju, a 36-year-old porter in the Karombasan traditional market. 'I spend my free time during the school break at the Boulevard', said Jane, a 25-year-old university student. 'We now have a great public place for city events and public gatherings. Before the BCP, Manado did not have such place', said Tommy, a 50-year-old Department of Education officer. 'Before the BCP, outsiders were afraid to enter this area. These neighbourhoods were well known for their high criminality. Residents were unwelcoming to outsiders, and they closed this coastline off to them. After the BCP, everybody can enter this area freely, and the residents of these neighbourhoods have drastically changed to be very welcoming to outsiders', said Rizal, a 38-year-old taxi driver.

On the other hand, interviews with members of the Sario fishermen community captured the scepticism associated with the BCP, especially due to their marginalization from the newly transformed environment. For instance, a 55-year-old fisherman named Yudi said, 'We don't care whether other people like the BCP. We don't need that kind of space.' Another fisherman named Yeremia, aged 52 years, added, 'I strictly asked my wife and my children to never ever enter the BCP no matter how much they want to do it.' These expressions exemplify the unpleasant feelings surrounding the BCP from the viewpoint of this community.

18 Interviews were conducted with assistance from Merryana Korompis, Willy Lontoh and Valentino Kalalo from Sam Ratulangi University, Manado, from 1 April to 12 June 2012. 
These contradictory perceptions about the $\mathrm{BCP}$ are evidence of the absence of a singular meaning of it. These differences mirror each group's needs for various models of space and place that can accommodate each expression of public interaction. These contradictory perceptions about the BCP also shows the limitation of collective space in facilitating space of expression in broader urban societies, as expressed by Rignolda Djamalludin:

The Boulevard perhaps attracts the majority of the Manadonese nowadays, to the extent that some consider it as the current 'everyone's place' of Manado. However, for us Sario fishermen, the BCP is obviously not our public space. This Daseng Sario is our real public space because here, we have the freedom to express our existence. Ironically, without the BCP, the Daseng Sario may have not existed as it is today. Perhaps it will be just a regular daseng later on. Perhaps we will not be tied to this Daseng. (interview by Cynthia Susilo, 30 May 2012, Manado)

\section{$5 \quad$ Conclusion}

The case of the $\mathrm{BCP}$ is a lesson on the significance of the contribution that a physically built form can make to an urban space. The spatial articulation of an urban-scale project can be the source of a force that can either create bridges between people or cause an urban space to fragment. A physical project can bring benefits or cause destruction to its existing environment, depending on the qualities of the project. A built space is not simply produced by societal processes; it is also a condition produced by the interaction between the material built environment, the existing environment, and the people who live with and within it.

The development trend that privileges profit-oriented commercial mega projects tends to have a negative impact on the existing urban context. Challenged by strong private and profit-oriented actors, local authorities often prioritize the realization of this type of project over others. As a result, ordinary citizens' rights to their city are increasingly taken away as the project proves the presence of 'development' in the city. The process of establishing such projects in Indonesian cities often marginalizes less powerful groups within urban space, and quickly and systematically generates social and economic exclusion.

The advent of the Daseng Sario reflects this state of affairs and expresses the complexity of Manado's contemporary urban transformation after the 
construction of the BCP. The market-driven development exemplified by the $\mathrm{BCP}$ has led to competition over the urban spaces of Manado, influencing the nature and life of the neighbourhoods and the character of the city's urban (public) space. The lack of a comprehensive urban vision following the conception of the BCP has created new polarization and fragmentation, as shown by the fracture between the Wenang (ex-)fishermen and the Sario fishermen. In the micro-urbanism of Manado, the BCP has restructured its neighbouring urban space from homogeneous fishermen neighbourhoods into heterogeneous ones.

These changes have given rise to groups and individuals with different characteristics, interests, and responses to the BCP. Consequently, each group has different needs and asks for different settings of space to maintain each group's existence toward the BCP. For less powerful communities, the advent of mega commercial projects often causes substantial destruction to living and working resources. For this reason, marginalized groups find it harder to adapt to and reconcile with the new environment. The pressure of exclusion experienced by the marginalized group can produce an alternative worldview regarding their new living environment, which in turn produces an alternative space that is different from the mainstream one.

As exemplified by the case of the $\mathrm{BCP}$, the built environment of the project can contribute to the production of different kinds of spaces for different groups. Since the materiality of built forms constitutes a capacity to establish boundaries, mark a physical territory, produce a contrast, and emphasize differences, the BCP actors-who recognize the capacity of built forms - have chosen to extend the physical territory of the BCP's built form to oppress the surrounding communities. As seen in the experience of the Sario fishermen, the BCP uses pressure, domination, and intimidation to exert control over this opposing marginalized group.

The marginalized group can, however, resist this condition by organizing themselves to generate alternative spaces to challenge the pressure of this developmental model. The community's employment of the Daseng Sario to express their struggle for rights also recognizes the capacity of built forms. The Sario fishermen, the community that feels excluded and out of sync within the new spaces of the $\mathrm{BCP}$, has requested the right to produce their own civic community and collective space: the space where they can express themselves fully, such as seen in the Daseng Sario.

Protest needs a grounded medium as a platform. The physical space of built forms, their permanence and visibility, are employed by this fishing community to underscore their resistance. The Daseng Sario offers a 
sophisticated strategy of social manifestation: the built form of the Daseng creates a new material symbol of identity, which is present, permanent, and real. Its capacity to shelter the activities of the community builds attachment between its members and the place. At the same time, its physical visibility makes it possible to establish an observable territorial boundary. As such, the visibility of the forgotten fishermen comes to the fore through the physicality of the Daseng Sario in the BCP area.

The Daseng Sario inserts a different spatial reality into the homogenized image of the BCP. Both the built forms of the BCP project and the Daseng Sario reflect the way in which built environments could mirror the tension and (counter)reaction among oppositional stakeholders in an urban space. While the groups of (ex-)fishermen from Wenang face the pressure of urban transformation by adapting to the new situation, the Sario fishermen have chosen the opposite response, challenging the BCP through the construction of their own symbolic and communal space. Both spontaneous and unplanned responses serve as mechanisms to create space for the survival of the group within the urban space. These opposing responses also reflect the complexity and multifaceted space of the BCP, demonstrating the nature of a city as an assemblage of differences. The Daseng Sario also challenges the capacity of the BCP area to accommodate differences and externalities.

The Daseng Sario is a story of the success of ordinary citizens in taking back an urban space from an abusive project. It does not show the real success of the project itself. On the contrary, it shows the many failures that a commercial megaproject can bring but have been redeemed by the adaptive capacity of the local people. The case of the Daseng Sario shows how a marginal group can find a way to defend their rights to an urban space. This group demonstrates their vitality to deal with the impacts of the advent of a commercial megaproject in their urban space. They have shown their productive capacity of moving independently beyond the narration of victimization and unjust development by (re)producing their own alternative spaces near the physical territory of the development project.

However, since the process of appropriation and localization is not an explicit battle but is carried out on the grassroots level, this process has not received consistent support from decision-making actors. The rights of the marginal remain unsecured in 'formal' decision-making process, and they continue to face the i threat of exclusion from the project. To what extent this grassroots movement can maintain the victory of a marginalized community in its acts of protest remains uncertain. As Djamalludin said: 
The Daseng Sario is just a symbol of our struggle. The spirit of this struggle itself resides in our hearts. Winning or losing our land is only a second priority. Raising the consciousness of our local government and the broader Manadonese society about our equal rights to this city and to its development is much more important. The city also belongs to the members of a weaker community like us. Constructing this Daseng is our interruption to their oblivion. Moreover, raising the consciousness of our members about our rights to this city is equally important. (interview by Cynthia Susilo, 30 May 2012, Manado)

\section{Works Cited}

Block, Fred L. 2001. Introduction to The Great Transformation: The Political and Economic Origins of Our Time, edited by Karl Polanyi, xviii-xxxviii. Boston: Beacon Press Books.

Colombijn, Freek and Aygen Erdentug. 2002. Conclusion to Urban Ethnic Encounters: The Spatial Consequences, edited by Aygen Erdentug and Freek Colombijn, 226-45. London: Routledge.

De Meulder, Bruno and Hilde Heynen. 2006. 'The Role of Space in Processes of Exclusion and Normalization: De Coninckplein in Antwerp'. In 'Comment vivre Ensemble': Protoptypes of Idiorrhythmical Conglomerates and Shared Spaces. Quaderni del Dottorato di Ricerca in Urbanistic 3, edited by Paola Pellegrini and Paola Vigano, 153-78. Rome: Officiana Edizioni.

De Meulder, Bruno and Kelly Shannon. 2010. 'Orchestration of Nature in Urbanism'. In (re)Designed Nature, edited by Susanne Witzgall, Florian Matzner, and Irish Meder, 20-37. Ostfildern; Hantjen Cantz.

Desfor, Gene and Jennefer Laidley. 2011. 'Introduction. Fixity and Flow of Urban Waterfront Change'. In Transforming Urban Waterfronts: Fixity and Flow, edited by Gene Desfor, Jennefer Ladley, Quentin Stevens, and Dirk Schubert, 1-13. New York: Routledge.

Dovey, Kim. 2010. 'Silent Complicities: Bourdieu, Habitus, Field'. In Becoming Places. Urbanism/Architecture/Identity/Power, edited by Kim Dovey, 31-41. Oxon: Routledge.

Dovey, Kim and Wiryono Raharjo. 2010. 'Becoming Prosperous: Informal Urbanism in Yogyakarta'. In Becoming Places. Urbanism/Architecture/Identity/Power, edited by Kim Dovey, 79-101. Oxon: Routledge.

Evers, Hans-Dieter and Rudiger Korff. 200o. Southeast Asian Urbanism: The Meaning and Power of Social Space. Hamburg: LIT. 
Firman, Tommy. 1997. 'Land Conversion and Urban Development in the Northern Region of West Java, Indonesia'. Urban Studies 39(7): 1027-46.

Firman, Tommy. 2009. 'Decentralization Reform and Local-Government Proliferation in Indonesia: Towards A Fragmentation of Regional Development'. Review of Urban and Regional Development Studies 21(2-3): 143-57.

Irazabal, Clara and John Foley. 2008. 'Space, Revolution and Resistance: Ordinary Places and Extraordinary Events in Caracas'. In Ordinary Places, Extraordinary Events. Citizenship, Democracy, and Public Space in Latin America, edited by Clara Irazabal, 144-69. Oxfordshire: Routledge.

Lalenoh, Robert. 2014. 'Walikota Pimpin Penertiban PKL di Pusat Kota [The mayor lead the PKL's raiding operation in the city centre]'. Oke Manado, 23 July. http://www. okemanado.com/2014/walikota-pimpin-penertiban-pkl-di-pusat-kota56689/.

Leaf, Michael. 1994. 'The Suburbanization of Jakarta: a Concurrence of Economics and Ideology'. Third World Planning Review 1(4): 341-56.

Leirissa, Richard. 1995. 'Dynamics of the History of Minahasa'. In Minahasa Past and Present: Tradition and Transition in an Outer Island Region of Indonesia, edited by Reimar Schefold, 107-116. Leiden: Research School CNSW.

Low, Setha M. 2000. On the Plaza: The Politics of Public Space and Culture. Austin: University of Texas Press.

Luhukay, Sien. 2001. 'Sondakh Backing Investor, Pencemaran Dilegitimasi [Sondakh offers his support to investor, [environmental] pollution found legitimation]'. Manado Post newspaper, 29 October.

Kumurur, Veronica A. 2010. 'Nelayan Teluk Manado Tergulung Arus Modernisasi Pembangunan Kota [The fishermen of Manado rolled-up by the wave of developmental modernisation of the city]'. Lingkungan Perkotaan (blog), 1 December. http://veronicakumurur.blogspot.be/2010/12/nelayan-teluk-manadotergulung-arus.html.

Kusno, Abidin. 2000. Behind the Postcolonial: Architecture, Urban Space and Political Cultures in Indonesia. London: Routledge.

Kusno, Abidin. 2010. The Appearance of Memory: Mnemonic Practices of Architecture and Urban Form in Indonesia. Durham, NC: Duke University Press.

Kusno, Abidin. 2013. After the New Order: Space, Politics, and Jakarta. Honolulu: University of Hawai'i Press.

Madanipour, Ali. 2003. Public and Private Spaces of the City. London: Routledge.

Madanipour, Ali. 2010a. 'Marginal Public Spaces in European Cities'. In Whose Public Space? International Case Studies in Urban Design and Development, edited by Ali Madanipour, 111-30. Oxon: Routledge.

Madanipour, Ali. 2010b. 'Public Space and Everyday Life in Urban Neighborhoods'. In Whose Public Space? International Case Studies in Urban Design and Development, edited by Ali Madanipour, 107-10. Oxon: Routledge. 
Makkelo, Ilham Daeng. 2010. Kota Seribu Gereja:Dinamika Keagamaan dan Penggunaan Ruang di Kota Manado [City of a thousands churches: Religious dynamics and the use of space in the city of Manado]. Yogyakarta: Ombak.

Mawikere, F. R. 2005. 'Infrastruktur Kota Manado (1900-1970) [The infrastructure of the city of Manado (1900-1970)]'. In Kota Baru, Kota Lama: Sejarah Kota-Kota di Indonesia Sebelum dan Setelah Kemerdekaan [The new city, the old city: The history of Indonesian cities before and after independence], edited by Freek Colombijn, Martine Barwegen, Purnawan Basundoro, and Johny Alfian Khusyairi, 45-72. Yogyakarta: Ombak.

McCulloch, Neil, Arianto A. Patunru, and Christian von Luebke. 2009. 'To Squeeze or not To Squeeze: Characterising the Investment Climate in the City of Manado, Indonesia'. LPEM FEUI Working Paper, no. 17.

Miller, Michelle Ann. 2013. 'Decentralizing Indonesian City Spaces as New "Centers"'. International Journal of Urban and Regional Research 37(3): 834-48.

Nas, Peter J.M. 1995. 'Miniature of Manado. Images of a Peripheral Settlement'. In Minahasa Past and Present: Tradition and Transition in an Outer Island Region of Indonesia, edited by Reimar Schefold, 58-71. Leiden: Research School CNWS.

Niessen, Nicole. 1999. Municipal Government in Indonesia. Policy, Law, and Practice of Decentralization and Urban Spatial Planning. Leiden: CNSW Publications.

Padawangi, Rita. 2013. 'The Cosmopolitan Grassroots City as Megaphone: Reconstructing Public Spaces through Urban Activism in Jakarta'. International Journal of Urban and Regional Research 37(3): 849-63.

Parengkuan, F.E.W., L.Th. Manus, Rino S. Nihe, and Djoko Suryo. 1986. Sejarah Kota Manado 1945-1979 [The history of Manado City 1945-1979]. Jakarta: Departemen Pendidikan dan Kebudayaan.

Patunru, Arianto A., Neil McCulloch, and Christian von Luebke. 20og. 'A Tale of Two Cities: The Political Economy of Local Investment Climate in Solo and Manado, Indonesia'. IDS Working Papers, no. $33^{8}$.

Polanyi, Karl. 2001. The Great Transformation: The Political and Economic Origins of Our Time. Boston: Beacon Press Books.

Salim, Wilmar and Benedictus Kombaitan. 2009. 'Jakarta the Rise and the Challenge of a Capital'. City 13(1): 120-28.

Schefold, Reimar. 1995. Introduction to Minahasa Past and Present: Tradition and Transition in an Outer Island Region of Indonesia, edited by Reimar Schefold, 1-6. Leiden: Research School CNWS.

Silver, Christoper, Iwan J. Azis, and Larry Schroeder. 2001. 'Intergovernmental Transfers and Decentralization in Indonesia'. Bulletin of Indonesian Economic Studies 37(3): $345^{-62 .}$ 
Sondakh, Lucky and Gavin Jones. 2003. 'An Economic Survey of Northern Sulawesi: Turning Weakness into Strength under Regional Autonomy'. Bulletin of Indonesian Economic Studies 39(3): 273-302.

Smith, Neil and Setha Low. 20o6. 'Introduction: The Imperative of Public Space'. In The Politics of Public Space, edited by Setha Low and Neil Smith, 1-16. New York: Routledge.

URDI [Urban and Regional Development Institute]. 2005. Kota-kota Dalam Transisi: Tinjauan Sektor Perkotaan Pada Era Desentralisasi di Indonesia [Cities in transition: Urban sector review in Indonesia's decentralisation era].Jakarta: World Bank.

Vickers, Adrian. 2005. A History of Modern Indonesia. Cambridge: Cambridge University Press.

\section{Maps and Images}

Doaly, Themmy. 2013. 'Komisioner Kommas HAM, Developer dan Pemkot Manado kala berdiskusi bersama nelayan Sario Tumpaan di Daseng [HAM Commissioner, the developer and the city government of Manado in a discussion with the Sario Tumpaan fishermen in the Daseng]'. Photograph, 16 November, jpeg image. http://www.mongabay.co.id/tag/nelayan-manado/.

Hartanto, Sindu Dwi. 2012. 'The Sario Fishermen's protest against the BCP expansion'. Unpublished photograph, jpeg image.

Harsono, Sapariah Saturi. 2013. 'Posko Antra di Daseng. Satu-satunya tempat mangkal para nelayan di tengah Kota Manado, yang telah dikelilingi pusat perbelanjaan. Ribuan nelayan telah tersingkir dari wilayah hidup mereka atas nama pembangunan (reklamasi) [The only remaining spot where the fishermen of Manado city is still possible to meet together is now surrounded by shopping malls. In the name of development (or reclamation), thousands of fishermen have been driven away from their original territory]'. Photograph, 31 July, jpeg image. http://www.mongabay.co.id/tag/nelayan-manado/.

Magali. 2011. 'The Boulevard Commercial Project from above'. Photograph, 21 November, jpeg image. http://www.skyscrapercity.com/showthread.php?t=790876.

Mamahit, Donny. 2013. 'The Daseng Sario when there was no activity'. Unpublished photograph, 15 July, jpeg image.

Nugraha, Themmy Aditya. 2012. 'Dibutuhkan Relawan Tenaga Pengajar (Educator volunteers are needed)'. Photograph, 17 May, jpeg image. http://komunitaspasir. blogspot.co.id/2012/o6/dibutuhkan-relawan-tenaga-pengajar.html.

Nugraha, Themmy Aditya. 2012. 'Daseng'. Photograph, 23June, jpeg image. http:// komunitaspasir.blogspot.co.id/2012/o6/daseng.html. 
Susilo, Cynthia. 2013. 'The location of the BCP along the coast of Manado and the location of the (ex-) fishermen' influenced areas'. Unpublished map, 15 September, jpeg image.

\section{About the authors}

Cynthia Ratih Susilo is Independent Researcher for Habitus Platform Initiative. She was an external reviewer of Semarang's 100 Resilient Cities Program for Mercy Corps Indonesia and was a researcher for the OSA Research Group, Katholieke Universiteit (KU) Leuven. She earned her doctorate from the Department of Architecture, Urban Design and Regional Planning at University of Leuven (KU Leuven). She also holds a master's degree in Human Settlements from KU Leuven and an undergraduate degree in Architecture from Gadjah Mada University, Indonesia. Her research interests include postcolonial urbanisms of Southeast Asian cities, land grabbing and housing issues in climate change resiliency, the rural-urban development of eastern Indonesian cities, and the production of collective spaces in Asian cities.

Bruno De Meulder is Professor at the Department of Architecture, University of Leuven (KU Leuven). He obtained his doctoral degree from the Department of Architecture, KU Leuven (Belgium), where today he teaches urbanism: its history, theory, and practice. His teaching takes place through urban design studios. He also cherishes combining activities between research and practice. He co-edits book series of UFO: Explorations of Urbanism (Zurich, Park Books) and regularly publishes on issues of urbanism in the post-industrial and postcolonial era. He is currently working on an international oeuvre engaging with dispersed urbanism and what Dennis Cosgrove labelled 'promiscuous territories'. He is the program director of the Master of Architecture and Human Settlements (MaHS) and the Master of Urbanism and Strategic Planning (MaUSP). 



\title{
12 Ethnic Place-Making in Cosmopolis
}

\author{
The Case of Yeonbeon Village in Seoul
}

Myung-rae Cho

\begin{abstract}
This chapter delves into how a Korean Chinese community called 'Yeonbeon Village' was formed as an ethnic enclave and has evolved into a transnational space in cosmopolitan Seoul. The chapter focuses on three analytical points. First, from the perspective of 'place-making of the people', it analyses how an ethnic space for Korean Chinese migrant workers came into being in globalizing Seoul. Second, from the view of 'place-making by the people', it examines how the place was built into a transnational community to accommodate the reproduction of everyday ethnic life. Finally, from the angle of 'place-making for the people', it examines how both citizen and non-citizen actors are engaged in constructing the public sphere of inclusive life in this transnational enclave.
\end{abstract}

Keywords: globalization, cosmopolis, migrant workers, global village, Yeonbeon

\section{Introduction}

Just like the South Korean economy, Seoul, its capital city, has undergone an astonishingly rapid globalization in the past three decades. In 2014, Seoul hosted 9.4 million overseas visitors from 200 countries, becoming the $13^{\text {th }}$ most tourist-attracting city in the world (KBS 2016). The number of foreign registered residents in the city has also been increasing. As of December 2015, 457,806 foreign residents (including naturalized foreigners) reside in Seoul, accounting for 4.53 per cent of Seoul's total population. This share is nine times bigger than the share in 1998 ( 0.49 per cent), when the Asian financial

Cabannes, Yves, Douglass, Michael and Padawangi, Rita, Cities in Asia by and for the People. Amsterdam: Amsterdam University Press, 2018 DOI 10.5117/9789462985223/CH12 
Figure 12.1 Maps of (a) South Korea and (b) location of Yeonbeon in Seoul
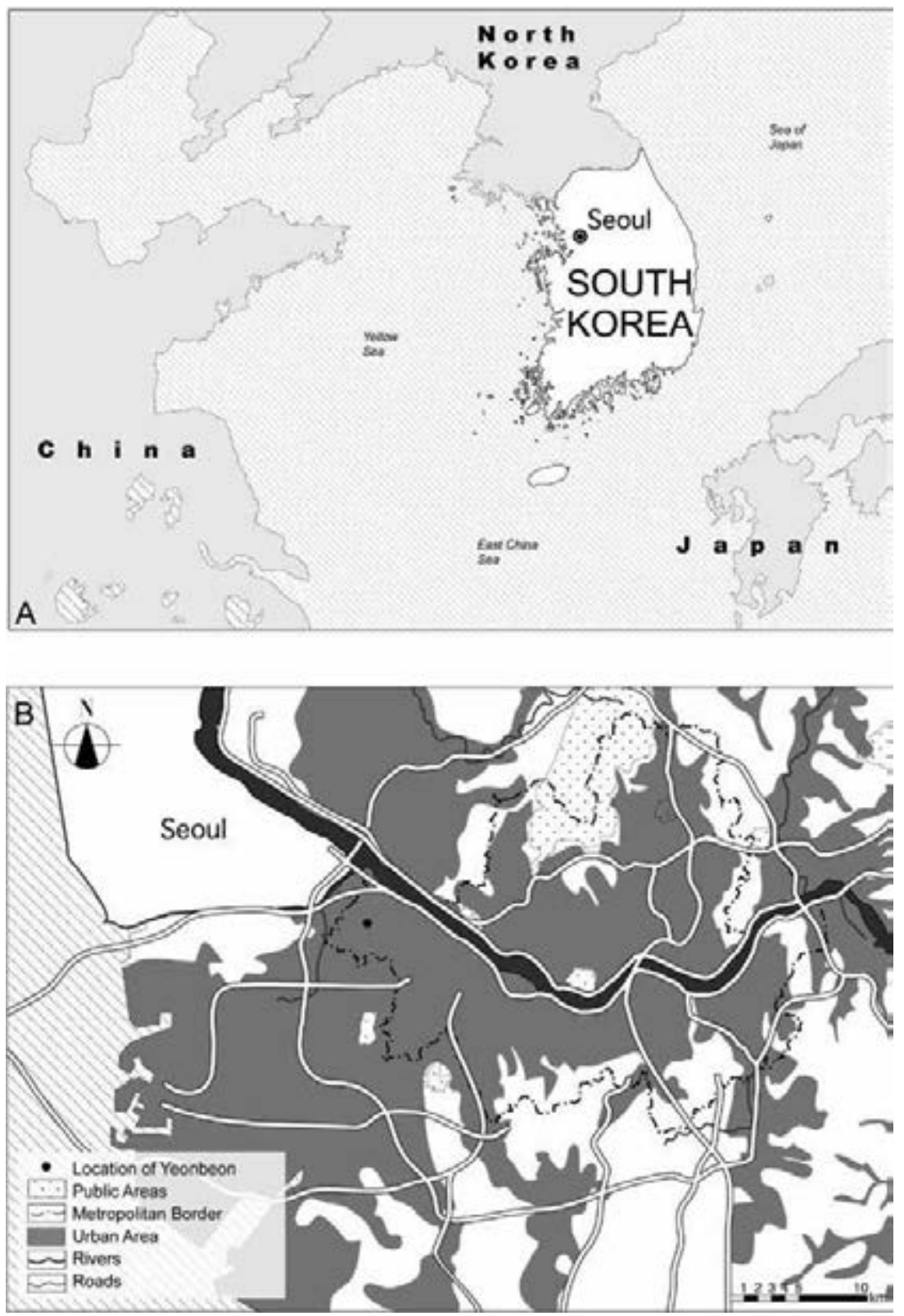

Source: Ariel Shepherd 
crisis broke out with a neoliberalist impact on the country's economy. The new influx of foreigners was mostly based on economic motives because Seoul's post-crisis development had increasingly become entrenched in economic globalization. In December 2015, 25.5 per cent of the registered foreign residents in Seoul were migrant workers. Another quarter (25.5 per cent) were overseas Koreans and migrant workers from China. Marriage migrants (10.1 per cent) and foreign students (7.1 per cent) were the next largest groups of foreigners (Ministry of Public Administration and Security 2015). In other words, approximately two-thirds of the foreign residents of Seoul have come for the sake of employment, business ventures, or for the pursuit of an easier economic life in the neo-liberal, globalized milieu. The locations of their residences in Seoul are chosen largely in accordance with their economic capability in the city's fragmented housing and employment market. For instance, foreign workers and businessmen - who mainly come from advanced countries - tend to reside in the central (CBD) and Southeastern (upper-class and service businesses) areas of Seoul, while migrant workers - who are mainly from China-and marriage migrants live in the Southwestern (lower-class and industrial businesses) area (see Cho 2015b for more detail). However, economics is not the only factor leading to the formation of these foreign residential enclaves which have made Seoul an ethnically diverse, global city.

With the influx of this foreign population, 30 places with concentrations of foreign dwellers, called 'mini global villages', have emerged across Seoul. Thus, Seoul is now attaining a new metropolitan character that goes beyond a globopolis - a place characterized by global neoliberalism that makes it exclusive, homogenous, and focussed on global consumption and the economy - to a cosmopolis: a place characterized by democratization and an increased role for the civil society in governance, which makes it an inclusive, diverse, and convivial space (Douglass 2008). Seoul's cosmopolitanism is expressed through a mosaic of diverse ethnic enclaves or foreign residential communities. Each enclave or community appears to be formed through the different reactions of incoming groups of foreigners to the conditions of urban housing and the employment market at the macro level (Cho 2015b). At the same time, they are also built by internalizing a different kind of social capital that allows the reproduction of ethnicity-based everyday lives at the micro level. Differences in the macro and micro processes of community building leads some of these global villages to be more inclusive than others (Cho 2015b). This is entirely dependent on whether individual and institutional actors - including foreign residents, local residents, municipal governments, and NGOs - make a concerted effort to create a public sphere of discursive engagement for inclusive life within their community. 
Against this conceptual backdrop, this paper delves into how a Korean Chinese community called Yeonbeon Village was formed in Guro-gu, a typical working-class district, and evolved into a transitional space for Seoul as a cosmopolis. The paper focusses on three analytical points. First, from the perspective of 'place-making of the people', it analyses how an ethnic space for Korean Chinese migrant workers comes into being in globalizing Seoul. Second, from the view of 'place-making by the people', it examines how the place is built into a transnational community to accommodate the reproduction of everyday ethnic life. Finally, from the angle of 'place-making for the people', it examines how citizen and non-citizen actors are engaged in constructing a public sphere of discursive engagement for inclusive life in a transnational enclave. Much of the empirical information about the village is drawn from my field observations and interviews with community activists and Korean Chinese workers conducted in January 2013, May 2013, and December 2015 .

\section{Multi-Cultural Spaces in a Global City and Beyond ${ }^{1}$}

Underpinned by neoliberalism, contemporary globalization entails socalled bipolar migration flows: at one extreme are 'globalized professionals', whose lifestyles vary little from one country to another, and at the other are marginalized, poorly-skilled migrants who cannot afford to discard their ethnic lifestyles (Keyder and Öncü 1994). One consequence of their concentration in globally attractive cities is the fragmentation of the labour and housing markets, with the latter producing what Davis (1992, 206) calls 'a complex class, ethnic and land use mosaic' (Poulsen, Johnson, and Forrest 2002, 229).

The nature and extent of the fragmentation of cities along ethnic lines has occasioned much academic study, starting from the 1920s Chicago School. The existing explanation is that such fragmentation results from twin sorting processes, assimilation and ghettoization, that operate in multi-ethnic cities. Assimilation involves the initial spatial separation of ethnic groups, reflecting the combination of economic and cultural factors, with changes in both leading to the subsequent reduction of segregation and increased integration into the everyday social processes of the city. Ghettoization, on the other hand, combines economic disadvantages,

1 This and the following section are revised versions of Sections 2 and 3 of my previous paper (Cho 2015b). 
which severely restrict the housing choices of the members of a particular group, with overt discrimination. This produces extreme spatial segregation combined with social deprivation (Poulsen, Johnson, and Forrest 2002, 230).

This view has only limited applicability for explaining the cultural diversity and ethnic pluralism in the contemporary global cities that attract diverse groups of people from all over the world, either short-term - such as migrant workers and students — or longer-term residents—such as marriage migrants. While mechanisms of discrimination are at work either implicitly or explicitly, some ethnic people or groups also choose to stay in relatively exclusive residential areas in order to retain their cultural identity. For them, assimilation entails forceful acceptance of the national narratives of the host country, denying them the right to the city as non-citizen residents or minority citizens. The mutual recognition of cultural difference is much more appreciated than assimilation or the overcoming of ghettoization. Adding to this tendency is the pluralism of urban families that have many foreign members or members living in other countries due to international marriages.

Contemporary global cities are encountering an increasing need for new types of space that can accommodate differences based on the region of origin, ethnic identity, income, and other attributes of residents. This is ascertained by the tendency of globalizing urban societies to change into a mosaic of culturally diverse spaces. However, a multicultural space within a city is shaped and is functioning differently from one to another. As the locus of the interplay between globalization and localization, multicultural spaces have received various names: transnational spaces, ethnic enclaves, ethnic places/communities, the third space, hybrid spaces, post-colonial spaces, in-between spaces, interstitial spaces, and the like. This varied naming begs the question of how multicultural spaces should be defined, and from what perspective.

There are several competing theoretical interpretations of multicultural spaces that emerge in the process of urban globalization. Multiculturalism emphasizes the spatial co-existence of diverse ethnic cultures-especially between indigenous residents and immigrant residents - in an urban society nested within a nation-state. Post-colonialism brings to light the role of these spaces as a 'third' or 'hybrid' space of culture or value-orientation that lies in-between the West (the colonizers) and the Other (the colonized) within a global city. Transnationalism gives prominence to the space of transnational actors and how their culture flows and is shared across country boundaries. Cosmopolitanism highlights the deeper change of global cities to accommodate the socially equitable and inclusive living of citizen and non-citizen residents through renewed urban democracy and governance. 
Of these theoretical viewpoints, cosmopolitanism best describes the future of cities in which multi-cultural spaces develop into a spatial polity of mutual aid and equitable accommodation among residents, who imprint their own identities in the urban landscape (Douglass 2008, 3). Considering that roots for the reproduction of everyday subsistence are now being established transnationally by a great number of people from all over the world, the idea of a city worth living in that celebrates its cultural diversity is what Douglass (2008) calls a 'cosmopolis'. This implies that cosmopolitanism should be realized through the multicultural space of the global city. How can a multicultural space be a theatre of inclusive social life in a city (cosmopolis)? The nature of such cosmopolitan space should be examined from an entangled perspective combining three dimensions of people-centred place-making: place-making of the people, by the people, and for the people.

\section{$3 \quad$ Global Seoul in Transition and Progressive Place-Making}

The developmental state and its city in Korea began to experience formidable changes in the 1980 os (Douglass 2008, 5-6). Major changes began to take hold along two lines: the ascendancy of the neo-liberal state's role in the planning of the economy; and political reforms towards civic and local democracy. These reforms have given rise to two modes of producing urban space after the developmental city: one, a neo-developmental city evolving into a globopolis, and the other, a convivial city leading to cosmopolis (see Figure 2).

Post-crisis ${ }^{2}$ Seoul's tendencies have been towards the preponderance of a neo-liberal globopolis over a convivial cosmopolis. Some key characteristics of a neo-liberal globopolis are: private, commodified space; global imaginaries; corporate-led, mega-scale, and economically competitive. Missing from this city are unscripted public and civic spaces, place-making by residents and neighbourhoods, vernacular architecture, low-income populations, and participatory planning (Douglass 2008, 72).

A dramatic shift in the course of this city-making occurred with the election of a civic activist, Park Won-soon, as the mayor of Seoul in the 2011 byelection. ${ }^{3}$ The result of this election was motivated by a debate about whether

2 This refers to the 1998 financial crisis that swept East Asian developing countries.

3 The conservative then-mayor of Seoul reacted to the progressive fraction's (opposition party and civil society) demand for general free school meals by offering a referendum vote. He stated that would resign if a majority of citizens supported the demand. The vote turned out to be against him, and his resignation led to the election of the progressive candidate Park Won-soon, Korea's first civic activist and former human-rights lawyer mayor. 
Figure 12.2 After the developmental city - two modes of urban space production

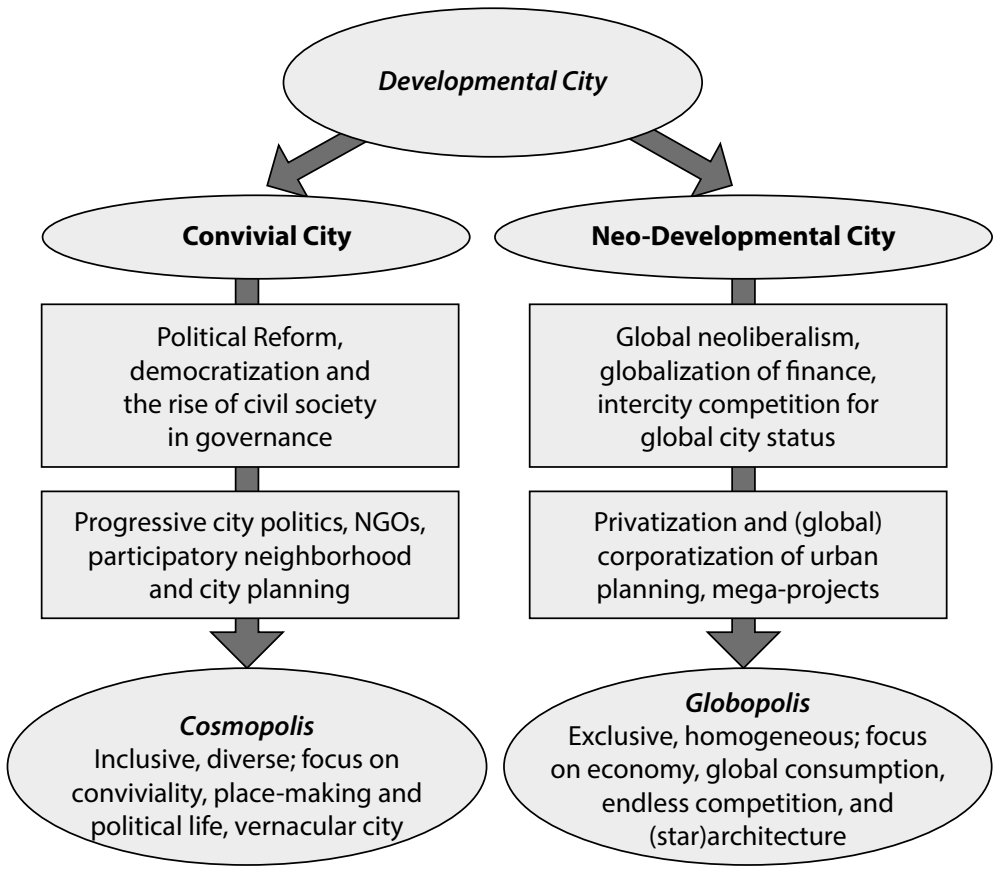

Source: author, following Douglass 2009, 68

to provide free school meals - a debate that was just the tip of the iceberg of the nation-wide public debate between conservatives and progressives about universal welfare. Rising with a diversity of grassroots mobilizations, Mayor Park brought the imperatives of the civil society movement into the government and made two landmark changes to the municipal administration. One is the substitution of people-centred living welfare agendas in place of economy-centred development agendas; the other is the replacement of bureaucratic governance tinted with 'statism' with democratic governance based on 'civicism'. The former is epitomized by 'agenda innovation', with the latter typified by 'governance innovation' (Cho 2014).

These changes have brought about an array of reform policies that prioritize human flourishing over economic growth, people prosperity over place prosperity, welfare provision over mega development, and democratic governance over bureaucratic governance. Formulated with the principles (e.g., participation, civic empowerment, association) of civil society, these policy experiments, in aggregate, have brought a dramatic change to the process of Seoul's city-making. This change also halted the neoliberal globopolis mode of city-making that had 
Table 12.1 Globopolis versus Cosmopolis

\begin{tabular}{|c|c|c|}
\hline Dimension & Globopolis & Cosmopolis \\
\hline Orientation & $\begin{array}{l}\text { High global city status to } \\
\text { enhance economic competition }\end{array}$ & $\begin{array}{l}\text { Inclusive, convivial, diverse, } \\
\text { multicultural city }\end{array}$ \\
\hline Drivers & $\begin{array}{l}\text { Economic profit, raising material } \\
\text { production and consumption }\end{array}$ & $\begin{array}{l}\text { Associational life, iden- } \\
\text { tity, place-making, tolerance, } \\
\text { accommodation. }\end{array}$ \\
\hline View of the City & $\begin{array}{l}\text { Composed of private spheres of } \\
\text { production and consumption, } \\
\text { economic engine, cultural } \\
\text { economy, fixed, functional divi- } \\
\text { sion of urban space }\end{array}$ & $\begin{array}{l}\text { Civitas, a public sphere, with an } \\
\text { active civil society; heteropolis, } \\
\text { negotiable meanings and uses } \\
\text { of urban space. }\end{array}$ \\
\hline $\begin{array}{l}\text { Foreigners/ } \\
\text { non-citizens }\end{array}$ & $\begin{array}{l}\text { Disposable labor; never to } \\
\text { become residents or citizens }\end{array}$ & $\begin{array}{l}\text { Full human beings with the } \\
\text { right to the city, family life and } \\
\text { equivalents of citizenship }\end{array}$ \\
\hline $\begin{array}{l}\text { Public/common } \\
\text { space }\end{array}$ & $\begin{array}{l}\text { Limited, pseudo-public, } \\
\text { controlled, ornamental, iconic } \\
\text { global architecture }\end{array}$ & $\begin{array}{l}\text { Plentiful, inclusive, flexible, site } \\
\text { of local place-making }\end{array}$ \\
\hline $\begin{array}{l}\text { Scale of urban } \\
\text { projects }\end{array}$ & Mega & Human \\
\hline Urban Planning & $\begin{array}{l}\text { Top-down government- } \\
\text { corporate partnerships }\end{array}$ & $\begin{array}{l}\text { Participatory/citizen- } \\
\text { government partnerships/local } \\
\text { business }\end{array}$ \\
\hline Governance & $\begin{array}{l}\text { Corporate management of } \\
\text { privatized urban spaces with } \\
\text { some state regulation }\end{array}$ & $\begin{array}{l}\text { Citizen-government } \\
\text { engagement in policy making, } \\
\text { planning, implementation, } \\
\text { monitoring }\end{array}$ \\
\hline Citizenship & $\begin{array}{l}\text { Reserved for majority ethnic } \\
\text { group and contained by the } \\
\text { nation-state }\end{array}$ & $\begin{array}{l}\text { Open to all who live in the city, } \\
\text { multiple levels of citizenship. }\end{array}$ \\
\hline
\end{tabular}

Source: Author after Douglass, 2009, p.73

predominated during the previous decade, during the tenures of Mayors Lee Myung-bak (2002-2006) and Oh Se-hoon (2006-2011). These two conservative mayors were enthusiastic about mega projects, such as the Han River plans and Cheonggyecheon restoration, for making Seoul a globopolis of world status, and less concerned about the living conditions of the people.

The cornerstone of the urban transformation unleashed by Mayor Park was bringing people back into the centre. Asserting that Seoul should be reoriented towards a 'people-centred city' - the Korean variant of a progressive city-, Mayor Park pulled the plug on the mega-development projects that were financially in trouble or had insufficient public support. Once clear of the neo-developmental mode of city-making, the mayor engaged the people in a dialogue about the city, and especially their right to it. The 
results of this dialogue include the 2030 Seoul Plan, Participatory Budgeting, and the Seoul Welfare Minimum, all of which were created through the initiative of the citizens. Mayor Park has gone further to reorganize the social and spatial structure of global Seoul based on communities and the social economy. In September 2012, the Seoul Metropolitan Government (SMG) put forward an ambitious plan to form 975 village communities by 2017 , together with the supply of 3180 community builders. It also proclaimed that it would help citizens create 8000 cooperative organizations over the next ten years, which would produce 5 per cent of Seoul's Gross Regional Domestic Product (Cho 2014). In May 2013, the metropolitan government released a plan to form 13 multicultural villages and establish seven global village centres to provide a helping hand to foreign residents. This plan is geared towards enhancing the inclusion of non-citizen residents in the public life of the increasingly multicultural city of Seoul.

The thrust of this progressive city-making is revisiting the right of people to be principal agents in the construction of their own space, both socially and physically. It targets the revival of human flourishing in a corporate and alienating mega city through civil society mobilization. In an increasingly multi-cultural world, inclusiveness is a critical constituent of progressive citymaking. Tenants, lower-class families, the elderly, youth, and migrant workers are chosen as the target groups for urban inclusiveness. With this progressive urban reform, the neoliberal globopolis of Seoul is shifting towards becoming a convivial cosmopolis (Cho 2015a). However, exactly how to localize these cosmopolitan ideals is yet to be determined. Place-making by non-citizen residents is one of the test cases for such a progressive urban experiment.

\section{Yeonbeon Village: Korean Chinese Place-Making}

\subsection{Ethnic Enclaves in Seoul: Spaces of Urban Globalization}

As stated in the beginning of this paper, the population of foreign residents of Seoul reached 457,806 individuals in December 2015, accounting for 26.3 per cent of the total foreign population $(1,741,919)$ of Korea and 4.53 per cent of Seoul's total population $(10,103,233)$ (Ministry of Public Administration and Security 2015). Even though they are still a small fraction of the overall population, foreign residents or non-majority ethnic groups are quickly growing in number, with a significant effect on Korean society that had remained ethnically homogeneous until at least the late 199os (Park et al. 2009). Some ethnic groups are more concentrated in some places than 
others, and these groups more easily form ethnic communities where their identity is distinctively expressed in the landscape of the place. In Seoul, there are currently 30 ethnic enclaves called 'mini global villages'. ${ }^{4}$

The formation of global villages in Seoul reveals the way that the Korean economy has globalized over the last few decades. In the 1970s and 1980s, the Korean industrial economy began to take its current shape with the aid of capital and high technologies sourced from advanced countries. This involved the inflow of professional and skilled personnel, who mostly worked for multinational corporations and related international organizations. These foreign employees resided near the inner city of Seoul to use the high-level cultural and residential facilities like international schools and mansions. By the 1990s, the Korean economy was faced with an increasing shortage of labour, which resulted in the opening of the labour market to a foreign workforce. This policy change led poorly-skilled workers from Asian developing countries to come in great numbers and fill the low-end urban labour market. They settled down around the deserted industrial zones on the outskirts of Seoul, where cheap accommodation was available after the Korean workers left. The pattern of the concentration of different groups of foreigners in Seoul fits with the urban ecological fragmentation forged by the bipolar migration flow of globalized professionals and marginalized, poorly-skilled migrants. Globalized professionals carry with them a global high-culture lifestyle that does not vary much between nationalities, but peripheral low-paid labourers tend to adhere to their own ethnic lifestyles. This bipolar labour flow interacts with the labour and housing markets of the recipient global city to create a 'complex class, ethnic and land use mosaic' on the urban space. The global villages emerging in Seoul form a multicultural spatial mosaic upon which each ethnic group engraves its own distinct sense of lived place through the articulation of the global bi-polar labour flow with the labour and housing market of Seoul.

These two contrasting ways of ethnic place-making are typified by two representative ethnic communities in Seoul, Seorae Village and Yeonbeon Village (see Cho 2015b for more detail). The former is a French community for globalized professionals or skilled workers located in the southern middle-class residential area of Seoul; the latter is a Korean Chinese community for peripheral un-skilled migrants located in the southwestern working-class residential area. Each ethnic community has a different spatial-historical background and a different capacity for place-making in

4 In this paper, the term 'global village' is used interchangeably with the term 'multicultural village or space'. 
Figure 12.3 Distribution of foreign residents by nationality (2011)

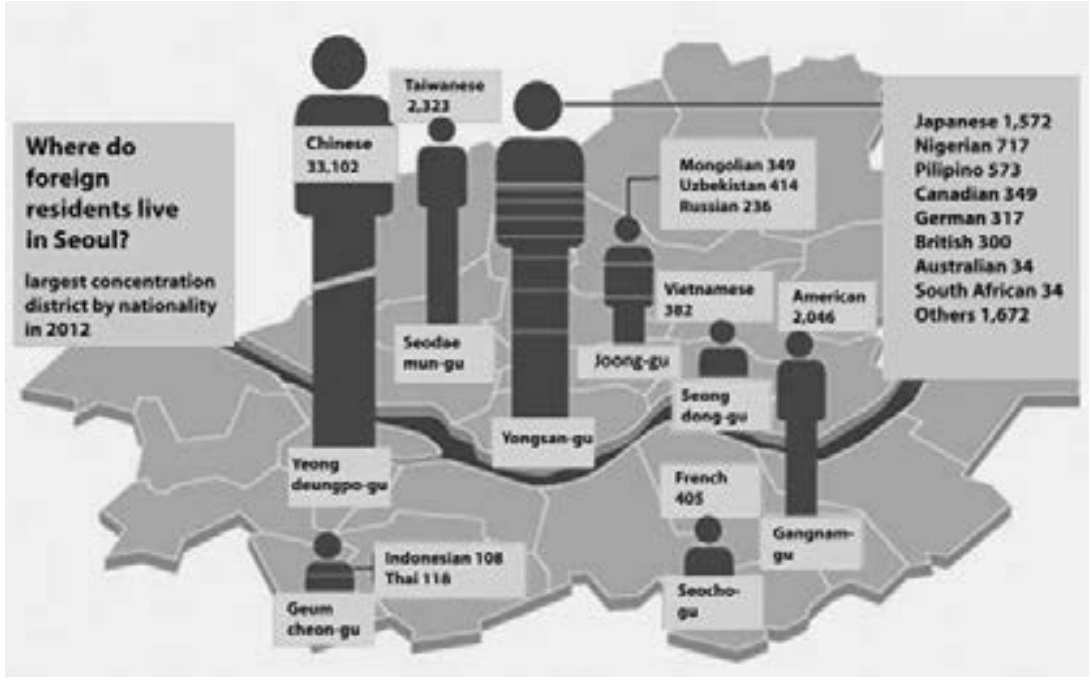

Source: author

relation to the foreign residents' host community. Due to their reciprocal integration with mainstream urban processes, the community life of the French residents tends to be more inclusive than that of the Korean Chinese residents, although both communities are supported by the SMG. On the other hand, the more isolated Yeonbeon villagers (Korean Chinese) are more engaged in making their space into a lived multicultural place, and have in fact formed a public sphere to claim residents' right to the city with the help of civil society and governmental actors. This place-making is part of Seoul's shift from globopolis to cosmopolis due to progressive urban governance.

\subsection{Confluence of the Labour and Housing Markets for Korean Chinese Workers}

Yeonbeon (Yanbian in Chinese) is the name of a town in northern China that is a central locus of the community of about two million Korean people in China. ${ }^{5}$ Seoul's Yeonbeon Village is named after this town because of 
similarities between the two streetscapes. The village is located in Garibongdong ('division'), Guro-gu ('district'), which was the site of Korea's earliest export-oriented industrial parks built in the 196os. After the Korea-China Diplomatic Normalization in 1992, this area quickly changed into a place for Korean Chinese migrant workers to concentrate and then disperse all over Seoul and beyond. Now Garibong-dong and its neighbouring areas are inhabited by about 30,00o Korean Chinese migrants. The Korean Chinese habitations stretch across several districts (wards), including Guro-gu, Geumcheon-gu, Yeongdonpo-gu, and Gwanack-gu, which are mostly lowincome, working-class areas with relatively cheap houses and good access to public transportation. Among the eight Korean Chinese enclaves ${ }^{6}$ in Seoul, Garibong-dong, nicknamed 'Yeonbeon Village', is the earliest settlement of Korean Chinese migrant workers as well as a place of entry for their ensuing chain migration arranged through community networks. As of 2012, Korean Chinese made up 43 per cent of the Garibong-dong population $(23,204)$. They are concentrated in narrow, dilapidated dwellings scattered along the streets of the Garibong traditional market.

The Korean Chinese are ethnically Korean but of Chinese nationality. Called Chosonjok ('Choson tribe'), they are mostly the second- or thirdgeneration offspring of the Koreans who were forced to immigrate to Manchuria (in Northern China) during the Japanese colonial period (19101945). They live in China as a minority, but since the implementation of Deng Xiaoping's opening policy in the 1980 os they are allowed to go abroad to earn money. A majority $(650,000)$ of the migrating Korean Chinese came to Korea with the 'Korean Dream'. Their migration to Korea was motivated by mixed reasons of finding a job overseas and visiting their grandparents' homeland. However, their dual identity as Korean Chinese renders their status precarious, as they are sometimes treated as fellow countryman and sometimes as foreign labourers. This duality is reflected in their employment status, which is different from that of other foreign migrant workers: Korean Chinese workers are permitted to visit Korea with a visiting employment visa, while other foreign workers are granted a work

called Chaoxianzu (Chinese: 朝鲜族) in Chinese or Chosonjok (Korean: 조선족, Choson is the name of Korea's last dynasty in 1392-1910) in Korean, who form one of the 56 ethnicities officially recognized by the Chinese government. Most of them live in Northeast China, especially in the Yanbian Korean Autonomous Prefecture, which had 854,000 ethnic Koreans living there as of 2000 (Wikipedia: https://en.wikipedia.org/wiki/Koreans_in_China).

6 These eight enclaves include Singil-dong Chinatown, Daerim-dong Chinatown, Guro-dong Chinatown, Garibong-dong Yeonbeon Street (or Village), Docksan-dong Chinatown, Bongcheondong Chinatown, Sindaebang-dong Chinatown, and Jayang-dong Lamb Brochette Street. 
permit visa that only allows them to work in strictly restricted areas of employment. Korean Chinese workers can work in 38 employment areas, such as daily construction work, restaurant services, domestic services, patient care, and the like. These jobs are typical of so-called '3D' (dirty, dangerous and difficult) jobs, which most Korean workers abhor and avoid. Since the early 199os, the Korean government's policy of importing foreign labourers has allowed a plethora of foreign migrant workers to flow into the country and occupy the marginalized, low-paid segment of the labour market that the local Korean workers had abandoned. Korean Chinese workers are typical examples of the marginalized, poorly skilled workers migrating along the lower circuit of global labour flows. Mostly middle aged (40s-50s) and conversant in the Korean language, they easily get precarious, low-paid jobs in personal services businesses in the inner city of Seoul; other foreign migrant labourers tend to work in manufacturing jobs on the outskirts or outside of Seoul.7 In the urban labour market, however, the Korean Chinese are called 'Chosonjok labourers' and are treated the same as other foreign workers. As a reservoir of cheap and disposable labour, they contribute to keeping the low-wage segment of the urban economy viable. After the expiration of their visas (usually after 5 years), they either go back to China and then return with a new visa or illegally stay until the Korean government lifts the measures of crackdown on them. Yeonbeon Village provides them with the chance to either find jobs in the street recruitment market or hide their illegal overstay with the help of fellow residents.

A practical reason for the settlement of the Korean Chinese in Yeonbeon Village is the availability of cheap accommodation and the suitability of the living environment to their low-cost living in Seoul. Seventy per cent of Korean Chinese residents live in Beol-Jip ('bee houses'), a complex of small box-like rooms that resemble a beehive. Some houses in the village have more than 20 rooms. This kind of housing appeared during the $1960 \mathrm{~s}$ and 1970s, when young Korean workers from rural areas started to live together near industrial parks to save on living expenses. After the factories closed, the 'beehive house village' in Garibong-dong was mostly deserted for a long time, though it was occupied by runaway youngsters and the homeless. It became a cause of local residents' economic hardship and the rapid downturn of the local economy.

745 per cent of migrant workers (mainly Korean Chinese) with visitors' visas reside in Seoul, whereas 65 per cent of migrant workers with employment visas work in small- and medium-sized cities outside Seoul. 
This situation began to reverse after the reestablishment of the KoreaChina diplomatic relationship in 1992, when Chinese Koreans came and filled in the places that Korean workers had left. Low-income house owners and local shopkeepers alike welcomed the Korean Chinese and the rejuvenation of the local economy, particularly the Garibong-dong traditional market. Entering the lowest segment of the housing market in Seoul, Korean Chinese workers gradually made Garibong-dong their ethnic enclave ${ }^{8}$ through their reciprocal relationship with the local Korean residents based on a feeling of brotherhood. This reciprocity developed into a collective effort toward place-making to some extent, in that the Garibong-dong area absorbed increasingly more Chosonjok and Chinese migrant workers and rose to become one of Seoul's 'Chosonjok Towns'.

Mainland Chinese are also an important group of foreign migrant workers. Chinese workers residing in Yeonbeon Village are known to be 20 per cent of foreign workers holding a Chinese passport. They tend to congregate around Yeonbeon Village to live close to the Chinese-speaking Korean Chinese workers. The addition of mainland Chinese workers further consolidates Yeonbeon Village as a Chinese enclave. Yet its current feature as an ethnic enclave began to appear with the entry of Korean Chinese workers in large numbers after the Korean government permitted Korean Chinese over-stayers to readjust their qualification for continued stay before the 2002 World Cup Game in Seoul. However, the form of cheap housing called Beol-Jip can be well kept even by now, paradoxically, due to the housing redevelopment introduced to the area which commenced in 2003 and was cancelled in 2014. With redevelopment planning in effect, no architectural act is allowed, leading to leaving the area physically isolated. In the meantime, this physical condition works as an important reason for some well-off Korean Chinese to get dispersed to more liveable neighbourhoods nearby or away.

\subsection{Yeonbeon Village as the Space of Ethnic Everyday Life}

In the survey conducted by Seong-hoon Bhang and Soo-hyeon Kim (2012), 75.5 per cent of the Korean Chinese survey respondents in the village were reported to have come directly to Garibong-dong after their arrival in Korea. When asked why they came to the village, 27.1 per cent answered 'cheap accommodation', 25.7 per cent responded 'local job availability', and 22.9 per cent replied 'acquaintance ties'. Together, these reasons underpin the making of Garibong-dong into a Korean Chinese ethnic place to accommodate 
the spatial reproduction of ethnic everyday life. Beol-Jip, as the 'cheap and easy residence', accounts most critically for the continued inflow of Korean Chinese migrant workers. A single room in these beehive houses costs them about US \$ 100-150 per month; with US\$ 1000-2000 for their monthly income, they could not but live in such cheap rental accommodations.

This low residential cost is critical to lowering not only the first cost of emigration, but also residents' living expenses in the host country. Beehive housing also suits the collective form of their everyday lives as single migrant workers without family companionship. Most new arrivals turn up at the village with information provided by earlier settlers from the same hometown or family. Though living alone, Korean Chinese residents are closely associated through various personal and social ties, especially in the form of this condensed residence. Building and sustaining these place-based ties are a crucial way of making the place into an ethnic enclave.

In addition to residential convenience and social networks, the availability of jobs is another reason for Korean Chinese migrant workers to congregate in or near the village. 78.4 per cent of the residents are known to be engaged in precarious daily labouring (Ji 2014, 266), which requires them to find new jobs every day or week. Daily recruitment markets are held near the Nam Guro subway station every day at dawn, where head hunters recruit 28 o people on average every day during the summer ${ }^{9}$ (Ji 2014). In addition, almost 200 labour-hiring or exchange offices are concentrated along the roads to the station. These job providers constitute the largest network of employment for Korean Chinese workers in Korea.

Many Chinese-run shops and agencies also provide diverse employmentrelated services — such as legal and financial support — for Korean Chinese workers in Seoul. In the early stage of village formation, Chinese-run restaurants played the role of informal service agents arranging housing, visa renewal, and job searches for Chinese migrants, including both Korean Chinese and Mainland Chinese workers. Now the village itself functions as a place-based network of employment for the Korean Chinese that also draws Mainland Chinese job seekers into the village.

In this way, the village provides a socio-spatial arrangement for low-paid Korean Chinese workers to solve their housing problems as well as find jobs through place-rooted relational networks such as personal ties, the street recruitment market, and job service agencies. The Nam Guro subway station is a gateway through which Korean Chinese workers can commute

9 It now recruits 1000 labourers every day, and is one of the largest street head hunting markets in Korea. 
cheaply to all locations in Seoul — and even to workplaces outside of Seoul. Some Korean Chinese work in the provinces on weekdays and return to the village on weekends. For them, Yeonbeon Village is not merely a site of cheap housing, but instead a transplanted hometown where they can live together and help each other as an ethnic population in the globalizing metropolis of Seoul.

Through placed-based interpersonal networks, Korean Chinese settlers invite their friends (including the Mainland Chinese) and families to come to Korea and stay with them until they move to other places. Even illegal over-stayers can hide from the authorities and find work with the help of their fellow countrymen or local Korean residents. Korean Chinese's place-making of Garibong-dong is thus a way to cope with their precarious and second-class-citizen status in the housing and labour market of Seoul. In this regard, the village is a space created by them as well as for them.

Their everyday living in the village is rather simple and was not very sociable until recently. Half of the Korean Chinese workers in the village came alone and only for the purpose of earning money to send to their family in China. Without family companionship, they keep their everyday life as cheap and humble as they can. Living in the village is the most suitable means to this end. In the early morning they go out for work; on the way home, they drop into the open market to buy cheap Chinese food, cook it at home, and then go to sleep. This pattern of everyday life is almost identical for all of the single Korean Chinese residents. They spend their leisure time at home or meet their fellow workers in the streets or drinking at bars after work or on weekends. Recently, however, with rising incomes and the increasing number of family members or friends residing together, an increasing number of Korean Chinese residents have become interested in consuming Chinese identity-related commodities as a way of pursuing an enhanced social life in Seoul. This includes eating cheap Chinese foods, drinking and singing together, gambling, chatting and drinking tea, watching movies in the theatre, shopping, job training, and educating their children.

The collective desire of Korean Chinese residents has transformed the Garibong traditional market, initially established for Korean workers, into a bustling folk market for Chosonjok and Chinese settlers. The main streets to the market are now full of Chinese commercial outlets, such as Chinese restaurants, Chinese grocery stores, money exchanges, travel agents, recruitment centres, karaoke, gambling rooms, and PC (personal computer) rooms, all targeted at Chinese customers living in Garibong-dong. This indicates that Garibong-dong has undergone a rapid change from the earlier collective 
residence of Korean Chinese migrants into an economic centre for Korean Chinese commercial businesses operating locally and transnationally.

From the mid-199os, petty businesses began to appear to sell cheap Chinese food and groceries to the single Chinese workers. Chinese restaurants were opened by Chosonjok women who rented and operated them alone, while Chinese grocery stores were run by local Korean merchants who sold imported Chinese food stuffs alongside Korean commodities. These stores were later taken over by the Korean Chinese. In 2002, when the Korean government provided a grace period to Korean Chinese over-stayers until March 2003, Garibong-dong rapidly became crowded with Korean Chinese workers, stimulating a commercial boom in the village. This brought new opportunities for some Korean Chinese to launch various business ventures related to China and Korean Chinese workers. New entrepreneurs engaging in Chinese commercial businesses were diverse and included Chinese females married to Koreans, Korean Chinese workers with savings, Chinese business immigrants, and naturalized Chinese Koreans.

Between 2003 and 2006, the Chinese market in the village shrank due to the Korean Government's crackdown on illegal over-stayers. With the housing redevelopment of the area decided in 2003, many residents of Garibong-dong began to move into neighbouring districts like Daerim-dong to find more stable residences, and even into new residential areas like Jayang-dong north of the Han River, where they launched new Chinese businesses. After 2006, many Korean Chinese workers who had gone back to China returned to Seoul with renewed visas and their family members (wives and children): a special visa for overseas Koreans had been introduced. This led to the further boom and extension of the Chinese market in the village. Bang and Kim (2012) reported that there were 137 commercial outlets related to China in Garibong-dong, including: 17 karaokes, 16 grocery stores, 12 bars and tearooms, 10 travel agencies, 10 clothing and miscellaneous stores, and 2 currency exchanges. More than 60 per cent of these commercial establishments were either rented or owned by Korean Chinese. Chinese businesses in the village now attract various types of investment capital, such as the accumulated capital of Korean Chinese workers, venture capital of Korean-Chinese joint investors, and even capital directly from China. Chinese investment also reaches into the housing properties around the village.

Through these kinds of economic activities around the village, Korean Chinese residents are in one way or another engaged in making the place into a transnational space that reflects their diasporic identity. Though ethnically Korean, most of them identify as Chinese. A survey from 2010 
shows that Korean Chinese residents believe that speaking the Korean language does not necessarily mean that they are the same ethnicity as the local Koreans (Park et al. 2010, 91). More precisely, Korean Chinese settlers in Korea have a hybrid identity flowing across two national spaces, Korea and China; making their area of residence into a transnational commercial space is a way of maintaining their ethnic identity. Chinese commercial outlets along the village streets are therefore a sort of spatial apparatus to assist with the cheap reproduction of Chinese Koreans' day-to-day living based on their hybrid identity.

Along with the reproduction of the Chinese identity in the neighbourhood, the main street of Garibong-dong has been designed to resemble a city with the same name in north China, with a fake Chinese streetscape as a result of the concentration of many commercial outlets with Chinese codes. This zone of the social reproduction of Korean Chinese residents is relatively secluded or disassociated from the mainstream everyday life of Korean residents in the village. Now, after Yeonbeon Village has been advertised by the mass media as a global village typical of Seoul, many Korean citizens visit to experience Chinese culture in a roundabout way. The village has therefore emerged as a multicultural tourist place in Seoul, as well as a transnational space expressing Korean Chinese identity.

\subsection{Yeonbeon Village as a Public Sphere for Non-Citizens}

As a former living area for factory workers, Garibong-dong is notorious for its concentration of low-income residents and its deteriorated residential environment. There are no public parks or public service facilities such as welfare or cultural centres in or around the village. The lack of public space in this area is such a chronic problem of urban planning that it affects both Korean and Chinese Korean residents alike. To relieve this planning deficiency, this area was designated in 2003 as a planning zone for clearance-based housing redevelopment due by 2014. This has been an excuse for the public authority to avoid its responsibility for the failure to provide public facilities to improve the lives of residents. Paradoxically, however, the retained environmental degradation has in effect created a ghetto, forming a Korean Chinese enclave immune to the interference of urban market mechanisms.

Yeonbeon Village's creation as a Korean Chinese enclave is due to both the residential conditions that are favourable to the settlement of socially weak, poor immigrants and the network of migrant residents who induce the inflow of their fellow countrymen and relatives from China or within 
Korea. Relationships between friends and relatives are known to function as the most important network for Korean Chinese migrants to obtain information on and mutual help with their employment and economic activities as migrant labourers and to organize social engagements such as family parties, folk festivals, and even gambling. Even Mafia organizations connected to mainland China have appeared in the area, fighting over the criminal market.

From the earliest stages of the formation of the settlement, the Korean Chinese migrants have formed various organizations to protect their rights and interests as non-citizens. These include: the Chinese Workers Association, for protecting their rights as migrant labourers (1996); the Chosonjok Federation, for the amendment of the Overseas Korean Act (2002); the Korea-Based Chosonjok Students Association, for extending the human resource network and solidarity of the Korean Chinese (2003); and the online Grand Assembly of the Korean Chinese Residing in Korea, for sharing and promoting information about the Korean Chinese diaspora (2003). In 2006, the Federation of Korean Returnees was formed to help with the settlement of overseas returnees. In 2009, the Federation of the Overseas Koreans in Korea was established to promote the civic status of naturalized and nonnaturalized Korean Chinese residing in Korea. In 2010, the China Federation Assembly was set up to protect and promote the rights of Chinese workers in Korea. In 2012, the Federation of Korean Chinese Voters was instituted to obtain the right to vote in elections as Korean citizens, and the Korean Chinese Business Club was created to promote cooperation and exchange among Korean Chinese businesspersons in Seoul.

These organizations are targeted at promoting the civic rights of the Korean Chinese population as non-citizens in Korea, and are mostly headquartered in or around the district of Guro-gu where Yeonbeon Village is located. Among these, the Federation of Korean Returnees has its most active local chapter in Garibong-dong, mainly composed of local Korean Chinese merchants. The chapter runs a shelter for the Korean Chinese homeless as well as a centre to arrange services for migrant workers' immigration, job finding, recruitment, and business advertising. Korean Chinese residents also form neighbourhood organizations to arrange social activities for community solidarity such as sports, folk festivals, and patrol. All of these associational activities weave together the networks among Korean Chinese workers to build social capital that is embedded in the village. Through these community-based actions, Korean Chinese settlers could open a public sphere for communication and cooperation among themselves in their residential area where there is no public space. 
Yet, this public sphere could not be possible without the active engagement of Korean NGOs protecting and advocating for the human rights and dignity of Korean Chinese migrant workers as foreign labourers as well as fellow Koreans. Churches were the earliest activists to enter Yeonbeon Village to help Chosonjok migrant workers from a religious and humanitarian standpoint. The Chinese Korean Church was the first to set up in Garibong-dong in 1996, followed by the Korea-China Adoration Church (1998) and the Seoul Chosonjok Church (1999). These churches ran various community programs offering legal consultations, arrangements for shelter, and medical services in parallel with religious activities. Seoul Chosonjok Church published the 'North East Newspaper' to circulate news about the Korean Chinese. The Korean Chinese House opened by Reverend Kim Hae-seong in 2001 has been a model organization providing humanitarian and institutional assistance to Korean Chinese migrant workers in need. Many Korean NGOs have followed suit.

A typical case is the Korea Chinese Town Center set up by a community activist in 2003. This centre publishes a newspaper called Korean Chinese Town News and provides comprehensive services for Korean Chinese residents, covering labour issues, immigration, legal disputes, business, and travel. Korea's leading global NGOs such as Global Sharing also have branch organizations in or near Garibong-dong. Global Sharing runs voluntary service programs to protect and advocate for the human rights of foreign workers according to global standards. It also operates the Foreign Worker Service Center with a commission from the government. Medical NGOs worked together to open the Migrant Worker Medical Center in Garibongdong in 2004. Human rights NGOs such as Aid to the Korean Chinese and Regaining Chinese Korean Rights are directly engaged in protecting and solving foreign workers' rights and interests that are likely to be encroached upon in a competitive urban society.

Many Korean Chinese workers suffer from livelihood challenges such as housing, legal disputes, employment, health problems, monetary hardship, and cultural distress, all related to their second-class-citizen status in Korea. The NGOs' voluntary activities fill the empty place of public service provisions that are supposedly the responsibility of the public authority. More importantly, the NGOs have brought the issues of non-citizen workers into the realm of civil society and made them a subject of public debate in cooperation with Korean Chinese organizations. This has led municipal governments to take action to protect foreign residents in globalizing Seoul.

In June 2013, the SMG opened Seoul Global Center, a headquarters that coordinates and controls the 42 agencies and organizations dealing with 
foreign resident affairs all over Seoul. South-West Global Village Center has recently opened as a branch office to provide public services for the multicultural families in this region, which includes Garibong-dong. As a partnership organization, the Center runs a variety of programs such as language learning, job training, legal advice, cultural learning, children's education, and medical care through the participation of the foreign residents. In cooperation with Korean residents, foreign (multicultural) residents are allowed to apply for a research grant to make a policy proposal for improving foreign residents' rights to the city. Children's education is the priority concern of multicultural families in this area, and this issue has been solved through a multi-layered arrangement among the Center, District Governments, Education Offices, and schools. In this arrangement, the district governments take increasingly more active roles in protecting and treating multicultural families as empowered members of the globalizing city. For instance, the District Government of Guro-gu has set up a commission consisting of local politicians, NGOs, foreign workers, employers, and residents to include their initiatives in local multicultural policy-making.

More positive and rigorous actions have also happened at the level of the Seoul Metropolitan Government (SMG). At the end of 2012, Mayor Park had a first-ever town-hall meeting with about 100 Chinese Korean residents, where the participants mentioned a variety of problems related to their everyday suffering in Seoul, such as limited access to public housing, a lack of public places for gathering, and a lack of schools for Chinese Korean children. In the meeting, Mayor Park promised that the Chosonjok Center (Chosonjok self-governance centre) would be established to help enhance the social status of Chinese Koreans, for they were just as human as their fellow Koreans. In 2014, with the financial support of the SMG, the district government purchased a building for conversion into the Chosonjok Center in Garibong-dong. In the same year, the SMG decided to cancel the planned demolition of Garibong-dong for housing redevelopment with eviction and instead apply a preservation-based village-making method to the area, thereby improving it and making it into a cosmopolitan village. With this change, foreign residents, whether tenants or property owners, were officially invited as stakeholders in the planning process of villagemaking - thereby showing inclusiveness, one sign of a cosmopolis. This was a symbolic action indicating that the SMG recognizes non-citizens' rights to the city in the institution of urban planning. At the end of 2015, Mayor Park invited representatives of the foreign residents in Seoul to his office for a full consultation on the SMG's multicultural administration. Since then, this meeting has been regularized as an institutional procedure. 
This new form of urban governance demonstrates the mayor's belief that in the making of Seoul into a progressive global city - the Korean variant of a cosmopolis - it is critical to include foreign or non-citizen residents in the public sphere. Recently, overseas Koreans staying in Korea, especially the Korean Chinese, have started a campaign to call for reinstatement of their Korean citizenship and, in the 2011 Seoul mayor by-election, demanded their right to be included in the election agenda of all mayoral candidates. Such collective efforts for progressive city-making will contribute to the enhancement of the Korean Chinese's rights to the city, thereby rendering the political and social life of Seoul more inclusive.

\section{Diasporic Identity and Recognition in Cosmopolis}

Globalizing cities entail the diversification of urban spaces and cultures, reflecting different ethnic identities. Global villages in Seoul have emerged as multicultural spaces along with the neo-liberal globalization of the metropolis. Each global village is dominated by foreign residents from a particular country, but in many villages they live hand in hand with other nationals. These spaces are considered multicultural places in Korea. 'Multiculturalism' is used to depict not only the mixed ethnicities and cultures in a place, but also the intention of co-existence, harmony, and mutual respect among the foreign and domestic residents of different ethnic groups.

However, all ethnic places do not reveal the same multiculturalism with regard to the integration of foreign residents with the host community. Some ethnic residents are more easily included in the host community and have managed to pursue their ethnicity-based everyday life in a more distinctive way. Others do not have the same experience. While villagers interact with the mainstream social processes of the city as non-citizens, their ethnicity is well expressed and reproduced in a social and spatial form. This difference of multiculturalisms is related to ethnic place-making, in which different groups of foreign residents attempt to engrave their ethnic identity on space.

This study shows that successful ethnic place-making is likely to lead to the transformation of residential space from a multicultural space of a globopolis into a transnational space of a cosmopolis. The transnationalization of ethnic space is another expression of the hybridization of spatial codes representing different ethnic identities through the everyday lives of residents who move across two countries. Once non-citizen residents of the place endeavour to acquire their rights to the city through engaging 
with a public discourse on civil rights, the multiculturalism of the space is likely to change into cosmopolitanism. The account made hitherto is about how Yeonbeon Village was actually formed as an ethnic community of the Korean Chinese and evolved into an ethnic space of cosmopolis.

Behind all this effort to make a place lies the diasporic identity of the Korean Chinese. Even though they are ethnically Korean and speak the Korean language, most of the Korean Chinese in Seoul identify themselves as Chinese. They come to Korea as 'visiting workers' and are privileged to work in the designated urban service sector. After the expiration of their visas, they return to China with earned wealth, but then came back again with a renewed visa, accompanied by family members or folks from home. Through these irregular visits, they extend their sojourn in Korea so as to regularize their everyday life relationships in the form of a community. Most of the Korean Chinese in Seoul travel back and forth between Korea and China regularly, while some (especially those who are highly skilled) circulate across neighbouring countries like Japan and Hong Kong, and even to the United States, in search of better job opportunities. They do not need to settle down and assimilate into Korean society for good. This fluid lifestyle has something to do with their identity of being part of the Korean diaspora. This diasporic consciousness is framed by their status on the border between Korea and China. While migrating transnationally in conjunction with China's open-door policy and Korea's neoliberal globalization policy, they underwent the conversion of their identity into 'mobile citizens' (Urry 2007). This means that even in their mobile everyday lives they have tried to make their lifestyle fit with their cultural and ethnic identity as Korean Chinese as a means of survival and adaptation (Urry 2007).

In the ecological process of urban spatial change, assimilation comes after the successful overcoming of ghettoization or extreme segregation (Poulsen, Johnson, and Forrest, 2002). However, the exploration of the development of Yeonbeon Village in this chapter does not fit this view. On the contrary, as revealed by Korean Chinese place-making, ethnic people or groups in contemporary global cities like Seoul are often opposed to being assimilated into the host society in which they reside. They strive to pursue their identity and lifestyle in the host society by constructing everyday life networks in their neighbourhood space. For them, assimilation means forceful integration with or being absorbed into the mainstream social processes of the host city, losing their identity and autonomy as a mobile tribe. In urban ecology theory, assimilation echoes the logic of force and hegemony related to the dominant group or class of the city. Hence this view is not relevant to the idea of the cosmopolis, where diverse social and ethnic 
groups coexist hand-in-hand, generating diversity, fluidity, equality, and symbiosis as new urban cultures. In such a city, separation and coexistence are more dominant than assimilation. In the previous sections, we saw how three kinds of ethnic place-making functioned as an instrument of this urban process: (1) place-making of the people, in the context of the labour and housing markets; (2) place-making by the people, in interaction with the host community; and (3) place-making for the people, through engaging with the public sphere to advocate residents' rights to the city. However, there is still the question of whether the collective identity of non-citizen residents is recognized and respected by others, especially Korean citizens.

Recognition of a group's ethnic identity and difference depends on how much they are respected by all parties in the cosmopolis. Compared with other ethnic groups, such as the French in Seorae Village, the Korean Chinese in Yeonbeon Village are not as respected by Korean citizens. They experience material deprivation due to their low status in the labour and housing markets of the city, as well as social marginalization by the host community, which is reluctant to accept them as equals. Even though they are ethnically Korean, Korean citizens consider them second-class citizens in Korean society. The same treatment is given to Koreans who flee from North Korea and settle in the free society of South Korea. This recognition is rooted in class consciousness, which Korean citizens embrace not only for themselves but also towards their fellow citizens in the process of capitalist urbanization. Most Chinese Korean migrant workers complain that in Seoul's everyday life they experience disdain, disregard, and dishonour from their Korean neighbours. This is undoubtedly attributed to the low opinion of the Korean Chinese in Korean society. Recognition of the identity and lifestyle represented by the village is an indicator for measuring how much this ethnic group is included in the everyday social process of the host city (Choi 2009). Paradoxically, this invisible discrimination against the Korean Chinese has been a cause for them to initiate community movements to promote their rights to the city, as well as to engage Korean NGOs in protecting their human and social rights as non-citizens.

Opening the public sphere in the village to advocate recognition of its residents' rights to the city is therefore equivalent to a 'place-making for the people'. As a result of this effort, the Korean Chinese have been able to construct and extend their place into a cosmopolitan space empowered with rights, equality, and justice. This enhancement is reflected in their inclusion in the progressive governance of the city. The completion of the urban shift 
into a cosmopolis is entirely dependent on how much 'recognition politics' is carried out through place-making for the people (Choi 2009).

\section{$6 \quad$ Conclusions}

Seoul is being reborn into a post-developmental city under new progressive leadership, reflecting a change in government-civil society relations. The direction of urban change is set to upgrade global Seoul into a human-centred, convivial cosmopolis, with all possible institutional and policy means mobilized to this end. Thanks to various ethnic place-making called 'global village', Seoul is now undergoing a shift from a globopolis to a cosmopolis, where all dwellers, whether citizens or non-citizens, are equally integrated into the everyday life systems of the city.

Yet it is true that some ethnic place-making is more inclusive than others. The experience of place-making in Yeonbeon Village shows ambivalence, in that that it used to be less inclusive but is increasingly becoming integrated into the city through villagers' claim of their right to the city. Ethnic placemaking is structured through the interaction between villagers and the city, but its inclusiveness is hermeneutically determined by the mutual recognition between residential citizens and residential non-citizens (Davey 200o). Recognition politics appears to be a key determinant for rendering place-making inclusive in a cosmopolis (Choi 2009).

Seoul lies between being a globopolis and cosmopolis. A swift shift towards a convivial cosmopolis requires the intensification of progressive urban movements towards the justice of recognition. This shift has already begun to take place with the growing engagement of the civil society, and recently the metropolitan government, in enhancing the city-wide recognition of the Korean Chinese community.

\section{Works Cited}

Bhang, Seong-hoon and Soo-hyeon Kim. 2012. 'A Study on the Differentiation of Minority Ethnic Residential Areas in Seoul, Korea-Focusing on Korean Chinese Community'. Korea Social Policy Review 19(2): 39-68. doi:10.170oo/ kspr.19.2.201206.39.

Cho, Myung-rae. 2014. 'The Governance of the Park Won-Soon Administration: A Performative Governance for a Progressive City'. Journal of Daegu Gyeongbuk Studies 13(2): 1-9. 
---. 2015a. 'A Progressive City in the Making: The Seoul Experience'. Paper prepared for the international symposium on Making a Progressive City: Seoul's Experience and Beyond, organized by The Seoul Institute, Seoul, Korea, October 15, 2015.

---. 2015b. 'Divided Cosmopolis?: Two Global Villages in Seoul'. Journal of the Korean Urban Management Association 28(4): 217-244.

Choi, Byung-doo. 2009. 'Multi-Cultural Space and Glocal Ethics: From Cultural Space of Transnational Capitalism to Space of Recognition Struggles'. Journal of the Korean Association of Regional Geographies 15(5): 635-654.

Davey, Andrew. 2000. 'Towards Cosmopolis'. City 4(1): 149-151. doi:10.1080/713656982. Davis, Mike. 1992. City of Quartz. London: Verso.

Douglass, Mike. 2008. 'Globopolis or Cosmopolis?-Alternative Futures of City Life in East Asia'. Studies in Urban Humanities 2: 67-115.

Ji, Chung-nam. 2014. 'Impact of Redevelopment Project on the Enclaves of Ethnic Korean-Chinese - With Priority Given to Garibong-Dong'.Journal of Koreanology 53: 65-81. doi:10.15299/jk.2014.11.53.235.

Keyder, Çağlar and Ayşe Öncü. 1994. 'Globalization of a Third World Metropolis: Istanbul in the 1980s'. Review (Fernand Braudel Center) 17(3): 383-421.

KBS. 2016. 'CNN Includes Seoul, Jeju in Top 100 Most Popular Destinations'. KBS World, 29 January. http://world.kbs.co.kr/english/news/news_In_detail. htm?No=11656o.

Ministry of Public Administration and Security. 2015. Statistics on Foreigner Residents in Korea.

Park, Se-hoon, Lee Young A, Kim Eun Ran, and Jung So Yang Jung. 2009. 'Reinventing Urban Policy in Response to Ethnic Diversity: A Report on Emerging Ethnic Places in Seoul, Korea'. Research Report 2009-19. Anyang: Korea Research Institute for Human Settlement.

Poulsen, Michael, Ron Johnson, and James Forrest. 2002. 'Plural Cities and Ethnic Enclaves: Introducing a Measurement Procedure for Comparative Study'. International Journal of Urban and Regional Research 26(2): 229-243. doi:10.1111/1468-2427.00377.

Urry, John. 2007. Mobilities. Cambridge, United Kingdom: Polity.

\section{About the author}

Myung-rae Cho is President of the Korean Environment Institute (KEI) and Professor of Urban and Regional Planning, College of Social Sciences, Dankook University, Korea. He obtained his D.Phil. in Urban and Regional Studies from the University of Sussex, England, where he studied spatial political economy. He has engaged in various advisory work for the public 
sector of Korea, such as chairing the Committee for Sustainable Development and Committee of Cheoggyecheon Restoration in the City of Seoul. He is currently President of the Korea Environment Institute affiliated to Prime Minister in Korea. He has produced about 78 books, among which nine are authored by him. Three of his own books won the Award for Distinguished Academic Book from the Ministry of Culture and Tourism, and Korean Academy House. Recent books include Reading Society by Space, Green Constructionism and Environmental Crisis, Beyond Creative Cities, Globalization: Looking Back and Forward. 



\section{Index}

Adorno, Theodor 183

ageing population $185,194,197$

agency, human 14-20, 27, 30, 36

in the construction of spaces 43

agents of change 114

agriculture see urban farming

Ahmedabad 19-23, 28-30, 37, 259-64, 270, 273

Ahmedabad Municipal Corporation (AMC)

$$
267-74,277-8
$$

Akihabara $178-80$

Alonso Gonzalez, Pablo 44

alternative spaces $24-33,37$

Ansell, Christ 104

appropriation of space $9-30,33,36,58,259-63$, 279

Argentina 73

Aristotle 35-6

Armitage, Derek 104

art

and society $182-3,186$

see also public art movement

art projects $25,28-33,177-98$

challenges faced by 194

co-creation of civic spaces $197-8$

flourishing of $178-82,186,193$

implications of $193^{-5}$

issues related to $195^{-7}$

specific goals of 196

artist communities $130-2$

'artistic citizenship' 132

Asatte Asagao Project 190-1

Ascher, François 74

Asian cities, common features of 17

Asian Coalition for Housing Rights 22

assimilation $314-5,335$

Baan Mankong policy 114

Baguio City Public Market (BCPM) 23, 26, 33,

201-23

map of 203

porters at 213-4, 217-8

Bang, Seong-hoon 326, 329

Bang Bour 116

Bang Bua 22-3, 27, 37, 77, 81-6

Bangkok 19-28, 31-4, 69-95, 99-122

City Farm Programme 107-22

maps of 71,100

physical planning for $77-9,83-4,92$

Bangkok Metropolitan Authority (BMA) 74, $77-8,85,90-2$

Bardha Market 33

Bardhan, Pranab 44-5

Barendregt, Bart 155

Batton, Julie 213-7, 221-2

Bauman, Zygmunt 184
Baumol, William J. 183

belonging, sense of 185

Benguet province 210-1, 220

Benjamin, Walter 183

Bhadra Plaza, Ahmedabad 259-79

maps of $266-7$

Boal, Augusto 137

Bollier, David 63-4

'bonding' ties 105, 121

Boonyabancha, Somsook 91

Born, Brandon 121

Boulevard Commercial Project (BCP), Hong

Kong 283-307

contrasting views on $303-4$

map of 285

Bourdieu, Pierre 24, 183, 185

Bowen, William G. 183

Brazil 72-3, 84, 94

'bridging' ties 105, 121, 213-4

Bristol, Graeme 80

bureaucratic hurdles 34

Cabannes, Y. 35, 40, 108

Cage, John 164

Campbell, Mary Schmidt 132

Cañada Réal 47

capitalism 22, 25, 28, 37, 103, 131

Casas-Cortés, Maribel 47

Castells, Manuel 23, 30, 130

Chan, King Fai 143

Chang, Marina 102

Chengdu 35

China 133-4; see also Korean Chinese

Chip Lee-Mok 244-5

Ciliwung Merdeka (NGO) 59

citizenship 18, 56, 61, 64, 69, 75, 94

and active agency 15

city centres 262

City Farm City Friends group 120

city-making 318-9

'cityness' 46, 206

civic awareness 94

civic involvement 181-4, 201-2

civic space $192-3,197-8$

'civicism' 319

civil society $22-3,28,50,85,128,315,319,321$, 337

Clarke, John $5^{2}$

Clement, Yang Xi 166-9

Clifford, James $195^{-6}$

climate change 14

Cobarrubias, Sebastian 47

co-creation 197-8

codification of space 263

Coleman, James 105 
collaboration creation and maintenance of 119-21 reasons for $118-9$

collaborative governance $22,34,104-5,117,119$, 122

collective action $17,31,34$

Colomb, Claire 131

Colombia 41

'Command A' 179, 186

'Command N' 195

commoners' rights 63

'commoning' 30, 45, 64

commons $44-8,5^{2-3}, 60-4$

collaborative governance of $104-5$

concept of $55^{2-3}$

definitions of 44,102

intrinsic value of 62

kampungs regarded as $48,62,64$

types of 46

communal land ownership 31, 84, 292, 294

communicative action theory (CAT) 105-6, 118,122

community

concept and definition of $20-1,5 \mathbf{5}^{-2}, 81-2,197$

development of $184-6,189-92,197$

revitalization of 181,197

community architects 93

community-based organizations (CBOs) 82-3,

101

community-based projects $181-2,187-8,193,198$ community-supported agriculture (CSA) 107, 120

Confucianism $35^{-6}$

consumption, culture of 263

'contact zones' (Pratt) 195

corporatization of cities 20

cosmopolis concept $15^{2-3}, 315^{-20}, 323,334-7$

cosmopolitanism 161-2, 165, 169-73, 315-8, 335

Cox, Kevin 153-6, 166

creativity, creative industries and the creative classes 130-1, 183-5, 193, 198

critical urban theory 15

cultural diversity $317-8$

cultural producers 130

currencies, local 17

Daseng Sario 288-9o, 296-307

Davis, Mike 316

De Certeau, Michel 3o, 166

deep sound 154

Delgado, Cecilia 35

De Meulder, Bruno 293

democratization 20, 315

Deng Xiaoping 324

deregulation of the economy 23

'developmental state' concept 23

devolution 24

diversity in cities 18, 222; see also cultural diversity
Djamalludin, Rignolda 304, 306-7

Dolsak, Nives 102, 121

Douglass, M. 40, 192, 206, 318

Dovey, Kim 293

Dunn, Kevin $15^{1}$

Eating and Sharing in the Park event (Bangkok) 120

economic growth 17

empowerment 35

environmental impact assessment 92

environmental issues $27-9$

ethnic communities $321-2$

ethnic fragmentation 316

Everett, Margaret 41, 53

Evers, Hans-Dieter 49-50

'everyday politics' (Kerkvliet) 208-9, 212, 218-23

eviction and fear of eviction 20-1, 27, 41-2, 47, $54-6,61,63,72,262,278-9$

exchange value 261

Facebook 6o, 113, 142

Feld, Steven 158, 161

festivals, cultural 25

fishing communities 19, 21, 25-6, 30, 283-4, 287-306

Florida, Richard 185,193

FM Theatre Power (FMTP) 127-30, 135-47

Fong, Chow Lam 142

food security concept 119

food sovereignty movement 99

food supplies $25-6,31-3,99-103,107,120-1$, 203-6, 210-2, 222-3; see also urban farming

Forum Permukiman Jakarta 59

Foucault, Michel 154-5

France 72

freedom of expression 143

freedom of performance $127-8$

Friedmann, John 22, 36

gaai si 234

Gallent, Nick 105

gardens for city communities 16-9, 102, 107-11, $114-6,119-22$

Gash, Alison 104

gated developments 133

gender roles 21

gentrification $20,84,130,250-1$

ghettoization $316-7,335$

Gilmore, James 205, 215-6

Gini coefficient 233, $25^{\circ}$

global cities 24, 317-8

global villages in South Korea 315, 321-2, 334, 337

globalization $16,314-7,322,334$

globopolis 315, 318-9, 334, 337

governance

mechanisms of $154^{-7}$

polycentric or multi-layered 104 
grassroots initiatives 19, 306

'gray spacing' 209, 215, 222

Green, Maia 220

Green Market Network 113, 120

Grêt-Regamey, Adrienne 43

Guarulhos 35

Guinness, Patrick 45-6, 55

Guitar 77 (shop) 152, 158-66, 171-3

de Guzman, Kathy 220

Habermas, Jürgen 105, 128, 135

Hagiwara, Sakutaro 182

Hamburg 131

happiness 36

Hardin, Garrett 44

Harvey, David 30, 45-6, 95, 103, 130-1, 153-4, $159,166-7,233$

hawkers $229-36,251-3$

control of 229-31, 249

functional importance of $235^{-6}$

numbers of 236

Health-me Organic Delivery 119

Helfrich, Silke 63-4

Hellman, Jörgen 68

heritage preservation $28,80-1$

Herzfeld, Michael 78,80

Heynen, Hilde 293

Hibino, Katsuhiko 190

Hiroi, Yoshinori 184-5

Ho, Chiu Fan 233

Ho, K.C. 206

Hong Kong 29-37, 127-47, 229-54

Bridges Street Market 241-3

Central Market 238-41

maps of 129,230

modern-day markets $243-50$

Western Market 237-8

Hood music club 157, 162-73

Horkheimer, Max 183

housing 27

human flourishing 14, 17-8, 34-6, 227-31, 321

human rights 36,103

incentive structures 104-6, 117-9

India 261,274

map of 260

individualization $184-5,198$

Indonesia $283^{-6}, 293,304$

maps of 42,285

indoor markets $230-2$

inequality $14,17,23,233,25^{\circ}$

information-sharing 117

infrastructure development 32

inheritance rights 55

institutional rational choice theory $104-6,118$, 122

Islamic Defenders Front 21

itinerant vendors 218-21

Izakaya shops 189-9o
Jacobs, Jane 103

Jakarta 19, 23, 28, 31, 37, 41-53, 56, 6o-4, 284

map of 42

Japan 19, 28, 31, 177-98

map of 178

Jellinek, Lea $47,5^{1}$

Judd, Dennis R. 172

kampung kota concept 51

kampung settlements 19-23, 28-31, 42-53,

$57-64$

definitions of $49-52$

regarded as commons $48,62,64$

vulnerability of $48,51,63$

karta tanda penduduk (KTP) identification $55^{-6}$

Kelurahan Kampung Melayu 53

Kennedy, Arthur Edward (and Kennedy Town, Hong Kong) 248

Kerkvliet, Benedict 208

Kim, Soo-hyeon 326, 329

Klong Toey settlements $87-8$

Kong, Lily 147, 155

Korea see North Korea; South Korea

Korean Chinese 324-37

Korff, Rüdiger 49-50

Kumurur, Veronica 287

Kunisada, Chuji 182

Lacey, Hugh 35

land reclamation 284-6, 294-6

Landolt, Patricia 209

Lee Myung-bak 320

Lefebvre, Henri 18, 29-30, 91, 95, 103-4, 153, 259-64

de Leon, Evelyn 202, 204

lifestyle 16,87

The Lifestyle Group (company) 238

Lim, Kiang 16o-5, 169, 173

Lin, Nan 105

local authorities 119, 122, 286, 304

Low, Kelvin 155

McGee, Terry 235

Machimura, Takashi 190

machizukuri 31, 185-6

Manado (Indonesia) 19, 21, 25-6, 30, 283-97, 302-7

Manek Chowk, Ahmedabad 263-4

March, James 104

Marcuse, Peter 207

marginalized groups 278-9, 283, 287, 295, 299-300, 303-6

market stalls, supply of and demand for (in Hong Kong) 251-2

marketplaces $26,30,33,35,202-3,235^{-6}, 251$, 270

semantics of $229-31$

markets 
control of $232-5,253$

in Hong Kong 229-54

modernization of $203-5,232-3$

see also street markets

Marston, S.A. 153

Martin, Randy 132

Matsumiya, Hideharu 188-9

Mattei, Ugo 62

Mayer, Margit 131

mega-projects 284-6, 304-6

metropolitanization $74-6$

Mexico 94

middle-class interests 24,120

Mignolo, Walter 152, 161

migrants $17-8,56,322$

Mo Lai 135-41, 143

mobilization 14, 21, 131, 278, 321

Mong Kok (MK) area, Hong Kong 127-9, 136-47

Monteban, Karen 212

Montelo, Heidi 216, 218, 221-2

Mookjai, Sarwa 247-8

Morris-Suzuki, Tessa 183

multicultural space $317-8,321-2$

multiculturalism $334-5$

Munoz, Aileen 221

museums $185,194-5$

music scene, the $31,33,151,155^{-6}, 160-1,171$

Nakamura, Masato 194

Nancy, Jean-Luc 164

Na Phra Lan 8o-1

Narotzky, Susana 64

neighbourhood projects 20

neighbourhoods recognised by state authori-

ties 43

neoliberalism $16,23,25,36,313-20$

networks $82-3,107$

Newberry, Jan 51-2

Nigeria 208

Nikmah, Siti Khoirun 52

noise pollution 155

North Korea 336

Novy, Johannes 131

Nunag, Nel 220

Oh Se-boon 320

Oldenburg, Ray 189

Olson, Johan 104

On-nut Hoksibhok 115-6

On-nut Sibsee Rai 109, 114

Ooi, Giok Ling 192, 206

oppression, forms of 20

organic food 113, 119-20

Organic Way 111

Osawa, Masachi 185

Ostrom, Elinor 48, 102-5, 121

Padawangi, R. 40, 59

pajak bumi dan bangaman tax $55^{-6}$
Park Won-soon 318-21, 333-4

participatory budgeting $17,25,35$

participatory processes $89-91,94-5$

Peck, James 130

'people energy' 82

Peresthu, Andrea 37-8

personalization $184-6,197$

Petropoulou, Chryssanthi 73

Philippines, the 197-9, 204-7

map of 203

Pickles, John 47

Pine, Joseph 205, 215-6

place, sense of 157,322

place-making 28,31

ethnic $324-5,334-7$

by non-citizens 321

of the people, by the people and for the people $313,316,318,336$

Poerwadarminta, W.J.S. 49

pollution 14, 27, 81, 83; see also noise pollution

Pom Mahakan 23, 27, 77-81, 95

popular culture 26

Pornchokchai, Sopon 70

Porter, Alejandro 209

Porter, Gina 208

post-colonialism 317

Pratt, Mary Louise 195

privatization of urban spaces 15

'production of space' theory $259-61$

'pro-poor' projects 115,118

public art movement $123-8$

public health concerns 234

public-private partnerships 24, 194

public space 132-6, 261, 279, 334

performing in $142-7$

value of 261

public sphere 128, 135, 315, 331-2

Pulo 15, 23, 49-59

map of 42

Purcell, Mark 121

Putnam, Robert 105

quality of life 223,250

quasi-autonomous national government organizations (QUANGOs) 99-102, 117-22

Raharjo, Wiryono 56, 293

Rao, Vijayendra 44

Ray, Isha 44-5

recognition politics 337

residential fragmentation 294

'right to the city' $29-30,76,91,95,102-3,114$, $159,207,259,261-4,277,304,307,317,320$ as a theoretical approach $262-4$

riverbank communities $22,41-3,48,53-8,116$

Robinson, Jennifer 206, 222

Robinson, Steve 105

rukun tetangga (RT) administrative units $5^{2-8}$, 61-3

Rydin, Yvonne 105 
Sakdina system 70

Samuel, Jane 34

Sario community (Indonesia) 19-23, 26, 30, 283-9, 292-9, 303-6; see also Daseng Sario

Sasaki, Koichi 194-6

Sassen, Saskia 75, 95

Savage, Victor R. $15^{8}$

security of tenure $41-3,54-5,70$

Self-Employed Women Association (SEWA), India $274-7$

Self-Labour Organization (SLO), India 274-7

Sen, Amartya 34

Seorae Village 324

Seoul $15,31,313-5,318-23,332-4$

foreign residents in $315,321-3$

Shirakawa, Yoshio 182

Sihombing, Antony 52

Simone, Abdoumaliq 46-7, 62

Singapore 19, 25, 30-4, 37, 151-73

Bugis+ Mall 166-9

Keong Saik Road 162-8

map of 152

Public Entertainment Act 159-6o, 172

slums and slum dwellers 27, 74-6, 86, 88, 114-6, $122,288,294$

Smart, Alan 209

Smart, Josephine 232-6

Smith, Neil 153-4

social action $16,99-102,108,122,198$ cities as theatres of 37

social capital $99,105-6,117-8,121,208-9,213-4$, 221, 315

dark side of 209,218

forms of 117

social construction of urban spaces 122

social dimension of cities $16,18,119-20,152-3$

social enterprises $26-7,112$

social housing 86-90, 262

social media 21

social systems $189-90$

Soja, Edward 102-3

'Solidarity' group (Bangkok) 114

South Korea 183, 322, 336

map of 314

Southhall, Aidan 152

spatial scales $153-4,158-60,167$

spontaneous housing settlements $69-76,82-95$ definition of $72-3$

squatters $47,54,61,69,294$

state institutions $22-3$

'stranger' in the city, concept of 17

The Straydogs $160-1,164$

street markets 229-35, 251-3

street performances $127-30,135-46$

street vendors $21-3,28-32,87-8,135,259-79$

suki relations 208, 212-4, 218, 221

Sullivan, John 49

supermarket shopping 212, 216-7, 220-2, 231, $252-3$
Susser, Ida $45^{-7}, 60-4$

sustainability 32, 81, 119

Swyngedouw, Erik 153

Sykes, Jim 155

Tang, Wesley Y.H. 247

Tanzania 220

Tarareanake Go Green 110-1

Tayad, Patricia 215-6, 221-2

tenure of land 17, 21, 84, 294; see also security of tenure

Thailand 85

maps of 71,100

theatre groups $34,37,143$; see also FM Theatre Power

Thornton, Sarah 193

3331 Arts Chiyoda 178-81, 186-97

Tokyo, map of 178

Tonnelat, Stéphane $45^{-7}, 60-4$

Toshiro Jin-jin, Kimura 182

town vending committees 262

transnationalism 317

Trench, Sir David 238

trickle-down economics 27

trust of customers 221

Tsang, Louisa $246-7$

Tu, Wei Min 36

Tunas, Devisari 41-2

Umbrella Movement 128, 130, 146

United Nations Educational, Scientific and

Cultural Organization (UNESCO) 79, 259, 268

URBACT program 33

urban farming 19, 31-2, 37, 85, 99, 103-9, 114-22

types of $108-9$

use value of space $261-3,278$

vacant land, use of 115

violence, state monopoly of $22-3$

Vollmer, Derek 43

Watson, Sophie 235, 249

Wenang area $293^{-4}, 305^{-6}$

Wilson, Ara 153

Winchester, Hilary 147

women's employment 202, 279

Woolcock, Michael 105

Yamamoto, Takayuki 182

Yap, Christopher 103

Yeoh, Brenda S.A. 162

Yeonbeon (Chinese town) 323

Yeonbeon Village (South Korea) 313, 316, 323-37

Yeung, Y.M. 235

Yiftachel, Oren 209

Young, Iris 20

Yúdice, George 196

Zerilli, Filippo 209 



\section{Publications / Asian Cities}

Norman Vasu, Yeap Su Yin and Chan Wen Ling (eds): Immigration in Singapore

2014, ISBN 9789089646651

Gregory Bracken (ed.): Asian Cities. Colonial to Global 2015, ISBN 9789089649317

Lena Scheen: Shanghai Literary Imaginings. A City in Transformation 2015, ISBN 9789089645876

Anila Naeem: Urban Traditions and Historic Environments in Sindh. A Fading Legacy of Shikarpoor, Historic City

2017, ISBN 9789462981591

Siddhartha Sen: Colonizing, Decolonizing, and Globalizing Kolkata. From a Colonial to a Post-Marxist City 2017, ISBN 9789462981119

Adèle Esposito: Urban Development in the Margins of a World Heritage Site. In the Shadows of Angkor 2018, ISBN 9789462983687 
